\title{
WestVirginiaUniversity
}

THE RESEARCH REPOSITORY @ WVU

Graduate Theses, Dissertations, and Problem Reports

2004

\section{Characterization of pyrolysis products from end-of-life electronic equipment}

\author{
Venkatadri E. Thiruvallur \\ West Virginia University
}

Follow this and additional works at: https://researchrepository.wvu.edu/etd

\section{Recommended Citation}

Thiruvallur, Venkatadri E., "Characterization of pyrolysis products from end-of-life electronic equipment" (2004). Graduate Theses, Dissertations, and Problem Reports. 1513.

https://researchrepository.wvu.edu/etd/1513

This Thesis is protected by copyright and/or related rights. It has been brought to you by the The Research Repository @ WVU with permission from the rights-holder(s). You are free to use this Thesis in any way that is permitted by the copyright and related rights legislation that applies to your use. For other uses you must obtain permission from the rights-holder(s) directly, unless additional rights are indicated by a Creative Commons license in the record and/ or on the work itself. This Thesis has been accepted for inclusion in WVU Graduate Theses, Dissertations, and Problem Reports collection by an authorized administrator of The Research Repository @ WVU. For more information, please contact researchrepository@mail.wvu.edu. 


\title{
Characterization of Pyrolysis Products from End-Of-Life Electronic Equipment
}

\author{
Venkatadri E. Thiruvallur \\ Thesis submitted to the \\ College of Engineering and Mineral Resources \\ at West Virginia University \\ in partial fulfillment of the requirements \\ for the degree of \\ Master of Science \\ in \\ Chemical Engineering \\ John W. Zondlo, PhD., Chair \\ Dady B. Dadyburjor, PhD. \\ Peter G. Stansberry, PhD. \\ Department of Chemical Engineering \\ Morgantown, West Virginia \\ 2004
}

Keywords: Plastics, Pyrolysis, Product Gas Composition, Atmospheric Distillation, Simulated Distillation, Coke and Ash content analysis

Copyright 2004 Venkatadri E. Thiruvallur 


\section{ABSTRACT \\ Characterization of Pyrolysis Products from End-Of-Life Electronic Equipment \\ Venkatadri E. Thiruvallur}

Tertiary Recycling of End-of-Life electronic equipment such as computer monitor casings and disk drives is considered in this project. This research aim's at finding new recycling processes that have a possibility for economic scale-up. The present work was divided into two parts. The first one dealt with the investigation of two mixed-plastics streams provided by MBA Polymers (MBAP). One of the streams consisted of fines (MBAP-1), and the other was a nonseparable stream, MBAP-2. These solid polymer streams from MBAP were reacted in a Tubular Reactor inerted with helium. The overall objective of these reactions is to determine the process parameters (Reaction Temperature and Pressure) required in order to achieve maximum oil yield. The reaction process parameters are the reaction temperature $\left(375^{\circ} \mathrm{C}, 400{ }^{\circ} \mathrm{C}, 425^{\circ} \mathrm{C}\right.$ and 450 ${ }^{\circ} \mathrm{C}$ ) and the reaction time (15min, 30min and 45min). Tetrahydrofuran (THF) and hexane are used as solvents to separate the non-gaseous products which are partitioned into THF-Insoluble, THFSoluble Hexane-Insoluble and Hexane-Solubles while the gaseous products are analyzed using a gas chromatograph (GC).

Adherent Technologies, Inc. (AT) uses a two-stage catalytic pyrolysis process. In the second part of the present work, the liquid after pyrolysis by AT but before upgrading was analyzed by studying the boiling-point curves obtained using ASTM D-86 atmospheric distillation and ASTM D-2887 simulated distillation methods. The objective of these distillation runs is to determine the percentage of feed in the diesel fuel range $\left(340-640{ }^{\circ} \mathrm{F}\right)$.

For MBAP-1, the optimum reactor conditions (which maximize the production of the oil fraction) are $425^{\circ} \mathrm{C}$ for $15 \mathrm{~min}$. The oil yield at this condition is found to be $62 \%$. For MBAP-2, the optimum reactor conditions are $425^{\circ} \mathrm{C}$ for $30 \mathrm{~min}$. The oil yield at this condition is found to be $65 \%$. Atmospheric distillation following the ASTM D-86 procedure, verified further with simulated distillation following the ASTM D-2887 procedure, indicated that $65-70 \%$ of the AT-1 oil and MBAP-2 product oil fraction was in the diesel fuel range. Presence of halogenated species (bromides and chlorides) poses a challenge for the AT oil to be used in the petroleum industry. The gas yield from pyrolysis of the MBAP-1 and MBAP-2 mixed-plastic samples was found to be very low (1-8\%) but the gas composition and heat recovery calculations reveal a very high fuel value (5,900-15,500 BTU/lb.) and available heat recovery (6.66 - 19.19 MMBTU/hr). The product gas could contribute significantly as a source of heat during the pyrolysis process. Coke analysis for MBAP and AT-1 samples revealed very poor coking values that required no further assessment. However, ash content analysis of MBAP and AT-1 oil revealed an ash content of less than $0.2 \%$, an important requirement to be classified as a diesel fuel. 
Dedicated to my Mother, Mrs. Gomathi Krishnamachari, the most humble and accomplished Individual I know. 


\section{Acknowledgement}

I would like to thank, with utmost sincerity, Dr. John Zondlo and Dr. Dady Dadyburjor for their guidance and support throughout this project. Also, my thanks to Dr. Peter Stansberry for his guidance and support in conducting lab experiments. I would like to express my thankfulness to Linda Rogers, James Hall and Bonnie Helmick for their support.

I would like to express my appreciation to US DOE for providing the funding for this research project. 


\section{TABLE OF CONTENTS}

ABSTRACT …........................................................................................................................................ II

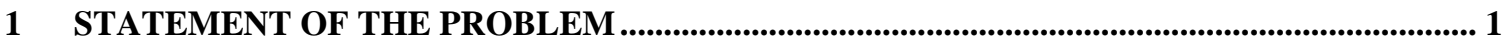

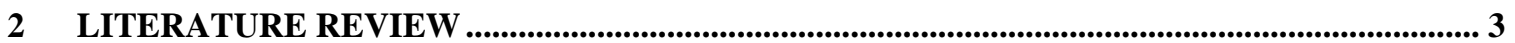

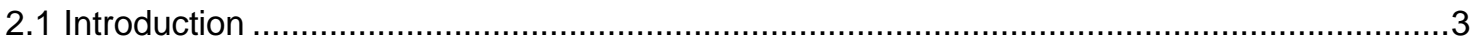

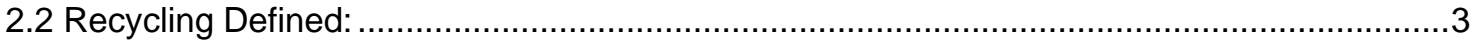

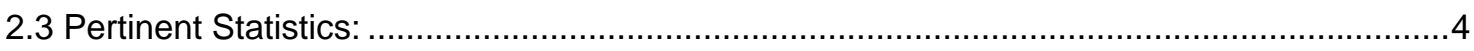

2.4 The Scope of Tertiary (or Chemical) Recycling: .........................................................

2.4.1 Processes that show Commercial Potential:......................................................... 7

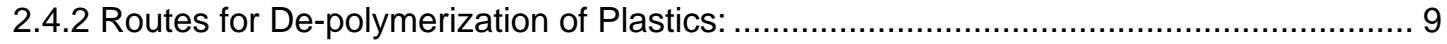

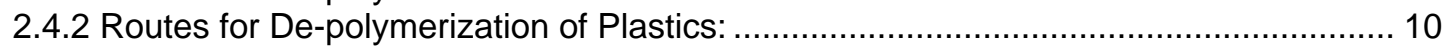

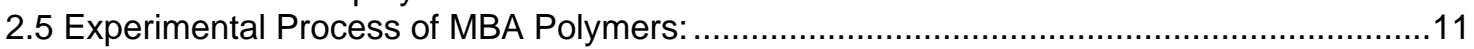

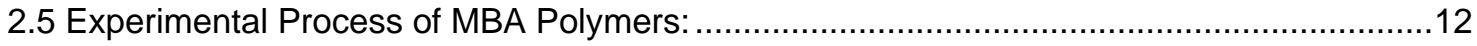

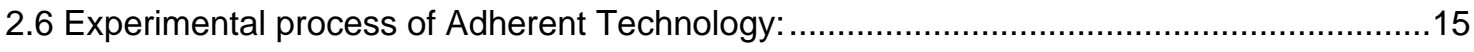

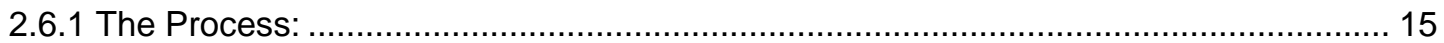

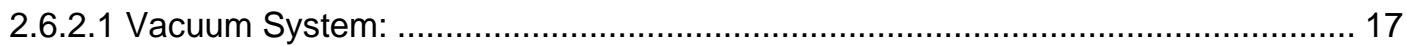

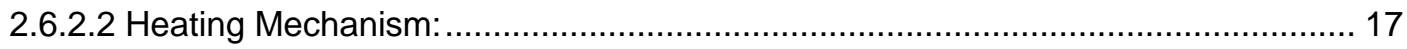

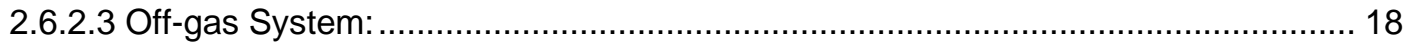

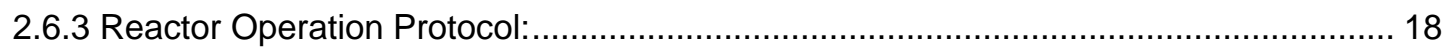

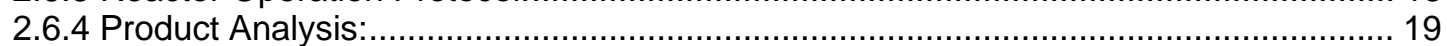

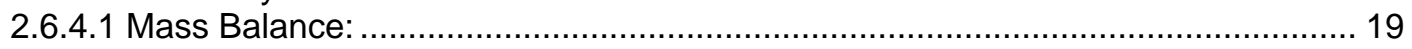

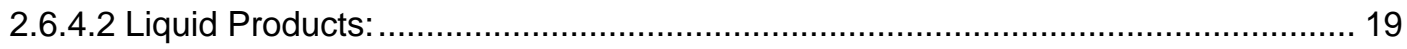

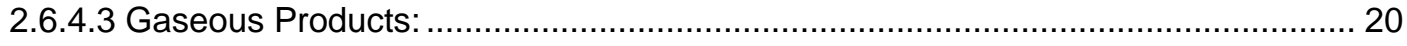

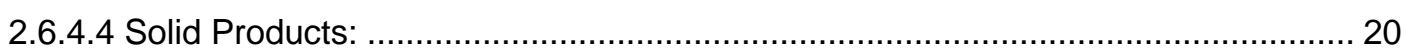

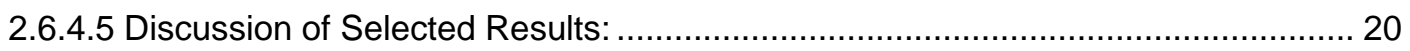

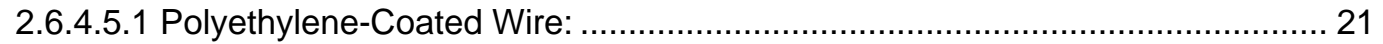

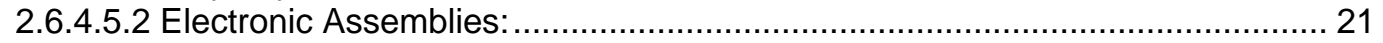

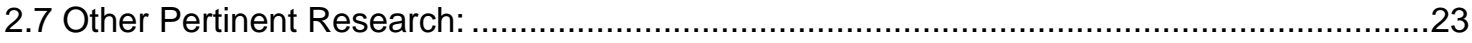

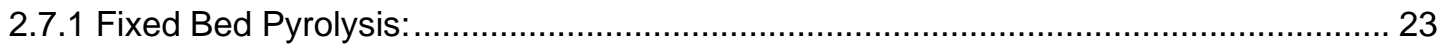

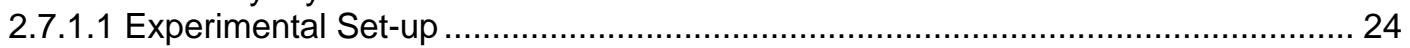

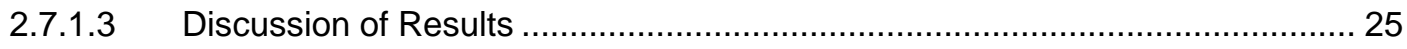

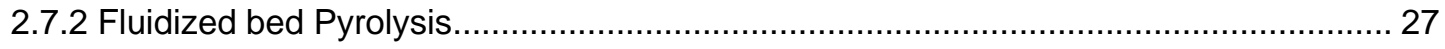

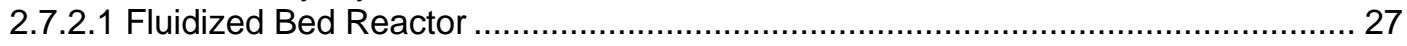

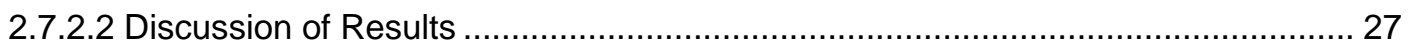

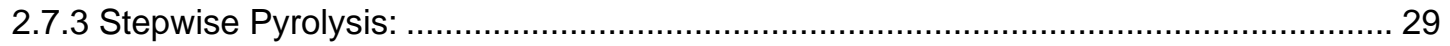

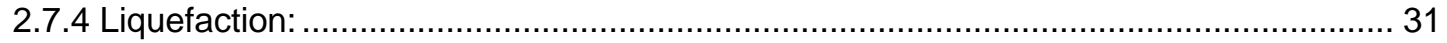

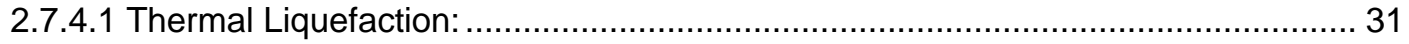

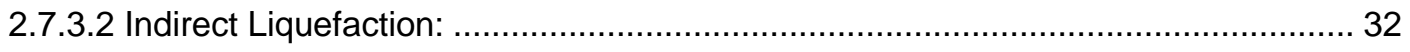

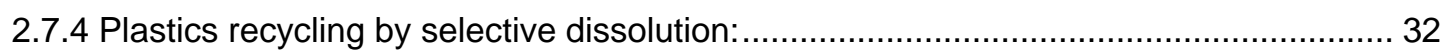


3 EXPERIMENTAL EQUIPMENT AND PROCEDURES .............................................................. 36

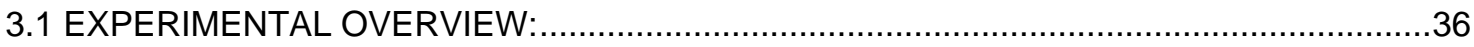

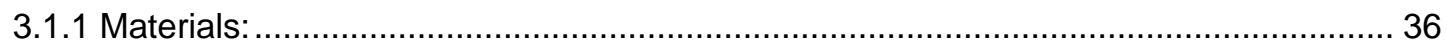

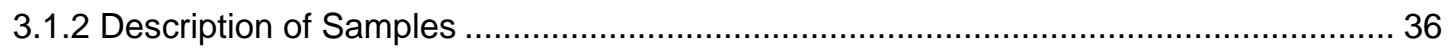

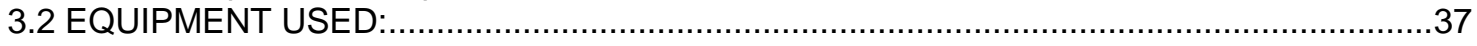

3.2.1 D-86 Atmospheric Distillation Apparatus: ........................................................ 37

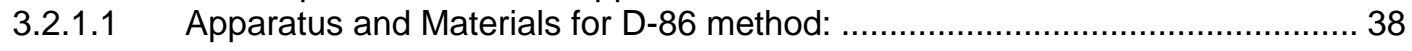

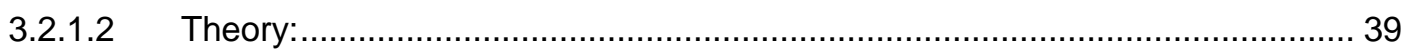

3.2.2 Tubular Batch Reactor (TBR):

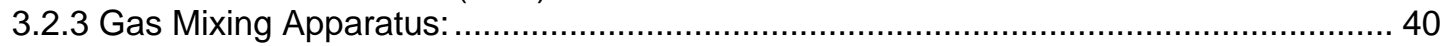

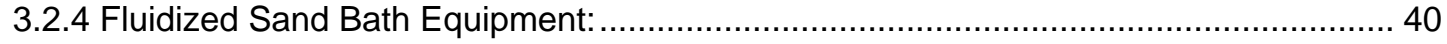

3.2.5 Batch Reactor Agitation Mechanism: .................................................................. 44

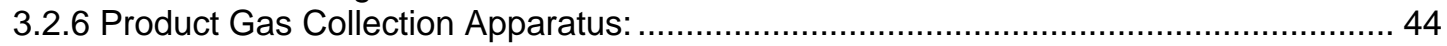

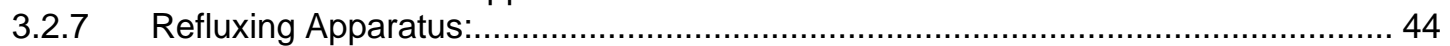

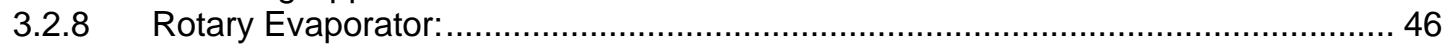

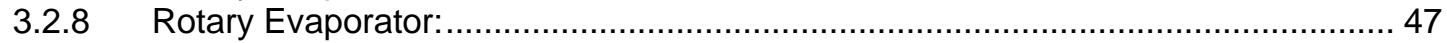

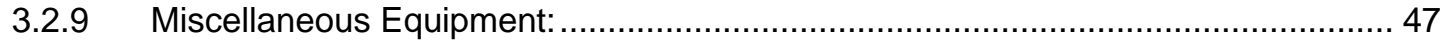

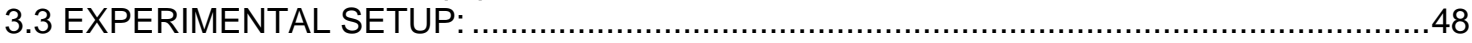

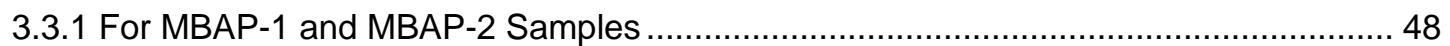

3.3.1.1 Mixed Plastic Sample Preparation For MBAP -1 and MBAP-2: ........................ 48

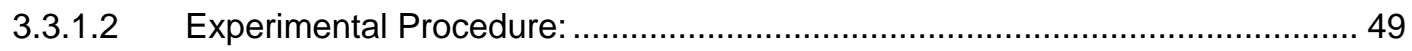

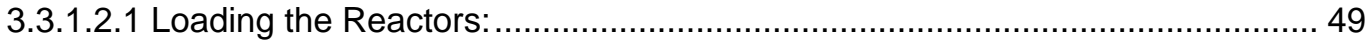

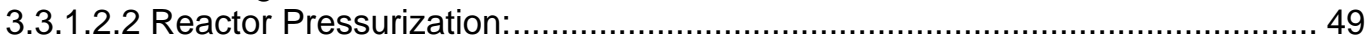

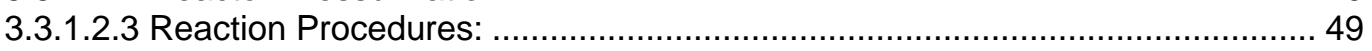

3.3.1.2.4 Product Gas Collection and Analysis:....................................................... 50

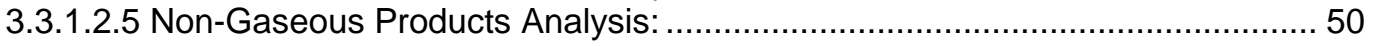

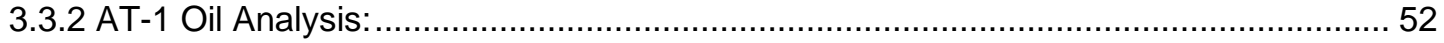

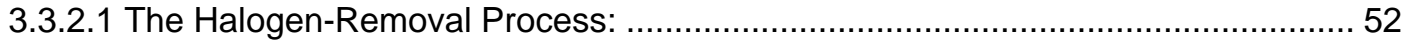

3.3.2.2 General Procedure for Distillation in the D-86 Apparatus: ............................... 52

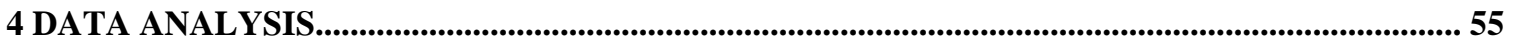

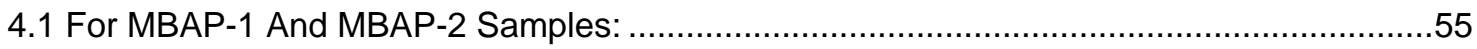

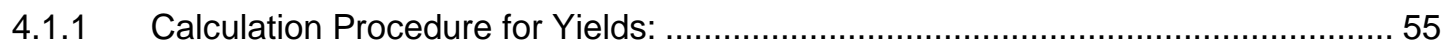

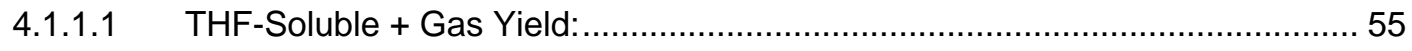

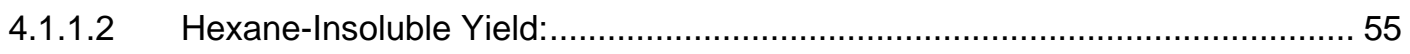

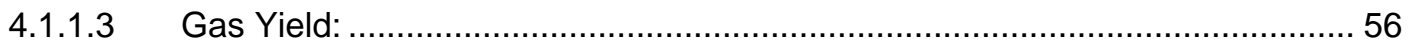

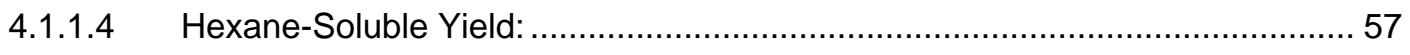

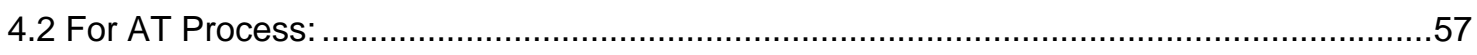

4.2.1 Distillation Temperature Calculation of AT-1 Oil for ASTM D-86 Analysis: .................. 57

5 RESULTS AND DISCUSSION:......................................................................................................... 58

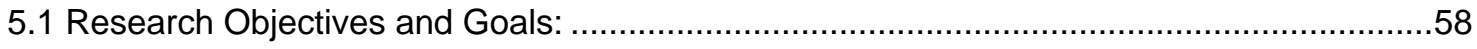

5.2 Characterization of Pyrolysis Products from MBAP samples: ........................................59

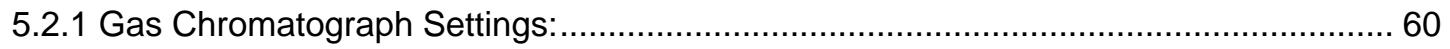




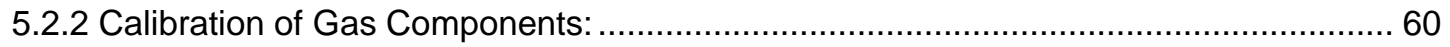

5.2.2.1 GC Calibration Curves of Permanent Gases Air, Carbon Dioxide and Helium:..... 61

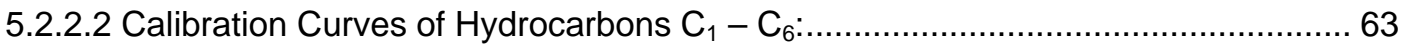

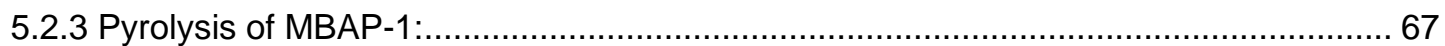

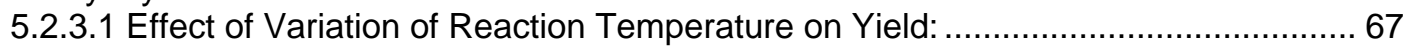

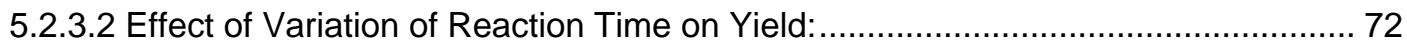

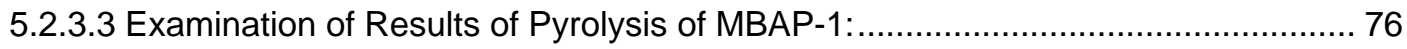

5.2.3.3 Examination of Results of Pyrolysis of MBAP-1:.............................................. 77

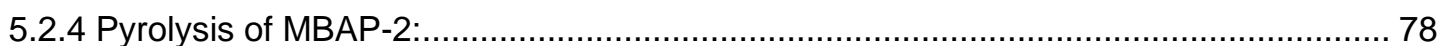

5.2.4.1 Effect of Variation of Reaction Temperature on Yield: .................................... 80

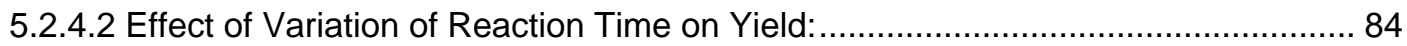

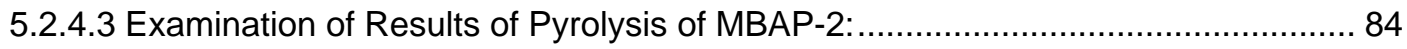

5.2.5 Effect of Iron Catalyst and Hydrogen on the Product Yields:....................................... 89

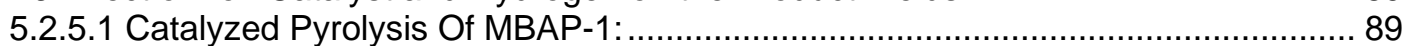

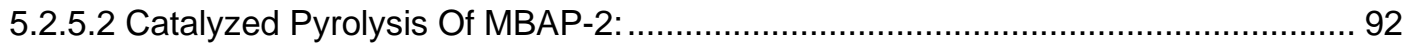

5.2.6 Comparison Of Results From Pyrolysis Of MBAP-1 And MBAP-2: ........................... 92

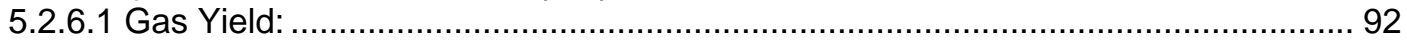

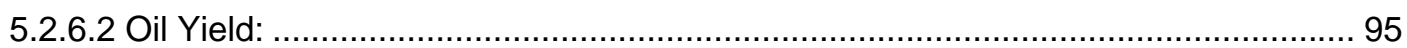

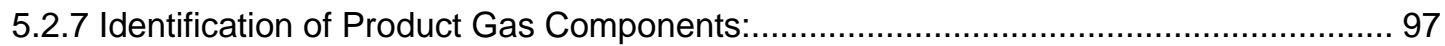

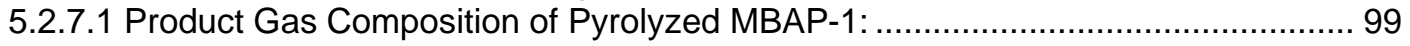

5.2.7.2 Product Gas Composition of Pyrolyzed MBAP-2: ........................................... 100

5.2.7.2 Product Gas Composition of Pyrolyzed MBAP-2: ............................................ 101

5.2.7.3 Heat Recovery from the Product Gas: ............................................................. 103

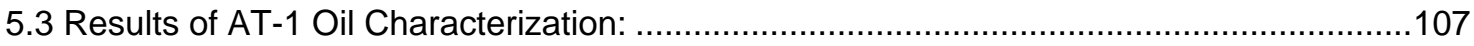

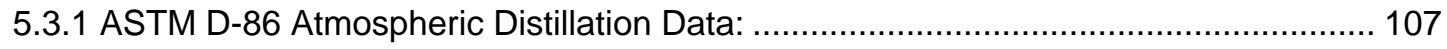

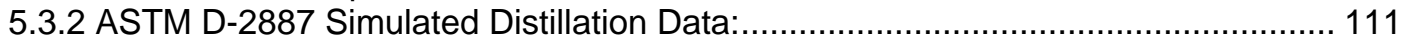

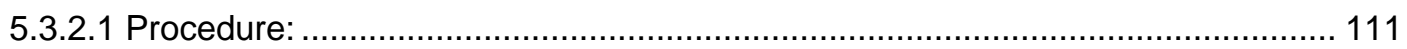

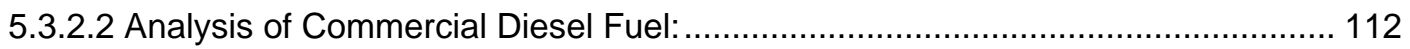

Note: the FBP and IBP are calculated by the D-2887 software............................... 113

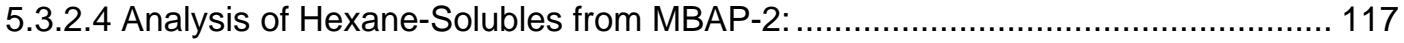

5.3.3 HPLC Analysis of High Boiling Fractions (> 662 ${ }^{\circ}$ F) of AT-1 Oil :............................. 120

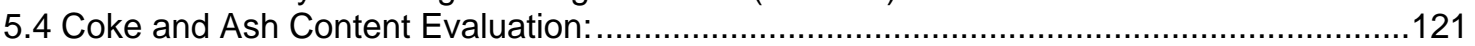

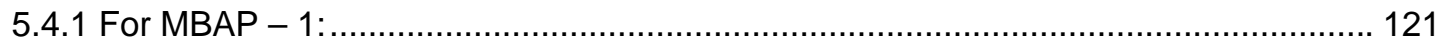

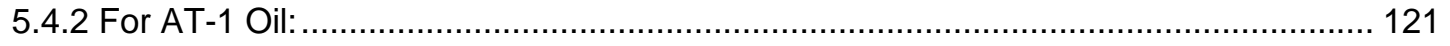

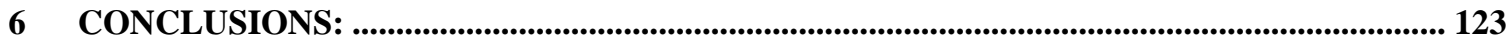

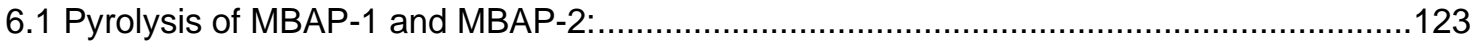

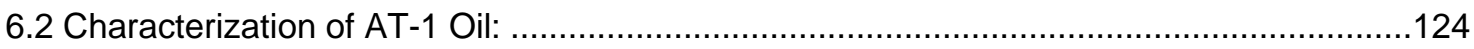

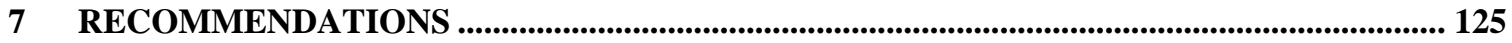

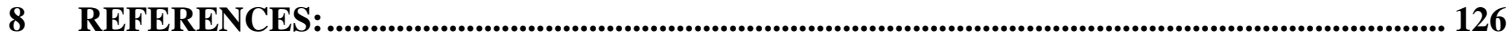

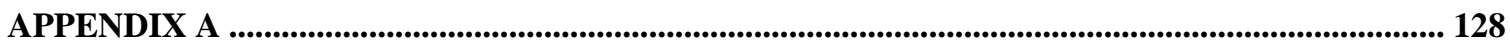




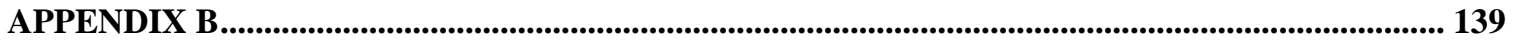

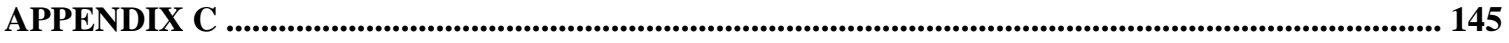

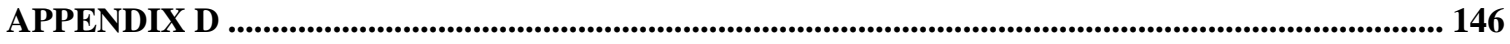




\section{Statement of the Problem}

This work aims at investigating pyrolysis, a tertiary recycling process, as a technique for recovering light oils and gases from non-separable waste-polymer streams generated from spent electronic devices, namely computer central processing units (CPU) and monitors, otherwise called End of Life (EOL) Electronic Residues. The oil and gas fractions are to be used as useful chemicals and fuel. A pyrolysis oil (AT-1) provided by Adherent Technologies (AT), Albuquerque, NM, from a waste polymer stream processed at their pilot plant and two waste polymer streams (MBAP-1 and MBAP-2) provided by MBA Polymers, Richmond, CA were analyzed and tested in this study.

AT recycles waste plastics, including those from spent electronic equipment, using a two-stage catalytic pyrolysis process. The liquid after pyrolysis but before upgrading has been provided and shall henceforth be referred to as AT-1 oil. The shredded EOL Electronic Plastics (supplied by MBAP) are of two streams, the fines and the non-separables. The fines (MBAP-1) consist of all types of polymer resins, such as Acrylonitrile-Butadiene- Styrene co-polymer (ABS), High-Impact Polystyrene (HIPS), Polyvinyl Chloride (PVC) and Polycarbonates (PC) that are too small in size to be separated further by the MBAP process. The non-separable stream (MBAP-2) is a mixture containing mostly the polymers ABS and HIPS that have the same density range (1.02 to 1.15$)$. This makes separation (to a high degree of purity) of these two polymers impossible using traditional Air Classification Techniques as practiced at MBAP. Pyrolysis of the streams is a very good alternative to landfilling, especially since landfilling has ceased to be an attractive option due to non-availability of land and subsequent pollution problems.

Pyrolysis is an integral part of this research and is defined as the thermal degradation of organic feedstock in an inert atmosphere or under vacuum causing the molecules to cleave at their weakest points to produce smaller, volatile fragments (pyrolysates). Pyrolysis is a simple and effective method for breaking polymers into simpler compounds (monomers and other useful compounds) and is usually independent of composition of the polymer/plastic feedstock. The proposed method for obtaining the pyrolysis products from the fines and non-separables streams, MBAP-1 and MBAP-2 respectively, is to heat the feed in a batch reactor under helium atmosphere and then separate the pyrolysates (gas, oils 
and solids). The operating temperature range of $375^{\circ} \mathrm{C}-450^{\circ} \mathrm{C}$ and operating pressure of 50psig was chosen based on earlier research indicating completion of thermal degradation of plastics at $450^{\circ} \mathrm{C}$. Pyrolysis at such lower temperatures is often referred to as Low Temperature Pyrolysis.

As mentioned earlier, AT uses a two-stage catalytic pyrolysis process. The AT-1 oil supplied, i.e., the liquid after pyrolysis but before upgrading, is to be analyzed by studying the boiling-point curves using ASTM Methods D-86 and D-2887. Both the methods provide temperature vs. distillate volume data. While ASTM D-86 is a simple distillation technique that plots True Boiling Point (TBP) curves, ASTM D-2887 is a simulated distillation technique that employs a Gas Chromatograph (GC) with a Flame Ionization Detector (FID). The GC contains a capillary column with temperature programming from $0^{\circ} \mathrm{C}$ to $350^{\circ} \mathrm{C}$ to separate the sample into constituent fractions that elute at their boiling points. The FID combusts the hydrocarbon fractions of the oil sample and sends a corresponding signal which is recorded as peak area. The software associated with the equipment (Varian $3400 \mathrm{GC}$ ), Chemstation, also provides a correlation to the ASTM D-86 technique. This correlation is useful in comparing the two techniques and corroborating the results. A few samples of the oil obtained through the pyrolysis of MBAP samples as well as the original AT-1 oil were analyzed by the ASTM D-2887 Method.

This research aims at finding new processes for the recycling of scrap plastics that have a possibility for economical scale up. Relatively less-severe process conditions (when compared to conventional pyrolysis, which has operating temperatures ranging from $500^{\circ} \mathrm{C}-700^{\circ} \mathrm{C}$ ) and simple procedures may enable this process to be economical. Also the characterizations of the pyrolysis products and the AT-1 oil will help in effective use of EOL Electronic residues. 


\section{LITERATURE REVIEW}

\subsection{Introduction}

Computers in general have become all- pervasive in modern society. Almost all day-to-day functions can now be carried out using the help of computers. The electronics industry is the fastest growing component of the Gross Domestic Product of the U.S. and hence is obviously a vital component of the U.S. economy ${ }^{1}$. Along with computers, there is a whole array of electronic goods that use plastics in substantial quantities. As older processors get replaced with newer ones, alternative methods need to be considered for proper and safe disposal of the potential harmful plastic, glass and metal components of this equipment. Moreover, recycling of these materials is of crucial importance since they represent a huge amount of hydrocarbon-based compounds that may be of commercial value if recovered ${ }^{2}$.

\subsection{Recycling Defined:}

Recycling $^{3}$ is the collection, reprocessing and use of materials that are recovered or diverted from the solid waste stream. "Recyclables" are spent materials that have useful physical and chemical properties and can be reused or remanufactured into new products. Recycling can be divided into three categories - primary, secondary and tertiary.

Primary recycling: or closed-loop recycling is the use of recycled products to make the same or similar products. Examples of primary recycling include the use of bottles to make bottles, etc.

Secondary recycling: is the use of recycled materials to make new products with different specifications than the original products. For example high-density polyethylene (HDPE), the plastic material used to make milk jugs, is often recycled into trash cans or drainage pipes. Reuse of resins in general, for purposes other than what they were originally used for, is referred to as secondary recycling.

It is to be noted here that both primary and secondary recycling, considered to be conventional recycling techniques, need manual segregation and usually result in poor economics. 
Tertiary recycling: The term "Tertiary Recycling" as defined by the American Plastics Council is the processing of plastics back to valuable chemicals or fuel for reuse ${ }^{4}$. It results in the formation of polymers, monomers, chemicals or fuel from thermal degradation of polymeric waste materials. Pyrolysis is an example of tertiary recycling and has been employed in this study. Tertiary Recycling combines all the feedstock thus eliminates the need for manual segregation, thereby decreasing the associated labor cost. This approach is totally contradictory to that of primary and secondary recycling methods. The ability of the tertiary recycling process to remove the cost of labor, which is such an integral part of the economics of conventional recycling processes, makes it a promising alternative in terms of economics.

Recycling can also be classified as "mechanical" and "chemical" recycling. Mechanical recycling refers to the direct recycling and conversion of plastics from discarded materials into plastic pellets. These recycled pellets are then reintroduced into the plastic production process to form new products. Chemical recycling deals with conversion of polymers back to short-chain chemicals for use as fuel and petrochemical feedstock ${ }^{5}$. The fundamental difference between tertiary recycling and conventional thermal and mechanical degradation forms is that "the purity of the plastics does not matter" in the former. Pyrolysis is a chemical recycling technique.

It should be noted that Primary and Secondary Recycling are basically mechanical recycling techniques which exploit the physical properties of materials (melting point, specific gravity etc.), to retrieve the resins in their virgin form and to use them for various applications. Chemical and mechanical recycling will be dealt with in Sections 2.4 and 2.5 .

\subsection{Pertinent Statistics:}

The use of plastics in all major markets has risen from 36.9 billion pounds (16.8 billion kilograms) in 1980 to 86.4 billion pounds (39.3 billion kilograms) in $1996^{2}$. Most of this material needs to be recycled.

Plastics recycling in general, and tertiary recycling in particular, make ethical and economic sense. Though constituting only $11 \%$ by weight and about $24 \%$ by volume, plastics constitute a highly visible component of trash and are blamed for a disproportionate share of the current waste disposal problems. The solutions to the disposal problems could be ${ }^{1}$ : 
- Bury them in landfills.

- Burn them in incinerators.

- Recycle them to useful products by mechanical recycling, i.e. primary or secondary recycling.

- Pyrolize them to industrial chemicals and fuels (chemical or tertiary recycling).

The first option might not be a long-term solution, as the use of plastics seems to be ever increasing while land available for landfilling is shrinking. But for the present, landfilling is an alternative as lack of landfill space is more a perception than a reality in most countries including the US. Further, plastics, being inert, and though not biodegradable, seem to cause no apparent problems to the environment ${ }^{1}$.

As of today, the majority of scrap plastics is being landfilled. The following issues will however nullify this method as an option for the disposal of electronic scrap ${ }^{3}$ :

- Though plastics themselves are considered inert, heavy metals (lead, cadmium etc.), a component in much electronic equipment, are harmful to the environment and restrictions have been placed on landfilling them.

- Environmental regulations are being considered to control disposal of electronic scrap, requiring manufacturers to "take back" EOL equipment.

- Overseas manufacturers are currently required to take back end-of-life products to dispose of them properly or recycle the materials; US manufacturers who use plastics in their manufacturing processes are beginning to develop programs similar to overseas companies.

In the second option, incineration, it is to be noted that to make one kilogram of plastics, it takes the energy equivalent of three to four kilograms of crude oil. Furthermore, the major products of incineration, $\mathrm{CO}, \mathrm{CO}_{2}$ and $\mathrm{NO}_{x}$, are the major pollutants causing the depletion of the ozone layer.

The third option, mechanical recycling, is very useful, but has certain opposing factors to contend with. The recycled plastic must meet some stringent quality checks (recycled plastic resins need to be about $99 \%$ pure), as they must compete with virgin polymers. In the case of most non-electronic items, 
the number of types of plastic resins is small and hence recovery of each type of plastic resin is economically feasible. However, in electronic equipment, as many as 13 different resins are used (one needs to just look at the back of a computer casing for proof). Separating the components to a purity of $99 \%$ or greater would be very difficult and might not be economically feasible.

The final option, pyrolysis, is of value in the disposal of plastics in Electrical and Electronic (E\&E) applications. In E\&E applications, plastics constituted about 3.5 billion pounds in $1995^{2}$. The E\&E sector consumed approximately 4.2 percent of the total US plastics production in the same year. Electronic plastics are made up of the following ${ }^{2}$ :

- Polystyrene, including High Impact Polystyrene (HIPS) : : $23 \%$

- Polyvinyl Chloride (PVC) $\quad: 15 \%$

- Polyethylene (PE) : $14 \%$

- Acrylonitrile-Butadiene-Styrene copolymer (ABS) $\quad$ : $11 \%$

- Polypropylene $\quad: 10 \%$

- Other* $\quad: 27 \%$

* Other: Polycarbonates (PC), Polyethylene terephthalate (PET) etc.

Surveys ${ }^{2}$ have shown that the scrap electronic waste stream is 1.8-2.7 million metric tons annually in the US and is growing rapidly, with the majority of the growth in the electronics industry. This includes computers, copiers, printers, video cassette recorders, televisions, cellular phones, radios, test instruments, medical devices and other electronic assemblies The waste stream contains two-thirds metals and inorganics and one-third plastic. Cathode Ray Tubes (CRTs), whose plastics content is increasing rapidly, are not included.

Most electronics are made up of a complex mixture of materials such as plastics, fiberglass, fillers and metals. This array of components in them makes recycling difficult. Hence, at present, less than 5\% of this waste stream is being recycled.

Researchers over the decades have found commercially viable techniques for recycling most plastics and metals (soda cans, milk containers etc.) using conventional secondary recycling processes, 
which primarily involve sorting of feedstock into similar materials as the first step. But this is not the case with electronic goods, due to their sheer diversity and complex material makeup. Furthermore, electronic plastics are often contaminated with metals for Electromagnetic Interference (EMI) shielding purposes, making them unrecycleable using conventional secondary recycling processes.

Under these circumstances, tertiary (or chemical) recycling, conversion of plastics into low molecular-weight hydrocarbons for use as chemical feedstock, monomers or fuels, is a potential first step in an overall recycling process for reclaiming materials from electronic scrap. Tertiary Recycling is rapidly emerging as an economical method for reclaiming valuable materials from electronic scrap that would otherwise be landfilled.

\subsection{The Scope of Tertiary (or Chemical) Recycling:}

Tertiary (or Chemical) Recycling is a process that converts polymers back into short-chain chemicals for reuse in polymerization or other petrochemical processes. There are two chief benefits to the technique:

1. The chemicals it yields, whether they are monomers or petrochemicals, are comparable to the originals.

2. Chemical Recycling is a more forgiving, universal technique that can effectively dispose of large amounts of post-consumer waste.

\subsubsection{Processes that show Commercial Potential:}

Many of the processes for tertiary (or chemical) recycling are already in use in the petrochemical industry. Four technologies, which have been previously employed in fossil fuel refining, can be applied to plastics, and are listed below ${ }^{5}$ :

1. Cracking: This process usually operates at $400-600^{\circ} \mathrm{C}$, and at pressures slightly above atmospheric to make liquids (usually highly viscous, waxy oligomers) that can be catalytically broken down to yield commercially useful fractions. Gases produced would be rich in hydrocarbon content, would possess a high calorific value and hence could be burned to supply process heat. 
2. Gasification: Operating temperatures could be $900^{\circ} \mathrm{C}$ to as high as $1400^{\circ} \mathrm{C}$, under 60 bar pressure, and an atmosphere of oxygen and steam, to produce mostly carbon monoxide and hydrogen. Temperatures beyond $1400^{\circ} \mathrm{C}$ would result in oxidation of $\mathrm{CO}$ to $\mathrm{CO}_{2}$. Gasification is fast becoming the preferred choice of many industries that deal with simple plastics, as the end products are very important raw materials for most chemical industries.

3. Hydrogenation: This reacts the polymeric material in a hydrogen atmosphere at $300-500^{\circ} \mathrm{C}$, and 100- 400 bar pressure to produce a mix of 65 - 90\% oil (Syncrude), 10 - $20 \%$ gases and up to 20\% solid residue.

4. Pyrolysis: Usually operating at $350^{\circ} \mathrm{C}-950^{\circ} \mathrm{C}$ in an oxygen-free atmosphere, this technique makes gaseous hydrocarbons, ammonia, and hydrogen chloride (up to 50\%, if PVC is present), Syncrude (25 - 40\%), and solid residue. Reactions performed at $350^{\circ} \mathrm{C}-450^{\circ} \mathrm{C}$ are generally referred to as lowtemperature pyrolysis. This is more energy efficient and provides better economic and environmental incentives for commercialization ${ }^{7,8}$. Conventional pyrolysis, unlike low-temperature pyrolysis, occurs between temperatures of $500^{\circ} \mathrm{C}-700^{\circ} \mathrm{C}$. High-temperature pyrolysis, at reaction temperatures of up to $950^{\circ} \mathrm{C}$, results in production of more gases than oils ${ }^{9}$. Although highly desirable chemicals such as ethene, propene and butane are produced, the problem with very high gas yields is the presence of hydrogen chloride gas (PVC is extensively used in the plastics industries, including those that manufacture electronics). PVC is said to degrade at about $150^{\circ} \mathrm{C}^{9}$. In high-temperature pyrolysis, $\mathrm{HCl}$ gas is formed and if not removed instantaneously, further combines with polar organics (secondary reactions) resulting in the formation of non-gaseous organo-chlorides (essentially liquid) 8,9. Removal of chlorine/chlorides from pyrolysis products is expensive and poses environmental problems. In low-temperature pyrolysis, the extent of secondary reactions is minimal thus resulting in minimal formation of organic-chlorides ${ }^{8,9}$.

It is important to note that conventionally, monomers and monomer precursors are derived from refining crude oil. Cracking, pyrolysis, hydrogenation and gasification are essentially thermal or chemical 
depolymerization techniques (see section 2.4.2). Thus, pyrolysis of polymer feedstock offers an alternative source for monomer and monomer-precursor production (if the plastic is produced through reversible reactions, e.g.: PET). Furthermore, this conversion process leads to production of either recyclable monomers or other products like gasoline, asphalt or heating oils (if the polymer is produced through irreversible reactions, e.g. HDPE, PVC etc).

The closed-loop nature of chemical recycling (unlike incineration) is detailed in Figure 2.1 which traces the path of plastics produced from the petrochemical industry. The petrochemical industry manufactures monomers (styrene, benzene, alkenes etc) that in turn are used by resin manufacturers to produce plastics. These plastics reach end user markets and after disposal are collected as "scrap plastics" and sent to recycling facilities. Here, the sorting, collecting and cleaning of scrap plastics is followed by "chemical recycling" (cracking, hydrogenation or pyrolysis) of the scrap plastics to convert them into "syncrude". This synthetic crude is then blended with the crude oil and is used in the refineries for production of fuels or monomers that used as feedstock for resin manufacturing. The extent to which each of the steps is utilized will depend on the polymer feedstock composition. The closed loop nature of chemical recycling is one major factor in favor of chemical recycling as opposed to incineration.

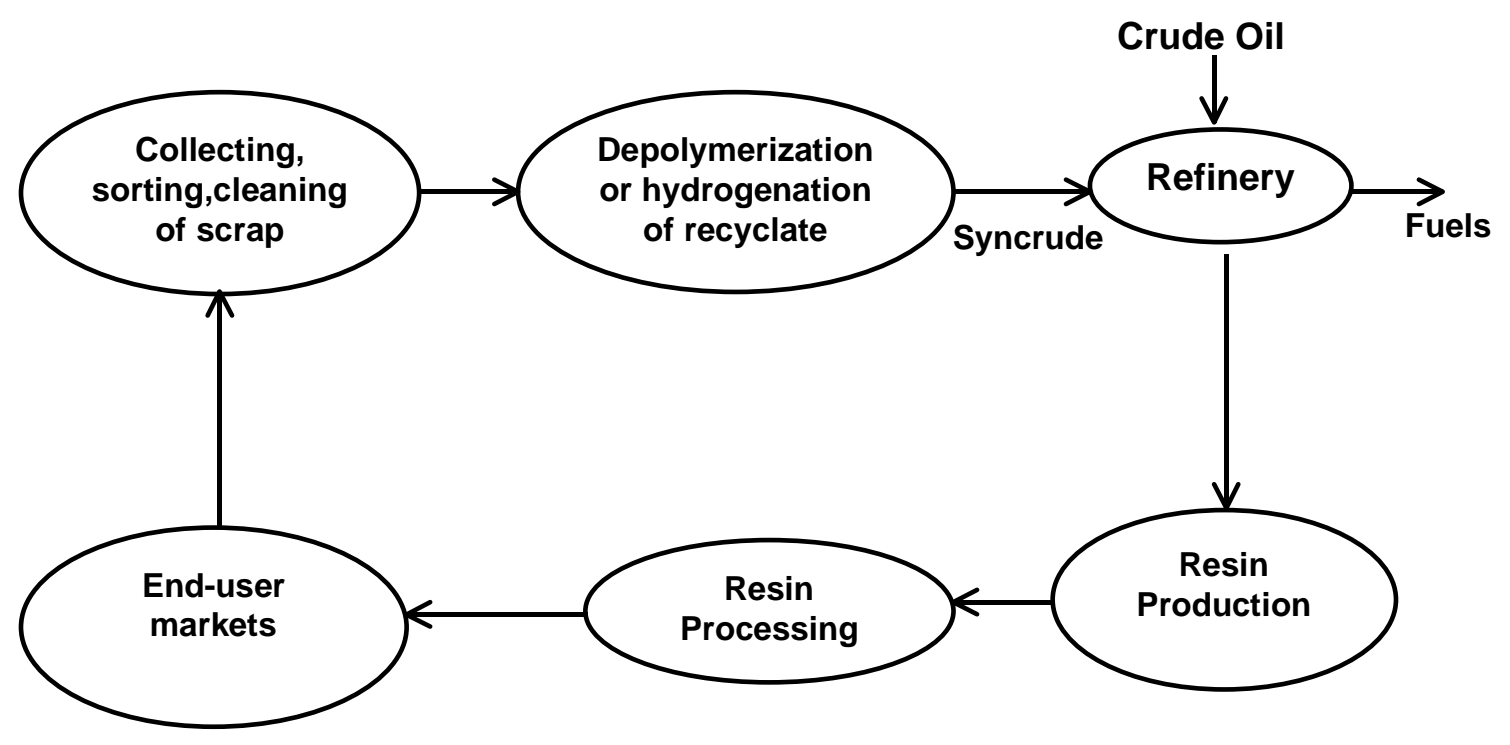

Figure 2.1 Chemical Recycling as a true closed-loop process ${ }^{5}$ 


\subsubsection{Routes for De-polymerization of Plastics:}

The chemical recycling route could be broadly classified into two pathways as illustrated in Figure $2.2^{5,6}$ :

1. Chemical and Thermal Depolymerization (ROUTE A)

2. Pyrolytic Liquefaction and Gasification (ROUTE B)

It is important to note that Route A in Figure 2.2 could be possible only for polymers produced by reversible reactions whereas Route $B$ has no such limitations. Alcoholysis-hydrolysis is a form of chemical depolymerization oxidation (Route A). Methanolysis and Glycolysis (forms of alcoholysis) effectively reduce condensation polymers to monomers or oligomers (which are polymerizable) by reversing the preparative chemistry.

Pyrolytic Liquefaction (Route B), which is similar to thermal depolymerization and must be conducted in the absence of oxygen to prevent oxidation of products, produces liquids similar to naphtha. The liquids produced by pyrolysis are important for they are rich in hydrogen (mostly aliphatic compounds). Pyrolytic Gasification (Route B) produces gases under extremely harsh conditions (high temperatures and catalysts). There are established processes which, from LDPE, LLDPE, PS and PVC, have produced $40 \%$ ethylene, $27 \%$ methane, $17 \%$ hydrogen and other fractions.

The appropriate technique for conversion of polymer feedstock into monomer or petrochemical feedstock/fuels depends upon the type of polymers with which one has to deal. If the sample in question is a polyester, polyamide, polyurethane or other polymers manufactured through a "reversible process" (i.e., when the polymerization reaction is reversible) then monomers or starting materials can be obtained and converted again into the respective polymers.

If the sample consists of polymers such as HDPE, PP or PVC (created via irreversible reactions), then converting them into only basic petrochemical components would be possible. Additional refining and purification steps would help in isolating monomers and high-performing fuel ingredients. 


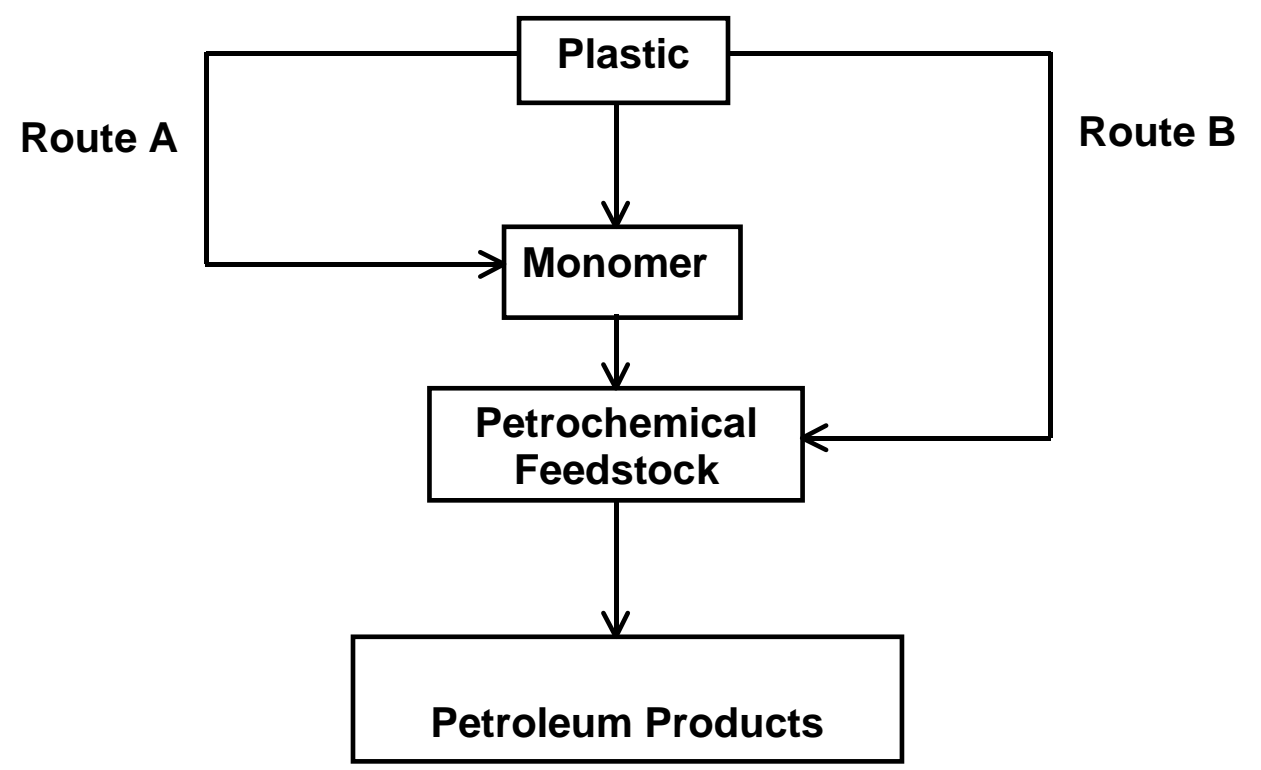

Figure 2.2 Routes for De-polymerization of Plastics 


\subsection{Experimental Process of MBA Polymers:}

MBA Polymers (MBAP) has developed a mechanical recycling process for separating polymers from mixed-waste plastics in electronic equipment ${ }^{9}$. As of December 1998, MBA Polymers acquired over $300,000 \mathrm{lbs}$. of dismantled whole parts and granulated material from computer and printer housings, monitor housing and other electronic components, over half of which was in the form of whole parts ${ }^{9}$. CRT and monitor housings supplied most of the granulated feed. All the plastics were ground in a mixed fashion so as to facilitate handling and storage and to reduce disposal costs. The plastic samples were analyzed to determine the number of plastic resins appearing in the feedstock. Predominant resin types are ABS, HIPS, PC, PC/ABS, PVC and polypropylene oxide (PPO).

MBAP has two methods for identifying and sorting whole parts prior to grinding. One method is an automated sorting line and the other is manual, using a bench-top spectrometric unit. The latter was found to be the most suitable technique. The automated sorting line resulted in malfunctions arising from the "parts sensing system" portion of the spectrometric unit that recognizes the plastic component according to existing library data, along with problems in detection and ejection of parts encountered in pilot-scale tests. Hence the automated sorting technique was discarded.

The bench-spectroscopic method (discussed hence) requires laborers to pick the part manually and place it in the vicinity of the measuring head of the spectrometer, read the identification codes (each resin has a unique code) displayed by the spectroscopic equipment and then place the part into a marked box. If a particular lot has a number of identical parts, then the throughput increases as the production line workers are able to identify "like parts". Depending upon the nature of the mixed streams, the average throughput rates are $1000 \mathrm{lb} / \mathrm{hr}$ to $3000 \mathrm{lb} / \mathrm{hr}$ for a group of three laborers.

The parts next go to the dry-processing unit, which has two processing lines, the primary and secondary lines. The main function of the primary (first) line is to reduce the size of the whole parts and remove metals. The main function of the secondary line is to further reduce the size of the plastic and remove the fines and the light contaminants (labels, foams, etc) via air classification. It is to be noted that the fines obtained from the secondary line were sent to WVU for use (these are labeled MBAP-1). 
The whole parts are passed through the primary line. The primary line reduces the size of the whole parts by employing size-reduction equipment and removes metals by magnetic separation and other techniques as explained further. The parts are passed from a large grinder to a magnet which removes ferrous metal pieces and then to a secondary mill to reduce the sample size to 1 inch. An eddycurrent separator then removes the non-ferrous metals from the plastic. The products from the primary line and the other granulated material obtained by MBAP pass through a secondary line. The secondary line is primarily used to reduce the size of the plastics further and to remove the fines and light contaminants (labels, foam etc.) via air classification. Here the materials are passed through another shredder, a ferrous-metal-removal magnet, a granulator to reduce the particles size to 3/8", and then again through a series of air-classification units. Air classification is a separation technique that exploits the density differences between various materials in the contaminated feed. Obviously, while the whole parts are granulated in both the lines, the pregranulated material is processed only in the second line. The mass balance of the each sample stream is then recorded and the products are put into bulk bags, weighed, labeled and put into storage. The mass balances for a sample stream of the whole-parts mixture (not pregranulated) for the two lines are presented in Tables 2.1 and 2.2. The mass balance for pregranulated, mixed monitor housings is presented in Table 2.3.

Table 2.1 Primary processing mass balance for mixed whole parts

\begin{tabular}{|c|c|c|c|}
\hline Incoming Material (lb.) & $\begin{array}{c}\text { Product } \\
(\mathrm{lb} .)\end{array}$ & $\begin{array}{c}\text { Ferrous Metals } \\
(\mathrm{lb} .)\end{array}$ & $\begin{array}{c}\text { Non-ferrous Metal } \\
(\mathrm{lb} .)\end{array}$ \\
\hline 91357 & 85397 & 5960 & 0 \\
\hline & $93.5 \%$ & $6.5 \%$ & $0 \%$ \\
\hline
\end{tabular}

Table 2.2 Secondary processing mass balance for mixed whole parts

\begin{tabular}{|c|c|c|c|}
\hline Incoming Material (lb.) & $\begin{array}{c}\text { Product } \\
(\mathrm{lb} .)\end{array}$ & $\begin{array}{c}\text { Ferrous Metals } \\
(\mathrm{lb} .)\end{array}$ & $\begin{array}{c}\text { Non-ferrous Metal } \\
(\mathrm{lb} .)\end{array}$ \\
\hline 85397 & 82070 & 3327 & 0 \\
\hline & $95.5 \%$ & $4.5 \%$ & $0 \%$ \\
\hline
\end{tabular}

Table 2.3 Dry processing mass balance for pregranulated, mixed monitor housings

\begin{tabular}{|c|c|c|c|}
\hline Incoming Material (lb.) & $\begin{array}{c}\text { Product } \\
(\mathrm{lb} .)\end{array}$ & $\begin{array}{c}\text { Ferrous Metals } \\
(\mathrm{lb})\end{array}$ & $\begin{array}{c}\text { Non-ferrous Metal } \\
(\mathrm{lb} .)\end{array}$ \\
\hline 151,384 & 144,393 & 6550 & 441 \\
\hline & $95.4 \%$ & $4.3 \%$ & $0.3 \%$ \\
\hline
\end{tabular}


The processed streams are then analyzed to determine their composition and density distribution. This information helps in determining the product contamination as well as the wet line processing strategy (explained later) for the streams.

Different analysis techniques are used for the two streams, the pre-sorted/pregranulated whole parts and the mixed whole parts. A grain thief is used as a sampling tool for the characterization of presorted whole parts in the primary and secondary lines. Then, spectroscopic instruments are used for characterization of the plastic chips that are later weighed and put into separate sacks according to the classification.

The procedure is more complex for mixed whole parts due to the polymer resin variability in each bag (containing approximately $1000 \mathrm{lb}$. of material). For each batch of mixed whole parts (1000 lb.), after thorough mixing, a $7 \mathrm{lb}$. sample is extracted using a grain thief. Analysis of this sample is then conducted by sorting the material into densities from $0.90 \mathrm{~g} / \mathrm{cc}$ to $1.45 \mathrm{~g} / \mathrm{cc}$ in increments of $0.01 \mathrm{~g} / \mathrm{cc}$, using aqueous alcohol solutions and salt solutions. For each aqueous solution density, the material floating is removed from the batch, washed, dried, pressed out using a platen press (which increases the surface area thereby making the chip more compatible with the spectroscopic heads), identified using spectrometry and sorted on a per chip basis. The remaining resins are separated in a similar fashion for each density increment and weighed.

The characterization of whole parts (both presorted/pregranulated or mixed) based solely upon spectroscopic instruments cannot ensure pure products due to contamination of varying level and origin. The reasons for contamination could be the improper dismantling of parts prior to identification, incorrect identification and human error. The whole parts can have smaller components of a different resin attached to them, which could be easily missed if the parts are of the same color. Also, the spectrometric instruments are not $100 \%$ accurate, as in some cases, the grade of the resin (e.g. whether it is fiber reinforced or not) is not comparable to the spectroscopic instruments calibration standard, leading to incorrect identification. Thus after dry processing, every sorted steam becomes a candidate for wet processing (which will not be described here due to lack of sufficient information). 


\subsection{Experimental process of Adherent Technology:}

Adherent Technologies (AT) takes a different approach. AT's process uses tertiary recycling ${ }^{2}$, accomplished by a low-temperature, catalytic conversion process. In this process, whole electronic components are reduced in size independent of feedstock composition. The unit operations in the AT process take care of the removal of components of computers such as Cathode Ray Tubes (CRTs) and other metal components both before and after the process. CRTs are removed and recycled by manual segregation to recover the lead, which constitutes over $28 \%$ by weight of the CRT.

\subsubsection{The Process:}

The AT process uses the "Phoenix Reactor" which employs feed with varying compositions (see Figure 2.3 for process flowchart). The feedstock, granulated plastics from electronic components, is held in a hopper/conveyer. The conveyer then advances the feed (ground plastics) into the holding chamber on a slot-by-slot basis. The material is then fed into the reaction chamber. A vacuum is pulled in the reactor in order to compensate for the addition of feed. A screw conveyor (not shown in Figure 2.3) is used to move the feed into the reaction zone. An isolation valve is used to maintain separation between the reactor and the process vacuum pump. The heat sources for the reactor are four gas-fired radiant heaters that are oriented along the axis of the reactor. They are placed equidistant so as to provide a uniform temperature distribution. The gas temperature is around $400{ }^{\circ} \mathrm{C}$. As the material is transported to the heated zone, the polymers begin to break down and vaporize. The vacuum created removes the gaseous hydrocarbons. The off-gas lines are heated to prevent condensation before they travel through a series of condensers where they are condensed to as low as $0^{\circ} \mathrm{C}$ to liquid. The gaseous products are drawn through a solids trap to prevent light, free-flowing solids from fouling the condensers. These inert solids (metals, fiberglass, ceramics etc.) are transported to storage areas. The non-condensable gases are collected and analyzed. The solids are removed from the reactor and collected for analysis. The remaining products in the reactor are usually all liquids. The analyses of solid, liquid and gaseous products for a few selected runs are described later under separate sections. 


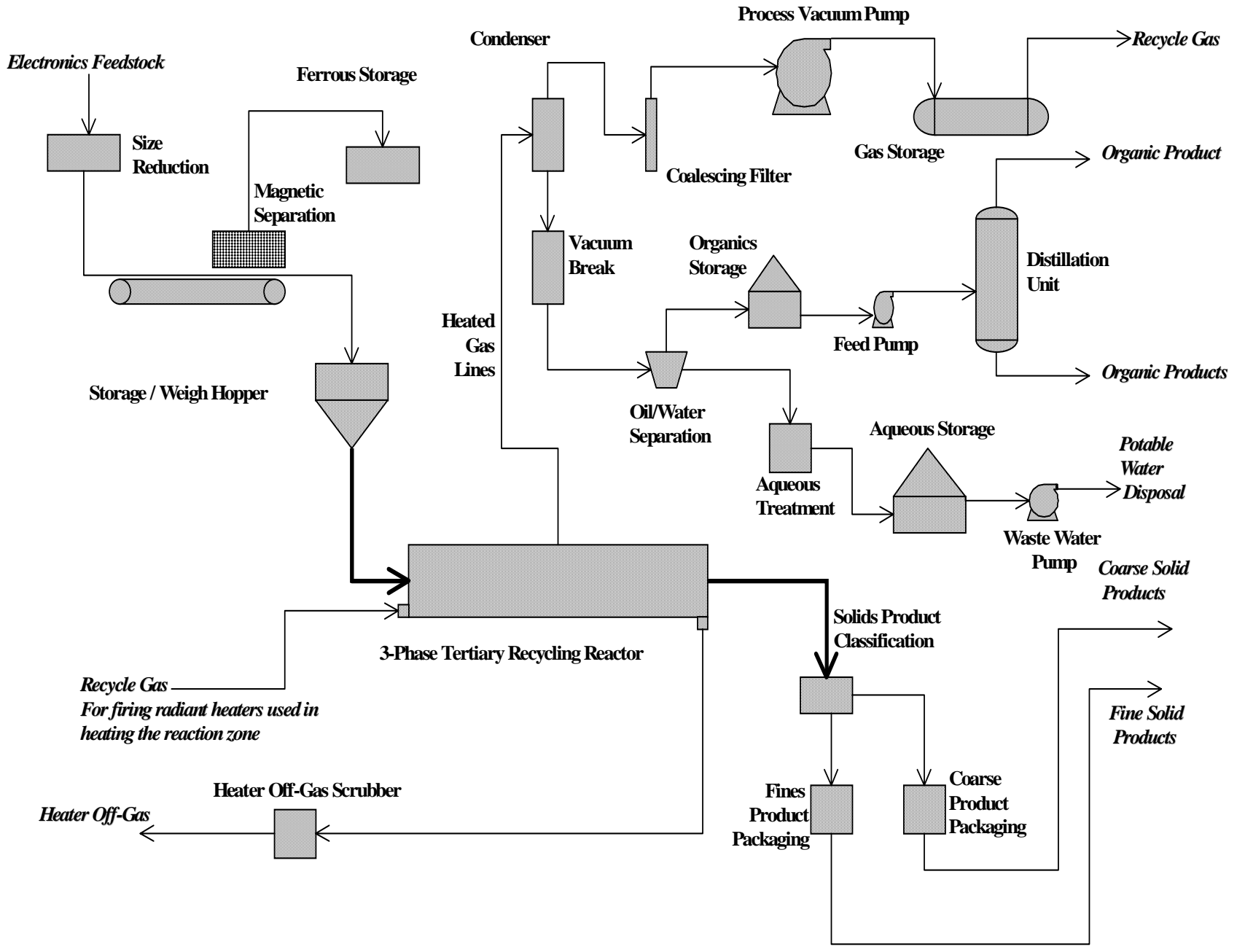

Figure 2.3 Block Diagram for ATs Tertiary Recycling System² 


\subsubsection{Process equipment details:}

The following subsections briefly discuss design considerations and the heat and mass balances for the process equipment in the AT system ${ }^{2}$.

\subsubsection{Vacuum System:}

Fundamental to the success of the process is the maintenance of vacuum. This allows the products to evolve at a lower temperature and aids in shifting the equilibrium to the product side of the reaction. Otherwise the products would be formed at higher temperatures and hence would be off-gases instead of condensates at atmospheric pressure. The vacuum pump chosen, producing at least $10^{-3}$ Torr, needs to be robust enough to handle small amounts of contaminant hydrocarbons and particulates. After careful consideration of various pumps available, AT chose a liquid-ring pump (SIHI Pumps, Grand Island, NY) to be the most suitable for the operation.

\subsubsection{Heating Mechanism:}

AT found that a lack of uniform heating was a major problem . The initial system had a forcedconvection burner fired directly onto the beginning section of the retort which was surrounded by carbonsteel pipe and ceramic blanket insulation. The excessive heat at the beginning section of the reactor resulted in overheating and warping of the retort. Providing a uniform, controllable, gas-fired heat source is important to the overall quality of the reactions, as well as maintaining safe operating conditions for the equipment. The factors that influenced the selection of the heater are

- Gas-fired, radiant heater selection

- Insulation selection

- Integration of heaters, insulation and the retort (batch).

Three gas-fired radiant heaters were evaluated: Glenro, Redray and Spaceray. The Spaceray heater was finally selected due to its ability to provide a uniform heat supply for the lowest cost. These radiant heaters provide uniform heat distribution (radially and longitudinally), controllability and cost effectiveness. 


\subsubsection{Off-gas System:}

The off-gas system is used to remove the gases and organic vapor from the reactor. The off-gas lines need to handle high molecular-weight fractions of high-boiling organic products. These fractions often wind up as a tar-like buildup in the off-gas lines and result in clogging. Therefore, the off-gas lines are designed to have have large $(5-8 \mathrm{~cm})$ diameter tubes to prevent clogging and reduction of the vacuum on the system. Similarly, to reduce the plugging of condensors by these high-boiling organics downstream, a solids trap at the beginning of the tube is used to remove the solid particles flowing with the gases. Several filtration steps are included in the design. A coalescing filter installed at the vacuum pump helps in preventing organics from entering the pump. The condensers are shell-and-tube heat exchangers, with the process gas passing over the shell side and cold water through the tube side. The condensers remove the condensable organics fraction from the offgas product.

\subsubsection{Reactor Operation Protocol:}

This section deals with the Phoenix reactor operations protocol. There were two main classes of runs performed, the evaluation and the verification runs. While the former evaluates operating parameters such as temperature, pressure, flow rate etc and determines the optimal operating conditions, the latter verifies the repeatability of results at these conditions.

The general reactor operation protocol is described below. The feed material is dried, weighed and placed in the hoppper/conveyor. Then the catalyst is added to the feed. The feed is then fed into the reactor. The run time measurment is started and the flow rate is determined. While the material inside the reactor is processed, temperature and pressure data are recorded and analyzed. The feedstock composition varies from run to run and the feedstock amount is maximized (which leads to an increase in run times) in order to estimate the economics of the process. This maximization of feed accounts for variations in composition of different feeds, which in turn might affect the repeatability of the results. Typical run times are 6-8hrs. Solid products exiting the reactor are collected in a box and weighed for mass balance. Each liquid fraction collected from the condensors is weighed. A sample of each fraction is then frozen in vials for future analysis of product composition. The gas collected in a gas chamber is 
analyzed using a Fourier Transform Infrared (FTIR) Spectrometer. Finally, the reactor and off-gas systems are cleaned.

\subsubsection{Product Analysis:}

Product analysis is performed in parallel with individual experiments. The methods used to analyze the products are broken down by product phase. Liquid products are analyzed using gas chromatography/mass spectrometry (GC/MS), the gases using Fourier Transform Infrared (FTIR) spectrometry, and solids using multiple analytical techniques such as carbonate fursion, screening and elutriation.

\subsubsection{Mass Balance:}

The mass balance performed by AT is different from that of the WVU process. The solid and liquid products are separated and weighed while the gas yield is found by difference (Refer Chapter 4 for mass balance calculations employed by WVU ). The mass balance is not a closed one, but neither is the one employed by WVU.

Mass balance is performed thus by AT is:

$m_{\text {Gas }}=m_{\text {Feed }}-\left(m_{\text {Solid }}+m_{\text {Liquid }}\right)$

where,

$\mathrm{m}_{\text {Gas }}$ : Mass of product gas

$m_{\text {Feed }}:$ Mass of feed

$m_{\text {Solid }}$ : Mass of Solid products

$\mathrm{m}_{\text {Liquid: }}$ Mass of liquid products

\subsubsection{Liquid Products:}

GC/MS is used to analyze the liquid product samples gathered over a series of runs and the results are combined. This is to prevent variation in composition of feed in each run from affecting the 
results. While helium is the carrier gas, methylene chloride is used to dilute the samples. The use of hexane or any other such hydrocarbon as a solvent is avoided, as hydrocarbons would appear as false peaks in the analysis spectrum using a Flame Ionization Detector (FID). The results are averaged over a number of runs.

\subsubsection{Gaseous Products:}

Product gases (non-condensibles) are analyzed using FTIR. The sampling system consists of the spectrometer with a sampling tube. FTIR spectroscopy allows for simultaneous determination of a variety of compounds in near- real time. The spectra thus are obtained rapidly without the use of sampling bags etc., minimizing contamination, absorption, etc. Also, unexpected compounds can be identified by relating IR absorption to individual groups from standards.

\subsubsection{Solid Products:}

The solid products require a series of tests such as physical separation (screening and elutriation), chemical separation (acid and caustic leaching) and pyrolytic separation (carbonate fusion) tests. These tests are conducted to determine the salability of the solid products from the pyrolysis of plastic feed. Physical separation steps are employed to remove impuritites such as glass, fillers, etc. The chemical separation tests are employed to remove metals by dissolving them in acids. Carbonate fusion involves addition of sodium carbonate, sodium oxide and lead-tin solder to samples recovered from physical and chemical separation steps in graphite crucibles operating in excess of $850^{\circ} \mathrm{C}$. The product, mainly metal slags, is sold to metal recycling firms.

\subsubsection{Discussion of Selected Results:}

Selective results from AT's research documentation, pertinent to tertiary recycling of electronic plastics, such as tertiary recycling of polyethylene-coated wire and electronic assemblies are considered here. 


\subsection{Polyethylene-Coated Wire:}

Most computer wiring is coated with polyethylene for insulation. Hence the results for pyrolysis of polyethylene coated wire is considered. Hydrocarbons generated from this feedstock were basically alkanes and mono-saturated alkenes ranging from $\mathrm{C}_{1}-\mathrm{C}_{24}$.

\section{Reactor conditions:}

Reactor Outer Wall Temperature: $500^{\circ} \mathrm{C}$

Reactor Vacuum: -510mm Hg

Residence Time: 30 min

Average Mass Flowrate: $3.1 \mathrm{~kg} / \mathrm{hr}$

The mass fractions of the products were solids: $50 \%$; liquids: $32 \%$ and gases:18\%. The gaseous products expected from this feedstock were basically $\mathrm{C} 1$ - C4 alkanes which were converted to carbon dioxide due to sufficient presence of oxygen. No valuable gaseous commodity was identified.

The liquid products were similar to paraffinic hydrocarbon feedstock, with hydrocarbon chain lengths varying from $\mathrm{C}_{4}$ to $\mathrm{C}_{24}$ with a $20 \%$ aromatic content. Atmospheric distillation of the liquid products using ASTM D-86 analysis indicated a significant combined fraction (70\%) of gasoline, naphtha and kerosene indicating further use as a feedstock for a reformer unit in the petroleum industry. It is to be noted that these liquid products, straight-chain alkanes and mono-unsaturated alkenes, do not have a high enough octane number to be used as gasoline blend.

The solid products are essentially copper and steel and were separated from each other by dissolving copper in acids.

\subsection{Electronic Assemblies:}

End-of-life electronic assemblies such as computers, copiers, fax machines and VCRs constitute this feedstock that was pyrolyzed by AT. It is important to note that the MBAP -1 and MBAP-2 feedstock are somewhat similar to the above feedstock. Target materials produced from tertiary recycling of this 
feedstock includes a variety of metals (iron, copper, lead, tin, gold, etc) and hydrocarbons (styrene, phenol and heating fuels).

\section{Reactor Conditions:}

Reactor Outer Wall Temperature: $450^{\circ} \mathrm{C}$

Reactor Vacuum: -560mm Hg

Residence Time: 30 min

Average Mass Flowrate: $10.3 \mathrm{~kg} / \mathrm{hr}$

The mass fraction of the products was $60 \%$ solids; $16 \%$ liquids and $24 \%$ gases.

Though it was expected that the gases produced would be low molecular-weight aromatics and saturated and unsaturated aliphatics with a notable heating value, FTIR scans and GC/MS results were found to be inconclusive (due to the presence of water vapor and halogens). Additionally, it is to be noted that all electronic components have bromine/chlorine compounds added to them for flame retardancy.

The liquid products were indicative of the starting materials used in most electronic assemblies. The most important compounds found, phenol and styrene (see Table 2.4), were targeted for further separation and commercialization. The remaining liquid could be used as fuel oil, provided that the amount of corrosion-promoting agents such as bromine was found to be low enough. Of course the cost of separation of phenol and styrene vs. cogeneration of the entire liquid would be a determining factor with regards to electronic assemblies.

AT provided the pyrolysis liquid analyzed in Table 2.4 as the oil sample (AT-1) to WVU. The HPLC analysis of AT-1 oil by WVU indicated a very high amount of aromatics (phenols, styrene, etc). The GC/MS results tabulated in Table 2.4 validate the HPLC runs done in-house (see Section 5.3.3).

The solid products were essentially metals, fillers, fiberglass and carbon black separated from the hydrocarbon fraction by a recycling reaction. While steel was separated using magnetic separation, leaching was used to separate copper, zinc, tin, etc. from non-metallic fines. 
Table 2.4: Liquid products from Tertiary Recycling of Electronic Assemblies by AT (Supplied to WVU as Oil Sample AT-1)

\begin{tabular}{|c|c|c|}
\hline Compound & $\begin{array}{c}\text { Mass conversion per unit } \\
\text { feed } \\
\text { (kg/1000kg) }\end{array}$ & $\begin{array}{c}\text { Relative Mass Fraction (w/w, } \\
\text { \%) }\end{array}$ \\
\hline 1,3-Diphenylpropane & 8.2 & 5.43 \\
\hline 2.-Phenyl-2-propanol & 2.0 & 1.31 \\
\hline 3-Isopropylphenol & 3.8 & 2.51 \\
\hline Alpha-Methylstyrene/Phenol & 15.4 & 10.23 \\
\hline Benzenebutanenitrile & 4.4 & 2.95 \\
\hline Bisphenol-A & 2.0 & 1.31 \\
\hline Dimethylphenol & 4.9 & 3.25 \\
\hline Ethylbenzene & 11.4 & 7.59 \\
\hline Methyl metacrylate & 2.9 & 1.95 \\
\hline o-Cresol & 2.7 & 1.80 \\
\hline Styrene & 74.3 & 49.42 \\
\hline Toluene & 7.5 & 4.95 \\
\hline Miscellaneous & 11.0 & 7.29 \\
\hline Total & 150.4 & 100 \\
\hline
\end{tabular}

\subsection{Other Pertinent Research:}

Much work has been performed over the past few decades in the area of pyrolysis of plastics and plastic wastes. The majority of this research has been focussed on treating wastes containing PVC, PS, high density polyethylene (HDPE) and low density polyethylene (LDPE) but very little or no work has been done with respect to the polymers found in electronic plastics, ABS and HIPS. This is due to the fact that recycling of ABS and HIPS in electronic plastics is still a relatively new area. Hence work done on mixed plastics recycling/pyrolysis is discussed in the following pages. Additionally, alternatives to pyrolysis (Liquefaction, section 2.7.4 and Solvent Dissolution, section 2.7.5) are also discussed.

\subsubsection{Fixed Bed Pyrolysis:}

Williams et al. ${ }^{7,8}$ carried out pyrolysis of six thermoplastics (HDPE, LDPE, PS, polypropylene (PP), polyethylene terephthalate (PET) and PVC) separately as well as a mixture (composition given in 
Table 2.5a) in a fixed batch reactor. Additionally they also employed fluidized bed pyrolysis on the thermoplastic mixture (Section 2.7.2). These six thermoplastics constitute more than two-thirds of all polymer production in Western Europe and more than half in the US.

Table 2.5a: Amount of each polymer used in the simulated polymer fraction

\begin{tabular}{|c|c|}
\hline Polymer & Percentage (\%) \\
\hline Low Density Polyethylene (LDPE) & 31.25 \\
\hline High Density Polyethylene (HDPE) & 31.25 \\
\hline Polypropylene (PP) & 7.29 \\
\hline Polystyrene (PS) & 13.5 \\
\hline Polyvinyl Chloride (PVC) & 11.46 \\
\hline PolyethyleneTerephthalate (PET) & 5.21 \\
\hline
\end{tabular}

\subsubsection{Experimental Set-up}

The pyrolysis reactor employed by E.A. Williams et al was made of stainless steel with a diameter of $37 \mathrm{~mm}$ and length $250 \mathrm{~mm}$. The experimental set up is shown in Figure 2.4. The nitrogen flow was set at $200 \mathrm{~cm}^{3} \mathrm{sec}^{-1}$ that gives a residence time of $25 \mathrm{sec}$ through the hot reaction zone. This helps in carrying the reaction products out of the reactor immediately and hence reduces the extent of secondary reactions. This immediate removal of the vapors is a significant difference between the WVU pyrolysis process and this one, and could explain the lower gas yield in the WVU process (see section 5.2.6).

The temperature programmer provided a heating rate of $25^{\circ} \mathrm{C} / \mathrm{min}$ to a maximum temperature of $700^{\circ} \mathrm{C}$. The reaction temperature was held until no further gas formation. The vapors are then swept through a series of condensers (cooling down to $-78^{\circ} \mathrm{C}$ was achieved with the help of dry ice/acetone bath) where the oils are separated. The vapors then pass through a flask with glass wool to trap residual oil in the vapor stream. The vapors then pass through de-ionized water where any hydrogen chloride formed was absorbed. Finally product gas was collected in a bag. 


\subsubsection{Product Analysis Instrumentation and Methodology}

Any $\mathrm{HCl}$ dissolved in the de-ionized water was measured with the help of a $\mathrm{pH}$ meter. The gas analysis was accomplished using three different packed column gas chromatographs, one each for analysis of hydrocarbons, permanent gases and $\mathrm{CO} / \mathrm{CO}_{2}$. The char formed in the metal crucible after cooling was analyzed using an elemental analyzer. The oils were characterized using an FTIR and their molecular weight distribution was determined by employing Size Exclusion Chromatography (SEC).
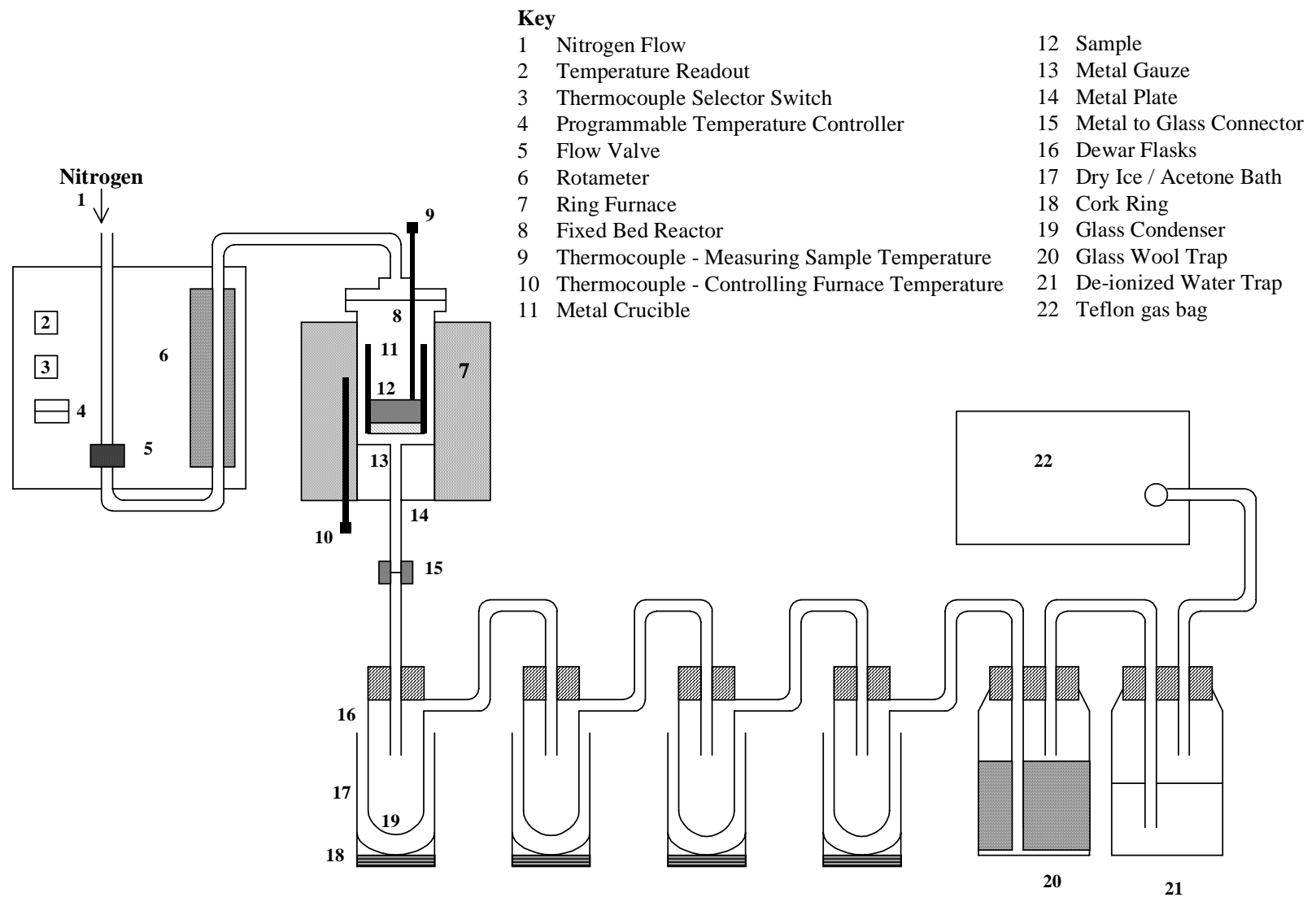

Figure 2.4: Schematic Diagram of the Fixed Bed Reactor ${ }^{7}$

\subsubsection{Discussion of Results}

The product yields are shown in Table $2.5 \mathrm{~b}$. It is to be noted that, while pyrolysis of any of the polymers and of the mixture yielded hydrocarbon gas and oil, only pyrolysis of PVC, PET and the polymer mixture yielded char. Polypropylene produced the highest oil yield (83.77\%) and PVC produced the lowest oil yield (31.69\%), while PET produced the highest gas yield (33.99\%). Oil was the major product formed from the pyrolysis of all the polymers except for PVC, which was dominated by the production of 
hydrogen chloride. Additionally the theoretical product yield for the polymer mixture (calculated by E A Williams et $\mathrm{al}^{7}$ ) matched with the actual except for the hydrocarbon gas yield and $\mathrm{HCl}$ production. While the theoretical gas yield was $\sim 13 \%$ compared to the $9.63 \%$ for the actual (possibly due to a smaller number of secondary reactions), the $\mathrm{HCl}$ produced was only one-third of what was expected (attributed to increased formation of organic chlorides in the oil fraction). The main product gas components were identified to be $\mathrm{H}_{2}, \mathrm{CH}_{4}, \mathrm{C}_{2} \mathrm{H}_{4}, \mathrm{C}_{2} \mathrm{H}_{6}, \mathrm{C}_{3} \mathrm{H}_{6}, \mathrm{C}_{4} \mathrm{H}_{8}, \mathrm{C}_{4} \mathrm{H}_{10}, \mathrm{CO}_{2}$ and $\mathrm{CO}$. The ratio of alkenes to alkanes was found to be 3:1. Also, there was a tendency for the smaller hydrocarbons to be present in greater amounts, i.e., ethene>propene>butene etc. Hydrogen was found to be in negligible quantities.

Table 2.5b: Comparison of product yields from pyrolysis of polymers in a fixed bed reactor (\%) ${ }^{7}$

\begin{tabular}{|c|c|c|c|c|c|c|c|}
\hline & HDPE & LDPE & PS & PP & PET & PVC & Mixture \\
\hline Gases & 16.77 & 15.02 & 3.41 & 13.63 & 33.99 & 2.47 & 9.62. \\
\hline Oil & 79.72 & 84.25 & 83.77 & 84.44 & 41.30 & 31.69 & 75.12 \\
\hline Char & 0.00 & 0.00 & 3.50 & 0.15 & 15.55 & 13.78 & 2.87 \\
\hline $\mathrm{HCl}$ & 0.00 & 0.00 & 0.00 & 0.00 & 0.00 & 52.93 & 2.31 \\
\hline Total & 96.48 & 99.27 & 90.67 & 98.23 & 90.84 & 100.87 & 89.93 \\
\hline
\end{tabular}

The major component of char was found to be elemental carbon (see Table 2.5c), probably because of the high bond energies required to break the $\mathrm{C} \equiv \mathrm{C}$ and $\mathrm{C}=\mathrm{C}$ bonds. Oxygen formed a significant percentage of char in PET (6.73\%). Low nitrogen levels indicate very little interaction between $\mathrm{N}_{2}$ and the polymer during pyrolysis.

Table 2.5c Elemental Analysis of Chars from the pyrolysis of polymers and polymer mixture in a fixed bed reactor

\begin{tabular}{|l|c|c|c|}
\hline & PET & PVC & Mixture \\
\hline Carbon & 84.93 & 90.15 & 87.73 \\
\hline Hydrogen & 2.48 & 2.55 & 1.99 \\
\hline Nitrogen & 0.00 & 0.15 & 0.13 \\
\hline Ash & 5.86 & 2.91 & 4.23 \\
\hline Oxygen (calculated by difference) & 6.73 & 4.39 & 5.92 \\
\hline
\end{tabular}


The FTIR spectra of the pyrolysis oils from HDPE, LDPE, PVC and PP revealed their aliphatic nature while that from PS indicated a very strong aromatic nature. FTIR spectra of pyrolysis oil from PVC didn't indicate a lot of chlorine. This was expected due to immediate removal of pyrolysis vapors from the reactor, resulting in minimal secondary reactions. The pyrolysis oils from PET and the mixture indicated possible presence of alcohols and carboxylic acids due to presence of the oxygen. It is to be noted that the MBAP-1 mixture analyzed in the WVU process contains polycarbonates $(P C)$ that have the $C=O$ bonds similar to PET. Finally it was found that the pyrolysis oil from the polymer mixture was more aromatic than aliphatic (attributed to possible reactions between the primary products).

The SEC data of the individual polymers and the polymer mixture show a molecular weight range from 64 to $2000 \mathrm{Da}$. For the individual polymers, the peak boiling point was $270^{\circ} \mathrm{C}$ while it dropped to $120^{\circ} \mathrm{C}$ for the polymer mixture. Also the boiling point range for the polymer mixture was similar to that of naphtha indicating a possible use of the pyrolysis oils as fuels.

\subsubsection{Fluidized bed Pyrolysis}

The experimental set-up for fluidized bed pyrolysis by E A Williams et $\mathrm{al}^{8}$ is similar to that shown in Figure 2.4 with the only difference being a fluidized bed reactor instead of a fixed bed reactor.

\subsubsection{Fluidized Bed Reactor}

The fluidized bed reactor was made of stainless steel with a $10 \mathrm{~cm}$ diameter and $\sim 70 \mathrm{~cm}$ total height. The top of the fluidization chamber had an expanded section to reduce the product vapor velocity before entering a cyclone (for separation of solids from the vapor stream). The rest of the set up is similar to that described in Section 2.7.1.1. The instruments and methodology for analysis of pyrolysis products are the same as described in Section 2.7.1.2.

\subsubsection{Discussion of Results}

The pyrolysis of the polymer mixture (Table 2.5a) was carried out in the fluidized bed as a function of temperature, and the results are shown in Table 2.6. 
Table 2.6: Product yields from the fast pyrolysis of the polymer mixture with change in temperature in a fluidized bed reactor: ${ }^{8}$

\begin{tabular}{|l|c|c|c|c|c|}
\hline \multirow{2}{*}{ Product } & \multicolumn{5}{|c|}{ Temperature of Fluidized Bed Reactor $\left({ }^{\circ} \mathrm{C}\right)$} \\
\cline { 2 - 6 } & 500 & 550 & 600 & 650 & 700 \\
\hline Gas & 9.79 & 24.52 & 43.33 & 88.76 & 68.81 \\
\hline Wax & 17.28 & 18.56 & 8.72 & 0.00 & 0.00 \\
\hline Oil & 37.29 & 38.55 & 34.44 & 20.49 & 18.44 \\
\hline Char & 2.82 & 5.87 & 7.59 & N/A & N/A \\
\hline HCl & 1.76 & 1.42 & 1.43 & 0.80 & 0.51 \\
\hline
\end{tabular}

N/A: Not Available

In general, Table 2.6 indicates that increase in reaction temperature results in increased gas formation. The amount of oil and wax produced decrease with increase in temperature. This behavior was attributed to the increase in available energy with increase in temperature, leading to greater amount of secondary reactions, which in turn leads to breaking of wax and oil molecules and hence greater gas formation. Compared to fixed bed pyrolysis, there is more gas formation and less oil formation in the fluidized bed process.

The majority of the gas collected was found to be hydrocarbon in nature with very little $\mathrm{CO}_{2}$ and negligible CO. A number of gas components were negligible in concentration independent of temperature. $\mathrm{H}_{2}$ and $\mathrm{C}_{4} \mathrm{H}_{10}$ was found to be lowest while $\mathrm{CH}_{4}$ and $\mathrm{C}_{2} \mathrm{H}_{6}$ concentrations were between $0-1 \%$ of the original polymer. The rest of the gases were influenced by temperature with the smaller hydrocarbons present in the majority (i.e. $\mathrm{C} 2>\mathrm{C} 3>\mathrm{C} 4$ etc). This was attributed to greater stability of the smaller molecules.

Once again, the $\mathrm{HCl}$ gas evolved was less than expected. This was attributed to a higher gas flow rate leading to insufficient time for absorption in water or formation of organic-chlorides. This trend, of formation of organic chlorides, was also found in analysis of pyrolysis oils from MBAP-1 and MBAP-2 (see Section 5.3). 
The elemental analysis of solid pyrolysates was not well established due to silica being entrained with the product ash. A better method was required to be established before developing any trends. In contrast to this problem, the WVU experimental set-up (see Section 3.3) for pyrolysis of plastics is a more effective method in terms of obtaining the solid pyrolysates.

The FTIR analysis of the oils indicated a greater complexity of compounds present at $700^{\circ} \mathrm{C}$ than $500^{\circ} \mathrm{C}$. The increase in temperature leads to increase in unsaturated compounds while decreasing oil yield. Finally, an increase in temperature leads to increased amounts of aromatic compounds and a corresponding decrease in aliphatic compounds.

SEC was employed to analyze the molecular weight distribution of waxes and oils. An increase in pyrolysis temperature led to a decrease in average molecular weight for the waxes indicating break up of the wax at higher temperatures to form lighter compounds. A similar behavior was found for the oils as well. Additionally the peak molecular weight at $650^{\circ} \mathrm{C}-700^{\circ} \mathrm{C}$ was about $160 \mathrm{Da}$ corresponding to that of naphtha. Hence, the pyrolysis oils and gases from this process could be used as fuels and/or chemical feedstock to produce petrochemicals.

\subsubsection{Stepwise Pyrolysis:}

$\mathrm{H}$. Bockhorn et al. ${ }^{10}$ discuss the stepwise pyrolysis of plastic wastes. The stepwise decomposition of polymers in a cycled-spheres reactor is an alternative pyrolysis procedure. $\mathrm{H}$. Bockhorn et al use a cascade of well-stirred reactors wherein mixing of reactor contents is carried out with the help of circulating steel spheres. The authors use a mixture of PVC, PS and PE (1:1:1 by weight) each being pyrolyzed in separately in each step. The authors contend that kinetic data analyzed from microthermogravimetry and gradient-free reactor experiments confirm that different molecular structures in commodity plastics bring about different thermal decomposition reaction mechanisms, rates and temperature dependencies. 


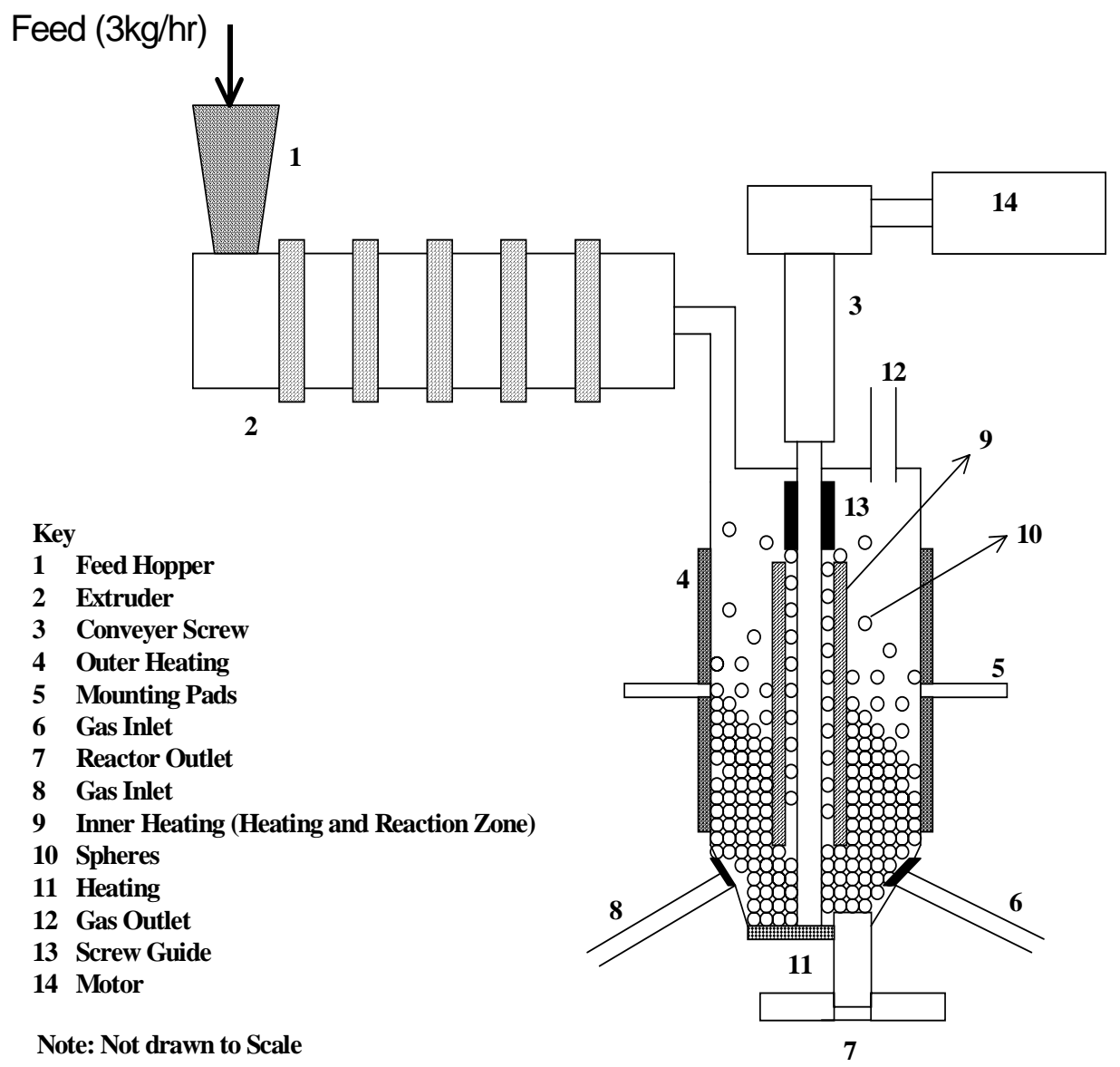

Figure 2.5: Stepwise Pyrolysis - Schematic of Extruder/Reactor Section ${ }^{10}$

The experimental set-up consists of three independent cycled-spheres reactors and of three steps (one reactor section is shown in figure 2.5). The first reactor is maintained at $330^{\circ} \mathrm{C}$, the second at $380^{\circ} \mathrm{C}$ and the third at $440^{\circ} \mathrm{C}$. The mean residence time in each reactor is 26 min. The first step, dehydrochlorination of $\mathrm{PVC}$, occurs at $300-350^{\circ} \mathrm{C}$, implying that most of the dehydrochlorination takes place is the first reactor. The second step occurs at $380^{\circ} \mathrm{C}$ and leads to depolymerization of most of the polystyrene and decomposition of the residue from dehydrochlorination of PVC. At $440^{\circ} \mathrm{C}$, the third step leads to decomposition of PE. The degree of dehydrochlorination achieved in the first reactor/step for the above-mentioned conditions was high (99.6\%). In the second reactor, at $380^{\circ} \mathrm{C}$, polystyrene decomposes into its monomer. The monomer obtained is found to be of high quality. In the third reactor, the decomposition of PE into paraffins and olefins takes place with $93 \%$ yield. On-line mass spectrometric analysis was used in determining product composition. The separation of PVC, PS and PE in the threestage process establishes this method as an alternative pyrolysis process. 


\subsubsection{Liquefaction:}

Some alternative technologies to pyrolysis are considered in next few sections.

\subsubsection{Thermal Liquefaction:}

Rangarajan et al. ${ }^{11}$ discuss direct liquefaction as an alternative to landfilling of plastics. Direct liquefaction is the thermal breakdown of polymers at high temperature in the presence of hydrogen and solvent. The $\mathrm{H} / \mathrm{C}$ ratio of some plastics is similar to that of alkanes. Therefore, direct liquefaction can be considered as a potential waste disposal option by generating oil.

The advantages of direct liquefaction include:

- High thermal efficiency.

- Variable output of high-octane gasoline and/or middle distillates.

- Middle distillates are suitable for jet fuel.

The major disadvantage of direct liquefaction is that it has yet to be demonstrated on a large scale to substantiate the claims made about it.

P. Rangarajan et al. studied the liquefaction of Low-Density Polyethylene (LDPE) to produce liquid hydrocarbon fuel. P. Rangarajan et al. characterized the reaction products using a thermogravimetric analyzer (TGA) which helped in profiling the weight change vs. temperature, a differential scanning calorimeter (DSC), simulated distillation and Gel Permeated Chromatography (GPC). GPC is also known as Size Exclusion Chromatography (SEC). The liquefaction results are shown in Table 2.7.

Under direct liquefaction treatment, the polymers degrade into very short chains and the chain ends are capped by hydrogen. While the THF-Insolubles increased from $16 \%$ to $24 \%$ with increase in $\mathrm{H}_{2}$ pressure from 100psig to 800psig, the pentane-insolubles and oils and gases did not change significantly. The table indicates a increase in oils and gases and decrease in pentane-insolubles when liquefaction is conducted in the presence of hydrogen vs. nitrogen at the same pressure (400psig). The major finding, though, is the decrease in the viscosity of oils with increase in the pressure indicating that heavier fractions are suppressed at higher hydrogen pressures. 
Table 2.7: Effect of pressure on the conversion of LDPE $(50,000)$ at $440^{\circ} \mathrm{C}, 45 \mathrm{~min}$ with tetralin as solvent ${ }^{11}$

\begin{tabular}{|c|c|c|c|}
\hline Products & $\begin{array}{c}\text { THF-insolubles (\%) } \\
\text { (Residue) }\end{array}$ & Pentane-insolubles(\%) & Oils + gases (\%) \\
\hline 400 psig $\mathrm{N}_{2}$ & 18 & 67 & 15 \\
\hline 100 psig $\mathrm{H}_{2}$ & 16 & 41 & 38 \\
\hline $400 \mathrm{psig}_{2}$ & 22 & 40 & 38 \\
\hline $800 \mathrm{psig}_{2}$ & 24 & 38 & 38 \\
\hline
\end{tabular}

\subsubsection{Indirect Liquefaction:}

Indirect liquefaction is the approach in which the carbonaceous sample is first gasified to produce synthesis gas (hydrogen and carbon monoxide) and is then catalytically converted to liquids. The FischerTropsch process is a classic example of indirect liquefaction.

The advantages of indirect liquefaction include ${ }^{12}$ :

- Ability to produce a wide variety of products selectively.

- Ability to be used for gasoline production on a large scale.

- Less-severe reaction conditions than for direct liquefaction.

- Quite insensitive to variations in feed composition.

Disadvantages include:

- Thermal efficiency is generally lower than for direct processes.

- Plant needs more equipment than for direct processes.

Indirect liquefaction, a two-stage process, is not widely used on plastics due to higher energy costs making it uneconomical.

\subsubsection{Plastics recycling by selective dissolution:}

Selective Dissolution is a process patented by Rensselaer Polytechnic Institute ${ }^{13}$. Six major plastics, Polystyrene (PS), Low-density polyethylene (LDPE)/Linear Low-Density Polyethylene (LLDPE), High-density polyethylene (HDPE), Polypropylene (PP), Polyvinyl chloride (PVC) and Polyethylene 
terephthalate (PET) were considered. Manual sorting (used by AT) and specific gravity separations (such as the sink-float method employed by MBA Polymers) might not always be suitable, especially if this recycled polymer is to have the same purity as the virgin polymer feed. Additionally, some polymers posses the same specific gravity range (HIPS and ABS) and hence are not effectively separated using specific gravity methods. Selective Dissolution process uses the very same thermodynamic differences (overlapping thermophysical properties) that pose problems during molding and extrusion operations of recycled plastics that are not adequately pure. The thermodynamic differences between the six major thermoplastic resins mentioned above are exploited to separate them at different temperatures in a solvent. Different solvents at the same temperature have also been employed to separate the polymers.

The key elements of the selective dissolution process are the dissolution of polymers in the solvent, flash devolatilization (most of solvent is flashed from the dissolved polymer) and finally devolatilizing extrusion (removal of remaining solvent from the polymer). These are further explained in Section 2.7.4.1.

The selective dissolution data for the polymers PS, LDPE/LLDPE, HDPE, PP, PVC and PET are presented in Table 2.8. While PS, LDPE/LLDPE, HDPE and PP are dissolved using xylene, PVC and PET (same specific gravity range) are separated by using a combination of solvents, xylene and cyclohexane.

Table 2.8: Rensselaer's selective dissolution process:

$\mathrm{A}=$ xylene; $\mathrm{B}=$ cyclohexanone

\begin{tabular}{|c|c|c|c|}
\hline Polymer & Solvent & Temperature, ${ }^{\circ} \mathrm{C}$ & Solution conc., \% \\
\hline PS & A & 15 & 6 \\
\hline LDPE/LLDPE & A & 75 & 10 \\
\hline HDPE & A & 105 & 10 \\
\hline PP & A & 120 & 10 \\
\hline PVC & A/B & 120 & 10 \\
\hline PET & A/B & 180 & 10 \\
\hline
\end{tabular}




\subsubsection{Process Description:}

The process flow diagram is detailed in Figure $2.6^{13}$. The plastics are delivered in compact bales for easier transportation and reduced in size to about $20-25 \mathrm{~mm}$. The initial size-reduction step is similar to that of the MBA size reduction step and employs a series of grinders and shredders. The traditional sinkfloat step for separation of commingled plastics require a size of $10 \mathrm{~mm}$ or less for effective washing and mechanical separation, whereas selective dissolution is more forgiving as the impurities (paper labels, dirt, residual contents of packages etc) can be later removed downstream in the process. This greatly reduces the cost of the size reduction equipment. Washing and drying follow the size-reduction step. These steps, again, are not as critical for selective dissolution as they are for the sink-float method, as any impurities left behind can always be removed in the steps downstream.

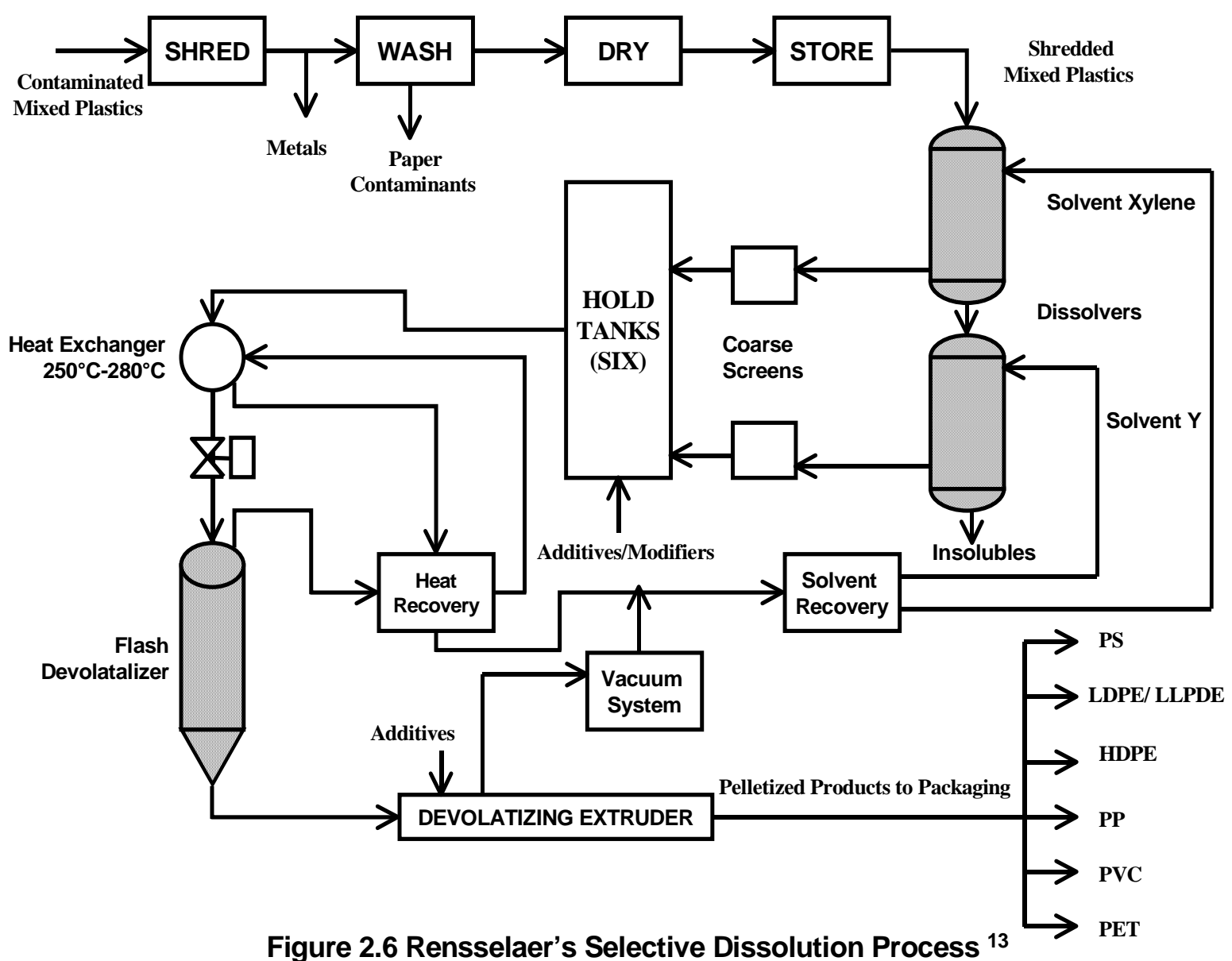


Selective dissolution is a batch process. The commingled plastic, removed from most impurities, is then subjected to dissolution in a "dissolver" where adequate solvent is added at ambient temperature. The PS dissolves almost immediately in xylene, forming a solution of 6-weight \% (refer to Table 2.8). After a short waiting period, the PS solution is drained off through a coarse screen into a hold tank. A second charge of solvent is used to flush the remaining PS. A second hotter charge of solvent (xylene) dissolves all of the LDPE at $75^{\circ} \mathrm{C}$. All the remaining plastics are then removed in a similar fashion using xylene and/or cyclohexane at temperatures indicated in Table 2.8. Several such batches are run and the various polymer/solvent solutions are then flash devolatilized in a heat exchanger at about $250-280^{\circ} \mathrm{C}$. This temperature is high enough to provide the required sensible heat to the polymer to strip off the solvent. The remaining polymer/solvent mixture $(85 \% / 15 \%)$ is then passed to a devolatilizing extruder where the remaining solvent is stripped off the polymer. In the same extruder, additives could be added to attain any desired properties. A simple solvent recovery system enables reuse of the solvent.

Several claimed advantages of the selective dissolution-flash devolatilization process are detailed below:

- It is able to reclaim $98 \%$ of all plastic in domestic waste stream.

- This process clearly separates PET from PVC. The sink-float or hydroclone separation processes are unable to separate these due to overlap in the specific gravity of the two components.

- Complete separation of polymers from the impurities is not essential with this process. Low level polymer cross-contamination and non-polymer impurities are removed during the flash devolatilization step.

- Products having superior properties than that of the virgin material can be produced by the introduction of additives into the dilute solution before devolatilization. 


\section{EXPERIMENTAL EQUIPMENT and PROCEDURES}

\subsection{EXPERIMENTAL OVERVIEW:}

Our proposed method for characterization of the pyrolysis products from the fines (MBAP-1) and non-separables (MBAP-2) was divided into two stages. The first stage was to pyrolize the feed in a batch reactor and then to separate the gas, liquid and solid reaction products. The product gas was separated from the liquid and solid products. In the second stage, the gases were analyzed in a Gas Chromatograph (GC) with a Thermal Conductivity Detector (TCD). The remaining non-gaseous products were separated by treatment with solvents tetrahydrofuran (THF) and hexane into fractions THFInsolubles (char or residue), THF-Soluble, Hexane-Insolubles (asphaltenes and pre-asphaltenes) and Hexane-Solubles (Oils). The weight fraction of Oils was determined by difference. Reacting the plastics sample from MBA Polymers with iron sulfide catalysts developed by WVU was also attempted.

The AT liquid was analyzed by studying the boiling-point curves obtained using ASTM D-86 method. The same sample from AT was also characterized using ASTM D-2887, simulated distillation. This is used to corroborate the data obtained through the D-86 method.

\subsubsection{Materials:}

The solvents THF and hexane are listed to be $99 \%$ and $90 \%$ pure respectively. Both these chemicals were supplied by Fisher Scientific and were used directly as received. Hydrogen (carrier gas for the GC) and helium (inerting gas in the reactor) were procured from Air Gas. Pure (99\% or greater) methane, ethane, propane, butane and gas mixtures, used for calibration of product gas components, were procured from Sigma Aldrich.

\subsubsection{Description of Samples}

Three samples were used in this study; two are solid streams of mixed plastics and one is liquid pyrolysis oil (please see Appendix B for additional information on the polymer mentioned in this thesis document). 
- MBAP-1: The waste stream of fines from the MBA process containing ABS, HIPS, PVC, PC, PE etc.

- MBAP-2: The non-separable stream in the MBA process. It contains ABS and HIPS (which possess the same specific gravity range) and trace amounts of other polymers.

- AT-1 Oil: The oil sample supplied by Adherent Technologies Inc. from their two-stage recycling process explained in Section 2.6.

Note: MBAP-1 and MBAP-2 were supplied directly by MBA Polymers Inc.

\subsection{EQUIPMENT USED:}

The D-86 atmospheric distillation apparatus is shown in Figure 3.4. The apparatus is explained in detail, as it is key equipment used in the research.

\subsubsection{D-86 Atmospheric Distillation Apparatus:}

Distillation may be defined as a process in which a liquid or vapor mixture of two or more substances is separated into its component fractions of desired purity by the application and removal of heat. The D-86 distillation method employs a simple distillation technique suitable for separating complex mixtures. This method is explained in Section 3.2.1.2.

Summary of D-86 method: A $100 \mathrm{ml}$ sample is distilled under prescribed conditions. Systematic observations of temperature and volumes of condensate are made and from these data the results of the test are calculated and reported.

Comments: Care was taken to insure that the sample to be distillated was at a temperature of $55-65{ }^{\circ} \mathrm{F}$. The samples that visibly contain water were not tested. All volumes were recorded to the nearest $0.5 \mathrm{ml}$ and all thermometer readings to the nearest $1^{\circ} \mathrm{F}$. 


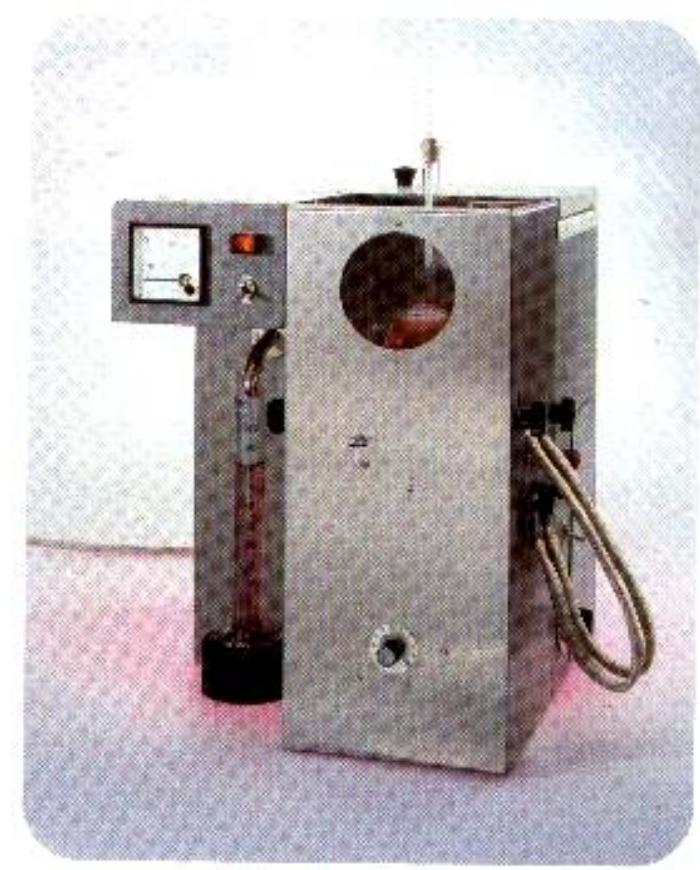

Figure 3.4 D-86 Distillation Apparatus

3.2.1.1 Apparatus and Materials for D-86 method:

- Distillation flask: $125 \mathrm{ml}$ (Figure 3.5)

- Graduated cylinder: $100 \mathrm{ml}$

- Thermometer: ASTM 7F

- Distillation apparatus suitable for petroleum products.

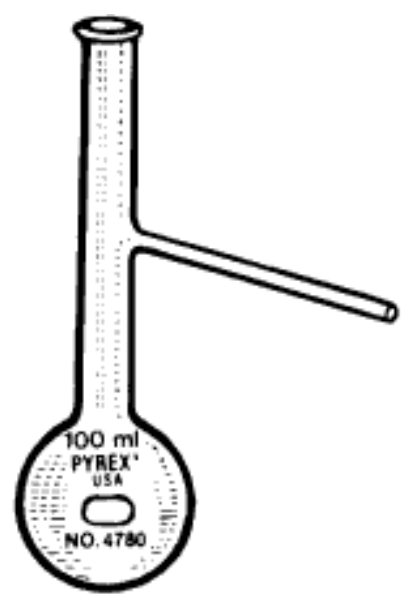

Figure 3.5: The flask used in D-86 apparatus 


\subsubsection{Theory:}

The curves obtained through the D-86 method are "true-boiling point" (TBP) curves (see Figure 3.6) and are used for characterizing extremely complex mixtures for which other distillation data might be impossible to obtain. The vaporization properties of petroleum mixtures are characterized by a batchdistillation curve wherein the percentage distilled is plotted against the temperature at which it is distilled. Such a TBP distillation method has been standardized and is known as the ASTM D-86 procedure. Theoretically, the TBP curve is a distillation method capable of making very close separations, so that the compounds present in the mixture will be separated each at its own boiling point and in the quantity present in the original mixture. Thus this TBP curve under perfect fractionation conditions, describes the boiling point / volume-percent-distilled characteristics of the mixture. According to ASTM D-975 specifications, for a petroleum oil to be in the diesel fuel oil range, the last $10 \%$ of the Distillate Volume should boil between $540-640{ }^{\circ} \mathrm{F}$ and the overall Boiling Point range should lie between $340-640{ }^{\circ} \mathrm{F}$. There are similar specifications for other fuels as well (e.g.: ASTM D1665 lists the Jet Fuel specifications).

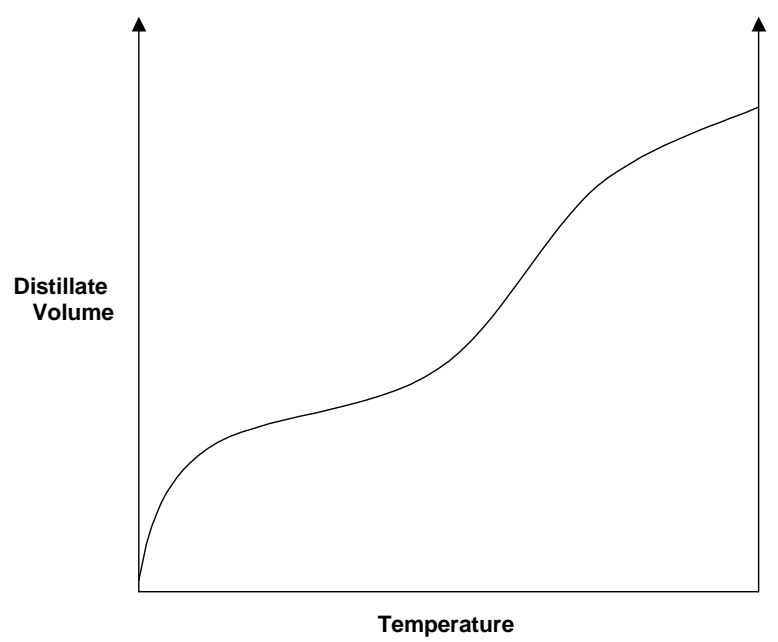

Figure 3.6: A typical true boiling point (TBP) curve 


\subsubsection{Tubular Batch Reactor (TBR):}

The TBR is a batch reactor made out of 316 stainless steel, has a capacity of about $17 \mathrm{ml}$ and can hold about 3 grams of a sample. It has a bulky base and a slender limb (See Figure 3.7). The top end of the limb provides access for gas pressurization of the reactor. A 100\% shut-off gas-purging valve, $V_{p}$, enables gas to be contained in the reactor. The sides of the base (fitted with swagelok plugs) provide for loading and removal of the reactants and products respectively.

\subsubsection{Gas Mixing Apparatus:}

The gas mixing apparatus, shown in Figure 3.8, is used to pressurize and purge the TBR. Needle valves $\mathrm{V} 1$ and $\mathrm{V} 2$ achieve the required composition of the gaseous mixture. Both or either one of the gas cylinders connected to the valves can be used to pressurize the reactor. The valves are connected to a pressure gauge, which in turn is connected to a "Quick Connector". A pressure vent valve set at 1500 psig and a gas relief valve V3 (a vent line), are provided for purposes of safety.

\subsubsection{Fluidized Sand Bath Equipment:}

A Techne SBL-2 sand bath preheated to $25^{\circ} \mathrm{C}$ above reaction temperature is used to heat a pair of reactors in tandem (See Figure 3.9). The sand bath is three-quarters full with a 100-mesh Aluminum Oxide powder (sand) possessing a high thermal conductivity. A Techne TC-8D proportional temperature controller is used to control the temperature of the sand bath. A light-to-moderate bubbling of air is used for fluidization and even heating. 


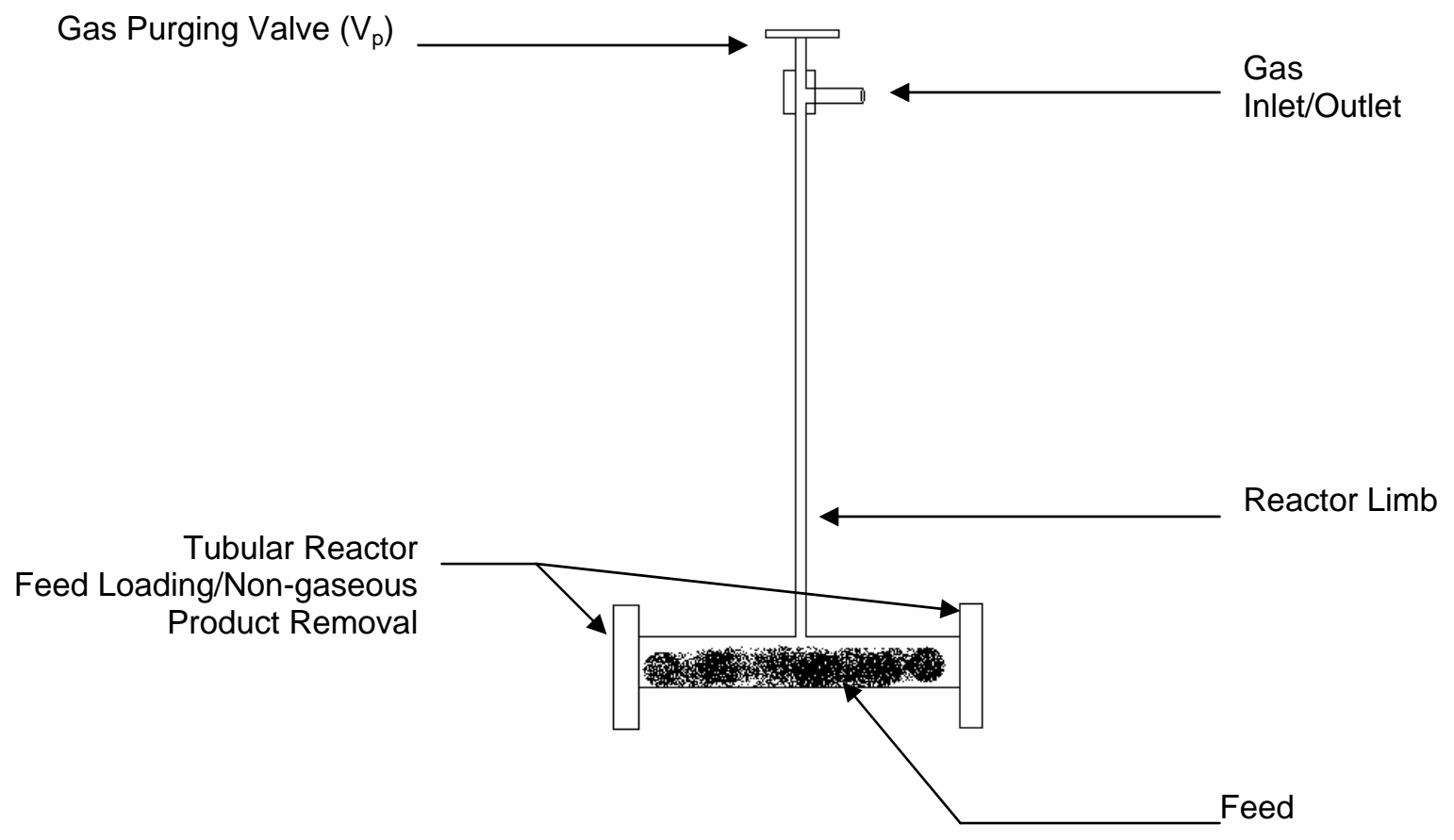

Figure 3.7: Tubular Batch Reactor 


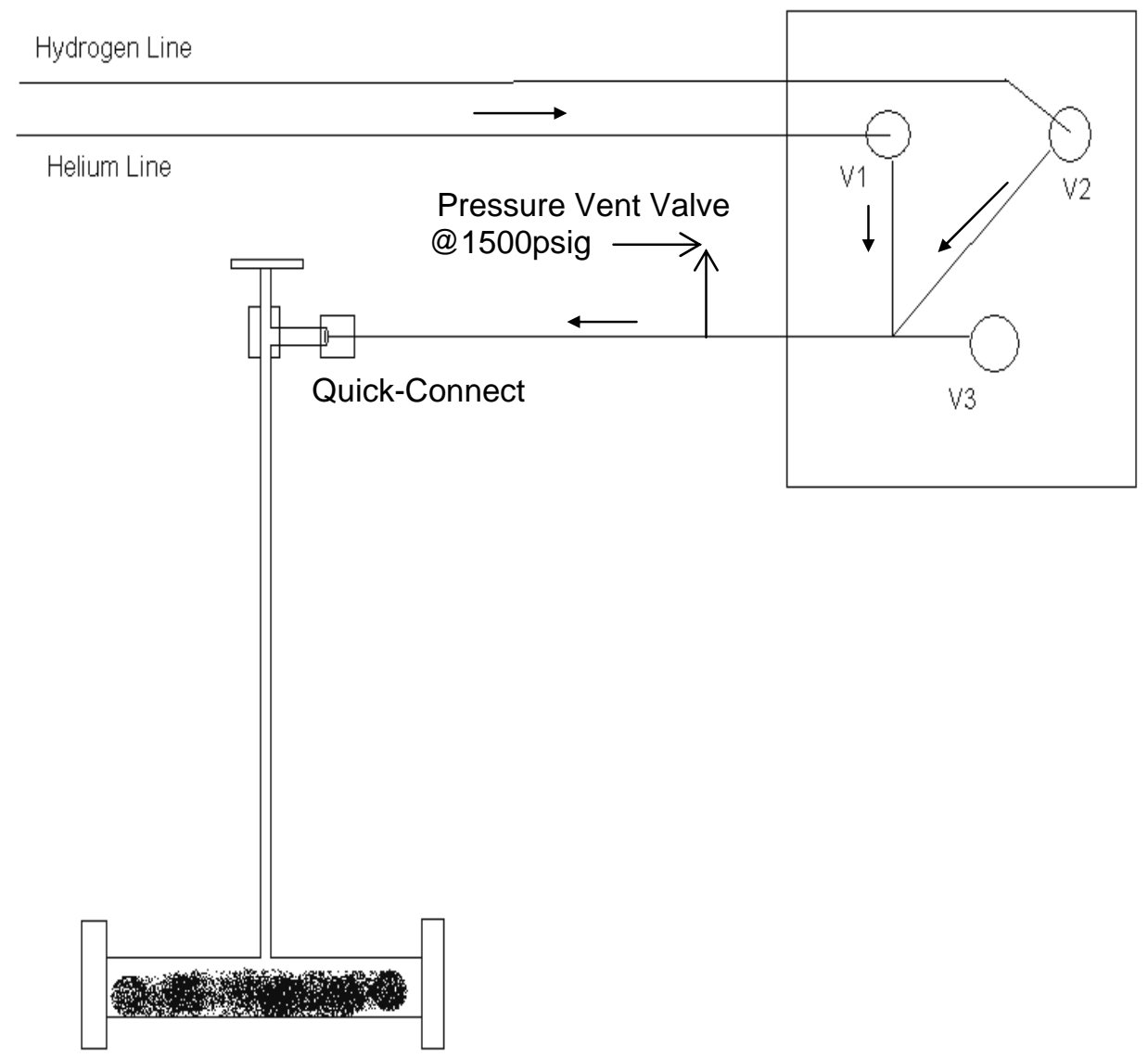

Figure 3.8: Gas Mixing Apparatus 


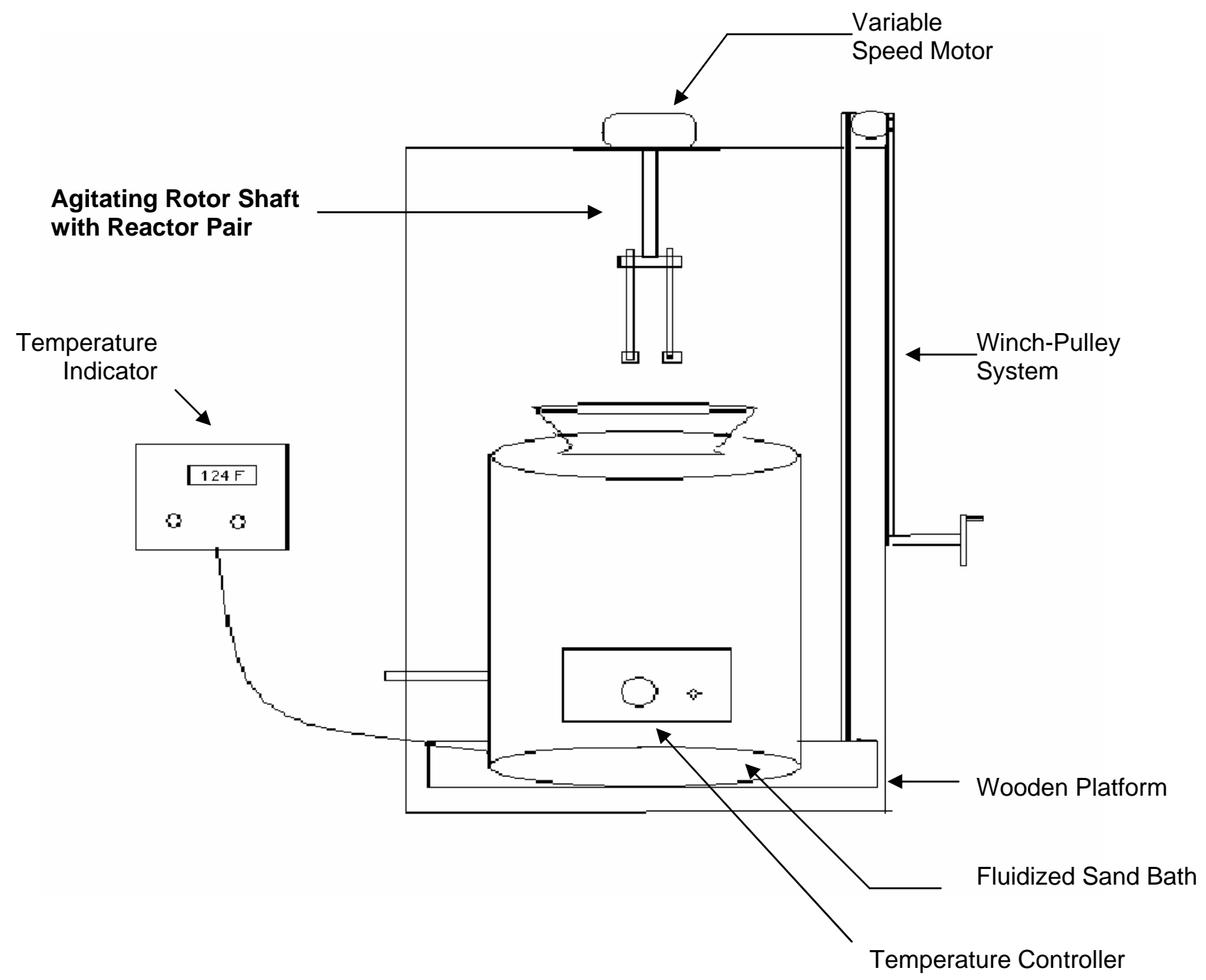

Figure 3.9: Fluidized Sand Bath Equipment and Reactor Agitation Mechanism 


\subsubsection{Batch Reactor Agitation Mechanism:}

A variable-speed motor controls the agitation of the reactor system (see Figure 3.9). The agitation is vertical and the maximum agitation rate is 1000 RPM. The two reactors are secured to the top of the rotor shaft to prevent any mishap during violent agitation. The reactor pair is then immersed into the sand bath using a winch with pulley system such that up to half the length of the limb is under the sand. This ensures uniform and complete heating of the reactor contents..

\subsubsection{Product Gas Collection Apparatus:}

The product gas collection apparatus, shown in Figure 3.10, is used to collect the product gas from the reactor after it has been cooled down. The system consists of a three-way valve, heavy-duty vacuum pump, a 1000-ml flask, and a mercury barometer. The total volume of the system (inclusive of the reactor) is $1133 \mathrm{ml}$. The reactor is connected to the three-way valve. A vacuum is pulled and is checked for any leaks. Then the valve is opened and product gas flows into the flask. With the help of a syringe, a known volume of the product gas (at the pressure indicated by the manometer) is injected into the Gas Chromatograph for analysis. Detailed procedure found in Section 3.3.1.2.

\subsubsection{Refluxing Apparatus:}

The extraction and separation of the product (liquid and solid) is performed using the Soxhlet Extraction Apparatus shown in Figure 3.11. The apparatus provides for continuous reflux that ensures maximum extraction and separation of the pyrolysis products into solvent-solubles and insolubles. The solvents are THF and hexane. The refluxing unit consists of a condensing unit, a boiling flask, a heating mantle and a variac. 


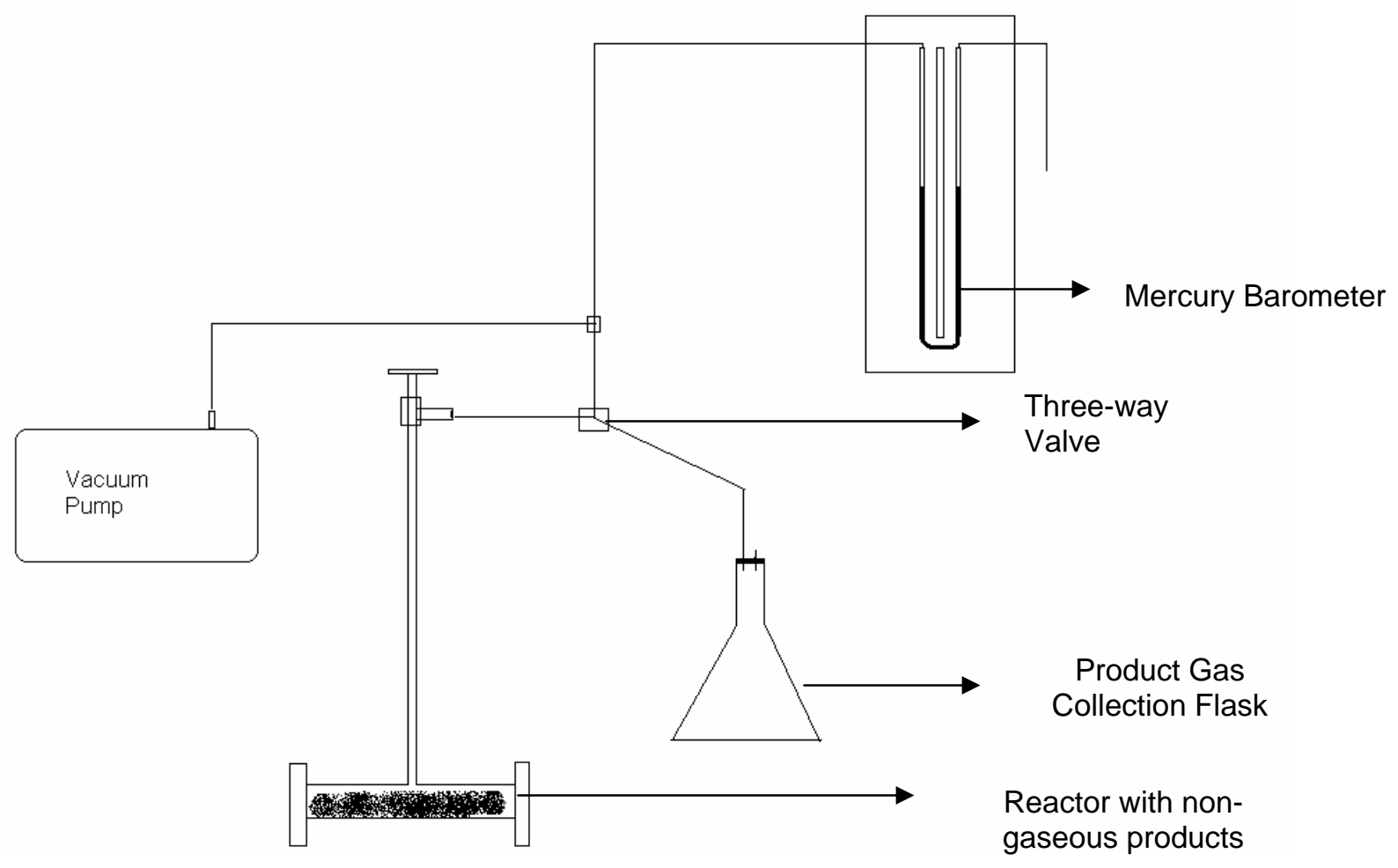

Figure 3.10: Product Gas Collection Apparatus 


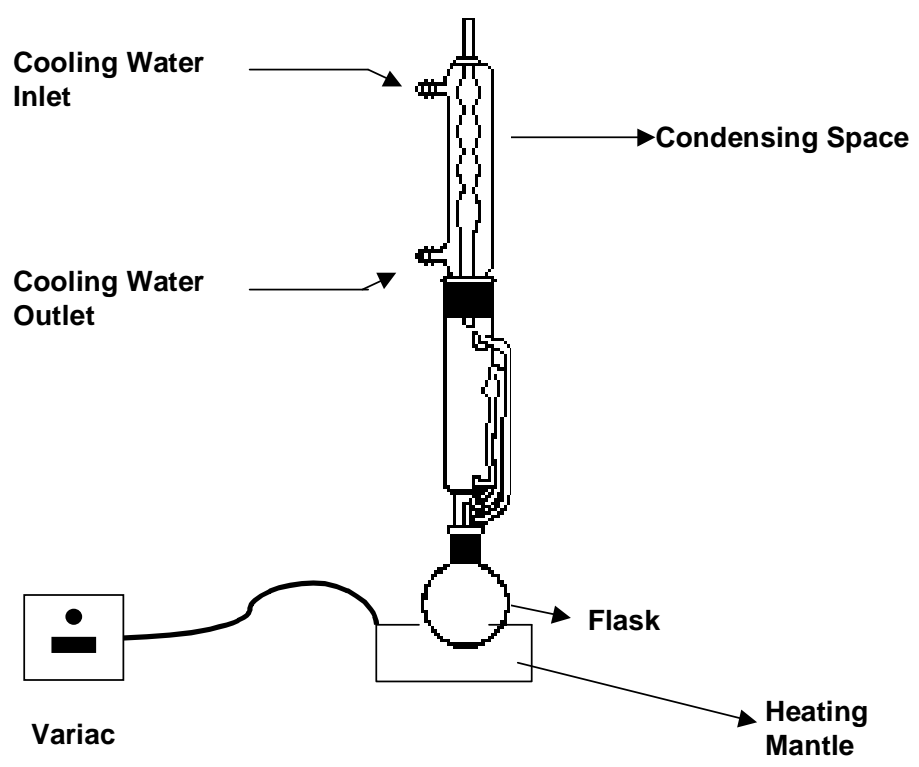

Figure 3.11: Soxhlet Extraction/Refluxing Apparatus 


\subsubsection{Rotary Evaporator:}

Rotary evaporators (Rotovaps) are used to separate the solvents from the solubles. Each Rotovap consists of a condenser, a motor with speed control, and an oil bath with heater controls.

\subsubsection{Miscellaneous Equipment:}

A weighing balance accurate to $0.1 \mathrm{mg}$ is used for all the weighing purposes. Vacuum ovens are used to dry the residue from the extraction process to enable moisture-free weight measurements.

A Varian 3400 Gas Chromatograph (equipped with a Petrocol-B packed column specified for ASTM D-2887) with auto sampler and Flame Ionization Detector (FID) was used for simulated distillation of the AT-1 oil sample. The column was programmed from $-35^{\circ} \mathrm{C}$ to $350{ }^{\circ} \mathrm{C}$ with a ramping rate of $10^{\circ} \mathrm{C} / \mathrm{min}$. Liquid Nitrogen was used to attain sub-zero temperatures. A mixture of air and hydrogen was used as the carrier gas. Air also was the medium in the auto sampler.

The Varian High Performance Liquid Chromatography (HPLC) system has three columns for separation of polar organic compounds, unsaturated hydrocarbons and saturated hydrocarbons, in that order. This analysis is useful since it gives some insight into the nature of the chemical species present in the oil fraction. Polar species are components containing heteroatoms such as $\mathrm{O}, \mathrm{N}, \mathrm{S}, \mathrm{Cl}$ and $\mathrm{Br}$. Unsaturated species contain unsaturated $\mathrm{C}-\mathrm{C}$ double and triple bonds such as those found in aromatic compounds. Saturated hydrocarbons consist of carbons bonded by single C-C bonds alone. These species are typical of those found in petroleum-derived products. The high-boiling range for the sample reveals the types of species left after all the diesel fuel range components have been removed by distillation.

The Shimadzu GC-8A was used for pyrolysis product gas analysis. 


\subsection{EXPERIMENTAL SETUP:}

\subsubsection{For MBAP-1 and MBAP-2 Samples}

A description of the sample preparation procedure will precede the experimental procedure. The sample acquired from MBAP needed further treatment to remove impurities such as glass beads, paperlabels and copper wires, which could easily alter the data and make them irreproducible. Hence the sample preparation was an essential step in the experimental procedure.

\subsubsection{Mixed Plastic Sample Preparation For MBAP -1 and MBAP-2:}

A protocol was established to convert MBAP-1 and MBAP-2 samples from a heterogeneous 100Ib lot to one suitable for the generation of small but reproducible feeds. See Figure 3.12 for a flow chart of the procedure. The plastics were ground to -20 mesh and were allowed to settle in a beaker filled with distilled water. Glass particles, sand and copper wires sank to the bottom and were separated from the polymers that floated in the water. Leaving these contaminating components in the polymer samples would have seriously degraded the reproducibility of the experimental runs since each reaction only involved three grams of the polymer. The washed plastics were then vacuum-dried, weighed and bottled. The bottled plastics were kept in a desiccater to prevent humidity from affecting the weight of the plastic sample.

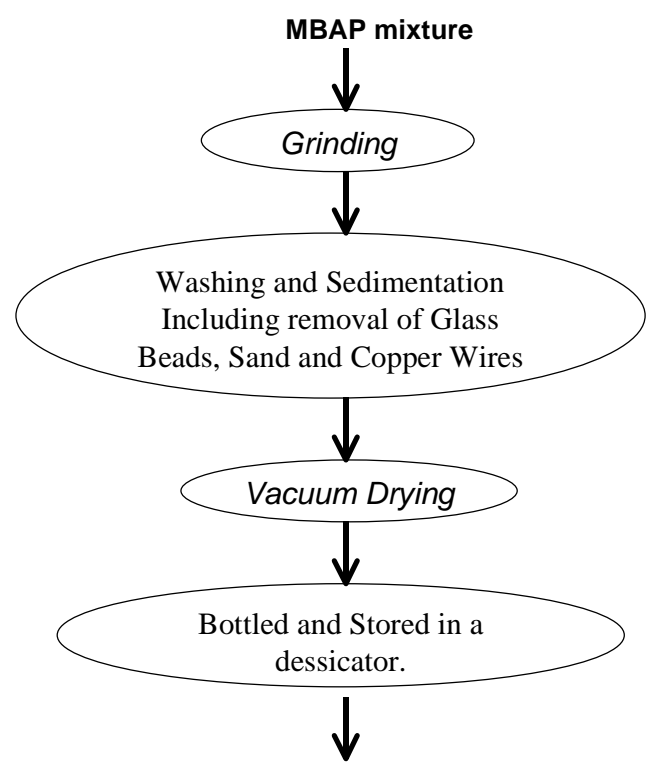

3 GRAM SAMPLES FOR REACTION

Figure 3.12: How chart for the preparation of clean homogeneous polymer samples. 


\subsubsection{Experimental Procedure:}

Experimental procedures for the MBAP samples, MBAP-1 and MBAP-2, include material weighing and loading into the reactor, reaction, and analysis of reaction products. The whole process is illustrated in Figure 3.13.

\subsection{Loading the Reactors:}

A cleaned polymer sample weighing three grams was transferred from the dessicator to a clean TBR. The end caps of the reactors were sealed using copper grease. The sealing not only prevents leakage of product gas but also prevents the end caps from jamming with the reactor ends at high temperature.

\subsection{Reactor Pressurization:}

The reactors are pressurized with Helium using the Gas Mixing Apparatus (Figure 3.8). The reactor limb is connected to a Swagelok quick connector which is in turn connected to the apparatus. The valve $\mathrm{V} 1$ is opened and the helium gas is allowed to enter the reactor to a pressure of 350psig. The reactor is then vented to atmospheric pressure and this pressure-purge process is repeated at least three times to make sure that reactor is inerted (air is absent). The final helium pressure is then maintained at 50psig.

\subsection{Reaction Procedures:}

The sand bath was maintained at a temperature of $25^{\circ} \mathrm{C}$ greater than the reaction temperature, to compensate for the heat transferred to the initially cold reactors. The reactors were connected to the rotor shaft of the agitator. Experiments were always done in sets of two for validation of results as well as for stability of the agitator.

The reactors were clamped tightly to the shaft and then lowered into the sand bath to the desired level with the pulley-winch mechanism. A stop clock was used to time the reaction (range 15min - 45min, in steps of $15 \mathrm{~min})$. The reaction temperatures ranged from $375^{\circ} \mathrm{C}$ to $450^{\circ} \mathrm{C}$ in steps of $25^{\circ} \mathrm{C}$. The 
pressure was maintained at 50psig helium. There were a few runs carried out in $\mathrm{H}_{2}$ atmosphere (50psig) as well.

\subsection{Product Gas Collection and Analysis:}

After the reaction time elapsed, the agitator was stopped, the shaft was raised, and the reactors were removed from the agitator shaft. The reactors were then cooled in a water bath and placed aside for five minutes to allow for any condensation that may occur. The reactors, one by one, were then connected to the Gas Collection Apparatus. It is to be noted that the product gas was still contained in the reactor until a vacuum of a few millimeters $\mathrm{Hg}$ was pulled in the gas collection apparatus. The gas was then admitted to the flask by opening valve $V_{p}$ (see Figure 3.7). The final pressure of collection apparatus was then noted. The total volume of the apparatus including the reactor was determined to be $1133 \mathrm{ml}$. The change in pressure and the overall volume of the gas collection apparatus allows the calculation of the amount of gas formed as explained in Section 4.1.1.3.

A syringe was used to collect a sample from the flask and the gas sample was analyzed in the GC. The initial GC column temperature was maintained initially at $60^{\circ} \mathrm{C}$ and then heated at rate of $5^{\circ} \mathrm{C} / \mathrm{min}$ to a maximum of $230^{\circ} \mathrm{C}$. The injection port and the detector were maintained at $230^{\circ} \mathrm{C}$. The carrier gas (hydrogen) flow was maintained at 30ml/min. A Chromatopac CR-601 chart recorder was used to obtain the data from the GC. Thus the total amount of gas (Pyrolysis gas + Helium) was calculated as explained in Section 4.1.1.3.

\subsection{Non-Gaseous Products Analysis:}

After the run was completed and product gas safely and completely transferred to the gas collection apparatus, the reactor contents were carefully transferred to a $250 \mathrm{ml}$ boiling-flask. The nongaseous product transfer was carried out by initially scraping out the solid product using a spatula and

then rinsing the reactor contents multiple times with a pre-calculated amount of THF, approximately 140ml. The boiling flask was then placed on the Soxhlet Extraction Apparatus. The extraction was carried out for a period of 12 to $14 \mathrm{hrs}$. The contents of the flask were vacuum filtered (hot) and the residue 
(considered THF-Insolubles) was then separated. Vacuum filtration removes most of the THF from the non-gaseous product.

The filtrate (considered THF-Solubles + remaining THF) was then added to $140 \mathrm{ml}$ of hexane and again extracted in the Soxhlet Extraction Apparatus for 4 hrs. Then the residue (THF - Soluble, HexaneInsoluble) and the filtrate (Hexane-Solubles + Hexane), are separated again using vacuum filtration. The Hexane-Soluble material is referred to as oils. It is to be noted that the solubles in both the cases (THF and Hexane) contain the solvent, which is removed by using a rotary evaporator. The rotary evaporator is heated to about $75^{\circ} \mathrm{C}$ and rotated at $90-120 \mathrm{rpm}$.

THF

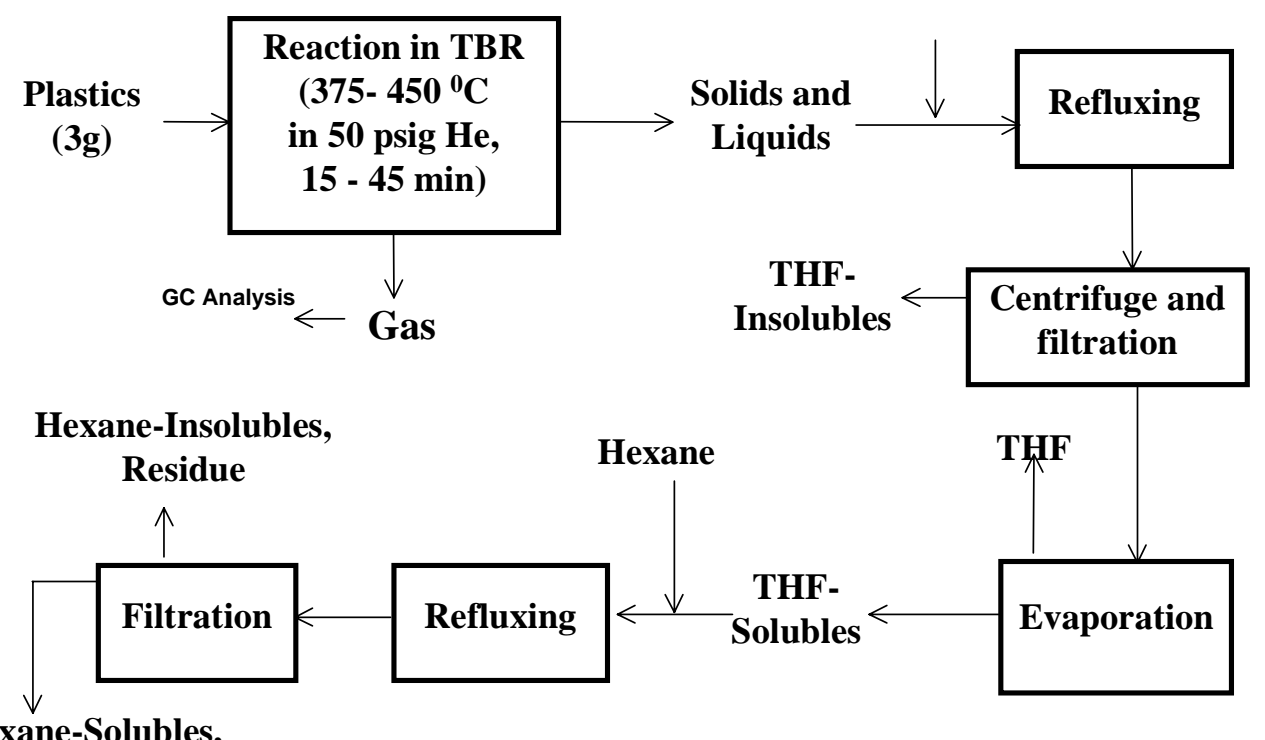

Hexane-Solubles, Filtrate

Figure 3.13: Flowchart - Experimental Procedure for Pyrolysis of MBAP-1 AND MBAP-2 


\subsubsection{AT-1 Oil Analysis:}

Most plastics used in electronic appliances are halogenated (bromine and chlorine) to render them flame-retardant. This beneficial step in electronic plastics manufacturing creates significant challenges when recycling the spent plastics. Pyrolysis of halogenated polymers would result in the release of these halogens, resulting in corrosion of process equipment (tube internals, process vessel materials etc.). Hence a treatment process is necessary to remove the halogens from the oil sample before analysis. Both the raw and the treated samples are analyzed in the D-86 apparatus.

\subsubsection{The Halogen-Removal Process:}

The raw sample is transferred to a separatory funnel. An equal amount of nano-pure water is added to the oil. The contents are then mildly stirred for about 30 minutes and left to stand. After the intended settling time has elapsed, the oil phase (which is heavier than water) is removed and measured with a graduated cylinder. Then $100 \mathrm{ml}$ of this oil is distilled in the D-86 apparatus. The lighter aqueous phase contains the halogens removed from the oil.

\subsubsection{General Procedure for Distillation in the D-86 Apparatus:}

A $100 \mathrm{ml}$ feed of either AT-1 oil or pyrolysis oils from MBAP-1 or MBAP-2 was used to perform the distillation (refer the Figures 3.4 and 3.14). The condenser box is filled with ice and water so as to cool the tube (not shown in Figure 3.14) to $32-34^{\circ} \mathrm{F}$. Any residual liquid in the condenser tube is removed by swabbing with a piece of soft, lint-free cloth attached to a cord or copper wire.

The temperature of the sample is brought to $55-65^{\circ} \mathrm{F}$ by adjusting the thermostat of the heating coil. The thermometer is fit with the distillation flask by a snug-fitting stopper. The bulb is centered such that it is in alignment with the flask neck and is level with the highest point on the bottom of the inner wall of the vapor tube of the distillation apparatus. The prevailing barometric pressure is recorded (See Section 4.2.1 for pressure correction equation). 


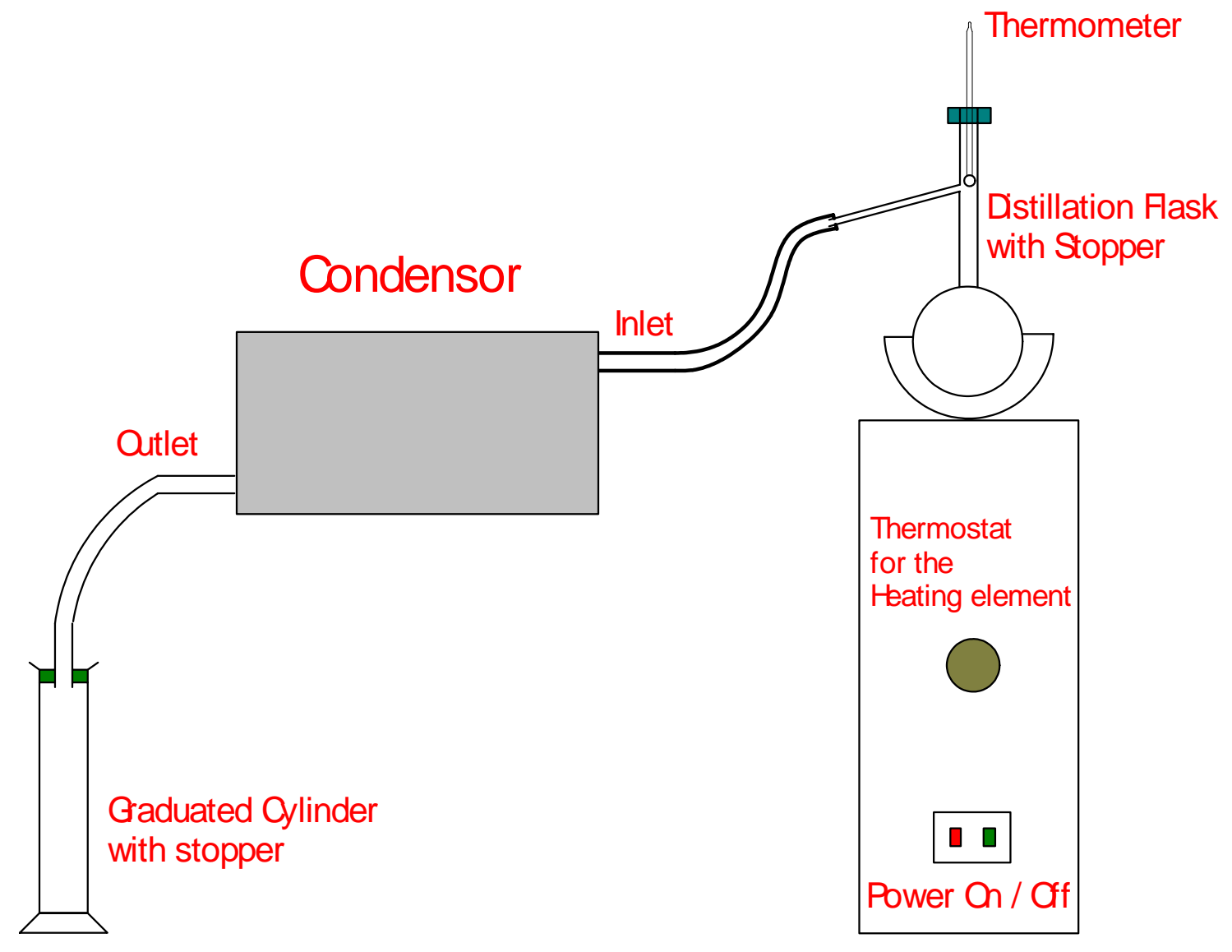

Figure 3.14: Schematic of D-86 Atmospheric Distillation Apparatus

The flask is in a vertical position and the vapor tube extends a distance of 1 to 2 inches into the condenser tube. A clean empty graduated cylinder is placed under the lower end of the condenser tube so that the end of the condenser tube is centered in the cylinder and extends for a distance of at least 1" but not below the $100 \mathrm{ml}$ mark. The experiment is conducted in a controlled atmosphere so that the temperature around the cylinder will remain at $55-65^{\circ} \mathrm{F}$ during the distillation. A glass cap is provided to fit the cylinder snugly to the condenser outlet tube. This is to prevent any uncondensed process vapor 
(distillate) from escaping the cylinder as well as to absorb any liquid distillate that may escape the tongue of the cylinder.

The heating coil is turned on and a stopwatch is used to record time. Heat is applied to the flask so that the time interval between the first application of heat and the initial boiling point is 5 - 10 minutes. Immediately after the first drop comes over, the time is recorded. This time corresponds to the initial boiling point (IBP) and the boiling point temperature. The heating is now regulated so that the rate of condensation into the graduate is uniform and averages $4-5 \mathrm{ml} / \mathrm{min}$. At the $5 \mathrm{ml}$-condensate point the time and the temperature is recorded. As each minute is passed on the stopwatch, the volume of condensate is recorded to keep track of the rate.

In the interval between the recovery of $5 \mathrm{ml}$ and the end of the distillation the temperature is observed and recorded at each multiple of $10 \%$ recovered from $10 \%$ to $90 \%$ inclusive. The stopwatch the is stopped at the $80 \mathrm{ml}$ mark. When the residual liquid in the heated flask is about $5 \mathrm{ml}$, the stopwatch is started again and a final adjustment in the heat is carried, if necessary, so that the time from $5 \mathrm{ml}$ of liquid in the flask to the end point is between 3 and 5 minutes. The end point is the maximum observed temperature after which the temperature begins to drop. The stopwatch is stopped at the end point to record the temperature and the time from $5 \mathrm{ml}$ remaining in the distillation flask to the end point.

The heat is turned off and the flask allowed to cool. While the condenser tube continues to drain into the cylinder, the volume of condensate at 2-minute intervals is observed until two successive observations agree. This volume measured and noted is the percent recovered. After the flask has cooled, its contents are poured into a small graduated cylinder and allowed to drain until no appreciable increase in the volume of liquid in the graduate is observed. This volume recorded is the percent residue. 


\section{DATA ANALYSIS}

\subsection{For MBAP-1 And MBAP-2 Samples:}

The pyrolysis of the mixed plastics sample results in the following parameters: THF-Solubles + Gas Yields (THFS), Hexane-Insolubles (HexI) Yield, Gas Yield and Hexane-Solubles (HexS) Yield. The quantity (THFS + Gas) Yield reflects the "overall conversion" of the plastics feed to soluble or gaseous products. The total conversion to non-gaseous products is THF-Solubles (THFS) while the THFInsolubles (THFI) is the residue. The Hexl is the "asphaltenes" fraction while the HexS is the oil fraction. The main products of interest are the gas fraction and the HexS fraction.

\subsubsection{Calculation Procedure for Yields:}

\subsubsection{THF-Soluble + Gas Yield:}

The THFS yield is defined to be the percentage of dry matter present in the sample that is converted into THF-Soluble and gas phase materials. It is calculated from the data as follows:

$$
(\text { THFS }+ \text { Gas }) \%=\frac{\text { Wt.ofPlastics }- \text { Wt.ofTHFI }}{\text { Wt.ofPlastics }} \times 100
$$

The weight of THFI is obtained as in Section 3.3.1.2.5.

\subsubsection{Hexane-Insoluble Yield:}

Asphaltenes are defined as the THF-Soluble/Hexane-Insoluble fraction of the converted material. The THF-Soluble/Hexane-Insoluble fraction is calculated from the data as follows:

$($ HexI $) \%=\frac{\text { Wt.ofHexI }}{\text { Wt.ofPlastics }} \times 100$

The weight of Hexl is obtained as in Section 3.3.1.2.5 


\subsubsection{Gas Yield:}

The gas yield is measured independently by injecting a 1-ml sample via a gas- sampling syringe, into the gas chromatograph. The gas yield is calculated based on the peak areas obtained from the GC. Ethane has been used as the calibration standard to arrive at the calibration constant or "response factor". Different samples of pure ethane at known concentrations (amount of sample calculated based assuming ideal gas law), are injected into the GC at experimental conditions. The peak area obtained through the integrator is then plotted against the amount of ethane sample. The slope of the curve gives the response factor. Detailed graphs are provided in Section 5.2.2. The value of the sample peak areas in the GC are then multiplied by the response factor and expressed in terms of grams using the Ideal Gas Law relationship.

The result of this calculation is as follows:

$($ Gas $) \%=\frac{\text { Wt.ofGas }}{\text { Wt.ofPlastics }} \times 100$

where,

WtofGas $=\frac{\text { CCx }(\text { TotalGCArea }- \text { AirPeak }- \text { HePeak }) \times 1133}{V_{S}}$

where,

CC: Calibration Constant (g/peak area, see Section 5.2.2.2)

$V_{S}$ : Volume of sample in the syringe injected into the G.C. $(\mathrm{ml})$

Note: 1133 in the above equation corresponds to the total volume of the gas-collection apparatus including the reactor in $\mathrm{ml}$.

All weight measurements are in grams. 


\subsubsection{Hexane-Soluble Yield:}

The amount of Hexane-Soluble species resulting from the pyrolysis is determined by difference from the data as follows:

$($ HexS $) \%=($ THFS + Gas $) \%-($ HexI $) \%-$ Gas $\%$

\subsection{For AT Process:}

\subsubsection{Distillation Temperature Calculation of AT-1 Oil for ASTM D-86 Analysis:}

The ASTM D-86 procedure is used extensively in the petroleum industry to assess the amount of classes of distilled fuels in a particular oil sample. Such classes are gasoline, diesel fuel, kerosene, etc. and are determined primarily by their boiling point range. The D-86 data are given as the percentage distilled as a function of the boiling point temperature.

The ASTM D-86 results reported in Chapter 5 are based upon thermometer readings corrected to $760 \mathrm{~mm} \mathrm{Hg}$. The correction is applied to each thermometer reading and is described by the following equation from the ASTM D-86 procedure:

$$
C_{f}=0.00012(760-P)\left(460+t_{f}\right)
$$

where:

$\mathrm{C}_{\mathrm{f}}=$ Temperature Correction to be added algebraically to the observed thermometer reading $\mathrm{t}_{\mathrm{f}}\left({ }^{\circ} \mathrm{F}\right)$.

$\mathrm{P}=$ Prevailing barometric pressure, $\mathrm{mm} \mathrm{Hg}$, at the time of the test. 


\section{RESULTS AND DISCUSSION:}

\subsection{Research Objectives and Goals:}

The research work was divided into two parts. The first one dealt with the investigation of two mixed-plastics streams provided by MBA Polymers (MBAP). One of the streams consisted of fines (MBAP-1), and the other was a non-separable stream, MBAP-2. These solid polymer streams from MBAP were reacted in the tubular batch reactor inerted with helium.

The product gas fractions were analyzed using a Shimadzu 8-A Gas Chromatograph (GC). Apart from calculating the amount of gas produced under each process condition, the quantity of individual gas components, such as alkanes $\mathrm{C}_{1}-\mathrm{C}_{6}$, ethylene $\left(\mathrm{C}_{2} \mathrm{H}_{6}\right)$ and carbon dioxide $\left(\mathrm{CO}_{2}\right)$, was also determined. These data would help determine the heat content of the gas mixture and thus its suitability as a source of heat. If found suitable, the gas mixture could itself be used to heat the reactor system and thus improve the economics of the process. These results are found in Section 5.2.7.3.

The solid and the liquid product fractions from the tubular batch reactor were separated using common solvents, tetrahydrofuran (THF) and hexane, and analyzed. The THF-Insolubles are termed as "residue", THF-Soluble/Hexane-Insolubles as "Asphaltenes" and THF-Soluble/Hexane-Solubles as "Oils". The oil-fraction was analyzed using High Performance Liquid Chromatography (HPLC) and ASTM D-2887 simulated distillation apparatus (refer Sections 5.3.2 and 5.3.3). The goal of this work was to determine the optimum process conditions (reaction temperature, reaction time, reaction pressure, effect of catalyst, hydrogen, etc.) for "maximum oil yield". Also the results obtained from samples MBAP-1 and MBAP-2 were compared and the effect of reactor conditions on Oil yield was assessed (refer Section 5.2.6). The intent is to discover the mildest possible reaction conditions that optimize the production of the oil fraction.

AT uses a two-stage catalytic pyrolysis process. In the second part of this work, the liquid after pyrolysis by AT but before upgrading was analyzed by studying the boiling-point curves obtained using ASTM D-86 atmospheric distillation and ASTM D-2887 simulated distillation methods (refer Section 5.3). The data thus collected for the AT-1 Oil were compared with the data obtained from characterizing the oils produced by the reactions of the same polymer feed streams but with different process conditions 
determined by experimentation in this study. In addition to the analysis and characterization of the AT oils sample, considerable effort was spent in removal of chloride and bromide compounds present in the oil (refer Section 3.3.2.1). The halogenated substances are present in the original plastics as fire retardants. They severely limit the usefulness of the pyrolysis oil and are detrimental to the subsequent distillation and purification of the oil.

Apart from studying the distillation characteristics of the oils from AT, those produced by pyrolysis of MBAP samples were also analyzed using the ASTM D-2887 simulated distillation apparatus (refer Section 5.3.2). Also some HPLC runs were performed on the AT oil to analyze its high boiling fractions (with boiling point $>662^{\circ} \mathrm{F}$ ) using an Evaporative Light Scattering Detector (ELSD). The results are discussed in Section 5.3.3.

Finally, some time was spent studying the possible uses of the solid residue (THF-Insolubles), as a potential feedstock for the production of coke for the carbon-materials industries (refer Section 5.4).

\subsection{Characterization of Pyrolysis Products from MBAP samples:}

Pyrolysis experiments in the tubular batch reactor were completed using MBAP-1 and MBAP-2 samples (Refer to Chapter 3 for description of samples). Reaction temperatures ranged from $350-450^{\circ} \mathrm{C}$ in steps of $25^{\circ} \mathrm{C}$, with a constant helium pressure of 50psia, cold. Reaction times spanned the range of 15 to $45 \mathrm{~min}$, with emphasis placed on the shortest time period. The bulk of the reactions were carried out in an inert helium gas atmosphere (to prevent oxidation and combustion of the polymer). Some select runs, which had large oil yields, were repeated in a hydrogen atmosphere, to determine the effect of the presence of a reactive gas. Finally some select runs, which had large oil yields, were repeated in the presence of an iron-based catalyst, to discern any beneficial aspects of the catalyzed pyrolysis of the plastics.

While MBAP-1 had metal and glass impurities that had to be removed prior to reaction, MBAP-2 was essentially pure and did not require any sort of pretreatment. Also, MBAP-1 (fines) is a mixture of almost all polymer resins while MBAP-2 predominantly consists of ABS and HIPS. This implies that there 
should be more homogeneity/uniformity in results from MBAP-2 than from MBAP-1. The results discussed in this chapter corroborate these implications.

The results have been characterized in terms of the fraction soluble in tetrahydrofuran (THF), i.e. total conversion, and the fraction soluble in hexane, i.e. oils. THFS (i.e. total conversion) ranged from 74$80 \%$. Hexane-Soluble (oils) yields were essentially zero at $350^{\circ} \mathrm{C}$ but increased to around $60 \%$ at higher temperatures.

\subsubsection{Gas Chromatograph Settings:}

The Shimadzu 8A (Gas Chromatograph) was calibrated for various hydrocarbons $\left(\mathrm{C}_{1}-\mathrm{C}_{6}\right)$ and permanent gases (air, carbon dioxide, helium etc). The initial analyses were conducted at isothermal condition $\left(140^{\circ} \mathrm{C}\right)$, but the peak separation of the components was found to be inadequate. Hence, the temperature program for operating the GC column was changed to a temperature ramping at $5^{\circ} \mathrm{C} / \mathrm{min}$, from $100^{\circ} \mathrm{C}$ to $200^{\circ} \mathrm{C}$. This enabled better separation of carbon dioxide and light hydrocarbon components (methane, ethylene) that had eluted as a single peak at low retention times at $140^{\circ} \mathrm{C}$.

The operating filament current was maintained at a constant value of $80 \mathrm{~mA}$ in both the cases. It is to be noted that variations in filament temperature can alter the signal peak areas, while a change in column temperature alters only the elution time, but the signal strength (in terms of peak areas) remains the same. Hence for the temperature-programmed runs, the peak areas were the same as for the isothermal tests, while the retention times changed for each peak in the sample. This is important since through careful calibration, the absolute amount (i.e. grams) of each component is related directly to the peak area.

\subsubsection{Calibration of Gas Components:}

The gas quantity was determined assuming that the relationship between the peak area of the major carbonaceous components of the gas and the corresponding amount of the sample is comparable with that of pure ethane. It is to be noted that calibration curves for many product gas components have been determined. Calibration of select alkanes $\left(\mathrm{C}_{1}-\mathrm{C}_{6}\right)$, at $21^{\circ} \mathrm{C}, 60 \%$ relative humidity and atmospheric 
pressure $718 \mathrm{~mm} \mathrm{Hg}$, produced a linear relationship between peak area and weight of sample in the same range of weight as that found in the actual experimental runs. This helped determine with acceptable precision the quantity of gases such as methane, ethane, propane etc. in the product. Most of the peaks in the GC analysis were identified as specific carbonaceous compounds. Since not all the product gas components (most alkenes) were calibrated individually, ethane was used to average out the total amount of product gas produced.

\subsubsection{GC Calibration Curves of Permanent Gases Air, Carbon Dioxide and Helium:}

Calibration curves help determine the relationship between peak area of a particular gaseous component and its amount through the ideal gas law. The calibration curves are usually linear in nature over a small range of concentration (a few mg). Peak area of a gaseous component is a number (with arbitrary units) whose magnitude indicates the amount of gas in the injected sample. It is to be noted that Hydrogen is used as a carrier gas for all the GC runs and hence need not be calibrated. Helium is used to inert/pressurize the reactor. This of course means that hydrogen gas is not seen in the product gas sample. This does not lead to any significant error, as hydrogen usually constitutes less than $1 \%$ of most product gas samples produced through pyrolysis ${ }^{8}$. While helium is the inert gas used in the reactor, air is a contaminant and should be kept to a bare minimum. The calibration curves of helium and air enable the determination of the amount of product gas as a whole and the amount of individual product gas components. The calibration curves for a variety of gas species (in $\mathrm{mg}$ ) are shown in Figure 5.1. The calibration curves for helium and air are constrained to pass through the origin and can be seen to be linear in the ranges studied. The resulting equations for air, helium and carbon dioxide are as follows:

Peak Area $=658444.59$ * amount of air (in mg)

Peak Area $=551132$ * amount of helium (in $\mathrm{mg}$ )

Peak Area $=448831$ * amount of carbon dioxide (in $\mathrm{mg}$ )
5.1

5.2

5.3 


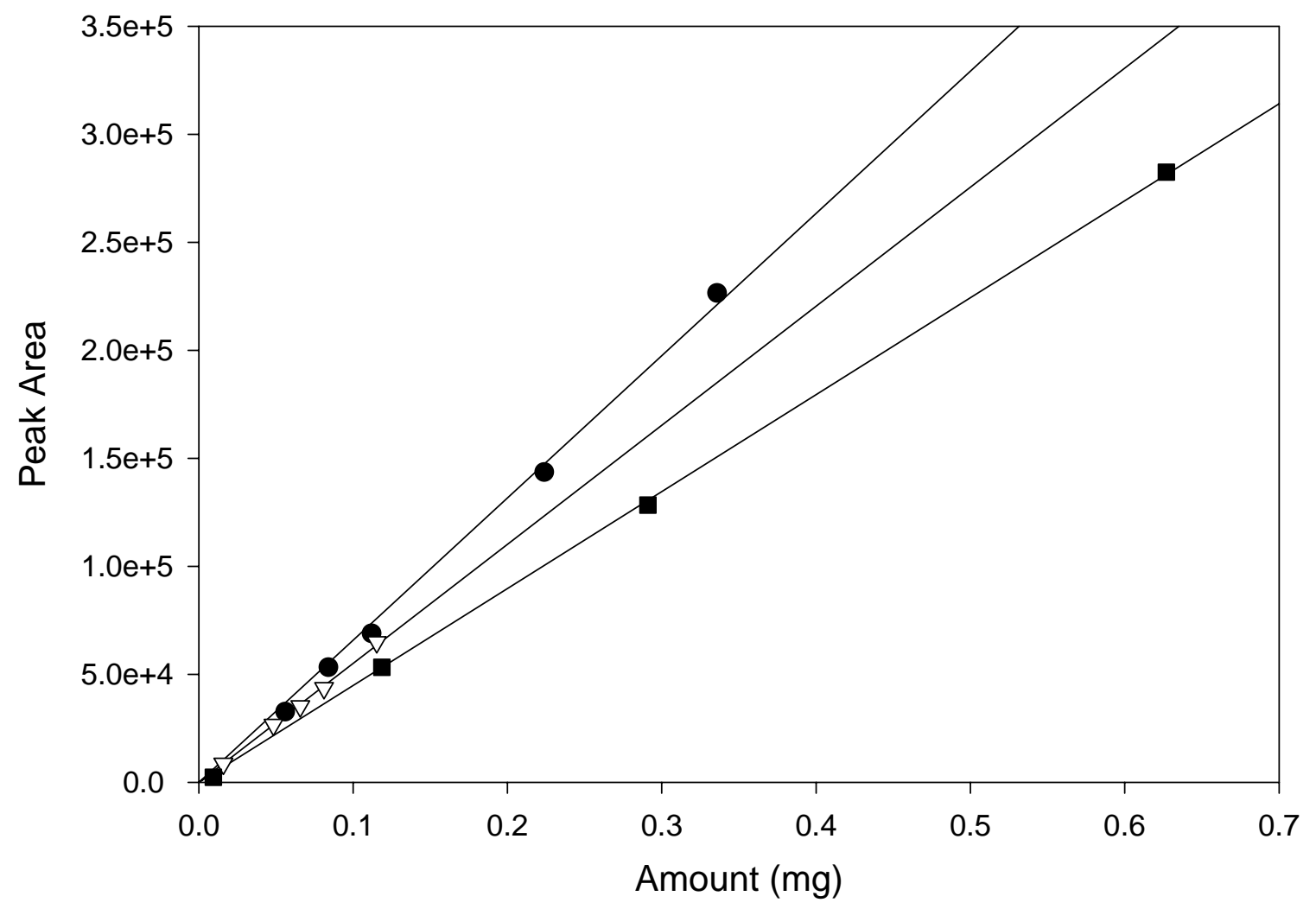

- Amt of Air (mg) vs Peak Area (Air)

$\nabla \quad$ Amt of $\mathrm{He}(\mathrm{mg})$ vs Peak Area $(\mathrm{He})$

- Amount of CO2 vs Peak Area(CO2)

- Regression Line

Figure 5.1: Calibration curves for helium, carbon dioxide and air 


\subsubsection{Calibration Curves of Hydrocarbons $\mathrm{C}_{1}-\mathrm{C}_{6}$ :}

The calibration curves for methane, ethane, ethene, propane, butane, pentane and hexane were similarly determined. Figure 5.2 and Figure 5.3 present the results for methane and ethane respectively and Figure 5.4 presents the results for the individual alkanes $C_{3}-C_{6}$. A known mixture of $C_{1}$ to $C_{6}$ gases, procured from Sigma-Aldrich, was used for calibration of propane, butane, pentane and hexane. Pure sample gases procured from Air Gas were used for calibration of methane, ethane and carbon dioxide.

The curves in Figures 5.2 through 5.4 are less linear than those in Figure 5.1, but a straight line can still be used, constrained to pass through the origin. The peak area for the same amount of substance decreases with increase in number of carbons. This is in accordance with what is expected for a GC with a Thermal Conductivity Detector (TCD). Thermal conductivity decreases as number of carbons in the hydrocarbon increases. It should be noted that there is a steep decrease in the value of the slope from ethane to higher hydrocarbons. Thus assuming the calibration of ethane to be the standard in calculating amount of gas (a common practice) might lead to erroneous results especially if $\mathrm{C}_{3}$ to $\mathrm{C}_{6}$ constitute the majority of product gas formed. The resulting equations for $\mathrm{C}_{1}-\mathrm{C}_{6}$ are given as follows:

Peak Area $=718831$ * amount of methane $($ in $\mu \mathrm{g})$ 


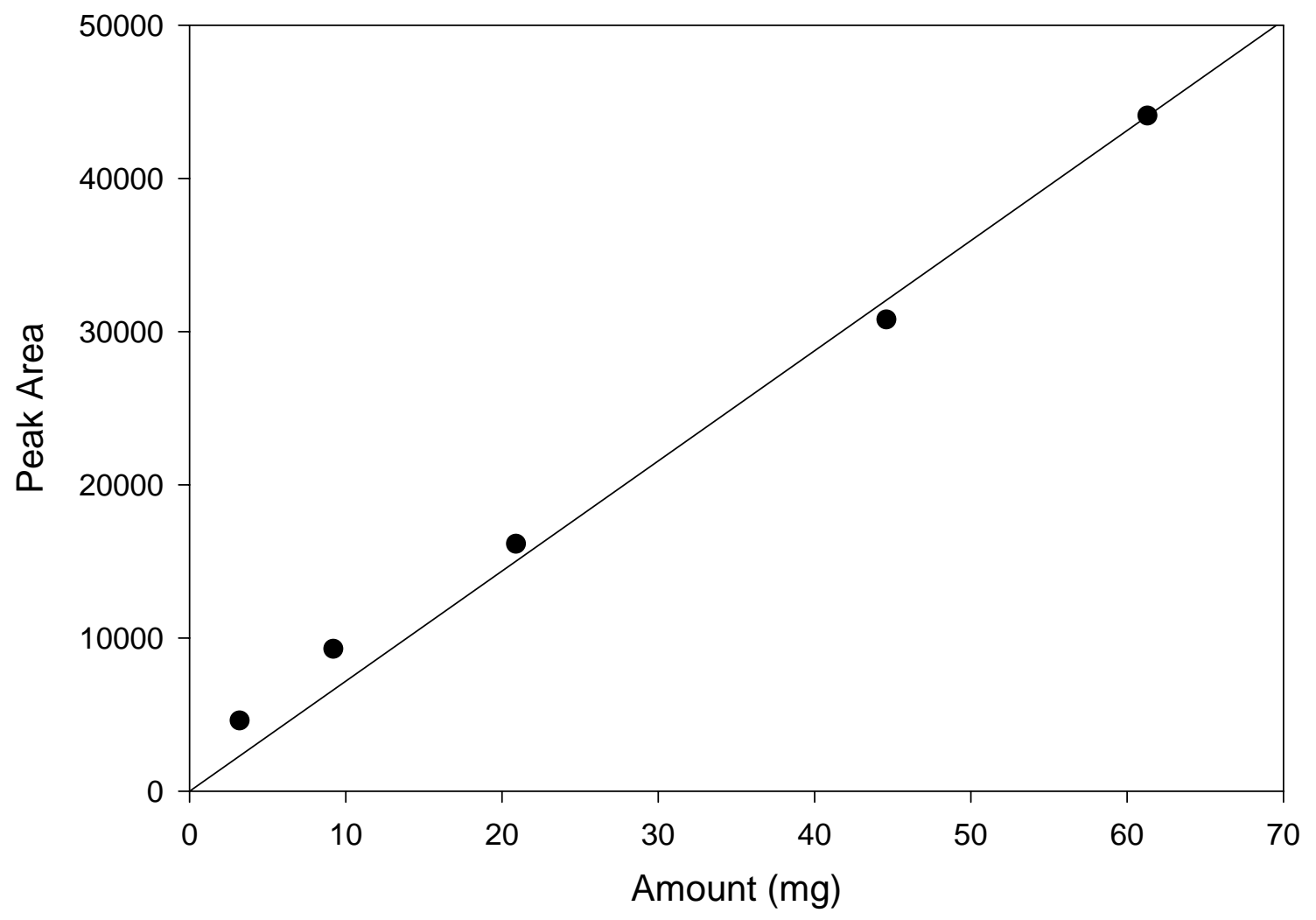

Figure 5.2 Calibration of Methane - Amount of Methane (mg) vs. Peak Area 


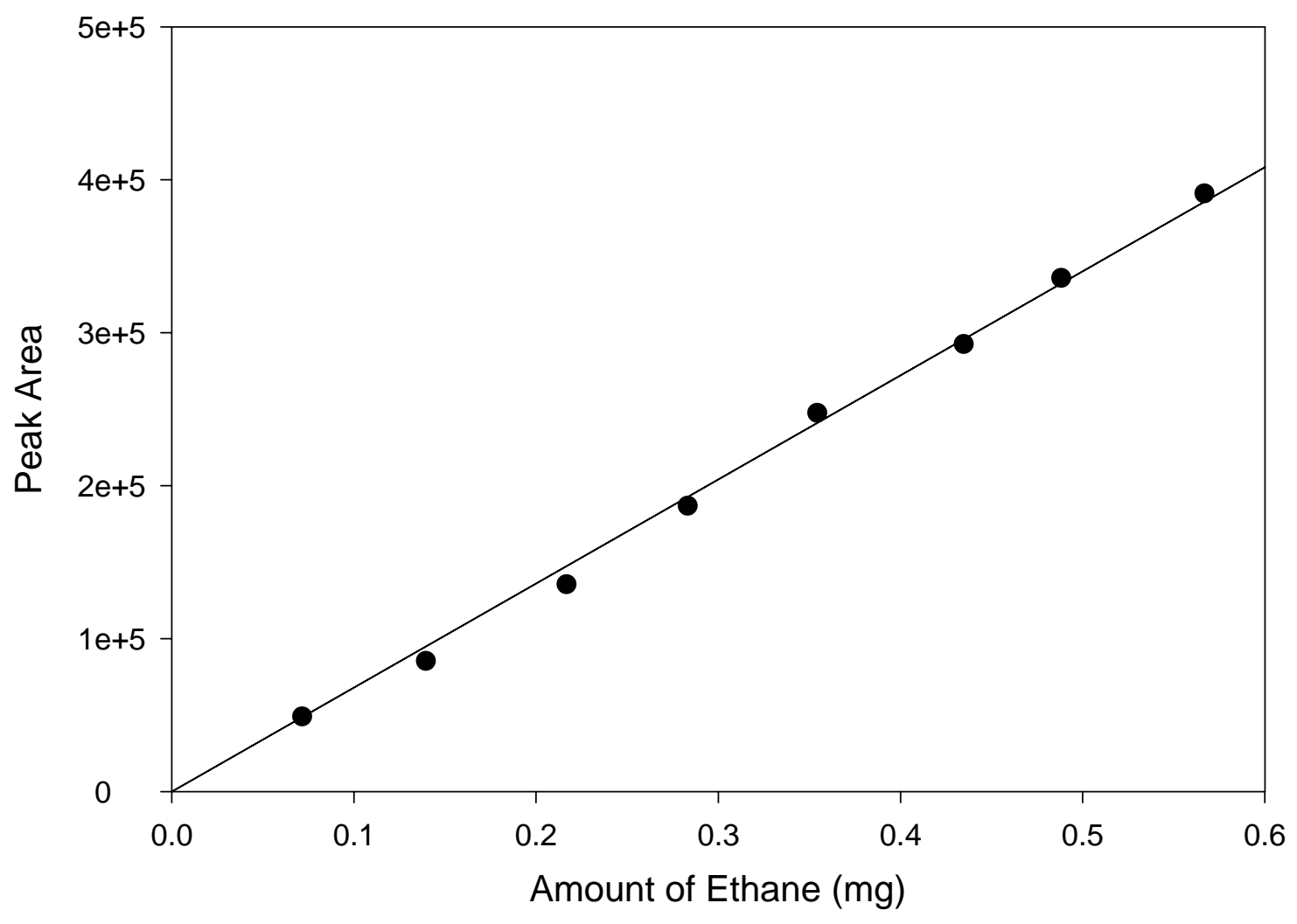

Figure 5.3: Calibration of Ethane: Amount of Ethane (mg) vs. Peak Area 


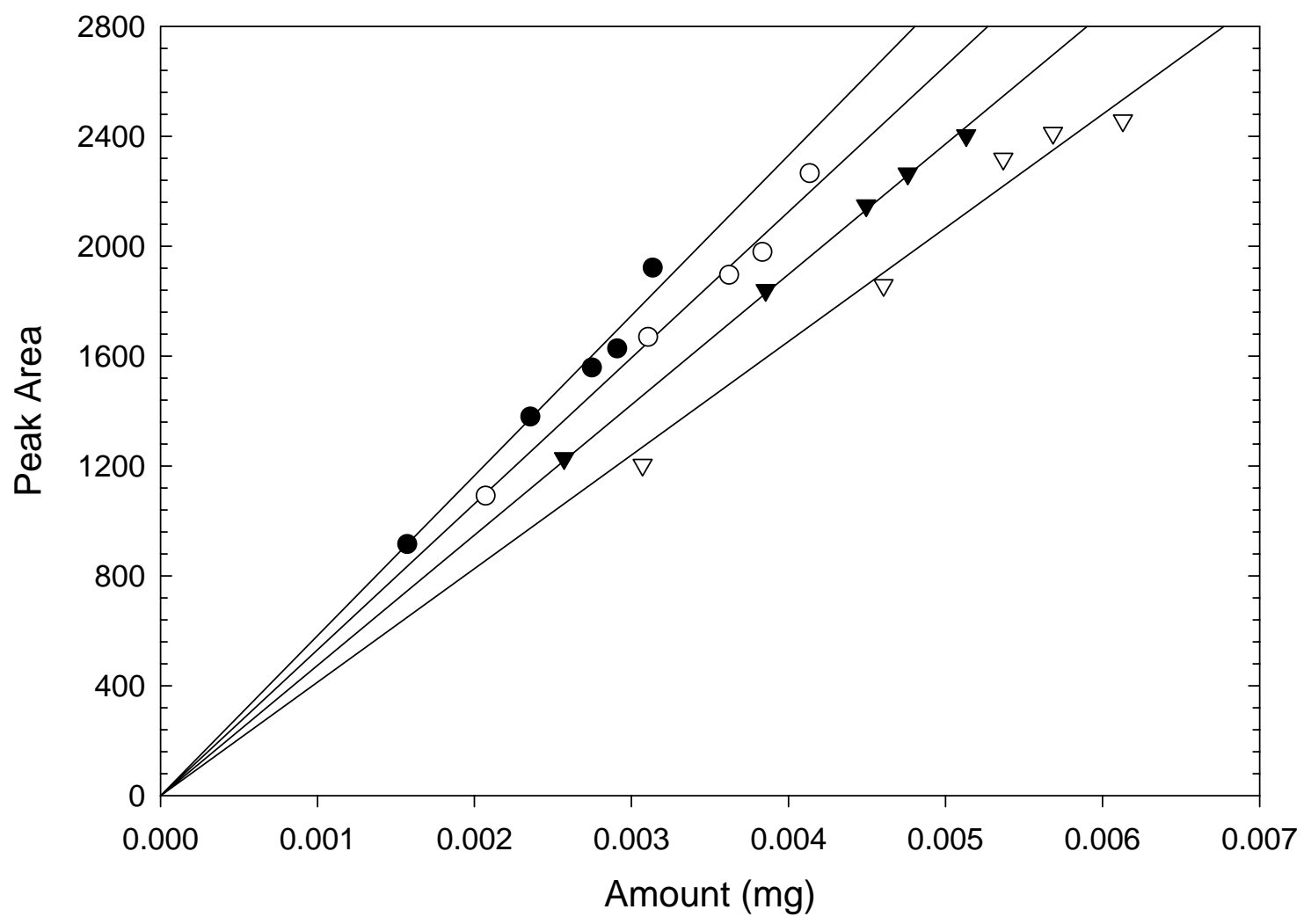

Figure 5.4: Calibration curves for alkanes $C_{3}-C_{6}$ 


\subsubsection{Pyrolysis of MBAP-1:}

Table 5.1 lists the comprehensive data on experimental results of pyrolysis of MBAP-1. Recall that MBAP-1 is a very complex mixture of fines (ABS, HIPS, PE, PVC, and PC) whose further separation is uneconomical. The pyrolysis of such a mixture can lead to non-homogeneity in product yields, resulting in experimental variability. The pyrolysis results of MBAP-1, though following a trend, do provide a few surprising spikes that will be pointed out and explained in the following discussion. It is to be noted that multiple runs were performed for each set of reaction parameters for establishing reproducibility of the results. The yields in all the fractions were found to be reproducible for the sample (true for both MBAP-1 and MBAP-2) irrespective of its shelf life. The error bounds, due to possible calibration and experimental errors, are $\pm 1 \%$.

As a comparison, the raw solid MBAP-1 samples were tested for solubility in THF and Hexane without reaction. These results are also shown in Table 5.1, under "Room Temperature". According to these results, $74 \%$ of MBAP-1 dissolves in THF, none dissolves in hexane and there are obviously no gas phase products. The effect of the variables in the process, reaction temperature and reaction time, on product yield is explained in Sections 5.2.3.1 and 5.2.3.2. The product gas composition is detailed in Section 5.2.7.

\subsubsection{Effect of Variation of Reaction Temperature on Yield:}

Figures 5.5- 5.7 show variation of yield with reaction temperature. The results are for MBAP-1 at a combination of three reaction times $\left(15,30\right.$ and 45 minutes) and four reaction temperatures $\left(375^{\circ} \mathrm{C}\right.$, $400{ }^{\circ} \mathrm{C}, 425^{\circ} \mathrm{C}, 450^{\circ} \mathrm{C}$ ). The data reveal the trend in the gas yield, the oil yield, the Hexl yield and the THFS yield, with variation in reaction temperature.

Figure 5.5 shows yields at a constant reaction time of $15 \mathrm{~min}$. The gas yield steadily increases from $3.6 \%$ at $375^{\circ} \mathrm{C}$ to $8.6 \%$ at $450^{\circ} \mathrm{C}$. The oil yield initially increases with temperature, and reaches a maximum of $61.9 \%$ at $425^{\circ} \mathrm{C}$. Incidentally, this is also the highest oil yield for pyrolysis of MBAP-1. The 
hexane-insolubles yield decreases with increase in reaction temperature. The overall conversion, decreases with increase in temperature.

Table 5.1: Comprehensive results of experiments conducted for MBAP-1

\begin{tabular}{|c|c|c|c|c|c|}
\hline $\begin{array}{c}\text { Reaction } \\
\text { Temperature } \\
\left({ }^{\circ} \mathrm{C}\right)\end{array}$ & $\begin{array}{l}\text { Reaction } \\
\text { Time } \\
\text { (min) }\end{array}$ & $\begin{array}{c}\text { Gas Yield } \\
(\%)\end{array}$ & $\begin{array}{c}\text { Oil yield } \\
(\%)\end{array}$ & $\begin{array}{c}\text { Hexane-Insolubles yield } \\
\text { (\%) }\end{array}$ & $\begin{array}{c}\text { Overall conversion } \\
\text { (THF-S + Gas) yield } \\
\pm 1(\%)\end{array}$ \\
\hline $\begin{array}{c}\text { Room } \\
\text { Temperature }\end{array}$ & - & - & - & 74.0 & 74.0 \\
\hline 375 & 15 & 3.6 & 41.0 & 37.9 & 82.5 \\
\hline 375 & 30 & 12.4 & 43.3 & 21.4 & 77.1 \\
\hline 375 & 45 & 8.0 & 45.4 & 22.7 & 76.1 \\
\hline 400 & 15 & 3.8 & 57.7 & 14.0 & 75.5 \\
\hline 400 & 30 & 3.9 & 58.7 & 11.9 & 74.5 \\
\hline 400 & 45 & 6.3 & 60.7 & 7.0 & 74.0 \\
\hline 425 & 15 & 4.4 & 61.8 & 8.3 & 74.5 \\
\hline 425 & 30 & 5.1 & 59.9 & 4.0 & 69.0 \\
\hline 425 & 45 & 11.0 & 49.1 & 3.1 & 63.2 \\
\hline 450 & 15 & 8.6 & 50.6 & 3.2 & 62.4 \\
\hline 450 & 30 & 10.9 & 43.7 & 4.8 & 59.4 \\
\hline 450 & 45 & 10.0 & 41.2 & 6.4 & 57.6 \\
\hline
\end{tabular}




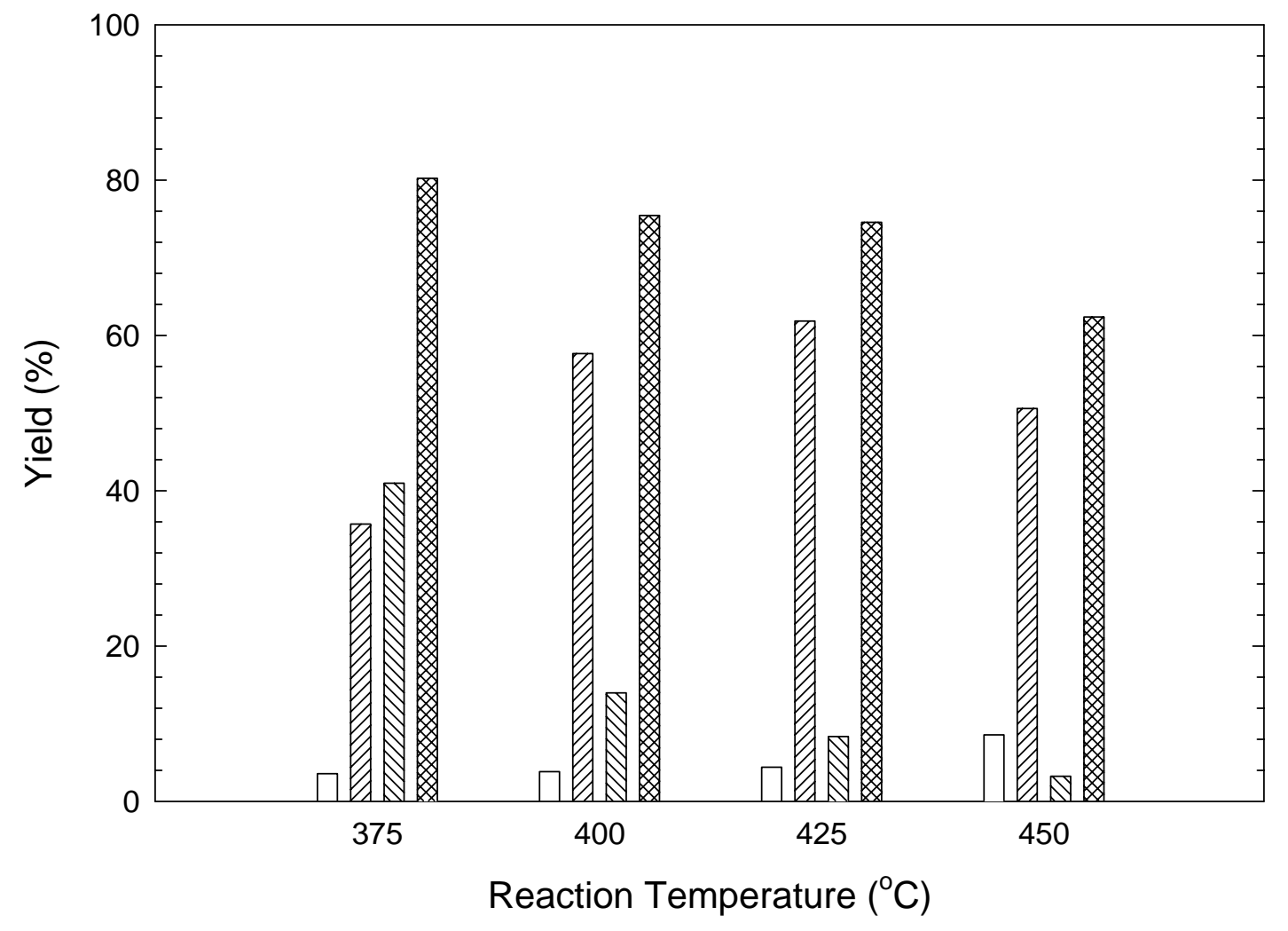

Gas \%
Oils \%
Oexane In-solubles \%
Overall conversion \%

Figure 5.5: Yields at various reaction temperatures for a reaction time of $15 \mathrm{~min}$ for MBAP-1 polymer 


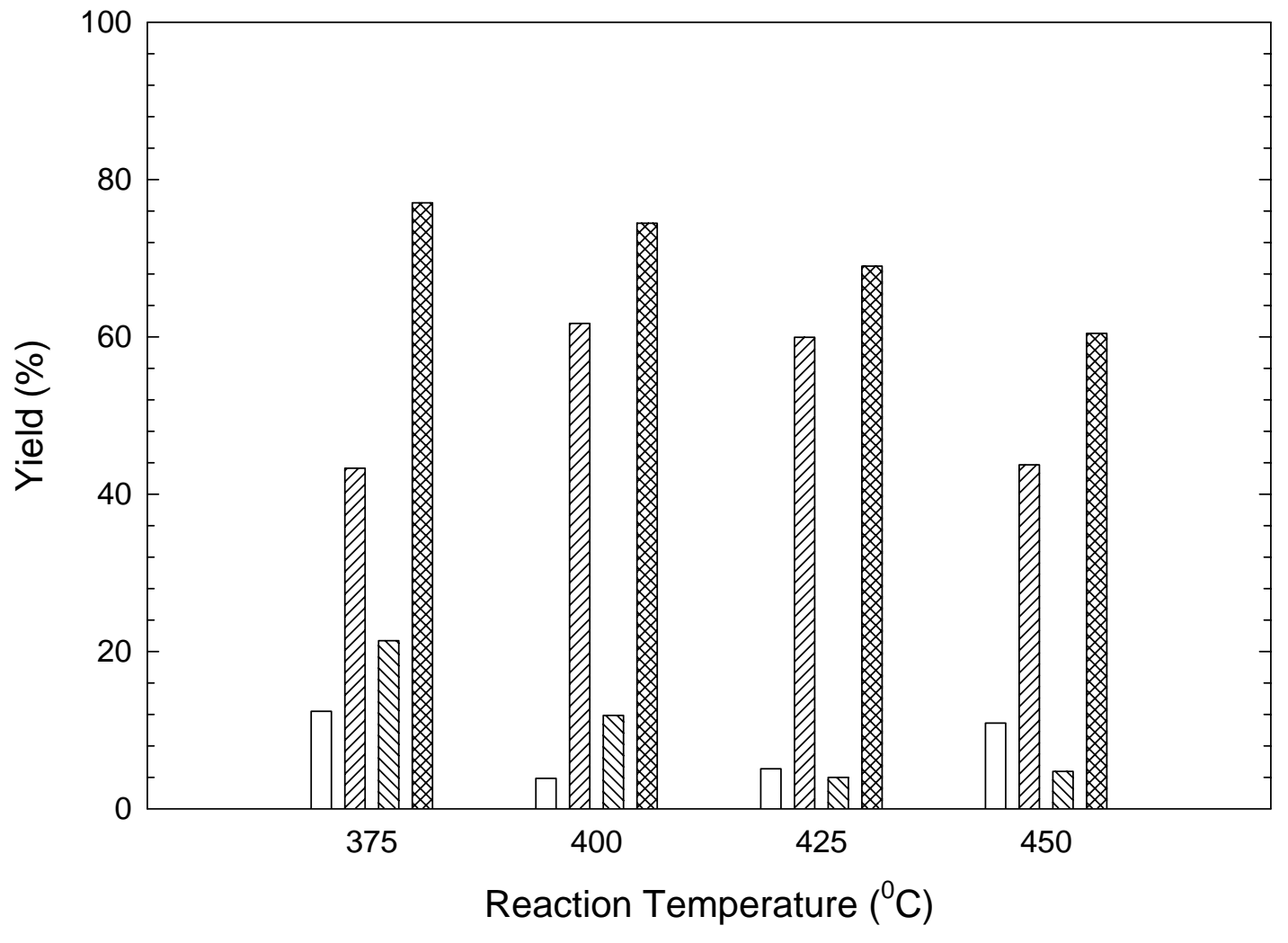

\begin{tabular}{l}
\hline Gas \% \\
Oils \% \\
Ond Hexane-Insolubles \\
Overall conversion \%
\end{tabular}

Figure 5.6: Yields at various reaction temperatures for a reaction time of $30 \mathrm{~min}$ for MBAP-1 polymer 


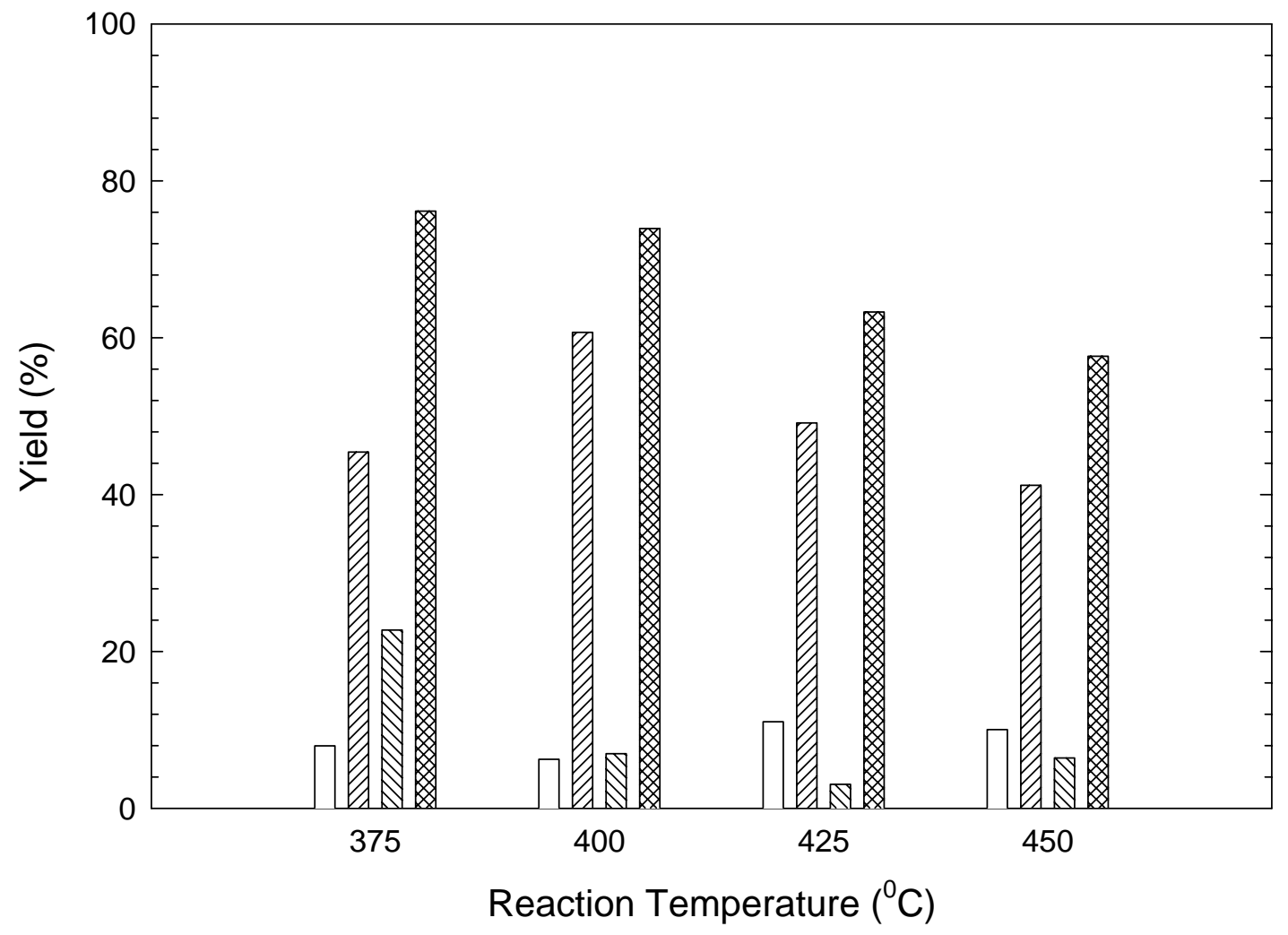

Figure 5.7: Yields at various reaction temperatures for a reaction time of $45 \mathrm{~min}$ for MBAP-1

polymer 
Figure 5.6 depicts yields at a constant reaction time of $30 \mathrm{~min}$. The gas yield initially decreases with increase in temperature, reaches a minimum of $3.9 \%$ at $400^{\circ} \mathrm{C}$ and then increases. On the other hand, the oil yield reaches a maximum of $59.9 \%$ at $425^{\circ} \mathrm{C}$. The Hexl yield decreases and levels off after $425^{\circ} \mathrm{C}$. The overall conversion as before, decreases with increase in temperature.

Finally, Figure 5.7 depicts the yields for various temperatures at a constant time of $45 \mathrm{~min}$. The gas yield is fairly constant over the temperature interval. The oil yield reaches a maximum of $60.7 \%$ at $400^{\circ} \mathrm{C}$. The Hexl yield reaches a minimum at $425^{\circ} \mathrm{C}$ with a slight increase at $450^{\circ} \mathrm{C}$. The overall conversion again decreases with increase in temperature.

\subsubsection{Effect of Variation of Reaction Time on Yield:}

In this section, the yields are discussed with respect to variation with reaction time at a particular reaction temperature. Figures 5.8-5.11 depict the yield variations with increase in time at constant temperatures. Figure 5.8 depicts the yield variation at $375^{\circ} \mathrm{C}$ for the three reaction times. The gas yield reaches a maximum of $12.4 \%$ at reaction time of $30 \mathrm{~min}$. This abnormal value is explained later. The oil yield increases slightly with increase in reaction time. The Hexl yield decreases and reaches a minimum of $21.4 \%$ at $30 \mathrm{~min}$. The overall conversion meanwhile decreases with an increase in reaction time.

Figure 5.9 depicts the yield variation at a constant temperature of $400^{\circ} \mathrm{C}$. While there is a negligible variation in gas yield, the Hexl yield decreases with time. The oil yield increases and levels off after 30min. The change in overall conversion also is negligible.

Figure 5.10 depicts the yield variation with time at $425^{\circ} \mathrm{C}$. While the gas yield increases with time, the oil yield, Hexl yield and overall conversion decrease with time.

Figure 5.11 depicts the yield variation with time at $450^{\circ} \mathrm{C}$. Here the gas and hexane-insolubles yields increase with time, while oil yield and overall conversion decrease with time. 


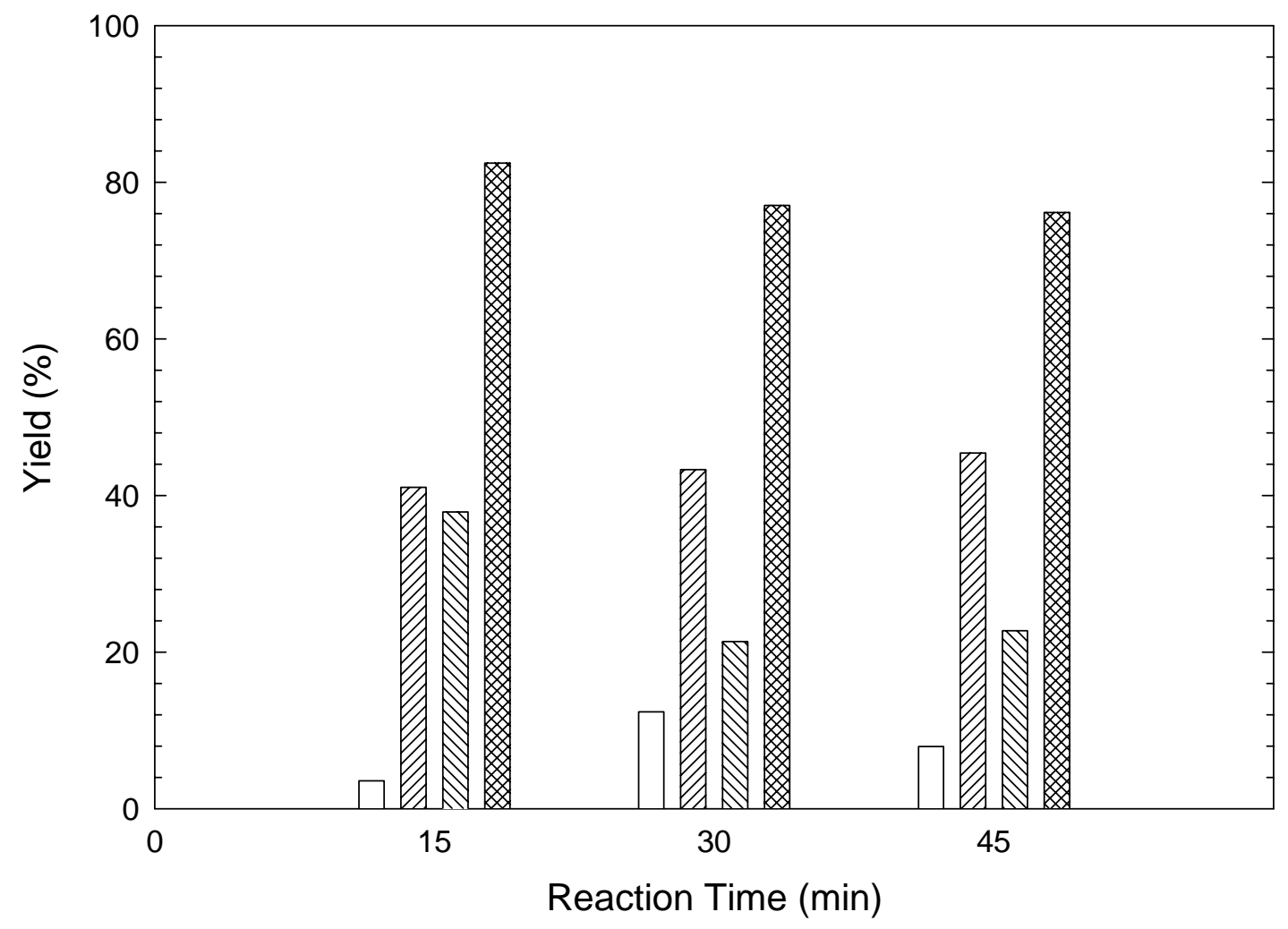

Gas \%

पIIIA Oils \%

Overall conversion \%

Figure 5.8: Yields for various reaction times for a reaction temperature of $375^{\circ} \mathrm{C}$ for MBAP-

1 polymer 


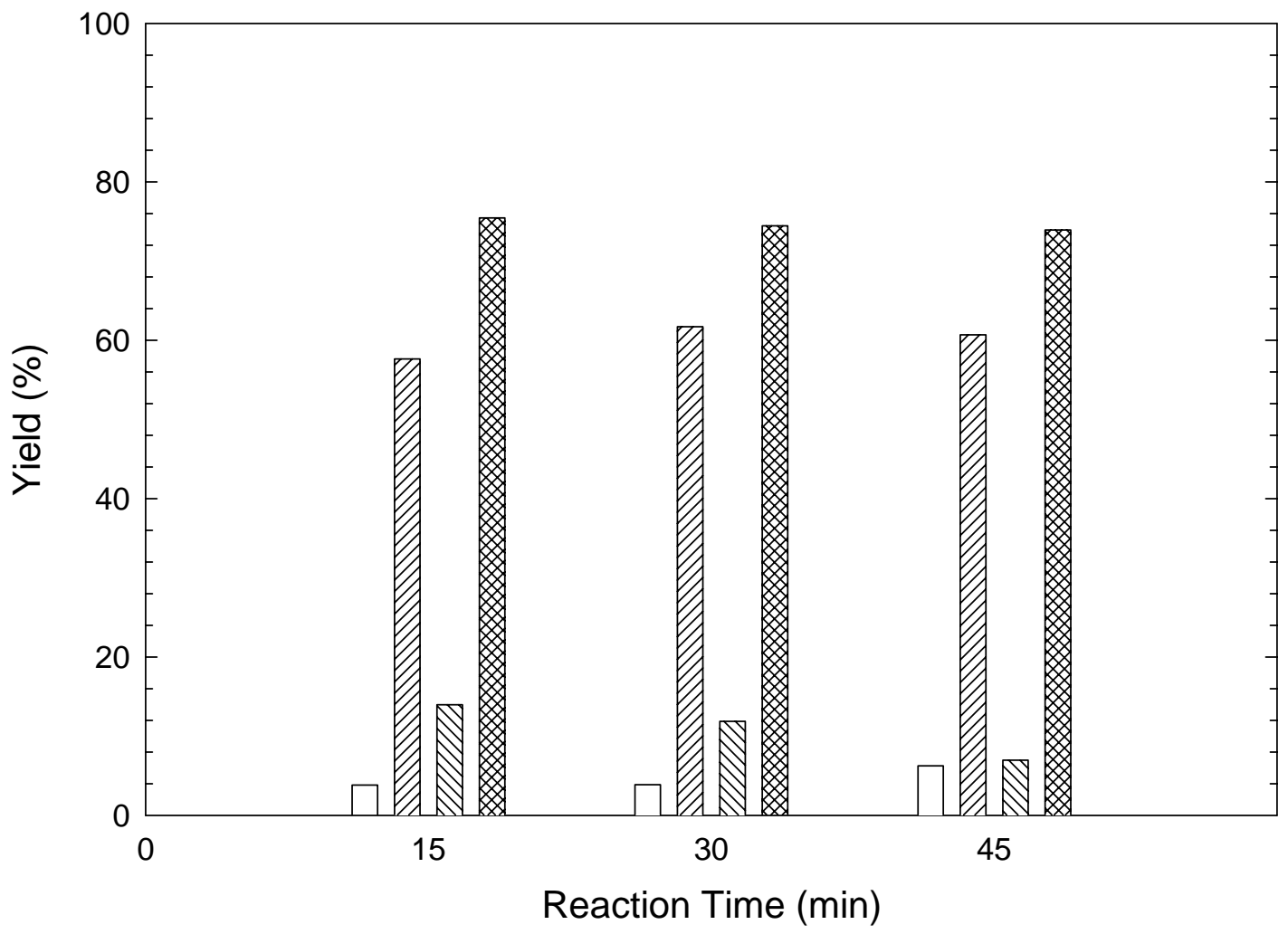

Gas \%

VIIIA Oils \%

MIII Hexane-Insolubles \%

Overall conversion \%

Figure 5.9: Yields for various reaction times for a reaction temperature of $400^{\circ} \mathrm{C}$ for MBAP-1 polymer 


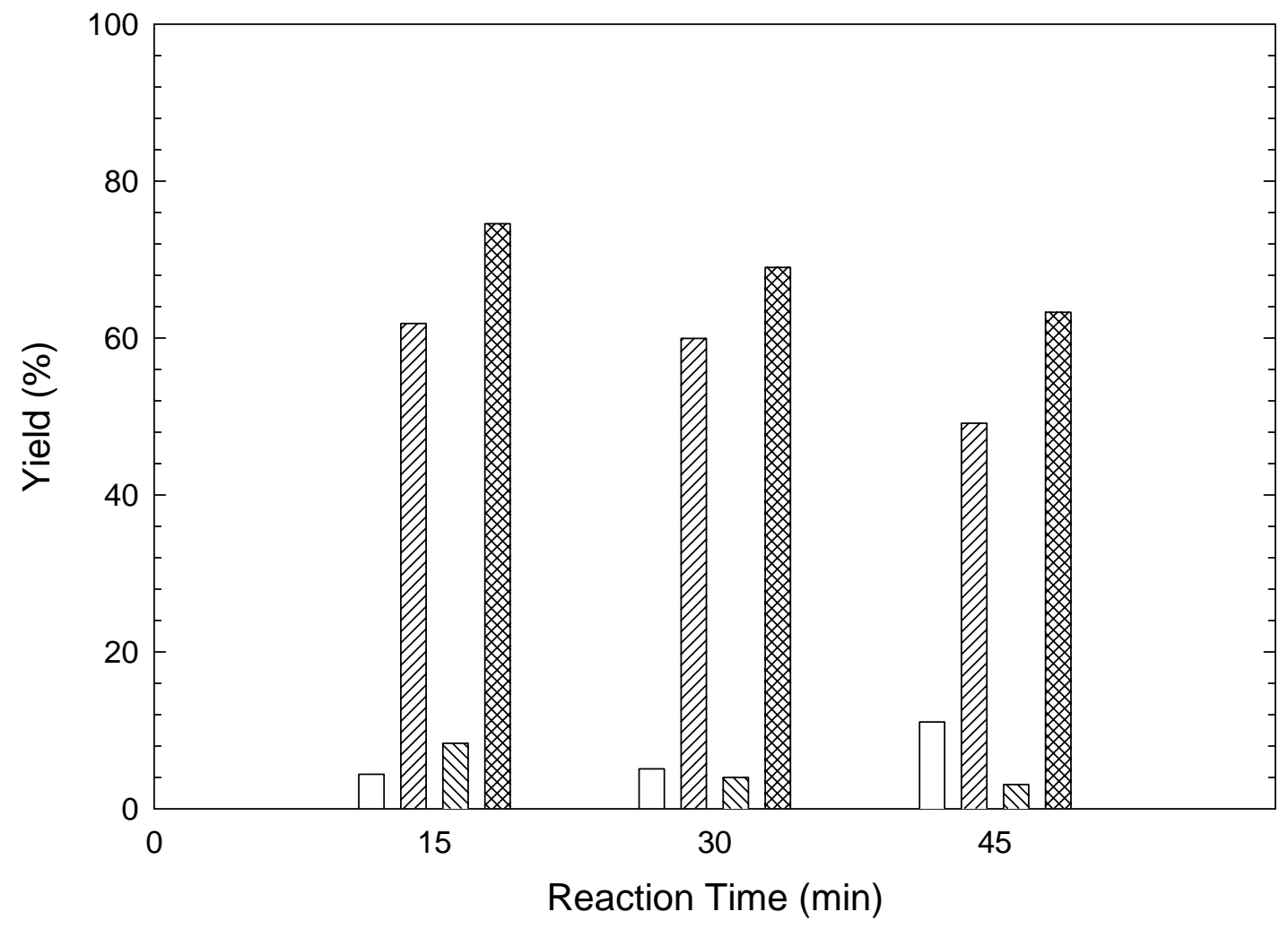

Gas \%

Oils \%

Miviv Hexane-Insolubles \%

Overall conversion \%

Figure 5.10: Yields at various reaction times for a reaction temperature of $425^{\circ} \mathrm{C}$ for MBAP-1 polymer 


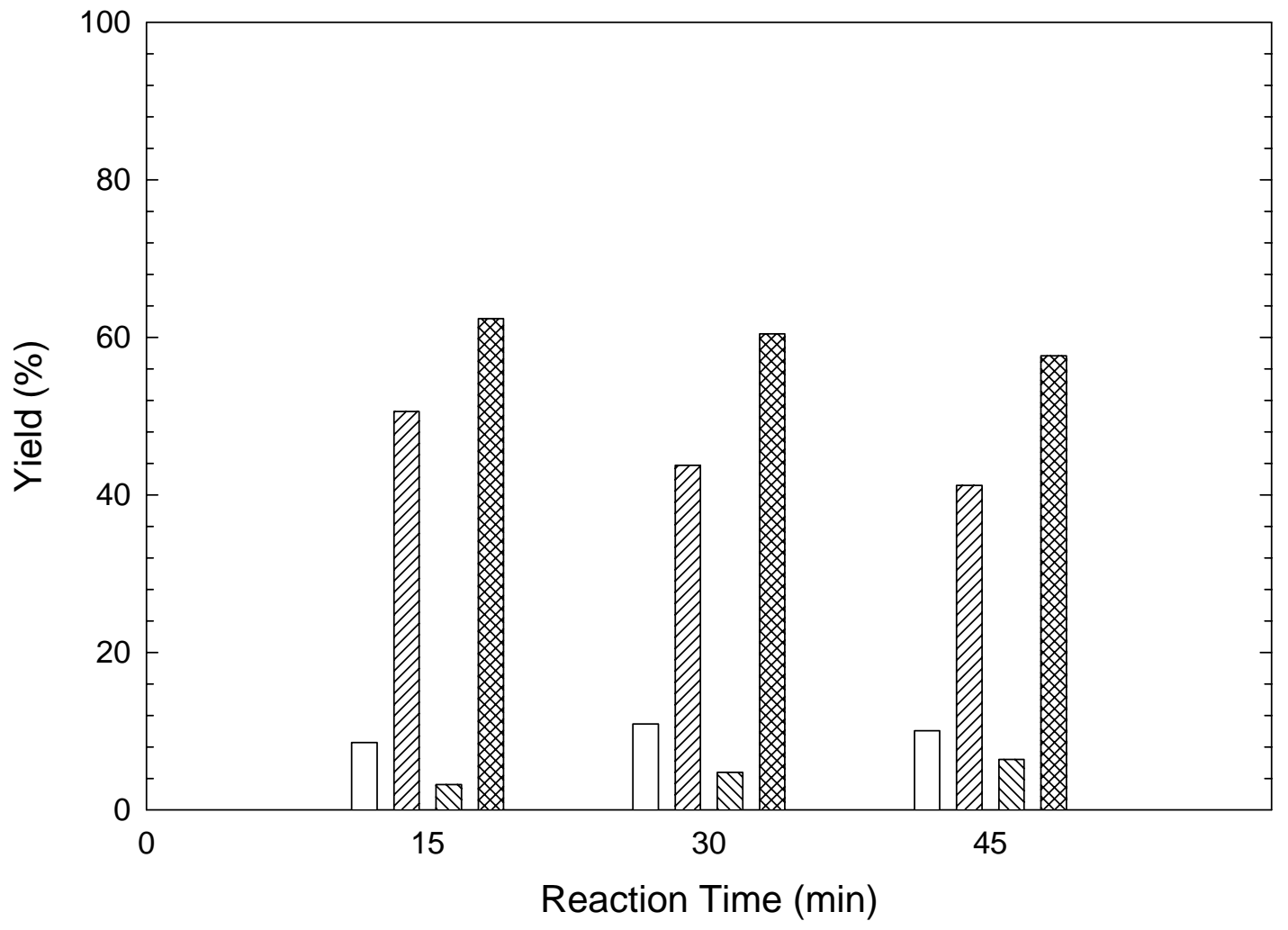

Gas \%

VIIIA Oils \%

MIIV Hexane-Insolubles \%

Overall conversion\%

Figure 5.11: Yields at various reaction times for a reaction temperature of $450^{\circ} \mathrm{C}$ for MBAP-1 polymer 


\subsubsection{Examination of Results of Pyrolysis of MBAP-1:}

The overall gas yields ranged from a minimum of $3.6 \%$ at $375^{\circ} \mathrm{C}, 15 \mathrm{~min}$ to a maximum of $12.4 \%$ at $375^{\circ} \mathrm{C}, 30 \mathrm{~min}$ with an average yield of $7.3 \%$. This is comparable to the results obtained by Williams et al. ${ }^{8,9}$. In general, gas yield increases with increases in time as well as temperature. The increase in gas yield with temperature may be due to the increased breaking of end-chain hydrocarbons with increase in reaction temperature. High-temperature environments seem to favor increased gas formation as the molecules breakdown and form a wide range of smaller organic molecules ${ }^{14}$. Additionally the heating rate is also high as the fluidized sand bath equipment is already at the reaction temperature when the tubular reactor containing the sample is loaded into the sand bath. The tubular reactor, at ambient temperature, experiences a sudden increase in its temperature and attains the set temperature, ranging from 350$450^{\circ} \mathrm{C}$, in the next one to two minutes. Thus, this combination of high temperature and high heating rate should provide higher than achieved gas formation ${ }^{10,15}$. But the gas formation is hindered, especially due to extended reaction times, due to secondary reactions leading to higher formation of oils/char. Secondary reactions can occur if volatiles are subjected to long residence times in a hot reactor resulting in recombination of low molecular weight hydrocarbons to higher hydrocarbons ${ }^{7}$. It is to be noted that most other pyrolysis experiments have reaction times in seconds rather than $15-45 \mathrm{~min}^{7,8,14}$.

The abnormal spike in the gas yield $(12.4 \%)$ at $375^{\circ} \mathrm{C}, 30 \mathrm{~min}$ is to be noted. This abnormality can be due to the non-homogeneity of MBAP-1 and/or the unique effect of the reaction parameters (temperature $375^{\circ} \mathrm{C}$ and time $30 \mathrm{~min}$ ). It can thus be hypothesized that a reaction time of 30 min and a reaction temperature of $375^{\circ} \mathrm{C}$ results in maximum splitting of end-chain hydrocarbons resulting in the formation of lower organics. An increase in either temperature or time results in recombination due to secondary reactions favoring the formation of oils. Alternatively, non-homogeneity of the MBAP-1 sample could have resulted in this aberration as evidenced by its composition (refer to Section 3.1.2).

At any particular reaction time, the oil yield reaches a maximum with increasing temperatures (Figures 5.9-5.11). At higher reaction times (30 and 45min), the maximum oil yield shifts to lower temperatures. The increase in oil yield with increase in reaction temperature at a particular time may be due to breaking down of higher organics (wax-like Hexane-Insolubles) into smaller organics (oils). 
The oil yield increases with time at lower temperatures $\left(375^{\circ} \mathrm{C}\right.$ and $\left.400^{\circ} \mathrm{C}\right)$ while decreasing with time at higher temperatures $\left(425^{\circ} \mathrm{C}\right.$ and $\left.450^{\circ} \mathrm{C}\right)$, as shown in Figures $5.12-5.15$. The former may due to the breaking down of higher organics (char, THFI and the waxes or Hexane-Insolubles) into smaller organics (oils) resulting in increasing oil yield. This is corroborated by a corresponding decrease in overall conversion and Hexl yield. However, at the higher temperatures, $425^{\circ} \mathrm{C}$ and $450^{\circ} \mathrm{C}$, oil yield decreases due to further cracking. This is consistent with an increased gas yield (a jump from about $4.4 \%$ gas to $11.0 \%$ at $425^{\circ} \mathrm{C}$ ) and corresponding decreases in oil yield.

There is a continuous decrease in Hexl yield with increase in time and temperature. This trend is reversed only at $450^{\circ} \mathrm{C}$, where the Hexl yield increases with increase in time. This trend again has been observed by Williams et al. ${ }^{7}$

The overall conversion steadily decreases with increase in time and temperature. This could be due to the charring effect in pyrolysis ${ }^{7}$. As overall conversion decreases, the THF residue (char) increases. This phenomenon has been observed in all previous work on pyrolysis. The charring effect is nothing but excessive combination of oils and Hexl to solid residues at higher temperatures. This trend is

also noted by Williams et al ${ }^{7,8,10}$. Notice that the maximum oil yield occurs at a range of processparameters, $400^{\circ} \mathrm{C}, 45 \mathrm{~min}$; and $425^{\circ} \mathrm{C}, 15 \mathrm{~min}$. It is to be noted that most research on pyrolysis of plastics at similar temperatures have reaction times in seconds rather than minutes (rapid pyrolysis) ${ }^{7,8,10}$. Thus future work must be conducted at lower reaction times to see if there is a significant change in results.

\subsubsection{Pyrolysis of MBAP-2:}

The results of runs with the MBAP-2 sample are presented in Table 5.2. The results are consistent, unlike those of MBAP-1. This is due to the increased homogeneity of the sample. The sample is predominantly made up of ABS and HIPS whose structure prevents gas formation and produces much $\operatorname{char}^{7,8}$. This is amply evident in the results discussed in Table 5.2. 
Table 5.2: Comprehensive results of experiments conducted for MBAP-2

\begin{tabular}{|c|c|c|c|c|c|}
\hline $\begin{array}{c}\text { Reaction } \\
\text { Temperature } \\
\left({ }^{\circ} \mathrm{C}\right)\end{array}$ & $\begin{array}{l}\text { Reaction } \\
\text { Time } \\
\left({ }^{\circ} \mathrm{C}\right)\end{array}$ & $\begin{array}{l}\text { Gas } \\
\text { Yield } \\
(\%)\end{array}$ & $\begin{array}{l}\text { Oil Yield } \\
\text { (\%) }\end{array}$ & $\begin{array}{c}\text { Hexane-Insolubles Yield } \\
(\%)\end{array}$ & $\begin{array}{c}\text { Overall conversion } \\
\text { (THF-S + Gas) Yield } \\
\pm 1(\%)\end{array}$ \\
\hline $\begin{array}{c}\text { Room } \\
\text { Temperature }\end{array}$ & - & - & - & 78.3 & 78.3 \\
\hline 375 & 15 & 1.0 & 46.9 & 31.7 & 79.6 \\
\hline 375 & 30 & 1.2 & 48.9 & 28.7 & 78.8 \\
\hline 375 & 45 & 1.3 & 50.3 & 29.1 & 80.7 \\
\hline 400 & 15 & 0.9 & 50.3 & 26.4 & 77.6 \\
\hline 400 & 30 & 0.9 & 51.0 & 24.1 & 76.0 \\
\hline 400 & 45 & 2.3 & 50.8 & 21.8 & 74.9 \\
\hline 425 & 15 & 3.2 & 54.5 & 8.0 & 65.7 \\
\hline 425 & 30 & 2.3 & 63.3 & 3.5 & 69.1 \\
\hline 425 & 45 & 2.8 & 52.7 & 14.5 & 70.0 \\
\hline 450 & 15 & 2.2 & 52.4 & 16.2 & 70.8 \\
\hline 450 & 30 & 2.2 & 52.1 & 18.1 & 72.4 \\
\hline 450 & 45 & 2.4 & 50.3 & 19.8 & 72.5 \\
\hline
\end{tabular}


The room temperature run for MBAP-2 sample yielded 78.3\% THF-Solubles, slightly higher than that for MBAP-1, and no Hexane-Solubles or gases.

Again, multiple runs were performed for each set of reaction parameters for establishing reproducibility of the results. The yields in all the fractions were found to be reproducible for the sample (true for both MBAP-1 and MBAP-2) irrespective of its shelf life. The error bounds are $\pm 1 \%$. It is to be noted that gas yields for MBAP-2 is negligible with a maximum of $3.2 \%$ at $425^{\circ} \mathrm{C}$ and $15 \mathrm{~min}$ and hence not discussed further.

\subsubsection{Effect of Variation of Reaction Temperature on Yield:}

The variation of yields of the product fractions with reaction temperature is similar at all reaction times (15,30 and 45min) as depicted in Figures 5.12-5.14.

Figure 5.12 depicts the variation of yield with temperature at a reaction time of $15 \mathrm{~min}$. The oil yields initially increase and reach a maximum at $425^{\circ} \mathrm{C}$ and then level off. The Hexl yield and overall conversion reach a minimum at $425^{\circ} \mathrm{C}$.

Figure 5.13 depicts the variation of yield with temperature at a reaction time of $30 \mathrm{~min}$. The oil yield increases with temperature, reaches a maximum at $425^{\circ} \mathrm{C}$ and then decreases. The Hexl yield decreases sharply to a minimum of $3.5 \%$ at $425^{\circ} \mathrm{C}$ and then increases. The overall conversion decreases with increase in temperature and then levels off.

Figure 5.14 depicts the variation of yield with temperature at a reaction time of $45 \mathrm{~min}$. The oil yield is a constant at approximately $51 \%$ at all reaction times specified. The Hexl yield reaches a minimum at $425^{\circ} \mathrm{C}$ and then increases. The overall conversion reaches a minimum at $425^{\circ} \mathrm{C}$ and then increases. 


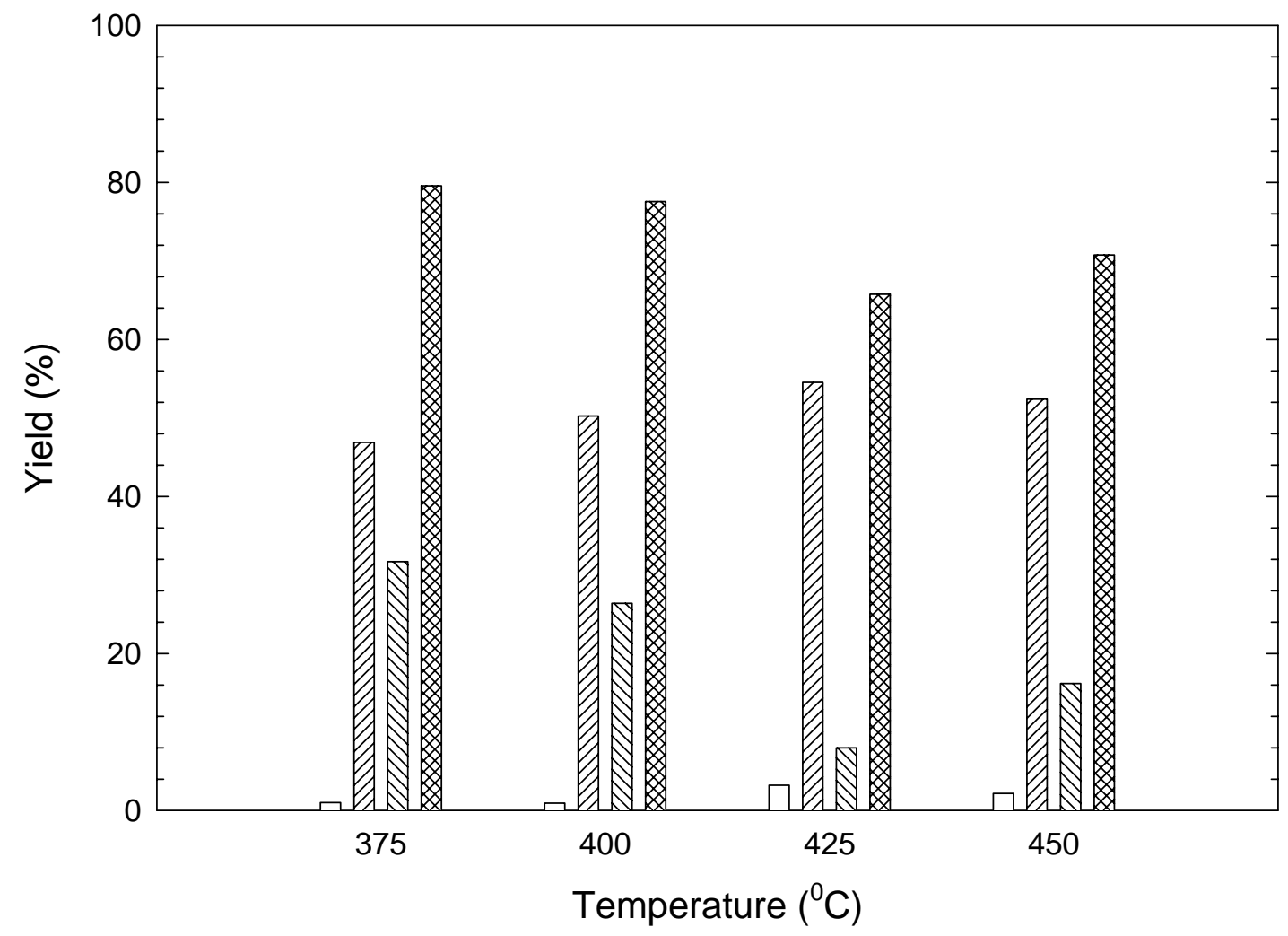

Figure 5.12: Yields at various reaction temperatures at a reaction time of 15min for MBAP-2 polymer 


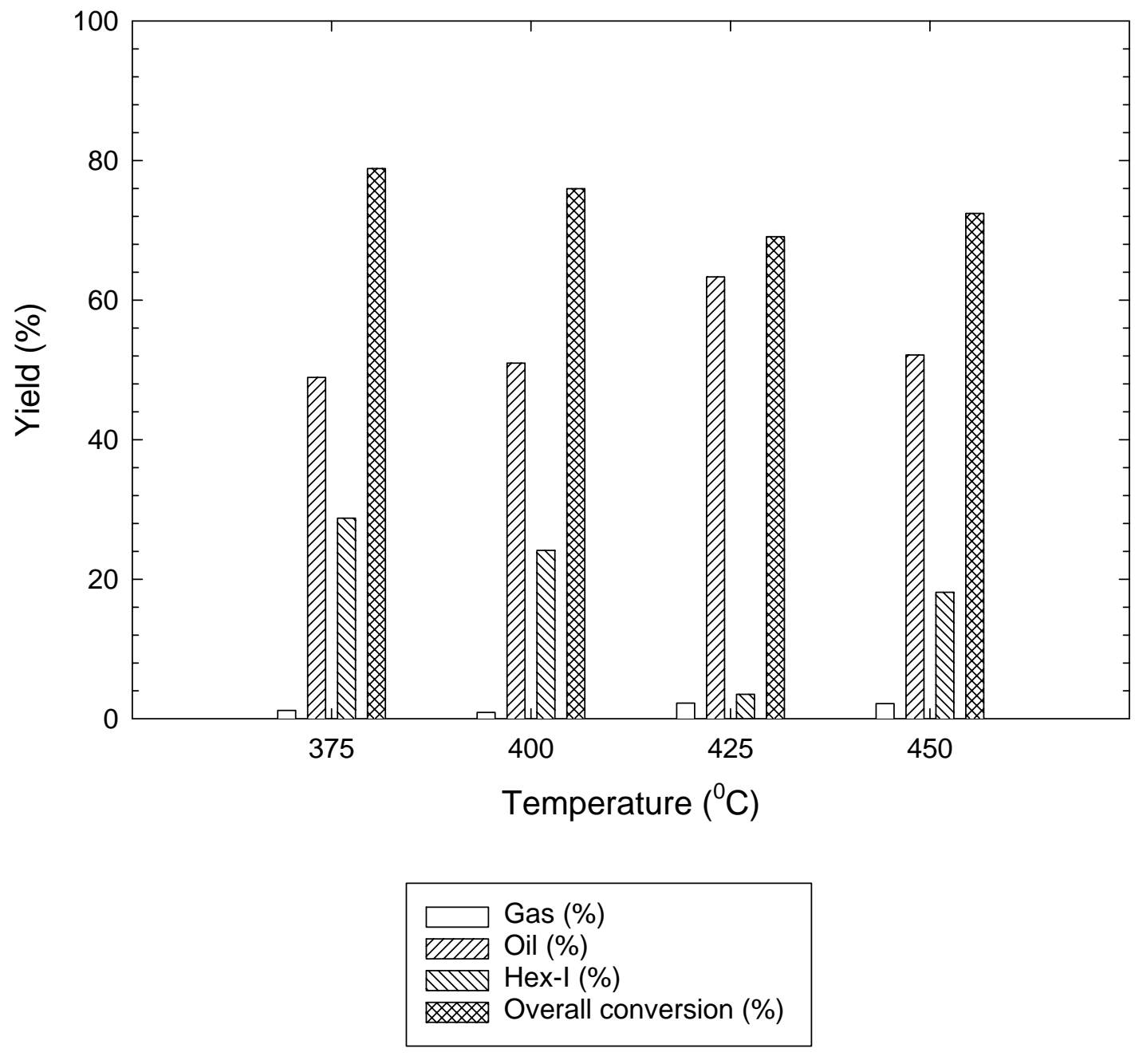

Figure 5.13: Yields at various reaction temperatures at a reaction time of 30min for MBAP-2 polymer 


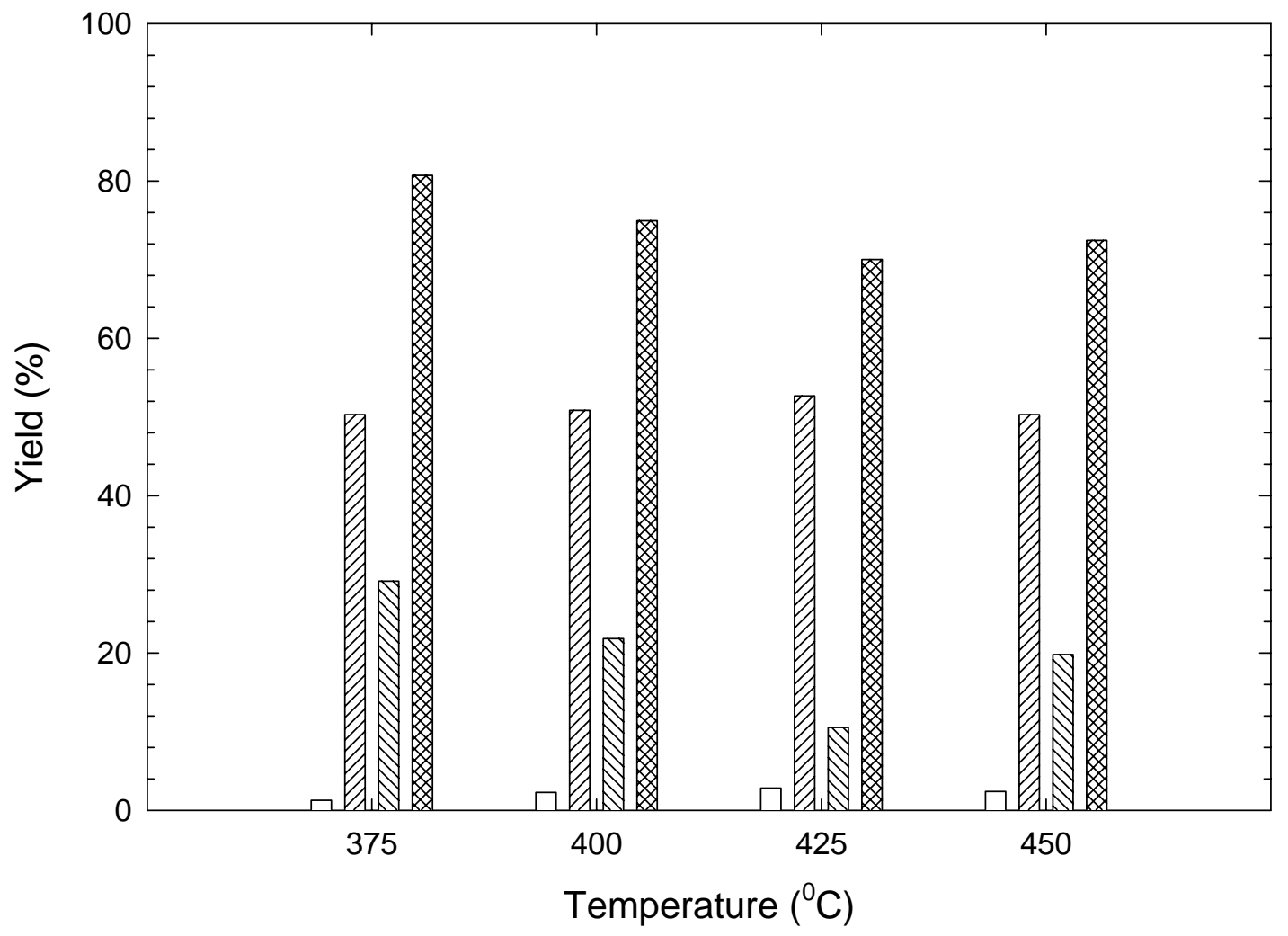

$\square$ Gas (\%)
Oil (\%)
Oex-I (\%)
Overall conversion (\%)

Figure 5.14: Yields at various reaction temperatures at a reaction time of $45 \mathrm{~min}$ for MBAP-2 polymer 


\subsubsection{Effect of Variation of Reaction Time on Yield:}

Figures 5.15-5.18 show the effect of variation of reaction time on product yield. The gas yield is very low and nearly constant. Though the amount of gas produced might be low, analysis of the gas composition indicates high hydrocarbon content and hence could be used to produce useful heat. This is further discussed in Section 5.2.7. Figure 5.15 depicts the variation of yield with reaction time at reaction temperature of $375^{\circ} \mathrm{C}$. The oil yield shows very little variation except for a maximum at $30 \mathrm{~min}$ for $425^{\circ} \mathrm{C}$ (Figure 5.17). This is the maximum yield on pyrolysis of MBAP-2. Figure 5.15 shows the overall conversion and Hexl yield to be fairly constant at a constant temperature of $375^{\circ} \mathrm{C}$, Figures 5.16 and 5.18 show decrease in overall conversion and Hexl yield respectively. Figure 5.17 shows a maximum oil yield of $69.1 \%$ at $30 \mathrm{~min}$.

\subsubsection{Examination of Results of Pyrolysis of MBAP-2:}

It should be mentioned here that the composition of MBAP-2 is a subset of that of MBAP-1, i.e. all the components of MBAP-2 are present in MBAP-1. Hence most of the trends seen in pyrolysis of MBAP2 should be applicable for MBAP-1. In general for MBAP-2, gas conversion is relatively constant. This is inline with results obtained by Williams et al. ${ }^{7}$ for PS. MBAP-2 consists mainly of HIPS and ABS (for more information about their polymer structure, please refer Appendix B). The oil yield hovers around $50 \%-54 \%$ at all times between temperatures $400^{\circ} \mathrm{C}-450{ }^{\circ} \mathrm{C}$ except for a clear maximum at $425^{\circ} \mathrm{C}$, 30min. The presence of fewer compounds of similar nature (HIPS and ABS have the same density range) in greater proportions may be the reason for such sharp maximum in oil yield. This also explains a sharp minimum in overall conversion, while for the MBAP-1 the overall conversion keeps decreasing with increase in temperature and time. The increase in the amount of char (THF-Insolubles) with increasing reaction time and temperature may be due to the recombination of organics to form residue (mentioned in Section 5.2.3.3). At $450^{\circ} \mathrm{C}$, the overall conversion and Hexane-Insolubles actually increases with an increase in reaction time. This may be due to recombination of liquid organics (there is a considerable increase in Hexl yield and overall conversion which offsets the drastic decrease in oil yield) to form solids. Overall, both MBAP-1 and MBAP-2 have some results in common. For example, the maximum oil yield occurs at $\sim 425^{\circ} \mathrm{C}$ and the gas yield increases with temperature. 


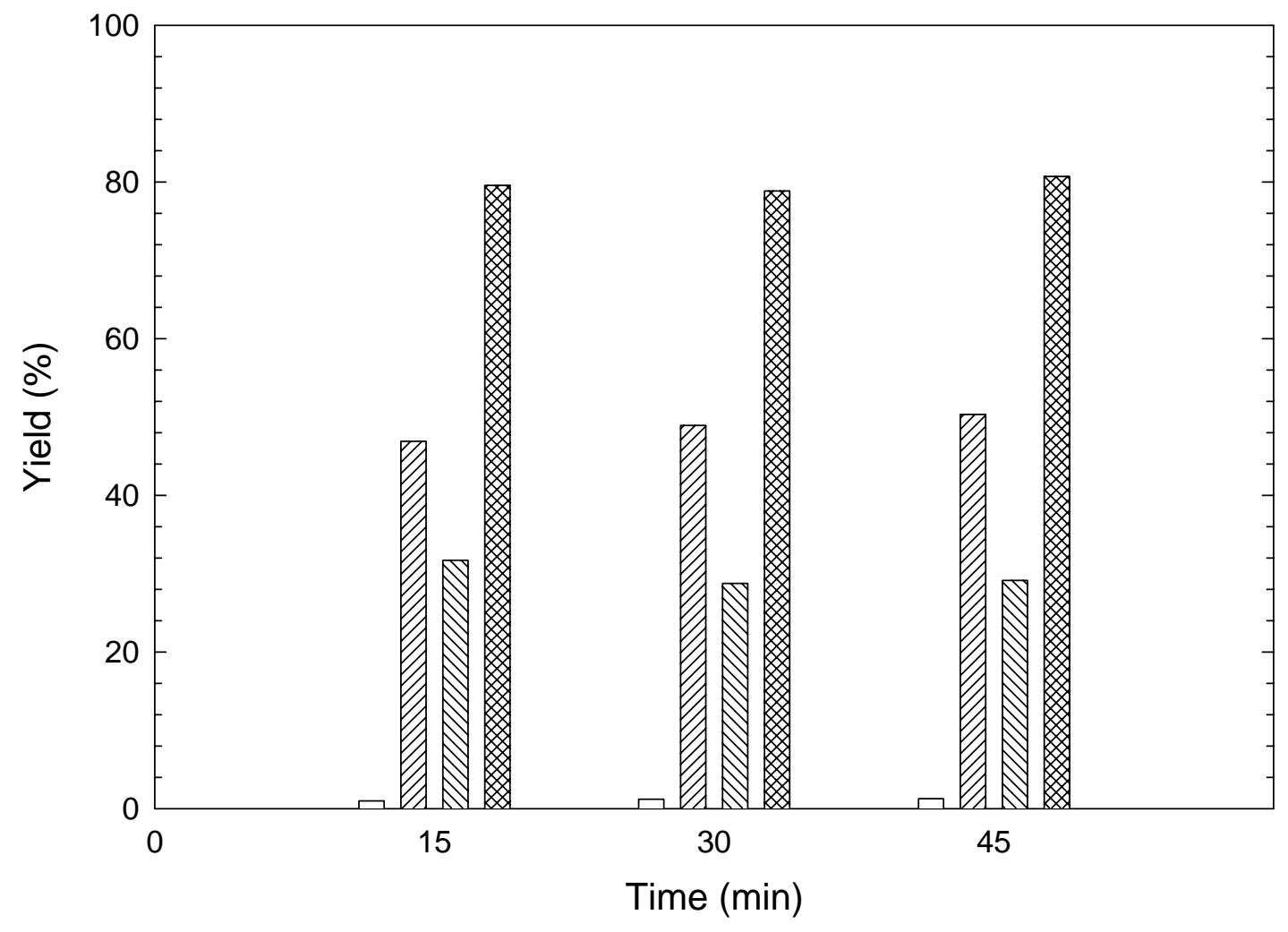

$\square$ Gas (\%)
Oil (\%)
OlII- Hex-I (\%)
Overall conversion (\%)

5.15: Yields at various reaction times at a reaction temperature $375^{\circ}$ for pyrolysis of MBAP-2 


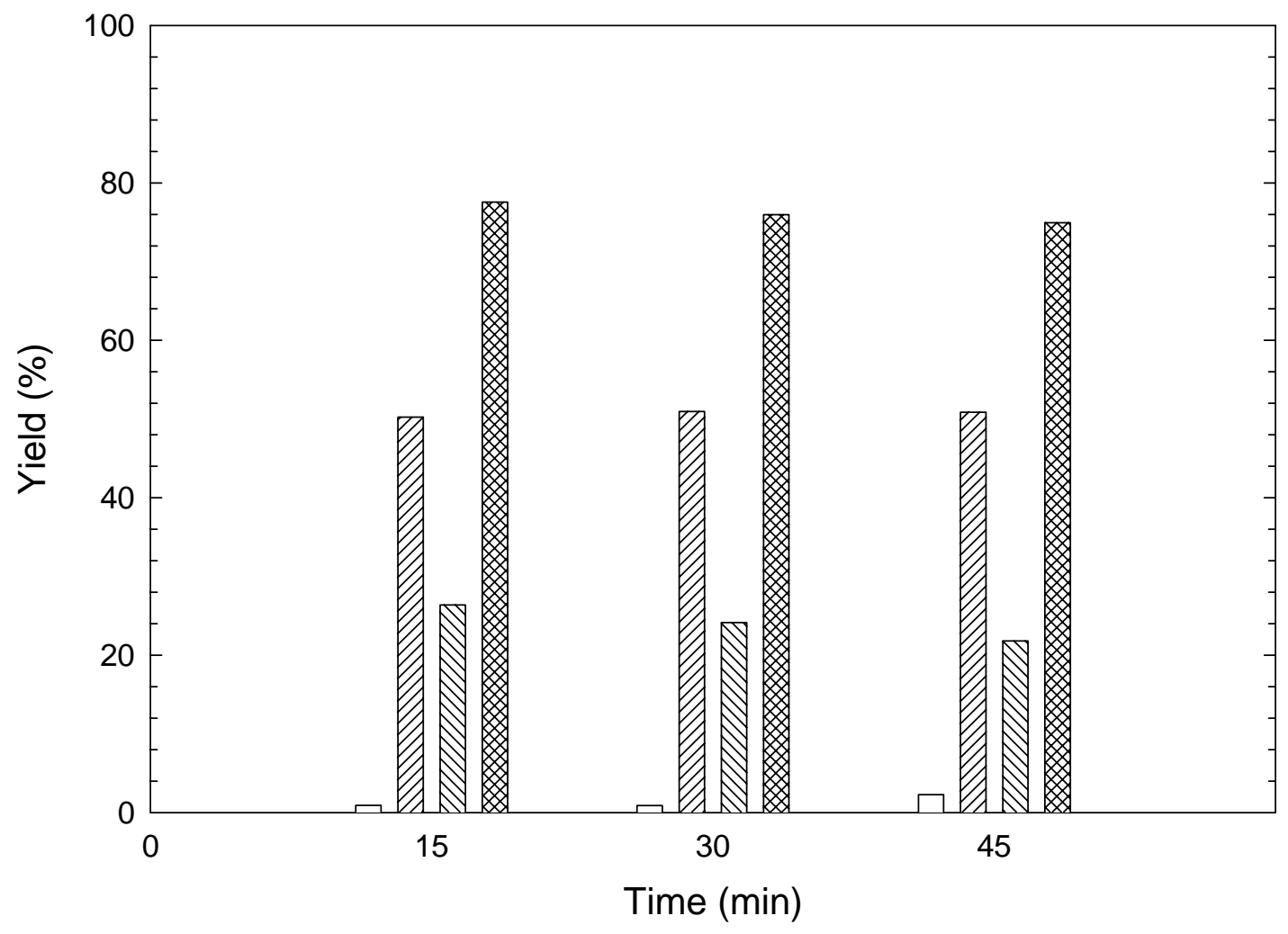

$\square$ Gas (\%)
$\square$ Oil (\%)
OIII Hex-I (\%)
Overall conversion (\%)

Figure 5.16: Yields at various reaction times at a reaction temperature of $400^{\circ} \mathrm{C}$ for MBAP-2 polymer 


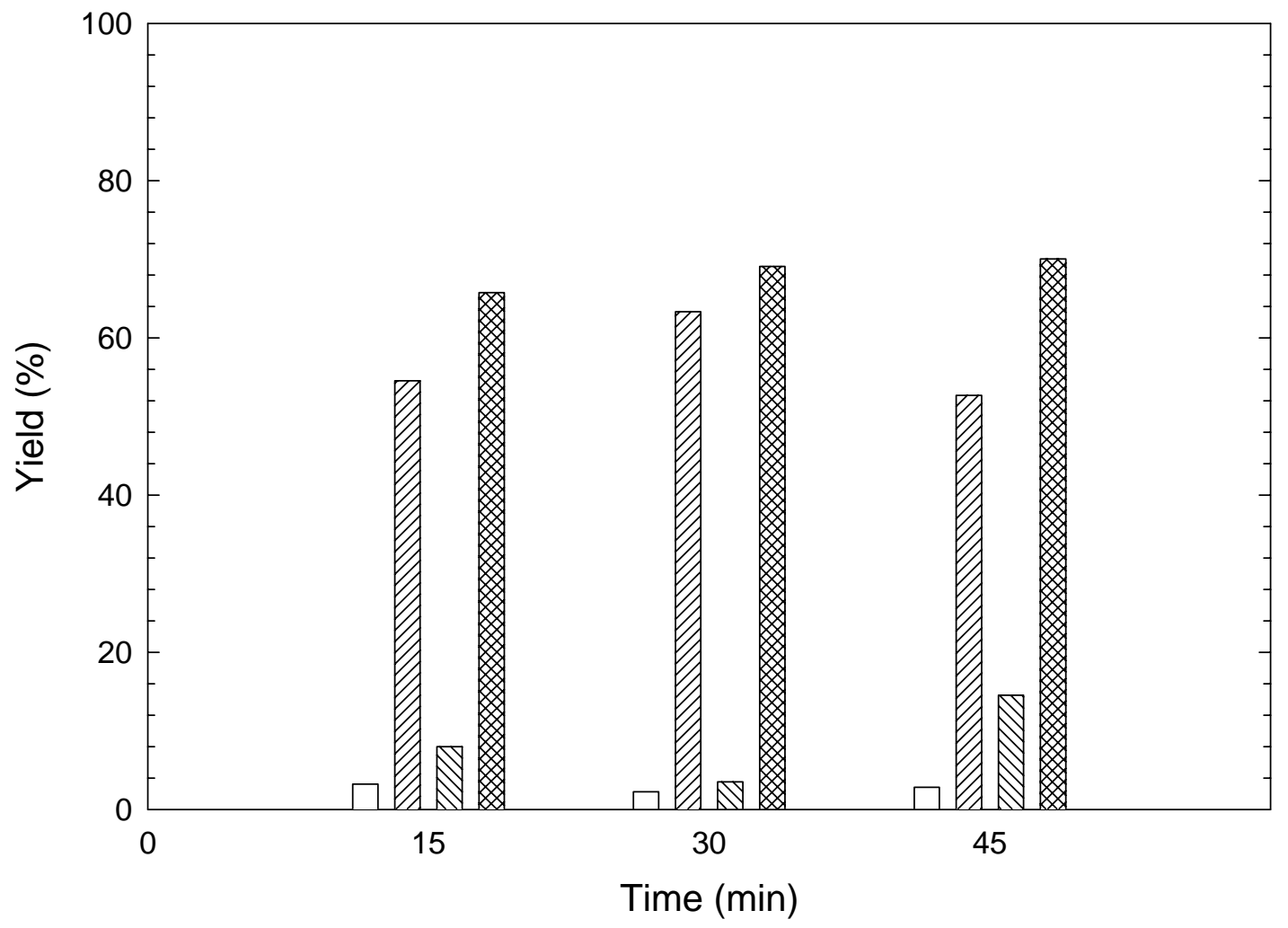

Figure 5.17: Yields at various reaction times at a reaction temperature of $425^{\circ} \mathrm{C}$ for MBAP-2 polymer 


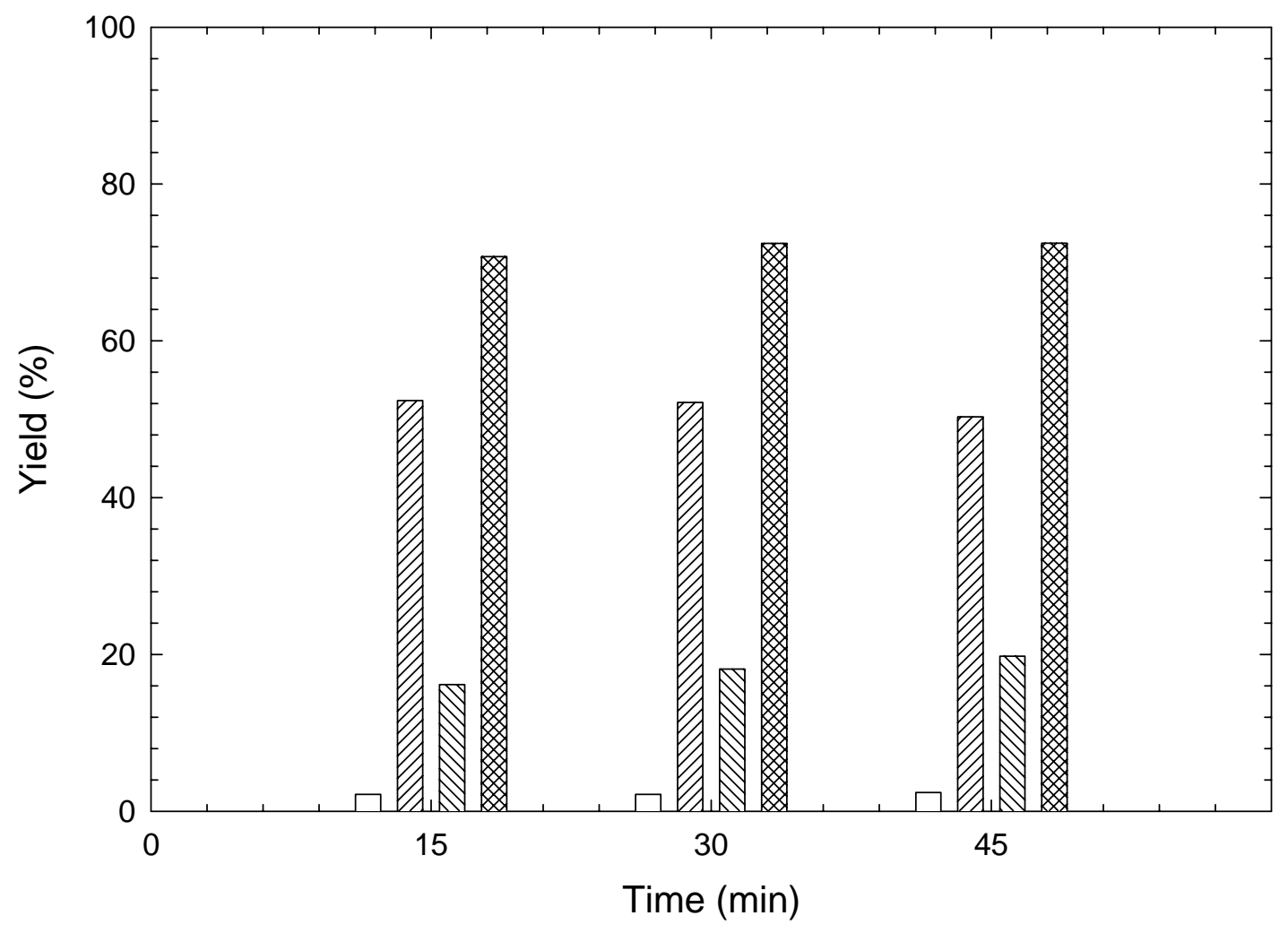

$\square$ Gas (\%)
Oil (\%)
Oiln Hex-I (\%)
Overall conversion (\%)

Figure 5.18: Yields at various reaction times at a reaction temperature of $450^{\circ} \mathrm{C}$ for MBAP-2 polymer 


\subsubsection{Effect of Iron Catalyst and Hydrogen on the Product Yields:}

The effect of a reactive gas (hydrogen) on the various yields was studied at process conditions that yielded maximum oil for both samples. These conditions are $425^{\circ} \mathrm{C}$ and $15 \mathrm{~min}$ and $400^{\circ} \mathrm{C}$ and $45 \mathrm{~min}$ for MBAP-1 and $425^{\circ} \mathrm{C}$ and $30 \mathrm{~min}$ for MBAP-2. Additionally, the effect of an iron-based catalyst (developed at WVU) in helium for MBAP-1 at $400^{\circ} \mathrm{C}$ and $45 \mathrm{~min}$, and for MBAP-2 at $425^{\circ} \mathrm{C}$ and $30 \mathrm{~min}$ was studied.

\subsubsection{Catalyzed Pyrolysis Of MBAP-1:}

Reaction parameters $400^{\circ} \mathrm{C}, 45 \mathrm{~min}$ and $425^{\circ} \mathrm{C}, 15$ min have been chosen as they yield the maximum Hexane-Solubles (oils) on pyrolysis of MBAP-1. From Figure 5.19 it is noted that at $400{ }^{\circ} \mathrm{C}$ and 45 min there is no significant difference between the pyrolysis with helium and with hydrogen gas. Reaction with catalyst at the above mentioned temperature and time was not performed. However, at 425 ${ }^{\circ} \mathrm{C}$ and 15 min there is a slight increase in the THF-Solubles for the run loaded with catalyst as shown in Figure 5.20. Also the Hexane-Insolubles (the asphaltenes) yield increases with either the addition of catalyst or the introduction of hydrogen. However, the important oil fraction remains about the same.

There seems to be no incentive to pyrolyze MBAP-1 in a reactive hydrogen atmosphere. A small increase in the THF-Solubles yield might possibly indicate the efficacy of the catalyst during pyrolysis but does not justify its future use mainly due to cost considerations. 


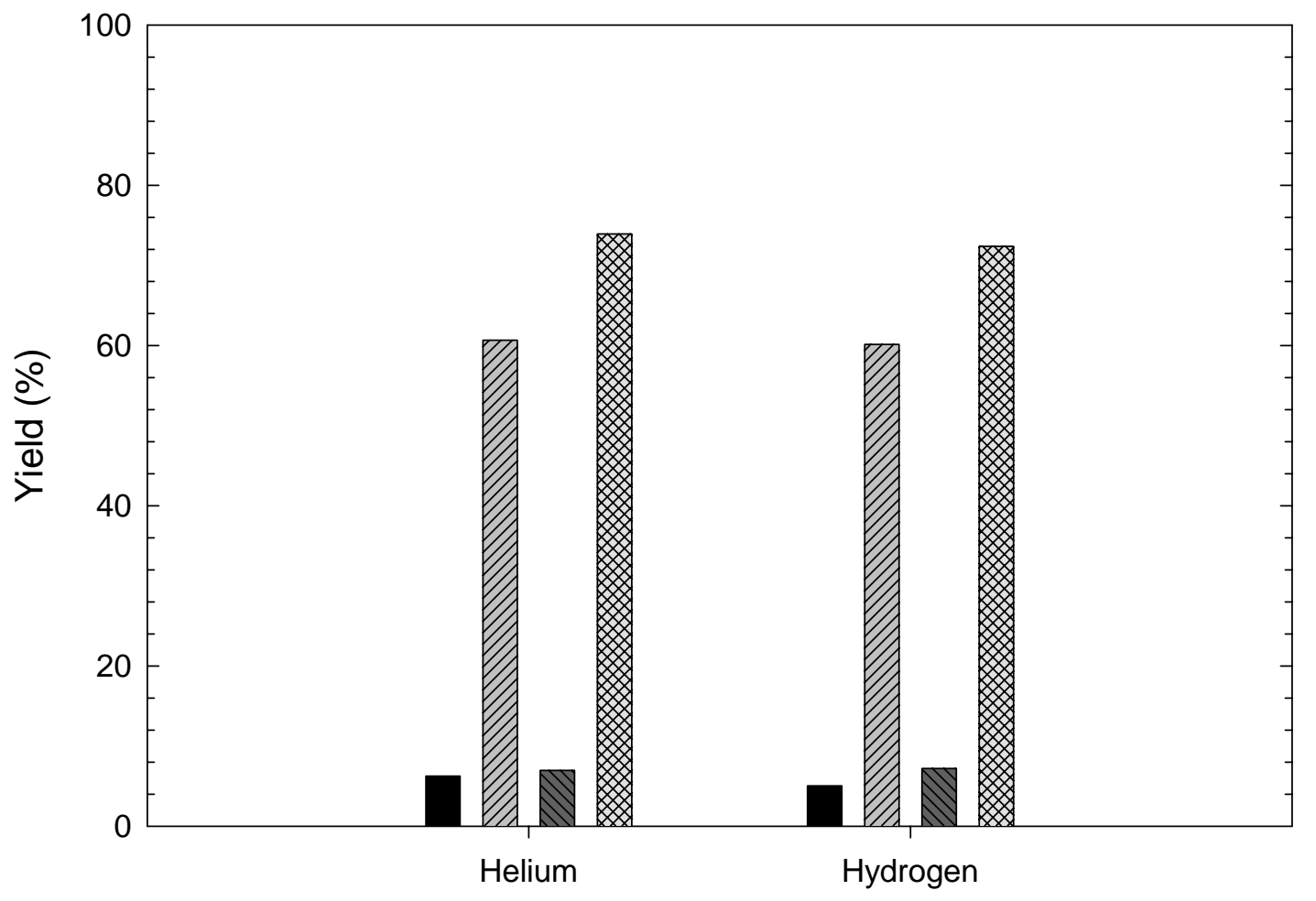

Gas \%
Oils \%
THIII Hexane-Insolubles \%
THF Solubles \%

Figure 5.19: Effect of Hydrogen on Pyrolysis of MBAP-1 at $400^{\circ} \mathrm{C}, 45 \mathrm{~min}$ 


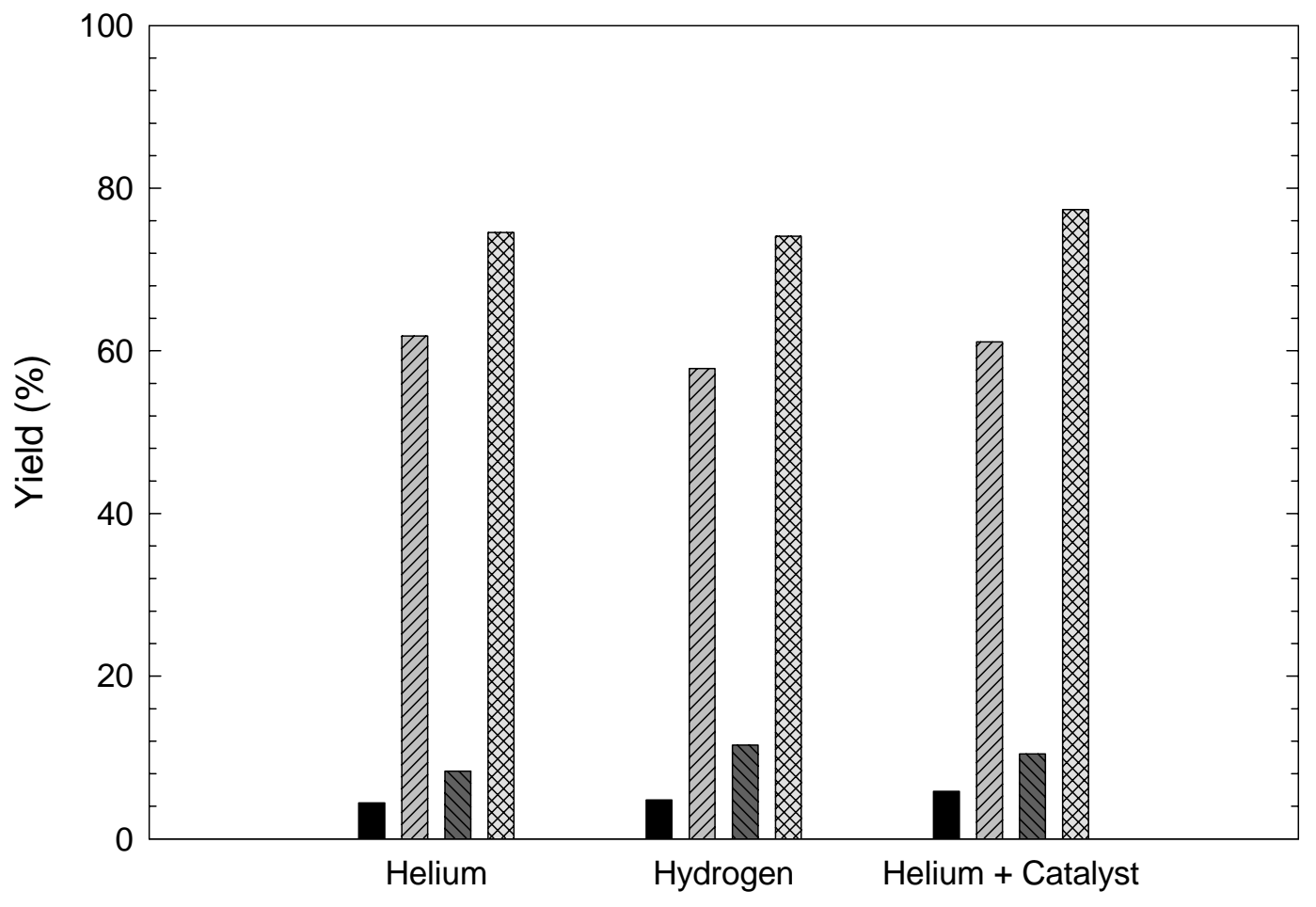

Gas $\%$
WIIn Oils \%
THIII Hexane-Insolubles \%
THF-Solubles \%

Figure 5.20: Combined Effect of Hydrogen and Catalyst on Pyrolysis of MBAP-1 at $425^{\circ} \mathrm{C}, 15 \mathrm{~min}$ 


\subsubsection{Catalyzed Pyrolysis Of MBAP-2:}

Results for the reaction of MBAP-2 with the catalyst and in the presence of hydrogen gas are shown in Figure 5.21. For MBAP-2, there is a significant increase in the oil and THF-Soluble yields with the use of a reactive hydrogen atmosphere. The increase can be due to the free-radical polymer chains coupling with hydrogen and thus being prevented from either being cleaved further into lighter/gaseous products or recombining to form insoluble matter. This behavior may be absent in MBAP-1 due to its nonhomogeneity. As in MBAP-1, the catalyst had little effect in the product slate. The incremental amount of change in the product slate does not justify the further use of the catalyst.

Iron sulfide catalysts, in order to be effective, require sufficient protonation of the feed upon pyrolysis. Plastics, unlike coal, are rich in hydrogen and hence do not require hydrogen as the medium for pyrolysis. Hence no reactions were performed with catalyst in the presence of hydrogen.

\subsubsection{Comparison Of Results From Pyrolysis Of MBAP-1 And MBAP-2:}

Though the overall trend of the various yields in both the polymer samples are similar, there are significant differences in their quantitative analysis.

\subsubsection{Gas Yield:}

The Gas Yield, in general, for pyrolysis of MBAP-1 is almost double that for MBAP-2 at most reaction conditions, as shown in Figure 5.22. The general trend is an increase of gas with increasing reaction temperature for MBAP-1. The Gas Yield for MBAP-2 is very low and hence no trends were obtained (greater than the error bars). The composition of the two polymer samples may hold the key to such a behavior. Some of the many different polymer resins, especially from the polycarbonates and polyethylene, could break up easily to form light gas fractions. MBAP-2 on the other hand contains mainly ABS and HIPS and these are not as susceptible to gas formation. For MBAP-1 the minimum Gas Yield occurs at roughly the conditions where the Oil Yield is a maximum, i.e. $425^{\circ} \mathrm{C}$ and $15 \mathrm{~min}$. For MBAP-2, however, the Gas Yield is maximum at the same conditions $\left(425^{\circ} \mathrm{C}\right.$ and $\left.15 \mathrm{~min}\right)$, which is also close to the conditions of highest Oil Yield for MBAP-2 (discussed in Section 5.1.6.2). 


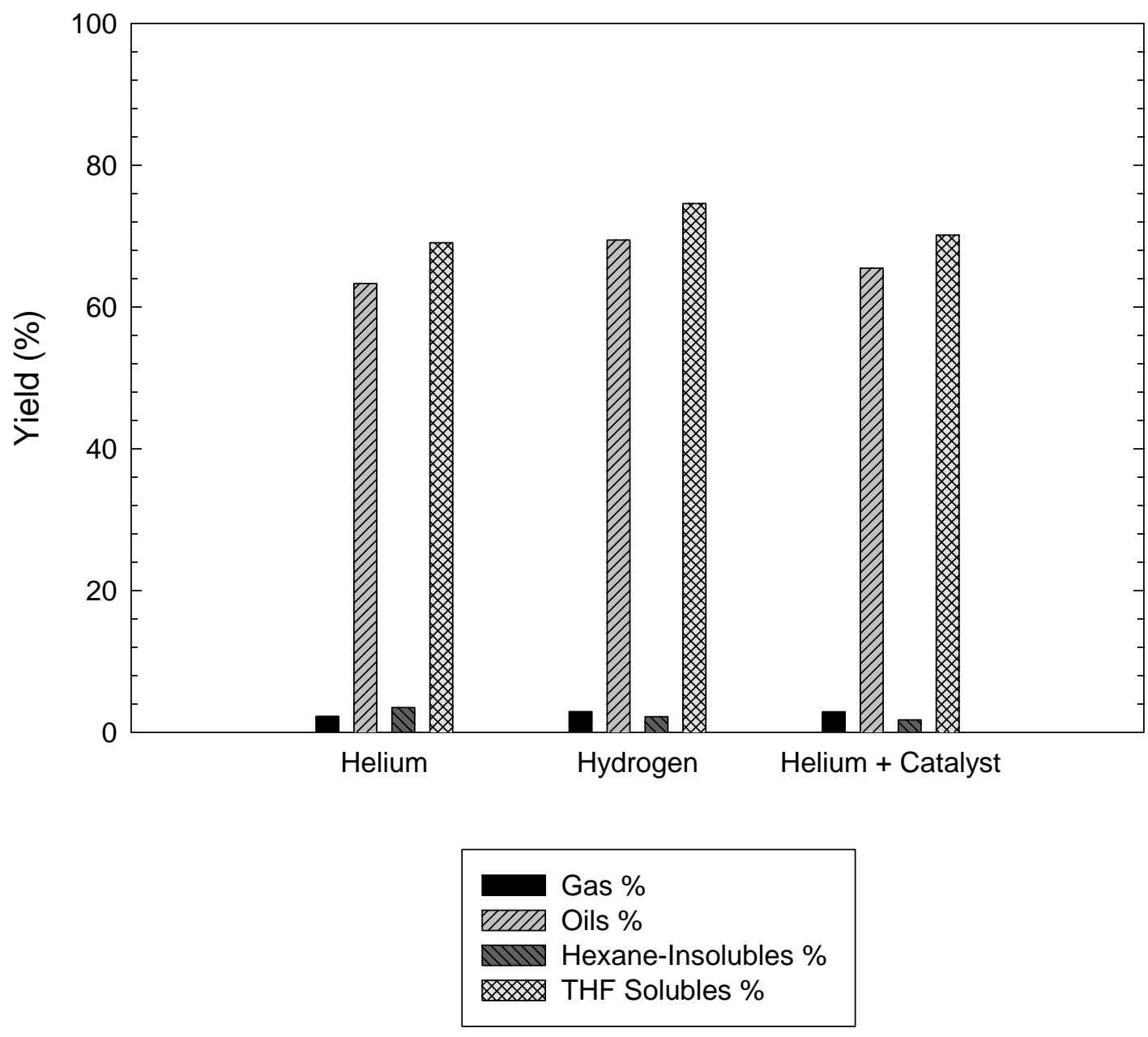

Figure 5.21: Effect of Hydrogen and Catalyst on Pyrolysis of MBAP-2 at $425^{\circ} \mathrm{C}, 30 \mathrm{~min}$ 


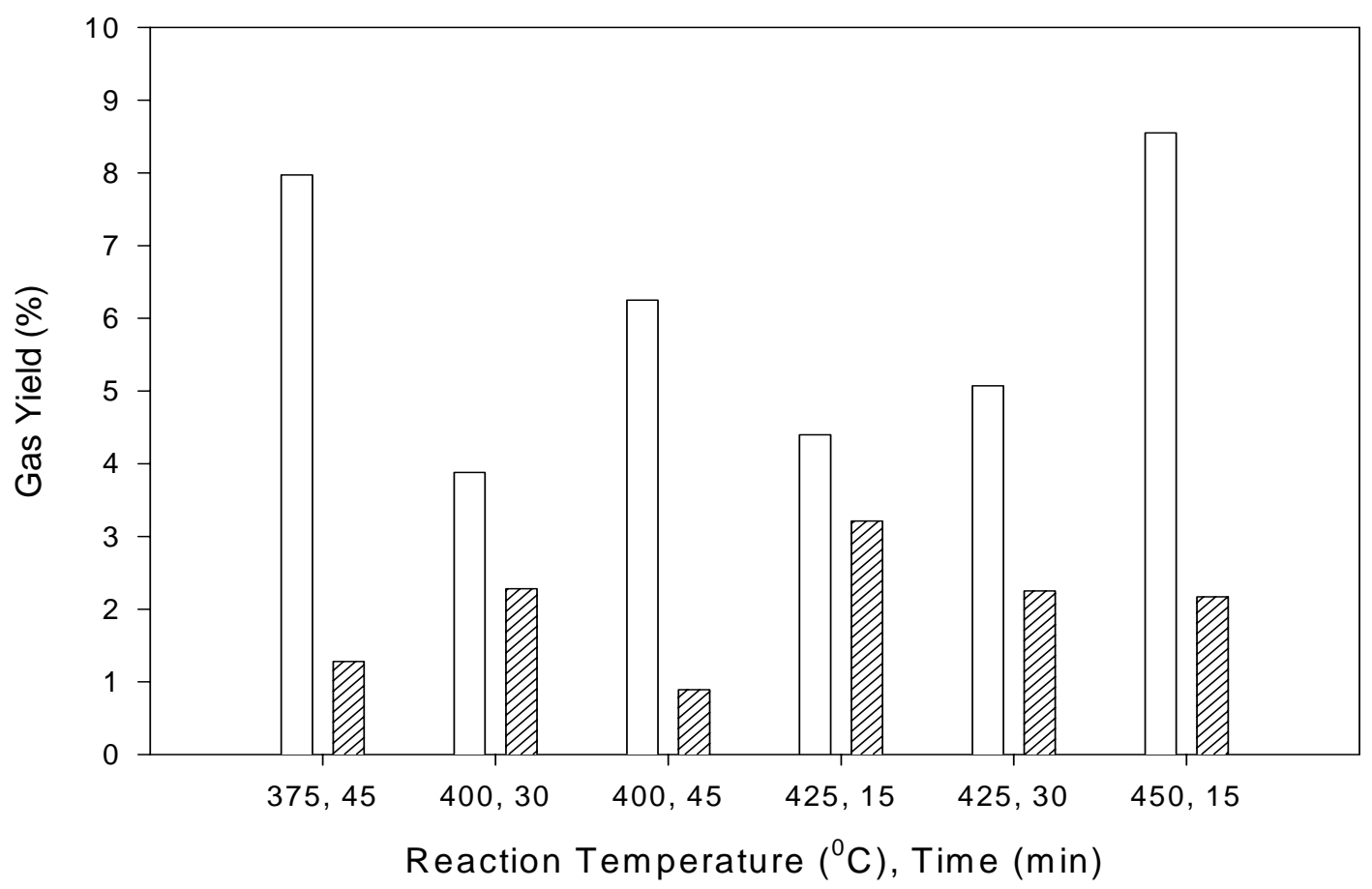

MBAP-1

VIIIA MBAP-2

Figure 5.22: Comparison of Gas Yield for MBAP-1 and MBAP-2 


\subsubsection{Oil Yield:}

The oil yields for the pyrolysis of MBAP-1 and MBAP-2 are shown in Figure 5.23. While the maximum oil yield for MBAP-1occurs in the parameter range of $400^{\circ} \mathrm{C}$ and $30-45 \mathrm{~min}$ as well as at $425^{\circ} \mathrm{C}$ and $15 \mathrm{~min}, \mathrm{MBAP}-2$ has a distinct maximum oil yield at $425^{\circ} \mathrm{C}$ and $30 \mathrm{~min}$. This again can be related to the composition of the two samples. MBAP-2 has fewer component polymers than MBAP-1 and hence shows a distinct maximum for all yields. MBAP-1, possessing a multitude of polymer species, shows a broader range of conditions for maximum oil yield. The broad range of process parameters (Temperature, Time) in which MBAP-1 has its maximum oil yield might indicate a forgiving process design. Research on low-temperature pyrolysis $\left(350^{\circ} \mathrm{C}-500^{\circ} \mathrm{C}\right)$ of mixed plastics ${ }^{7,8,910}$ were conducted with reaction time in seconds or milliseconds rather than in minutes. In future, runs should be conducted with much shorter reaction times to see if the results are different. 


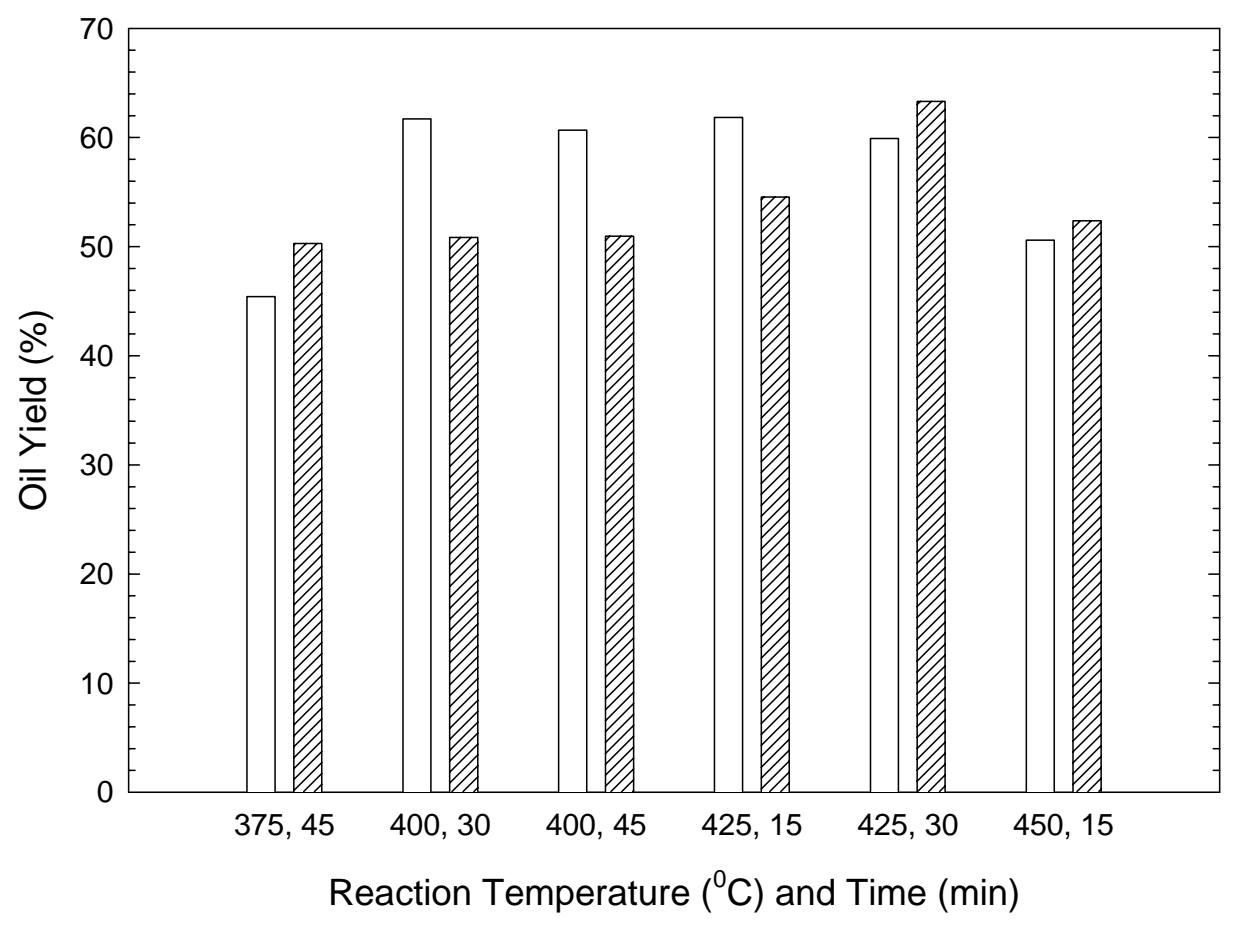

Figure 5.23: Comparison of Oil Yields on Pyrolysis of MBAP-1 and MBAP-2 


\subsubsection{Identification of Product Gas Components:}

The gaseous pyrolysates of MBAP-1 and MBAP-2 were analyzed using a gas chromatograph as explained in Section 5.2.1. The gaseous components identified were methane, ethane, propane, butane, ethene, propene, butene and carbon dioxide. The response factors for these gases are described in Section 5.2.2. The pyrolysis gas mixture for MBAP-1, apart from the gases mentioned above, should contain hydrogen chloride due to the presence of PVC. Hydrogen chloride gas was not measured in these analyses. For both MBAP-1 and MBAP-2, other possible gaseous components ${ }^{8,9,12}$ not identified in our product-gas analysis include propene and butene. Hydrogen is the carrier gas in the Gas Chromatograph and hence was not detected. But previous research ${ }^{8,9}$ on pyrolysis of plastic mixtures similar to the MBAP-1 and MBAP-2 indicate hydrogen to be an insignificant product of pyrolysis. Also, in general, reaction time seems to have little effect on gas composition.

The ratio of gaseous components identified to total gas produced (wt/wt \%) is plotted in Figure 5.24. At higher temperatures, the identified gases account for $>90 \%$ of the total gas formed but a significant percentage of total gas formed is unidentified at $375^{\circ} \mathrm{C}$ for MBAP-1. This could be due to the formation of hydrogen chloride (PVC is a component of MBAP-1). Williams et al. ${ }^{7}$ indicated that degradation of PVC starts at $150^{\circ} \mathrm{C}$. Bockhorn et al. ${ }^{10}$ determined that dehydrochlorination of PVC takes place at $300^{\circ} \mathrm{C}-350^{\circ} \mathrm{C}$ while monomer yield (for HIPS, PE, ABS, PC) starts only at about $380^{\circ} \mathrm{C}$. Hence, there are few free-radicals present at $375^{\circ} \mathrm{C}$ indicating a reduced possibility of secondary reactions with $\mathrm{HCl}$. This might explain the higher amount of unidentified product gas components at $375^{\circ} \mathrm{C}$. At higher temperatures $\left(>380^{\circ} \mathrm{C}\right) \mathrm{HCl}$ tends to react with available radicals to form organo-chlorides ${ }^{8,10,15}$.

HPLC runs conducted with higher-boiling fractions of AT-1 oil, similar in composition to MBAP-1, indicate presence of organic chlorides (Section 5.3.3). The plot for MBAP-2 in Figure 5.24 shows unidentified gaseous components to be less than $10 \%$ with very little variation with reaction temperature or reaction time. Some of the unidentified components in Figure 5.24 could be alkenes $\mathrm{C} 2-\mathrm{C} 4^{8}$. 


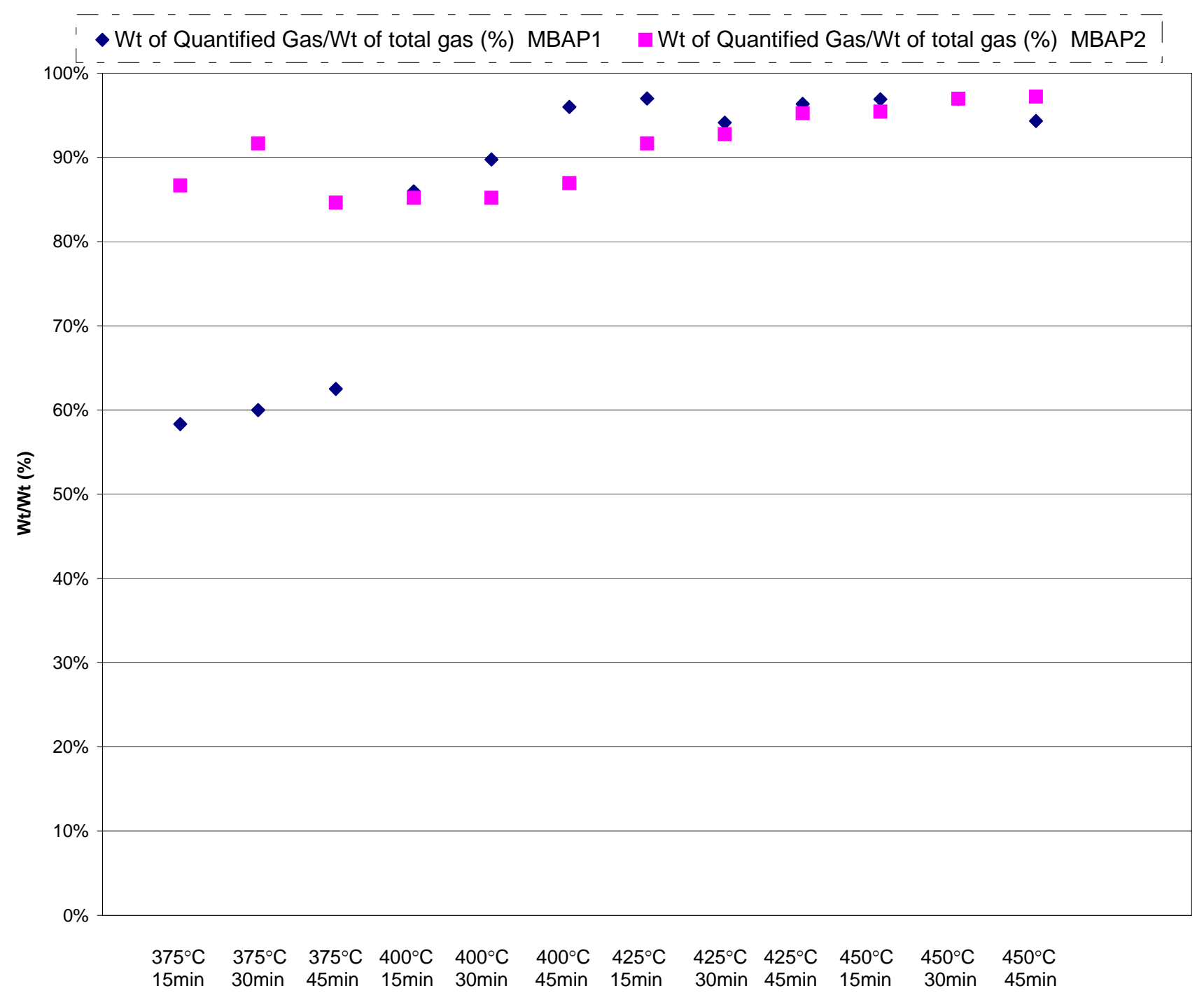

Figure 5.24: Wt of Quantified Gas vs. Wt of Total Gas Sample (\%) for MBAP-1 and MBAP-2 
Pyrolysis runs at similar process conditions, for individual plastics and mixtures, indicate greater presence of smaller components, i.e., whether for alkanes or alkenes, we expect $\mathrm{C} 1>\mathrm{C} 2>\mathrm{C} 3>\mathrm{C} 44^{7,8}$. Results from pyrolysis of MBAP-1 and MBAP-2 also indicate a similar trend. Moreover the product-gas analysis for both MBAP-1 and MBAP-2 (Figures 5.26 and 5.27) indicate the amount of alkanes is greater than the amount of alkenes. This is in direct contrast to the results produced by Williams et al. ${ }^{8}$ Finally, the presence of hydrocarbons in the product gas prompted looking into their heat content. The calorific value of product-gas from pyrolysis of MBAP-1 and MBAP-2 along with their recoverable heat is presented in Section 5.2.7.3. The bond energies and heat content relevant to the MBAP-1 and MBAP-2 are detailed in Tables 5.3a and 5.3b.

\subsubsection{Product Gas Composition of Pyrolyzed MBAP-1:}

There is a substantial production of carbon dioxide during pyrolysis of MBAP-1 (Figure 5.26). $\mathrm{CO}_{2}$ production increases with reaction temperature and reaches a maximum at $425^{\circ} \mathrm{C}$ and 15 min with a value of $71 \%$. This large amount of $\mathrm{CO}_{2}$ might be due to the presence of polycarbonates (PC) in MBAP1. $P C$ 's contain $\mathrm{C}=\mathrm{O}$ bonds all along the chain, and these could be fractured to liberate $\mathrm{CO}_{2}$ (Figure 5.25). Also from Figure 5.26, the formation of methane and ethane increased with increase in reaction temperature while that of propane and butane decreased with increase in temperature. Ethene was formed in trace quantities. Thus gas composition tended towards lower hydrocarbons with increase in temperature while remaining largely independent of reaction time. The smaller hydrocarbons, C1 and C2, are more stable than larger ones (lower possibility of splitting of end chains) and hence form in greater amounts than larger hydrocarbons (C3, C4 etc.). Finally, it was found that the percentage of alkanes (wt/wt \% of total gas produced) decreases with increase in reaction temperature while that of $\mathrm{CO}_{2}$ increases with increase in reaction temperature.

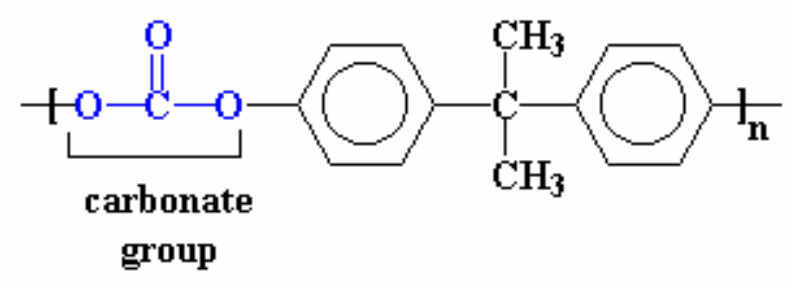

Figure 5.25 Carbon-oxygen bond in polycarbonate 


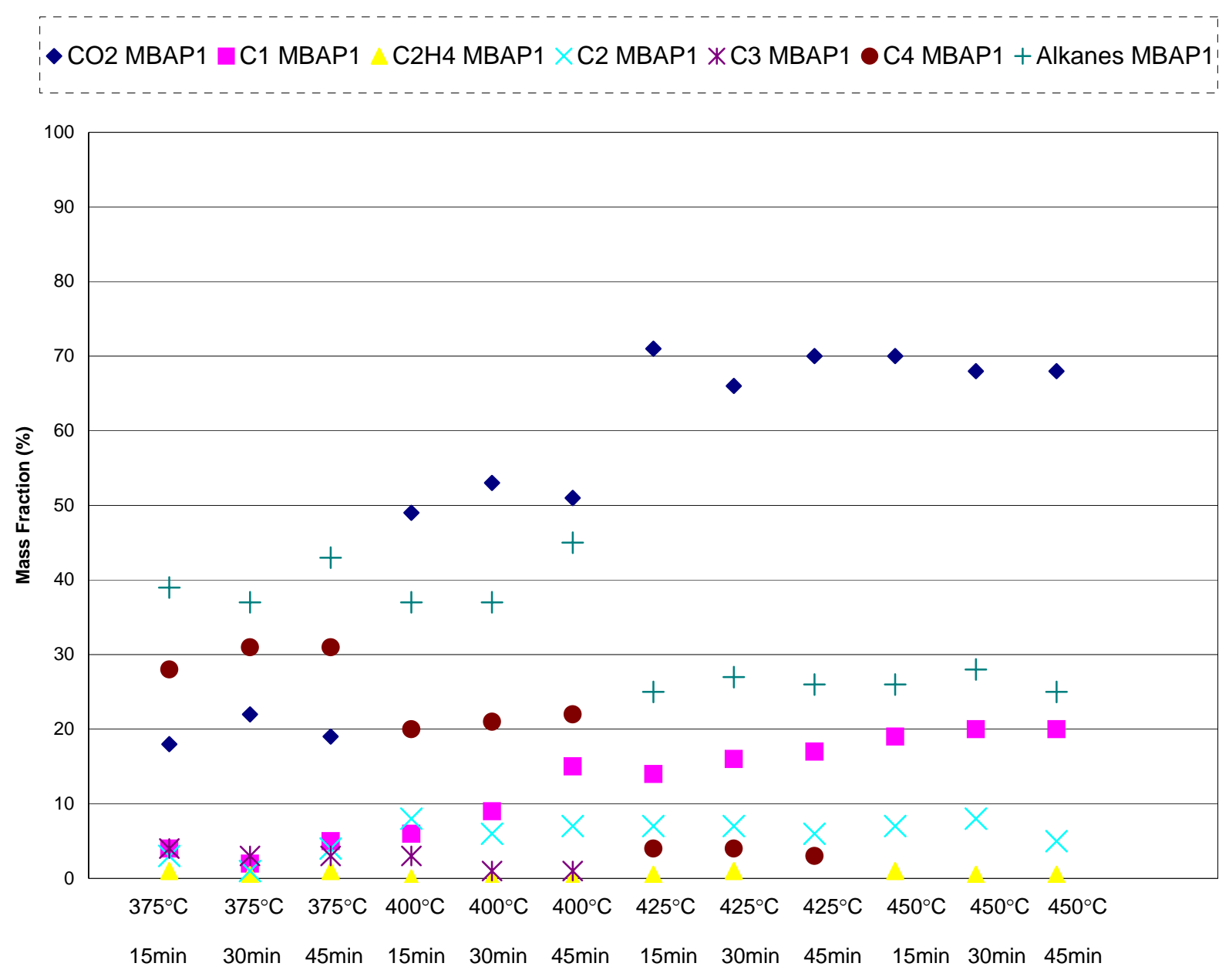

Figure 5.26: Gas Composition for Pyrolysis of MBAP-1 


\subsubsection{Product Gas Composition of Pyrolyzed MBAP-2:}

The product gas composition from pyrolysis of MBAP-2 is shown in Figure 5.27. It is to be noted that there is very little gas produced during the pyrolysis of MBAP-2. The most significant feature is the relatively even distribution of gas products, unlike in MBAP-1, which was dominated by the presence of $\mathrm{CO}_{2}$. While $\mathrm{CO}_{2}$ is still a major gas component, due to the presence of PC and PS in the sample, there is a noticeable presence of alkanes and alkenes in the product gas. While there are changes in hydrocarbon composition as a function of reaction temperature, the formation of alkanes remains relatively unchanged.

The formation of methane, ethene, ethane and $\mathrm{CO}_{2}$ increases with increase in reaction temperature while that of propane and butane decreases with increase in reaction temperature. Reaction time seems to have little effect on product gas composition. As in product-gas analysis of MBAP-1, the trend of formation of greater amounts of smaller hydrocarbons with increase in reaction temperature is repeated. But the trend of more alkanes than alkenes is not. Rather, for MBAP-2, methane and ethene are present in about equal numbers. Williams et al. ${ }^{8}$ observed this behavior for the pyrolysis of polystyrene. The MBAP-2 sample is a mixture of HIPS and ABS, both plastics containing polystyrene. Please see Appendix $\mathrm{C}$ for a tabulation of the raw data pertaining to product gas composition. 


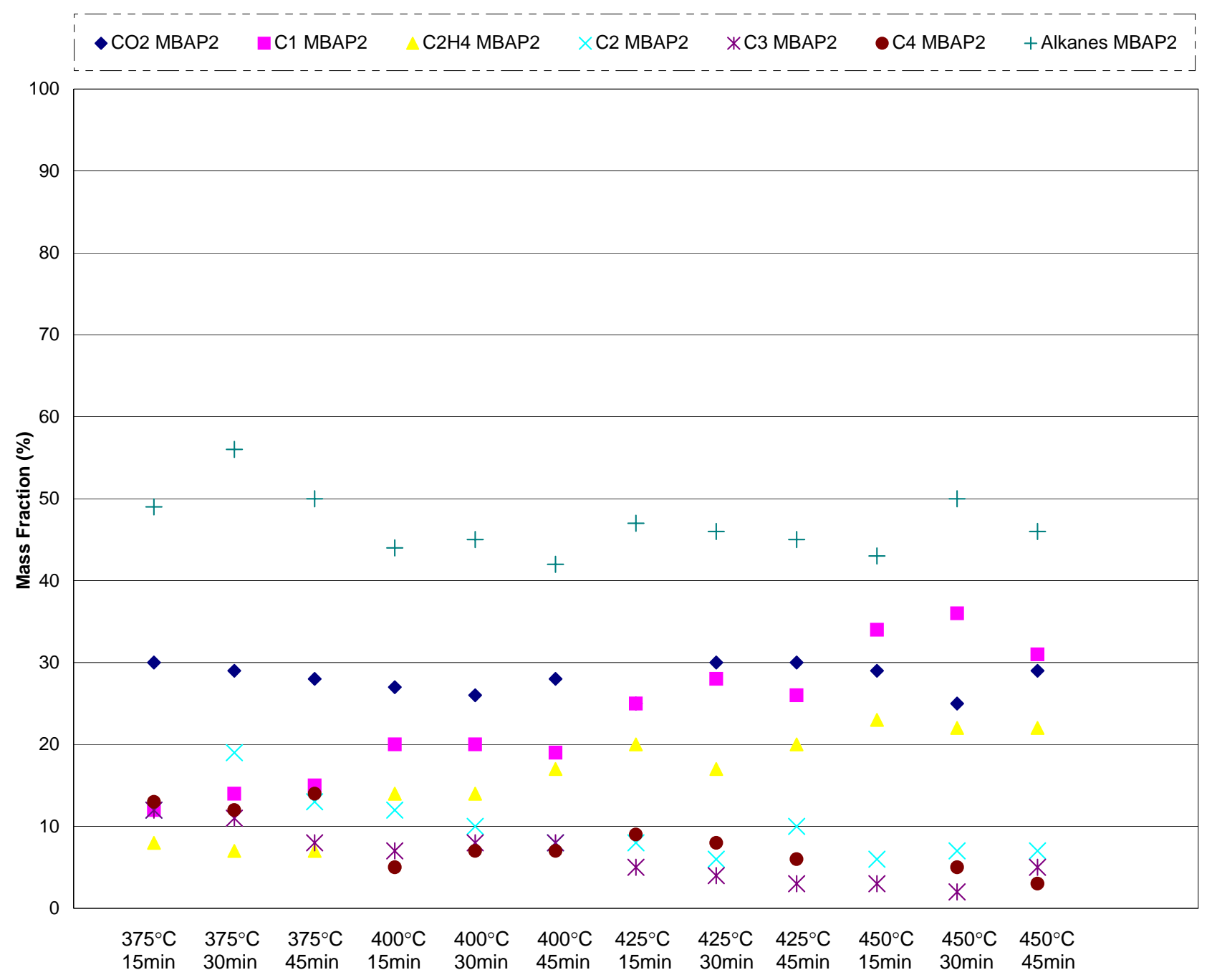

Figure 5.27: Gas Composition for Pyrolysis of MBAP-2 


\subsubsection{Heat Recovery from the Product Gas:}

The presence of hydrocarbons makes one consider the product gas to be used as fuel. The heat thus recovered, if substantial, can be used to sustain the temperature required for pyrolysis of the plastic feed or for producing steam that could be used elsewhere in an operating unit. Figure 5.28a shows the schematic of a combustion chamber and is used to determine the heat content of the product gas assuming complete combustion in a chamber at $800^{\circ} \mathrm{C}\left(\sim 1500^{\circ} \mathrm{F}\right)^{18,19}$ and slightly positive pressure.

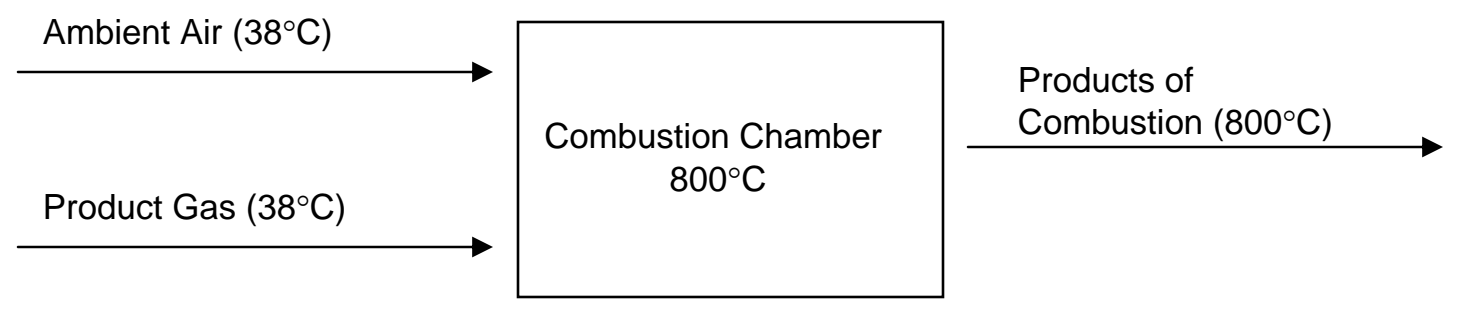

Figure 5.28a: Flow Diagram for Combustion of Product Gas

All the product gas samples have significant heat contents that could be recovered, especially in a continuous operation unit (see Table 5.3a, Table 5.3b and Table 5.4). An increase in reaction time, at the same reaction temperature, leads to a decrease in heat content of the product gases. Likewise, an increase in reaction temperature, irrespective of reaction time, seems to lead to an increase in heat content as well. And a look at the product gas composition confirms that the higher the percentage of hydrocarbons, the higher the heat content (See Figures 5.28a and 5.28b).

The average heat (heat duty) that could be recovered from the five fractions of MBAP-1 and MBAP-2 sampled ranged from $34 \mathrm{MJ} / \mathrm{Hr}-98 \mathrm{MJ} / \mathrm{Hr}$ (see Table 5.4). For a further look at the combustion model and the potential savings (which could be in excess of a $\$ 100,000 / y r$ ) please see Appendix A. Thus, if a continuous pyrolysis process is developed, the product gas can be used as a fuel source. 
Table 5.3: Heats of Combustion of the product gas components ${ }^{20}$

\begin{tabular}{|c|c|c|c|}
\hline Gas Sample & Heat of Combustion & Heat of Combustion & Avg MW \\
\hline & KJ/mole & KJ/gm & \\
\hline Methane & 801.55 & 49.97 & 16.04 \\
\hline Ethane & 1426.47 & 47.44 & 30.07 \\
\hline Propane & 2042.04 & 46.31 & 44.09 \\
\hline Butane & 2655.91 & 45.70 & 58.12 \\
\hline Pentane & 3268.93 & 45.31 & 72.15 \\
\hline Hexane & 3882.93 & 45.06 & 86.17 \\
\hline Ethene & 1321.70 & 47.12 & 28.05 \\
\hline
\end{tabular}

Table 5.4: Heat Recovery Analysis of the product gas samples

\begin{tabular}{|c|c|c|}
\hline Gas Sample & Heat Content $^{*}$ & Heat Available $^{\#}$ for \\
\hline KJ/gm. & Recovery ( MJ/hr) \\
\hline MBAP1-375C, 30min & 31.77 & 98.18 \\
\hline MBAP1-400C, 45min & 24.16 & 56.51 \\
\hline MBAP1-425C, 15min & 13.79 & 34.07 \\
\hline MBAP2-425C, 15min & 36.24 & 94.18 \\
\hline MBAP2-425C, 30min & 30.51 & 60.49 \\
\hline
\end{tabular}

*: Heat of Combustion, $-\Delta \mathrm{Hc}$ at $25^{\circ} \mathrm{C}$ and constant pressure to form $\mathrm{H} 2 \mathrm{O}$ (liquid) and $\mathrm{CO} 2$ (gas)

\#: Heat available for recovery at $800^{\circ} \mathrm{C}$ 


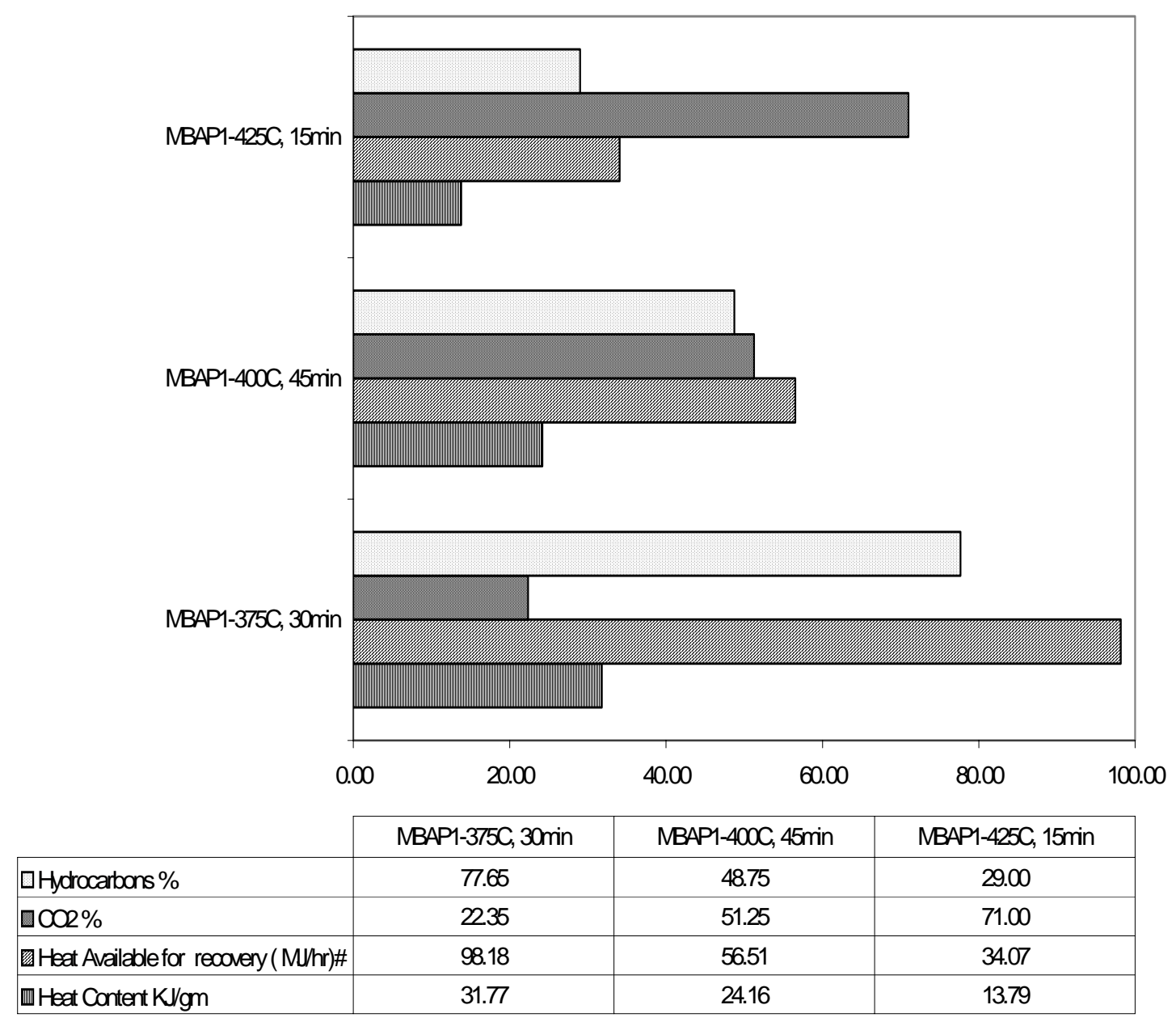

Figure 5.28b: Heat Recovery Analysis - MBAP-1 Product Gas Samples 


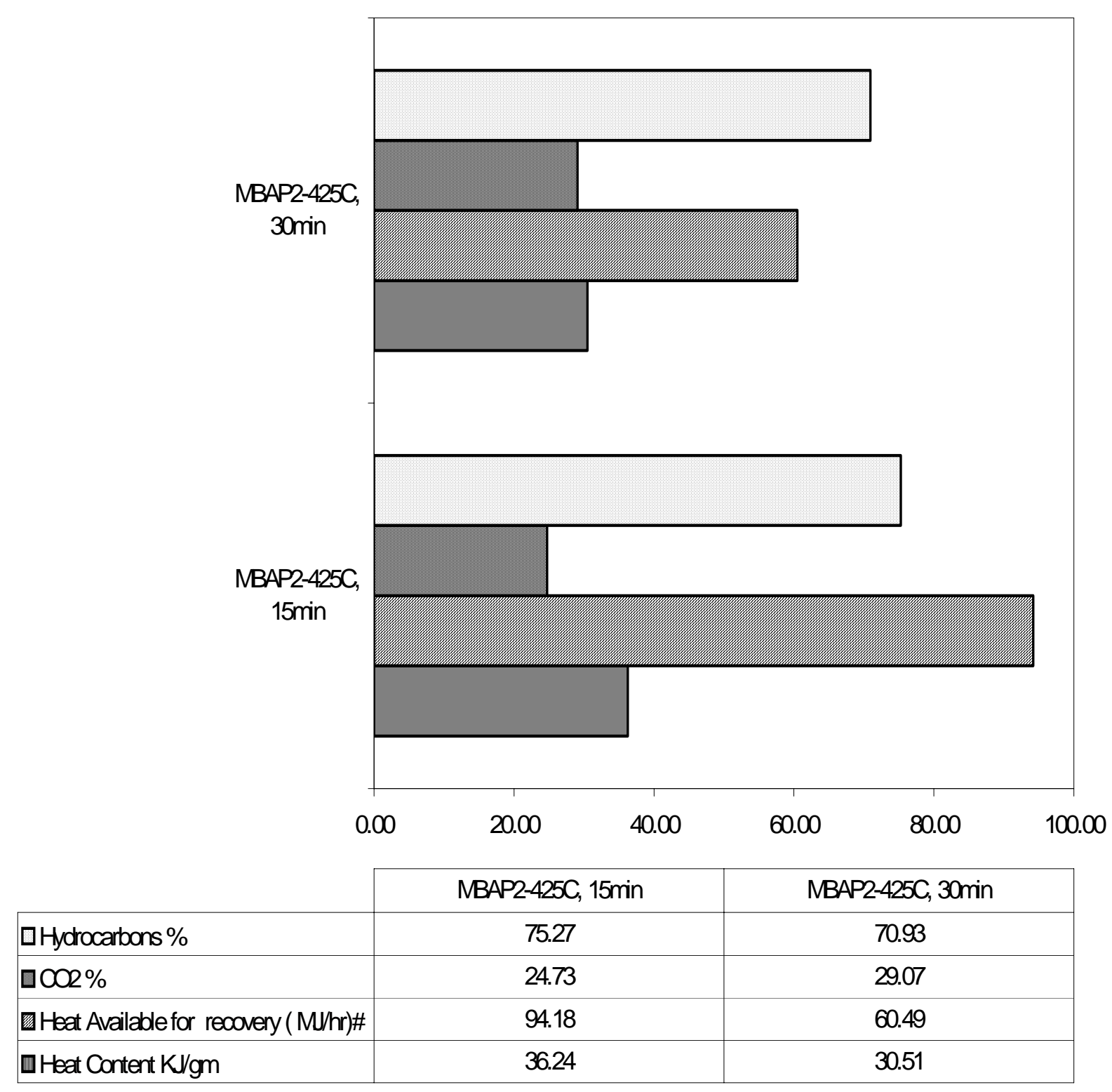

Figure 5.28c: Heat Recovery Analysis - MBAP-2 Product Gas Samples 


\subsection{Results of AT-1 Oil Characterization:}

As mentioned earlier, the AT-1 oil was characterized using the ASTM D-86, ASTM D-2887 and HPLC apparatus.

\subsubsection{ASTM D-86 Atmospheric Distillation Data:}

During initial distillation runs of AT-1 using the ASTM D-86 method, a large amount of solid white powder was formed inside the distillation apparatus around $400^{\circ} \mathrm{F}$. This not only significantly affected the effectiveness of the distillation and its products, but also caused significant fouling in the apparatus. The white powder was identified as ammonium chlorides and bromides that originate from additives added to the plastics as fire retardant. This is consistent with independent observations from AT.

A procedure was designed and tested which allowed partial removal of these compounds before the distillation commenced. The halogens were removed by contacting the oil with nano-pure water (impurities in ppb levels) in a separatory funnel for various "settling times", i.e. the time over which the oil phase was in contact with the aqueous phase. The polar salts were more soluble in the aqueous phase than in the oil phase and hence could be removed from the oil phase. The oil phase then was decanted for distillation and the aqueous phase was saved for quantitative analysis. The aqueous phase was then titrated with $0.081 \mathrm{~N} \mathrm{AgNO}_{3}$ (using fluroscien as an adsorption indicator) to precipitate the halogens via

$$
\mathrm{X}^{-}+\mathrm{AgNO}_{3} \rightarrow \mathrm{AgX}+\mathrm{NO}_{3}^{-} \quad(\mathrm{X}=\mathrm{Cl}, \mathrm{Br})
$$

The amount of halogens removed was calculated as follows: The total amount of $\mathrm{AgNO}_{3}$ added to the water sample is known and the amount of $\mathrm{AgX}$ precipitated is collected and weighed. Hence the total amount of halogen ions removed can be determined. This method, though simple and useful, cannot be assumed to remove all the halogens from the oil (as some of the halogens could exist as complex organo-halides). 
Though Table 5.5a indicates a substantial amount of salt removal using this method especially for longer settling times, the absolute percentage of salts removed by this method is unavailable at present.

The data plotted in Figures 5.29 A through 5.29D are the TBP curves of the AT oil sample, obtained using the ASTM D-86 atmospheric distillation method. The TBP curve of the raw AT-1 oil (Figure 5.29A) reveals that the oil is an extremely complex mixture. Please see Appendix D for tabulation of raw data.

The TBP curves shown in Figures $5.29 \mathrm{~B}, \mathrm{C}$ and $\mathrm{D}$ are distillation runs for AT oil samples that have been contacted with water and allowed to "settle" or "separate" into two immiscible phases, at "settling times" of 12,24 and 48 hours.

Quantitatively, the data are summarized in Table 5.5b. An increase in contact time leads to a decrease in overall distillate volume in the diesel fuel range (temperature range $340^{\circ} \mathrm{F}-640^{\circ} \mathrm{F}$ ) from $80 \mathrm{ml}$ to $63 \mathrm{ml}$ as well as the maximum boiling diesel volume (temperature range $540^{\circ} \mathrm{F}-640^{\circ} \mathrm{F}$ ) from $42 \mathrm{ml}$ to $25 \mathrm{ml}$. Even so, over $60 \%$ of the distillate is in the Diesel Fuel range $\left(340-640^{\circ} \mathrm{F}\right)$. Quantitatively, in going from Curve $A$ to Curve $D$, the points shift to the right causing a decrease in distillate volume in diesel fuel range. This might indicate removal of some lower molecular weight components along with the organohalides from the oil phase into the aqueous phase. Alternatively, it should be noted that the AT-1 is a complex mixture and longer settling times could have triggered the lower molecular weight species to combine and form higher molecular weight species.

As shown in Table 5.5b, the yield of diesel leveled off (also total Halogen removed leveled off) after a settling time of $12 \mathrm{Hrs}$. Similarly, the yield in the maximum boiling diesel range decreased with an increase in contact time. Thus a settling time $12 \mathrm{Hrs}$ is sufficient to obtain quantitative results. In practice, some sort of continuous counter-current extraction procedure would be employed to effect a similar treatment. Further, some reactive species could be added to the aqueous phases so that the removal of the halogenated species may be enhanced. Such experiments were beyond the scope of the present work. 
Table 5.5a: Total Halogens removed from $100 \mathrm{~g}$ of AT-1 oil at various Settling Times: ASTM D-86 Atmospheric Distillation method

\begin{tabular}{|c|c|c|c|c|}
\hline $\begin{array}{c}\text { Settling } \\
\text { Time } \\
(\mathrm{Hrs})\end{array}$ & $\begin{array}{c}\text { Amount of } \\
\mathrm{AgNO}_{3}\end{array}$ & $\begin{array}{c}\text { Amount of } \\
\text { Ag Added } \\
(\mathrm{gm})\end{array}$ & $\begin{array}{c}\text { Total AgX } \\
\text { Removed }\end{array}$ & $\begin{array}{c}\text { Total } \\
\text { Halogens } \\
\text { removed } \\
(\mathrm{gm})\end{array}$ \\
\cline { 2 - 5 } & \multicolumn{3}{|c|}{ Normality of $\mathrm{AgNO}_{3}$ solution $=0.081 \mathrm{~N}$} \\
\hline 0 & 13.85 & 8.8 & 9.31 & 0.51 \\
\hline 12 & 13.85 & 8.8 & 10.28 & 1.48 \\
\hline 24 & 13.85 & 8.8 & 10.33 & 1.53 \\
\hline 48 & 13.85 & 8.8 & 10.26 & 1.46 \\
\hline
\end{tabular}

Table 5.5b: Volume in Diesel-Fuel Range $\left(540^{\circ} \mathrm{C}-640^{\circ} \mathrm{C}\right)$ at various Settling Times: ASTM D-86 Atmospheric Distillation method; Basis: 100ml Sample

\begin{tabular}{|c|c|c|c|}
\hline \multirow{3}{*}{$\begin{array}{l}\text { Settling } \\
\text { Time } \\
(\mathrm{Hrs})\end{array}$} & \multicolumn{3}{|c|}{$\begin{array}{l}\text { Distillate Volume } \\
(\mathrm{ml})\end{array}$} \\
\hline & $\begin{array}{l}\text { Overall Volume / \% } \\
\text { Distilled in Diesel- } \\
\text { Fuel Range }\end{array}$ & $\begin{array}{c}\text { Overall Volume / \% } \\
\text { Distilled in Maximum } \\
\text { Boiling Diesel-Fuel } \\
\text { Range }\end{array}$ & $\begin{array}{l}\text { Ratio of distillate in } \\
\text { Maximum } \\
\text { Diesel-Fuel Range to } \\
\text { overall diesel -fuel } \\
\text { Range (\%) }\end{array}$ \\
\hline & $340-640^{\circ} \mathrm{F}$ & $540-640^{\circ} \mathrm{F}$ & \\
\hline 0 & 80 & 42 & 53 \\
\hline 12 & 63 & 37 & 59 \\
\hline 24 & 63 & 30 & 48 \\
\hline 48 & 63 & 25 & 40 \\
\hline
\end{tabular}




\section{Atmospheric Distillation Data at Various Settling Times}

X Axis: Temperature (F), Y Axis: Volume of Distillate (ml); Basis: $100 \mathrm{ml}$ of Oil Sample
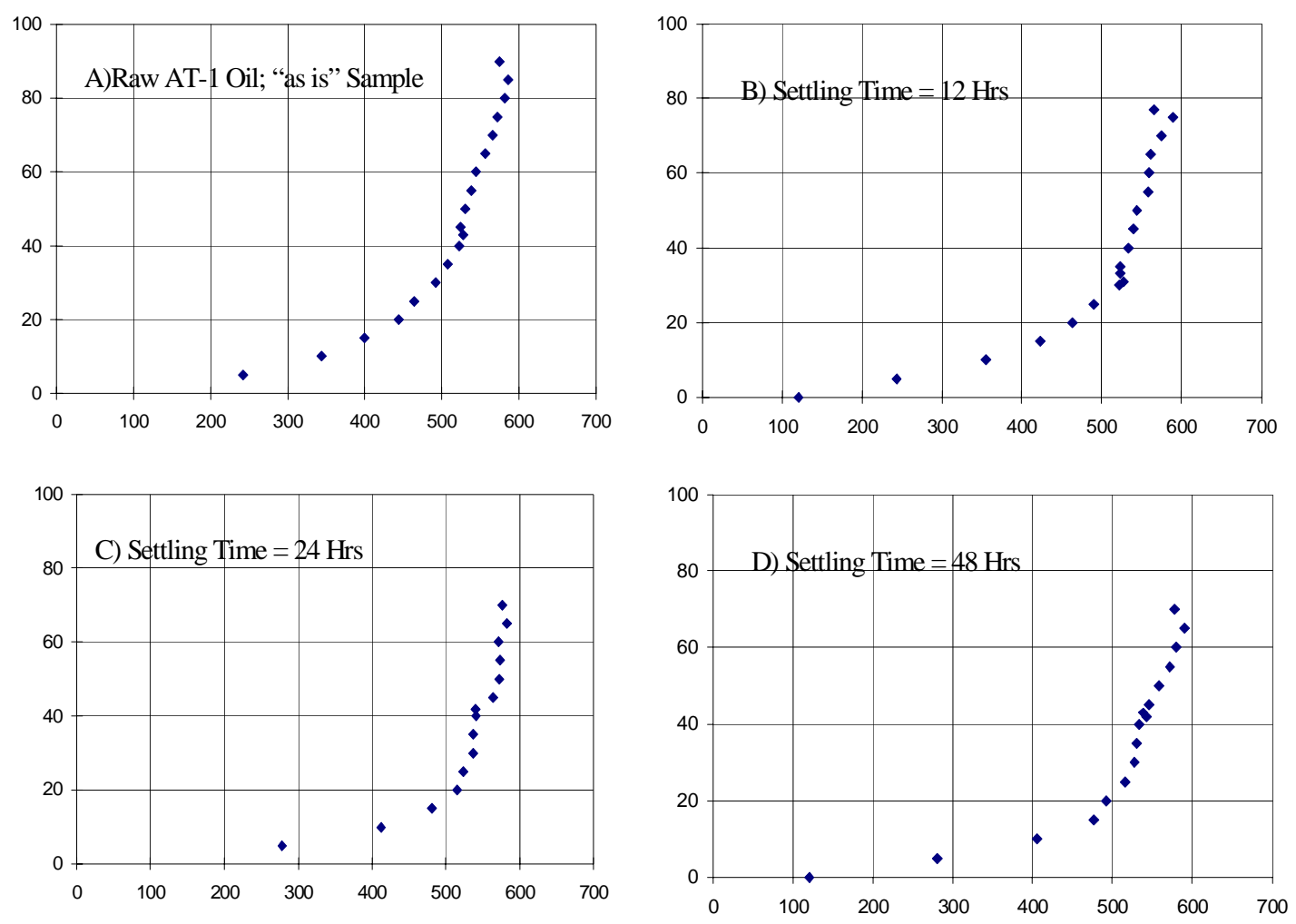

Figure 5.29 Results of D-86 data: A) raw AT-1 Oil; B), C) and D) AT-1 Oil which has been treated to remove halogenated species, 


\subsubsection{ASTM D-2887 Simulated Distillation Data:}

ASTM D-2887 (for obtaining simulated distillation data) is a robust method for characterization of petroleum fuels. It is highly automated and consists of sophisticated analytical apparatus. Though ASTM D-86 (for obtaining atmospheric distillation data) is a very useful method for characterizing complex hydrocarbon mixtures, the simulated distillation data is superior in terms of accuracy. The aim here was to validate the results obtained from the D-86 apparatus by running the same samples with the D-2887 apparatus.

\subsubsection{Procedure:}

The ASTM D-2887 method separates the components of the oil sample chromatographically but the data are plotted as "\% distilled vs. Boiling Point", i.e. as in the D-86 method. By using a known standard, component peaks in the output can be associated with their known boiling points. It is then assumed that any unknown component that elutes at the same peak location has a similar boiling point. This method thus gives information about the boiling point range of the sample. The first drop of liquid vaporized at a particular boiling temperature denotes the initial boiling point (IBP) of the mixture. The end of fractionation is similarly noted by the vaporization of the final drop of liquid mixture denoted as final boiling point (FBP).

A gas-oil standard was injected to standardize the procedure. Four oil samples were analyzed using the ASTM D-2887 method. The first sample was regular diesel fuel obtained at a local service station. This diesel fuel provided a reference for \% distilled in the "diesel-fuel range".

The second sample was raw AT-1 oil. When subjected to the D-2887 method, raw AT-1 oil gave no useful information as it contained too many high-molecular weight species that remained in the column and never eluted. Hence these data are not presented.

The third sample was derived from AT- 1 oil as a distillate cut $\left(340-640^{\circ} \mathrm{F}\right.$ at atmospheric pressure) taken from the AT-1 atmospheric distillation on the ASTM D-86 apparatus. This sample represents the components in the diesel fuel range $\left(340-640^{\circ} \mathrm{F}\right)$ contained in the original AT-1 pyrolysis 
oil. It should be noted that the halogenated impurities have also been separated from the sample first by contacting with water and followed by the atmospheric distillation. This helps protect the chromatographic column from the corrosive effects of the halogens.

The fourth sample consisted of the Hexane-Soluble (i.e. oil fraction) portion of the pyrolysis products from the reaction of the MBAP-2 plastic feed. The intent here is to compare the oils derived from pyrolysis of the raw plastics to standard diesel fuel.

As a matter of convenience, the software provided in the ASTM D-2887 analysis is capable of converting D-2887 data to the equivalent D-86 results. These data are shown in Tables 5.6, 5.7 and 5.8.

Once the system was calibrated with the gas oil standard, $100 \mu \mathrm{l}$ of each sample was injected and analyzed. The standard gas oil covered a range of $\mathrm{C}_{6}-\mathrm{C}_{41}$. Care was taken to prevent contamination of the samples.

Carbon Disulfide $\left(\mathrm{CS}_{2}\right)$ was used as a solvent. $\mathrm{CS}_{2}$ does not burn in the air/ $\mathrm{H}_{2}$ mixture of the FID and hence would not be detected. The use of any other solvent such as hexane would mar the results as such a solvent would be detected and counted as a product. The presence of peaks corresponding to hexane in the results for the hexane-soluble oil indicated that the hexane was not completely removed during rotary evaporation.

The ASTM D-2887 method is sensitive to the composition of the oil. Data from the analysis of an oil sample should indicate the amount of diesel fuel range or gasoline range fraction that it possesses.

\subsubsection{Analysis of Commercial Diesel Fuel:}

The ASTM D-2887 method was applied to the sample of commercial diesel fuel and the data are presented in Figure 5.30 and Table 5.6. The data conform to the diesel range between $340-640{ }^{\circ} \mathrm{F}$. 
Table 5.6: Corresponding D-86 Correlation from the D-2887 results for commercial diesel fuel

\begin{tabular}{|c|c|}
\hline Percent Off & D-2887 Data: B.P. $\left({ }^{\circ} \mathbf{F}\right)$ \\
\hline IBP $^{*}$ & 343 \\
\hline 10 & 408 \\
\hline 20 & 442 \\
\hline 30 & 466 \\
\hline 50 & 508 \\
\hline 70 & 548 \\
\hline 80 & 570 \\
\hline 90 & 603 \\
\hline FBP $^{\star}$ & 660 \\
\hline
\end{tabular}

*FBP: Final Boiling Point; *IBP: Initial Boiling Point

Note: the FBP and IBP are calculated by the D-2887 software. 


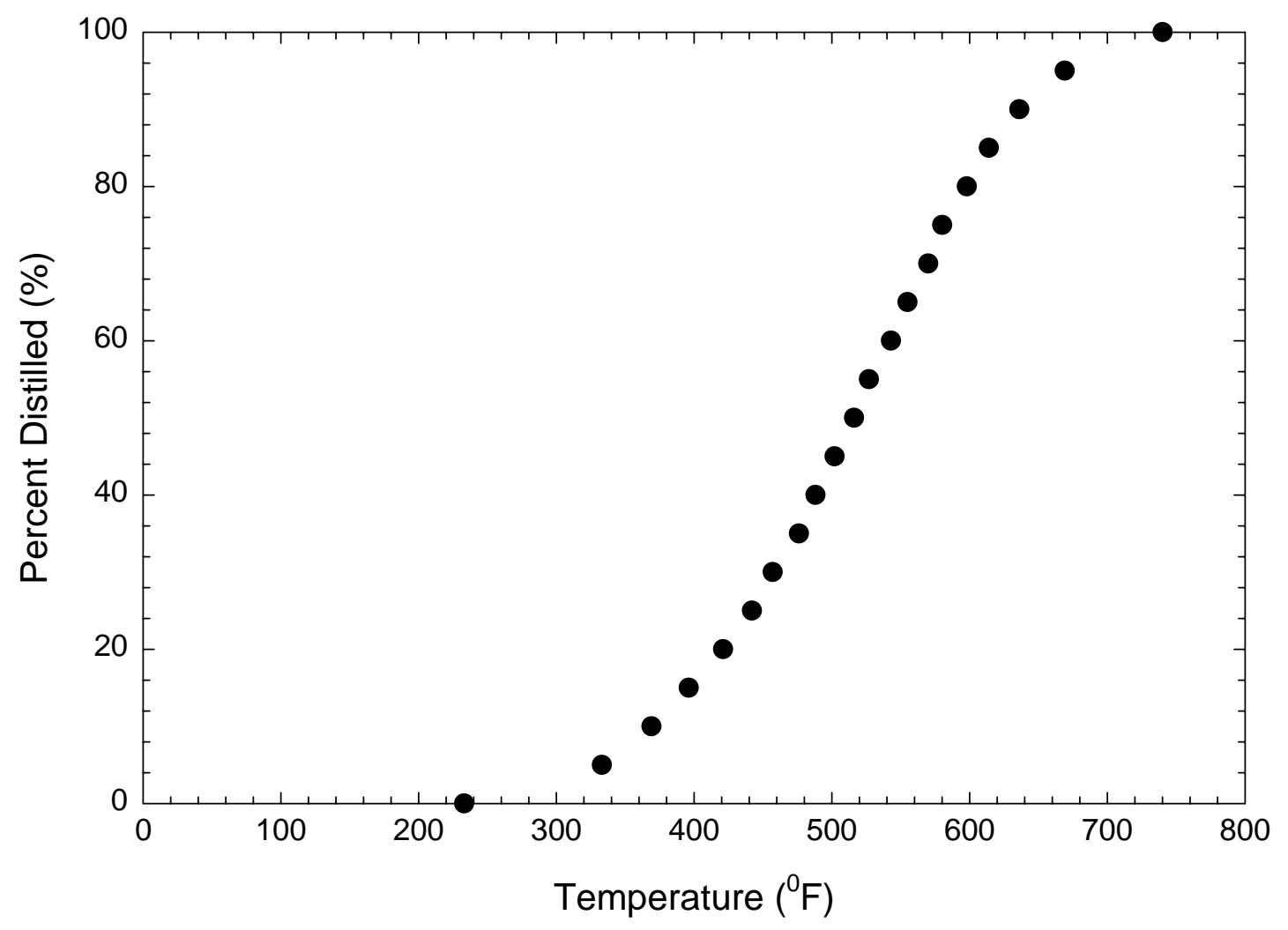

Figure 5.30: Simulated Distillation (ASTM D-2887) Analysis of Commercial Diesel Fuel 


\subsubsection{Analysis of ASTM D-86 Distillate Cut of Raw AT-1 Oil:}

The ASTM D-2887 method was applied to the diesel-fuel cut of the raw AT-1 oil. From the D-86 correlation shown in Figure 5.31 and Table 5.7 for the distillate cut of AT-1 Oil, it can be seen that approximately $80 \%$ of the distillate is in the diesel range $\left(340-640{ }^{\circ} \mathrm{F}\right)$. However, $100 \%$ of the sample should have been in the diesel fuel range. The chromatographic separation in the D-2887 method vs. a straight distillation in the D-86 method could explain this difference. The packing used in the GC Column along with the Flame Ionization Detector (FID) might have a certain characteristic, which could have affected the results (see Table 5.7). While $70 \%$ of the distillate in both the methods have a similar BP range, the FBP in the D-86 method corresponds with $80 \%$ distillate and in the D-2887 method it corresponds with $\sim 96 \%$ distillate. In any distillation technique the composition of heavy vs. light fraction in the distillate and residue will depend on the vapor-liquid equilibrium of the original mixture. It could be possible that there are some heavy fractions in the distillate cut from the D-86 method that are not characterized in the D-2887 method leading to the difference in results. Also, since the ASTM D-2887 analysis was not performed immediately after the ASTM D-86 analysis, some lighter fractions from the ASTM D-86 distillate cut could have recombined over time. Further investigation is required.

Table 5.7 Corresponding D-86 Correlation from the D-2887 results for the AT-1 Distillate

\begin{tabular}{|c|c|c|}
\hline Percent Off & ASTM D-2887: B.P. ( ${ }^{\circ}$ F) & ASTM D-86: B.P. ( ${ }^{\circ}$ F) \\
\hline IBP & 269 & 120 \\
\hline 10 & 350 & 355 \\
\hline 20 & 402 & 463 \\
\hline 30 & 445 & 522 \\
\hline 50 & 528 & 544 \\
\hline 70 & 579 & 575 \\
\hline 80 & 613 & $575(\mathrm{FBP})$ \\
\hline 90 & 652 & \\
\hline FBP & 690 & \\
\hline
\end{tabular}




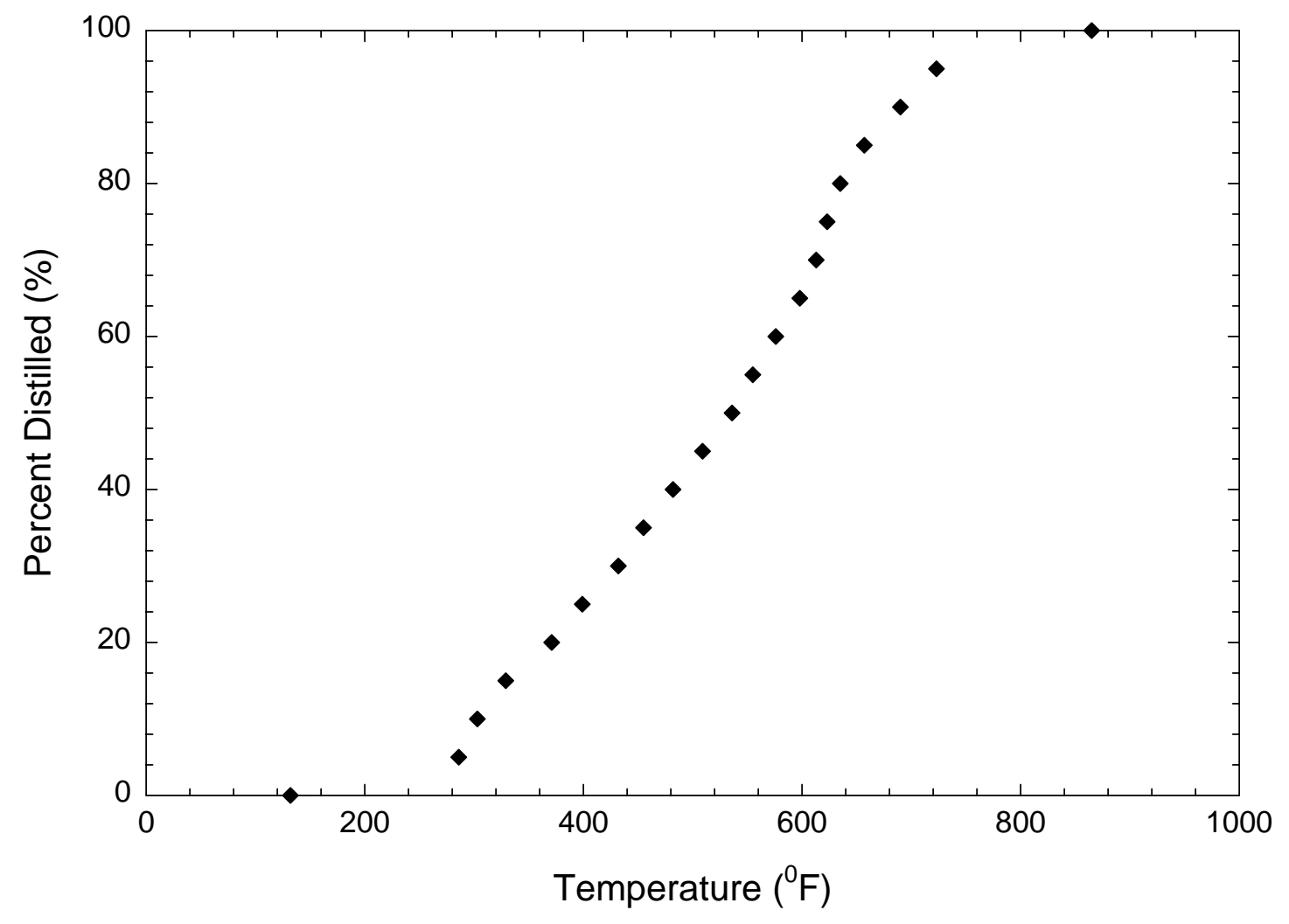

Figure 5.31: Simulated Distillation (ASTM D-2887) Analysis Plot for AT-1 Distillate 


\subsubsection{Analysis of Hexane-Solubles from MBAP-2:}

Finally the ASTM D-2887 method was applied to the Hexane-Soluble fraction from the pyrolysis product of MBAP-2. The Oils (Hexane-Solubles) from MBAP-2 (at $425^{\circ} \mathrm{C}, 30$ min : maximum Oil Yield) revealed that $80 \%$ of the sample had boiling points in the diesel range. This is illustrated in Figure 5.32 and Table 5.8 shown below.

It could be possible that the presence of peaks corresponding to hexane $\left(<200^{\circ} \mathrm{F}\right)$, indicate that the hexane (solvent) was not completely removed from the hexane-soluble (oil) fraction by rotary evaporation during the characterization of pyrolysis products. The percentage of hexane in the oil sample was found to be $10 \%$. Therefore, out of the remaining $90 \%$, a little more than $72 \%$ falls in the diesel fuel range. This implies that $80 \%$ of the oil sample (Hexane-Solubles from MBAP-2 at $425{ }^{\circ} \mathrm{C}, 30$ min: maximum Oil Yield) had boiling points in the diesel range.

The above data show that the Hexane Solubles from MBAP-2 have a similar percentage of distillate in the diesel fuel range as that of the distillate cut from AT-1 oil. This is a very important finding as this analysis has proven that the oil produced by the WVU process is comparable to that produced by AT process. This analysis also proves the potential of THF and hexane as solvents that can effectively separate the pyrolysis products of end-of-life electronic equipment.

These results confirm that pyrolysis of waste plastic streams is, in fact, capable of producing a substantial amount of quality diesel fuel that could be recovered by traditional distillation techniques currently practiced in the petroleum industry. 
Table 5.8 Corresponding D-86 Correlation from the D-2887 Results for Hexane-Solubles from MBAP-2

\begin{tabular}{|c|c|}
\hline Percent Off & B.P. ( ${ }^{\circ}$ F) \\
\hline IBP & 175 \\
\hline 10 & 228 \\
\hline 20 & 343 \\
\hline 30 & 425 \\
\hline 50 & 544 \\
\hline 70 & 604 \\
\hline 80 & 639 \\
\hline 90 & 660 \\
\hline FBP & 674 \\
\hline
\end{tabular}




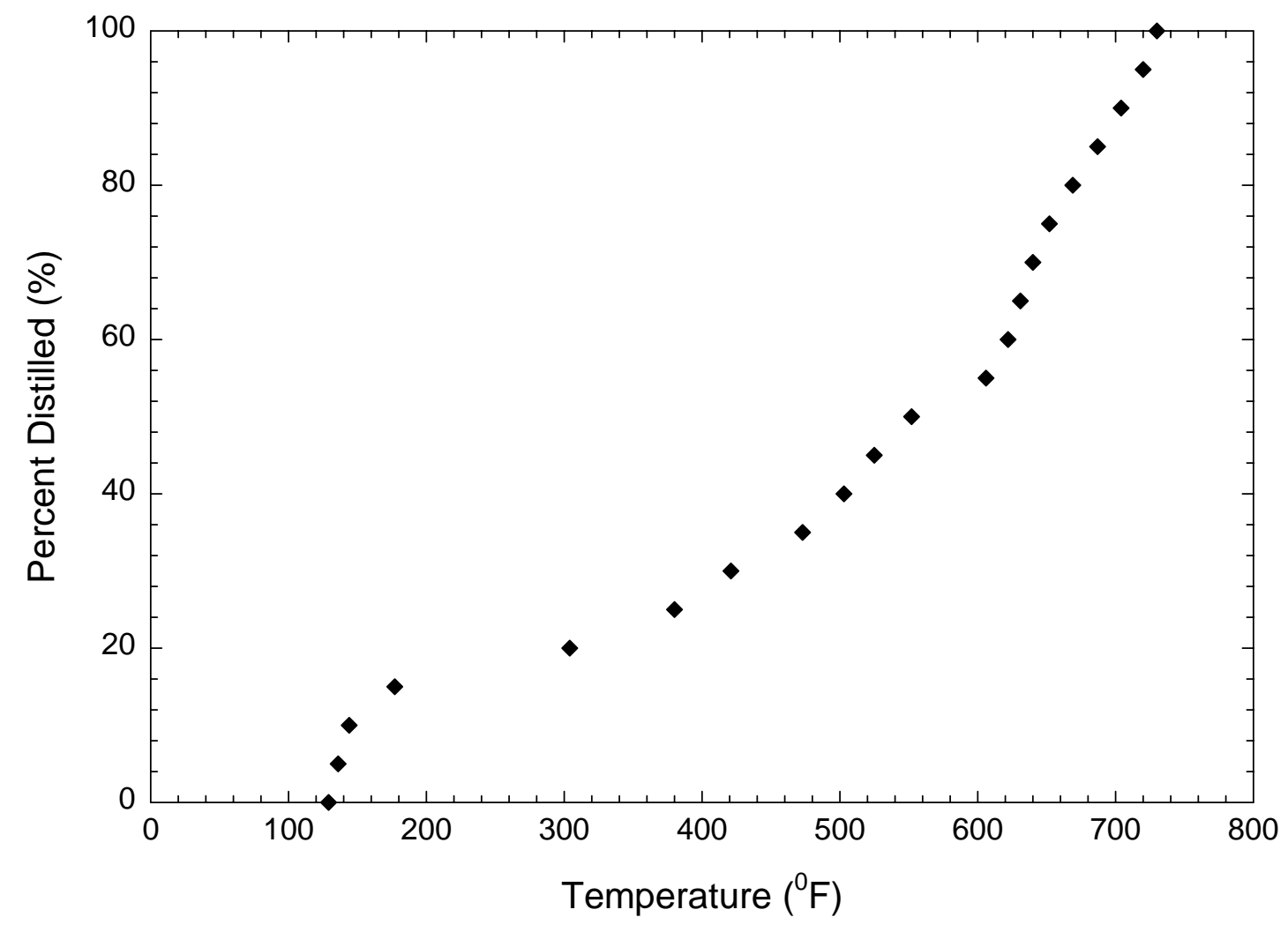

Figure 5.32: Simulated Distillation (ASTM D-2887) Analysis for MBAP-2 Hexane-Solubles 


\subsubsection{HPLC Analysis of High Boiling Fractions $\left(>662^{\circ} \mathrm{F}\right)$ of AT-1 Oil :}

Analysis of High Boiling fractions (those having boiling point greater than $662^{\circ} \mathrm{F}$ ) in raw AT-1 oil and pyrolysis oil from MBAP-2 was performed using a Varian High Performance Liquid Chromatograph (HPLC) equipped with a Varian 9095 Auto Sampler, 9010 Solvent Delivery System and an Evaporative Light Scattering Detector.

This analysis is necessitated by the temperature limitations of the ASTM D-86 and D-2887 methods. The D-86 method is incapable of distilling fractions greater than $662{ }^{\circ} \mathrm{F}$ and the maximum allowable column temperature in D-2887 method is $662^{\circ} \mathrm{F}$.

Characterization of this fraction is important since it reflects the nature of the chemical species present and the subsequent processing required for their further upgrading. Only fractions that have a boiling point greater than $662^{\circ} \mathrm{F}$ can be detected by the ELSD used for the above analysis. Thus this technique is a useful tool for analysis of the fractions boiling above the diesel fuel range (recall that the diesel fuel range is between $340-640^{\circ} \mathrm{F}$ ).

The raw data peaks appeared in the range of polar compounds, revealing that these higher boiling fractions of the AT oil and MBAP-2 oil consist mainly of polar species. This is expected as the AT samples (and possibly the pyrolysis oils of MBAP-2) are known to contain organic chlorides and bromides and compounds with oxygen and nitrogen functional groups. The exact functional groups responsible for this behavior are as yet unknown. 


\subsection{Coke and Ash Content Evaluation:}

The coke and ash content of the various non-gaseous fractions can be used to determine their applicability in the carbon-materials industry. Coke is defined as the product remaining after heating a carbonaceous material to roughly $1000^{\circ} \mathrm{F}$. It consists mainly of carbon atoms. Cokes make up a large portion ( $60-85 \%)$ of all feedstock that go in to producing valuable, industrially relevant carbon products such as anodes, electrodes and other graphite products. A low ash content is highly desirable for this feedstock as well. Both the coke and ash content analyses employed in this study are ASTM procedures. Coking values of greater than $50 \%$ and an ash level of less than $1 \%$ are usually considered desirable.

\subsubsection{For MBAP - 1:}

Since the THF-Insoluble fraction (the residue) of MBAP-1 consists mainly of high molecularweight carbon species, it was of interest to investigate its potential as a coke precursor. The THFInsoluble fraction from the pyrolysis of the MBAP-1 sample was selected for testing. For comparison, the Hexane-Insoluble and the Hexane-Soluble fractions were also investigated. The samples were weighed, placed in a furnace and heated to $1000^{\circ} \mathrm{F}$ in an inert atmosphere for 6 hours. Upon cooling, they were again weighed and the percentage weight retained was calculated as the coking value. Table 5.9 indicates that none of these product fractions are desirable feedstock for coke production.

\subsubsection{For AT-1 Oil:}

The coking procedure described above was applied to the raw AT-1 oil sample. The AT-1 oil yielded a coking value of $5.3 \%$ and an ash content of $0.2 \%$ (Table 5.9). While the coking value is extremely poor, the ash content is of interest, since an important factor in the classification of diesel fuels is that their ash content must be less than $0.2 \%$. 
Table 5.9 Coke and Ash content evaluation of MBAP-1 and AT-1 Oil

\begin{tabular}{|c|c|c|c|}
\hline Sample & Fraction & $\begin{array}{c}\text { Coking Value } \\
(\%)\end{array}$ & $\begin{array}{c}\text { Ash Content } \\
(\%)\end{array}$ \\
\hline MBAP-1 & THF-Insolubles & 15.8 & - \\
\hline & Hex-Insolubles & 31.6 & - \\
\hline & Hex-Solubles & 4.9 & - \\
\hline & & & 0.2 \\
\hline AT-1 Oil & - & 5.3 & \\
\hline
\end{tabular}




\section{CONCLUSIONS:}

\subsection{Pyrolysis of MBAP-1 and MBAP-2:}

Two samples of MBA Polymer streams were acquired and evaluated in this study. The samples were subjected to pyrolysis and the resultant products were separated to determine the amounts of various product fractions. The major conclusions from the pyrolysis study are as follows:

- For MBAP-1 (fines), the optimum reactor conditions, which maximize the production of the oil fraction, are $425^{\circ} \mathrm{C}$ for $15 \mathrm{~min}$. The oil yield at this condition is found to be $62 \%$

- For MBAP-2 (equal density mixture), the optimum reactor conditions, which maximize the oil fraction, are $425^{\circ} \mathrm{C}$ for $30 \mathrm{~min}$. The oil yield at this condition is found to be $65 \%$.

- The effect on pyrolysis of the reactive gas hydrogen and an iron-based catalyst was studied for both MBAP-1 and 2. While a slight improvement of the oil yield was realized, it is not large enough to warrant the use either of the hydrogen as a reactive gas or of the catalyst.

- A detailed analysis of both the gas-phase yield and composition was completed. In general, the gasyield was low (around 1- $8 \%$ ) but had a significant percentage of hydrocarbons (mostly methane in MBAP-1 and methane and ethene in MBAP-2) and hence had a high heat content.

- The heat content of the product gas fractions ranged from about $14 \mathrm{KJ} / \mathrm{gm}$ to $32 \mathrm{KJ} / \mathrm{gm}$. Also the recoverable heat in most cases was in excess of $10 \mathrm{MMCal} / \mathrm{hr}$. Considerable energy thus can be provided for pyrolysis of the samples by using the available heat of the product gas. Alternatively, the recovered heat can be used to produce steam or heat other process streams.

- A detailed analysis of the oil fraction from the MBAP-2 sample indicated that nearly $70 \%$ it boils in the diesel fuel range. The ASTM D-2887 simulated distillation method was employed in characterizing the MBAP-2 Oil.

- The economics and viability of the pyrolysis process must be determined by comparing its costs with the costs of landfill on the one hand and rising petroleum costs on the other. The credits for eliminating the landfill costs of the waste MBA streams and the associated fuel cost/credits to drive the process may very well offset the higher cost of pyrolysis and make the technique not only feasible but also attractive. This is especially true at the present time when oil prices are significantly on the rise. 
- Various MBAP-1and MBAP-2 sample fractions were subjected to coking conditions to determine their usefulness as feedstock for coke production. None of the samples which were tested showed a high enough coke yield to warrant serious consideration in this regard.

\subsection{Characterization of AT-1 Oil:}

An oil sample from a pilot-plant pyrolysis unit was characterized by a variety of analytical procedures. The main findings from these tests are as follows:

- Atmospheric distillation following the ASTM D-86 procedure indicated that about $65-70 \%$ of the oil was in the diesel fuel range.

- Significant amounts of halogenated species were found in the raw AT-1 oil. A procedure for their removal was developed and implemented. Subsequent distillation of the treated oil showed a decrease in the amount of components in the diesel range (63\%) when compared to the raw untreated oil (80\%). However, the removal of the impurities was extremely important since they severely impaired the distillation of the oil.

- Simulated distillation (ASTM D-2887) was performed on both the diesel cut of the AT-1 oil and the Hexane-Soluble fraction from the MBAP-2 sample. For both samples, nearly $80 \%$ of each was found to be in the diesel fuel range. Thus the optimum pyrolysis conditions for MBAP-2 produce an oil product comparable to that from the AT process. More importantly, the results demonstrate that a significant amount of diesel fuel can be produced by the pyrolysis of the MBA waste polymer streams.

- HPLC analysis of the high-boiling fractions of the AT-1 oil showed it to be composed of mainly polar species. This is an important finding since it indicates the type of upgrading that may be required for this fraction. 


\section{RECOMMENDATIONS}

Based on the results presented, the following recommendations can be made:

- Improvement in the liquefaction product analysis procedure is necessary for better material recovery, more accurate identification of product composition and improved understanding of pyrolysates behavior.

- Further analysis can be conducted based on specific catalysts. Though the catalysts employed indicate no substantial improvement in yield, there are possibilities that certain other catalysts might alter the yield substantially.

- Better analytical techniques/equipment would help better analyze the pyrolysis products. The liquid and gas fractions of both MBAP and AT samples can be better analyzed using GC/MS and other such suitable techniques.

- Oil analysis, ASTM D-2887 and ASTM D-86, must be done immediately after pyrolysis. This might prevent the lighter fractions to recombine.

- Two-stage co-processing of plastics and coal could be investigated ${ }^{20}$. This seems to be more beneficial than coal liquefaction and plastics pyrolysis separately.

- An economic feasibility study of the WVU process should be conducted. The current research results indicate a very promising economic potential for the pyrolysis of electronic plastics ${ }^{21}$. But, the economics and viability of the pyrolysis process must be determined by comparing its costs with the costs of landfill on the one hand and rising petroleum costs on the other. 


\section{REFERENCES:}

1. E. Bruce Nauman, Plastics Recycling: What makes sense. Unpublished material.

2. L.D. Busselle, R.E. Allred, T.A. Moore, J.K. Lifke, W.A. Averill, Tertiary Recycling Process for Scrap Electronics, Report from Adherent Technologies Inc., New Mexico to Materials and Manufacuring Directorate, Wright Laboratory, Wright-Patterson AFB, Ohio. October 1997.

3. M.W. Meszaros, J.C. Randall, Reversing polymerization recreates valuable feedstock and fuels, Modern Chemical Plastics, pp. A-53 - A-55, Mid-November1994.

4. John McElroy, Tertiary Recycling, Automotive Industries, pp. 5, April 1993.

5. Peter Mapleston, Chemical Recycling may be an option to meet mandated reclaim levels, Modern Plastics, pp. 58 - 61, Nov 1993.

6. J.C.Randall, Breaking down polymers into their building blocks can make economic and technical sense, Modern Plastics, pp. 35-38, Mid-Nov,1993.

7. E.A. Williams, P.T.Williams, The pyrolysis of individual plastics and a plastic mixture in a fixed bed reactor, J.Chem Tech. Biotechnology, Vol. 70, pp. 9-20, 1997.

8. E.A. Williams, P.T.Williams, Analysis and products derived from the fast pyrolysis of plastic waste, $\mathrm{J}$. of Analytical and Applied Pyrolysis, pp. 347-363, 1997.

9. MBAPolymers Monthly Report, Dec 1998.

10. H.Bockhorn, J.Hentschel, A. Hornung, U.Hornung, Environmental engineering: stepwise pyrolysis of plastics wastes, Chemical Engr. Science, J. 54, pp. 3043-3051, 1999.

11. Rangarajan, P., Grulke, E., and Bhattacharyya, D., Thermal Degradation hydrogenation of Commodity Polymers and Characterization of their Liquefaction Products. Fuel Process Tech., 49, 75-90,1996.

12. H. Shaikh, Effect of Process Parameters upon Coal Liquefaction and Coal-HDPE Co-Liquefaction, MSChE Thesis, Department of Chemical Engineering, WVU, Morgantown, WV., 1998

13. E. Bruce Nauman, Rensselaer's Selective Dissolution Process for Plastics Recycling, Unpublished material.

14. S. Lovett, F. Berruti, L.A. Behie, Ultrapyrolytic upgrading of plastic wastes and plastics/heavy oil mixtures to valuable light gas products, Ind. Eng. Chem., 36, pp. 4436-4444, 1997. 
15. G. De la Puente, J.M. Arandes, U.A. Sedran, Recycled plastics in FCC feedstocks: specific contributions., Ind. Eng. Chem., vol. 36, pp. 4530-4534, 1997.

16. ASTM D-86, Vol. 05.01.

17. Introduction to Process Combustion Corporation, PCC Brochure, 1999.

18. The Engineering Product Line for Industrial Air Pollution Control, GEOENERGY Intl Corp.

19. Perry's Chemical Engineer's Handbook, Sixth Edition, 3-155,156.

20. P.K. Ramadoss, A.R. Tarrer, Modeling of Two-Stage Coal Coprocessing Process, Energy and Fuels, Vol. 11, pg. 194-201, 1997

21. P.S. Bhandare, B.K. Lee, K. Krishnan, Study of Pyrolysis and Incineration of disposable plastics using combined TG/FT-IR technique, J. of Thermal Analysis, Vol. 49, pg. 361-366, 1997

22. www.psrc.usm.edu 


\section{APPENDIX A}

A combustion model was developed to study the fuel content of and heat recovery from the product gas fractions. The model assumes feed at $38^{\circ} \mathrm{C}$ and a combustion temperature of $800^{\circ} \mathrm{C}$. Combustion reactions for all the product components (methane, ethane, propane etc.) were built into the model. The Peng-Robinson equation of state was used for calculations. A conversion of .999 was assumed. In reality due to insufficient mixing, the combustion chamber is always fed with $4-10 \%$ excess air.

The results for each of the product gas samples analyzed are presented here.

MBAP-1 $\left(375^{\circ}, 30 \mathrm{~min}\right)$ :

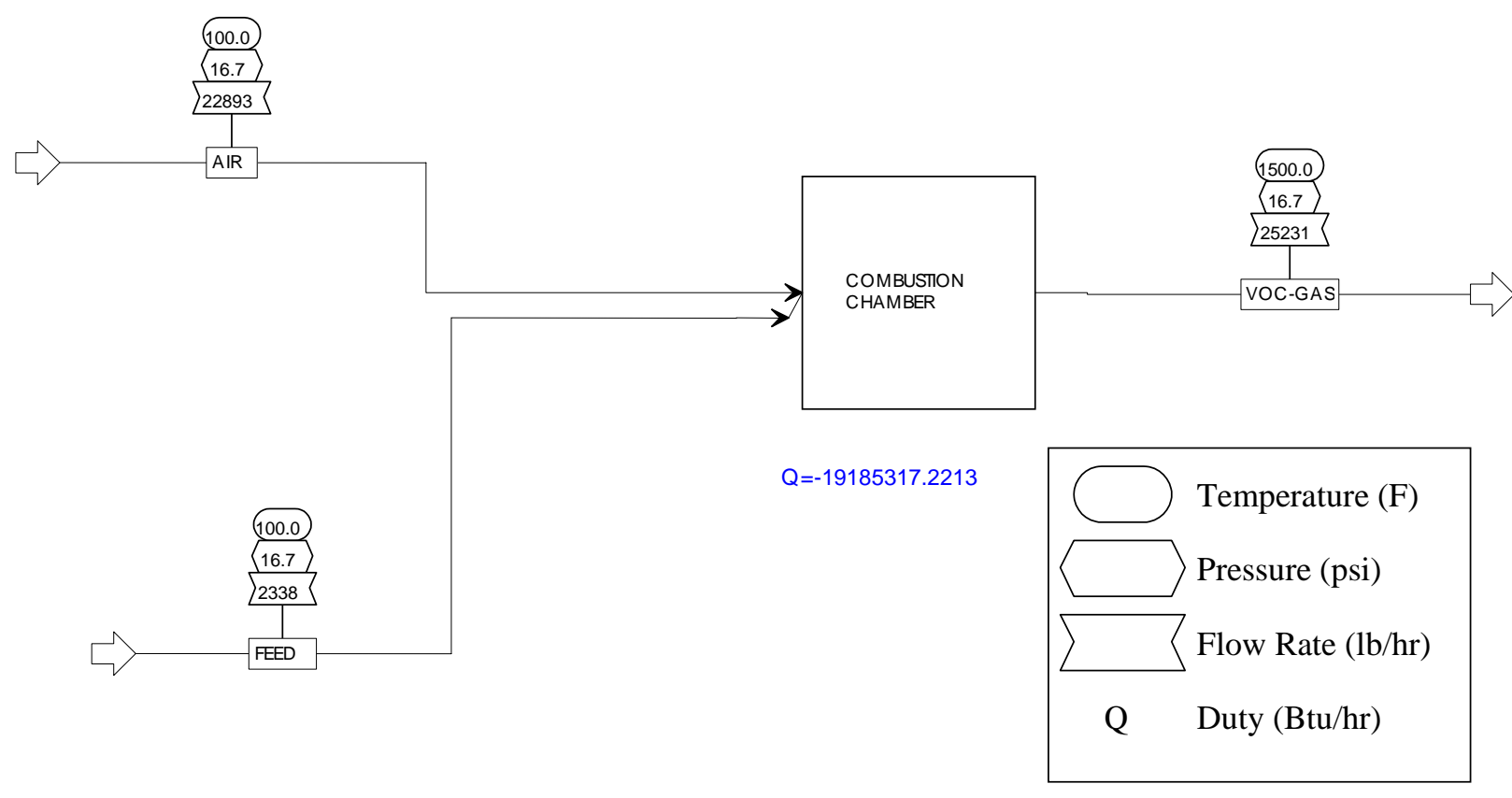


Table A1: ASPEN model results for product gas from pyrolysis of MBAP-1 at $375^{\circ} \mathrm{C}, 30 \mathrm{~min}$

\begin{tabular}{|c|c|c|c|}
\hline & AIR & FEED & VOC-GAS \\
\hline \multicolumn{4}{|l|}{ Mole Flow $\mathrm{lbmol} / \mathrm{hr}$} \\
\hline $\mathrm{CO}$ & 0 & 0 & 0 \\
\hline $\mathrm{O} 2$ & 166.635 & 0 & 0.05564339 \\
\hline $\mathrm{N} 2$ & 626.865 & 0 & 626.865 \\
\hline $\mathrm{CO} 2$ & 0 & 19.4963382 & 120.613537 \\
\hline $\mathrm{H} 2 \mathrm{O}$ & 0 & 0 & 130.924316 \\
\hline $\mathrm{C} 4 \mathrm{H} 10$ & 0 & 20.7958134 & 0.02079581 \\
\hline $\mathrm{C} 3 \mathrm{H} 8$ & 0 & 2.65095324 & 0.00265095 \\
\hline $\mathrm{C} 2 \mathrm{H} 6$ & 0 & 1.3217736 & 0.00132177 \\
\hline $\mathrm{CH} 4$ & 0 & 4.80918223 & 0.00480918 \\
\hline $\mathrm{HE}$ & 0 & 0 & 0 \\
\hline $\mathrm{C} 5 \mathrm{H} 12$ & 0 & 0.25923184 & $2.59 \mathrm{E}-04$ \\
\hline $\mathrm{C} 6 \mathrm{H} 14$ & 0 & 0 & 0 \\
\hline $\mathrm{C} 2 \mathrm{H} 4$ & 0 & 0.66670742 & $6.67 \mathrm{E}-04$ \\
\hline \multicolumn{4}{|l|}{\begin{tabular}{|ll} 
Mass Flow $\mathrm{lb} / \mathrm{hr}$ \\
\end{tabular}} \\
\hline $\mathrm{CO}$ & 0 & 0 & 0 \\
\hline $\mathrm{O} 2$ & 5332.12004 & 0 & 1.78052178 \\
\hline $\mathrm{N} 2$ & 17560.6701 & 0 & 17560.6701 \\
\hline $\mathrm{CO} 2$ & 0 & 858.029945 & 5308.17763 \\
\hline $\mathrm{H} 2 \mathrm{O}$ & 0 & 0 & 2358.63821 \\
\hline $\mathrm{C} 4 \mathrm{H} 10$ & 0 & 1208.72338 & 1.20872338 \\
\hline $\mathrm{C} 3 \mathrm{H} 8$ & 0 & 116.897813 & 0.11689781 \\
\hline $\mathrm{C} 2 \mathrm{H} 6$ & 0 & 39.7452563 & 0.03974525 \\
\hline $\mathrm{CH} 4$ & 0 & 77.1525564 & 0.07715255 \\
\hline $\mathrm{HE}$ & 0 & 0 & 0 \\
\hline $\mathrm{C} 5 \mathrm{H} 12$ & 0 & 18.70365 & 0.01870365 \\
\hline $\mathrm{C} 6 \mathrm{H} 14$ & 0 & 0 & 0 \\
\hline $\mathrm{C} 2 \mathrm{H} 4$ & 0 & 18.70365 & 0.01870365 \\
\hline Total Flow lbmol/hr & 793.5 & 50 & 878.489 \\
\hline Total Flow lb/hr & 22892.7902 & 2337.95625 & 25230.7464 \\
\hline Total Flow cuft/hr & 285312.794 & 17763.6612 & 1106830.35 \\
\hline Temperature F & 100 & 100 & 1500 \\
\hline Pressure psi & 16.6959488 & 16.6959488 & 16.6959488 \\
\hline Vapor Frac & 1 & 1 & 1 \\
\hline Liquid Frac & 0 & 0 & 0 \\
\hline Solid Frac & 0 & 0 & 0 \\
\hline Enthalpy $\quad$ Btu/lbmol & 156.65923 & -94581.556 & -27080.689 \\
\hline Enthalpy Btu/lb & 5.43005454 & -2022.7401 & -942.90064 \\
\hline Enthalpy Btu/hr & 124309.099 & -4729077.8 & -23790087 \\
\hline Entropy $\quad$ Btu/lbmol-R & 1.05415323 & -40.247894 & 10.2171856 \\
\hline Entropy $\quad$ Btu/lb-R & 0.0365386 & -0.8607495 & 0.35574394 \\
\hline Density lbmol/cuft & 0.00278115 & 0.00281473 & 0.00079369 \\
\hline 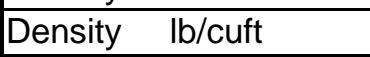 & 0.08023751 & 0.13161455 & 0.02279549 \\
\hline Average MW & 28.8503972 & 46.7591251 & 28.7206174 \\
\hline Liq Vol 60F cuft/hr & 680.754486 & 60.9431413 & 679.218573 \\
\hline
\end{tabular}


Table A2: Heat content calculation:

*: $\Delta \mathrm{Hc}$ to form $\mathrm{H} 2 \mathrm{O}$ (liq) and $\mathrm{CO} 2$ (gas) at $25^{\circ} \mathrm{C}$

\begin{tabular}{|l|r|r|r|}
\hline & \multicolumn{1}{|c|}{ Hc at $\mathbf{2 5}^{\circ} \mathbf{C}^{*}$ (B.t.u/lb) } & Mass Fraction & Heat Content (B.t.u/lb) \\
\hline CarbonDioxide & 0 & 0.367000001 & 0 \\
\hline Methane & 23861 & 0.033 & 787.4130015 \\
\hline Ethane & 22304 & 0.017 & 379.1680005 \\
\hline Ethene & 21625 & 0.008 & 173 \\
\hline Propane & 21646 & 0.05 & 1082.300005 \\
\hline Butane & 21293 & 0.516999999 & 11008.48099 \\
\hline Pentane & 21072 & 0.008 & 168.576 \\
\hline Hexane & 20928 & 0 & 0 \\
\hline Mixture & & 1 & 13598.938 \\
\hline
\end{tabular}

\section{MABP-1 $\left(400^{\circ} \mathrm{C}, 45 \mathrm{~min}\right):$}

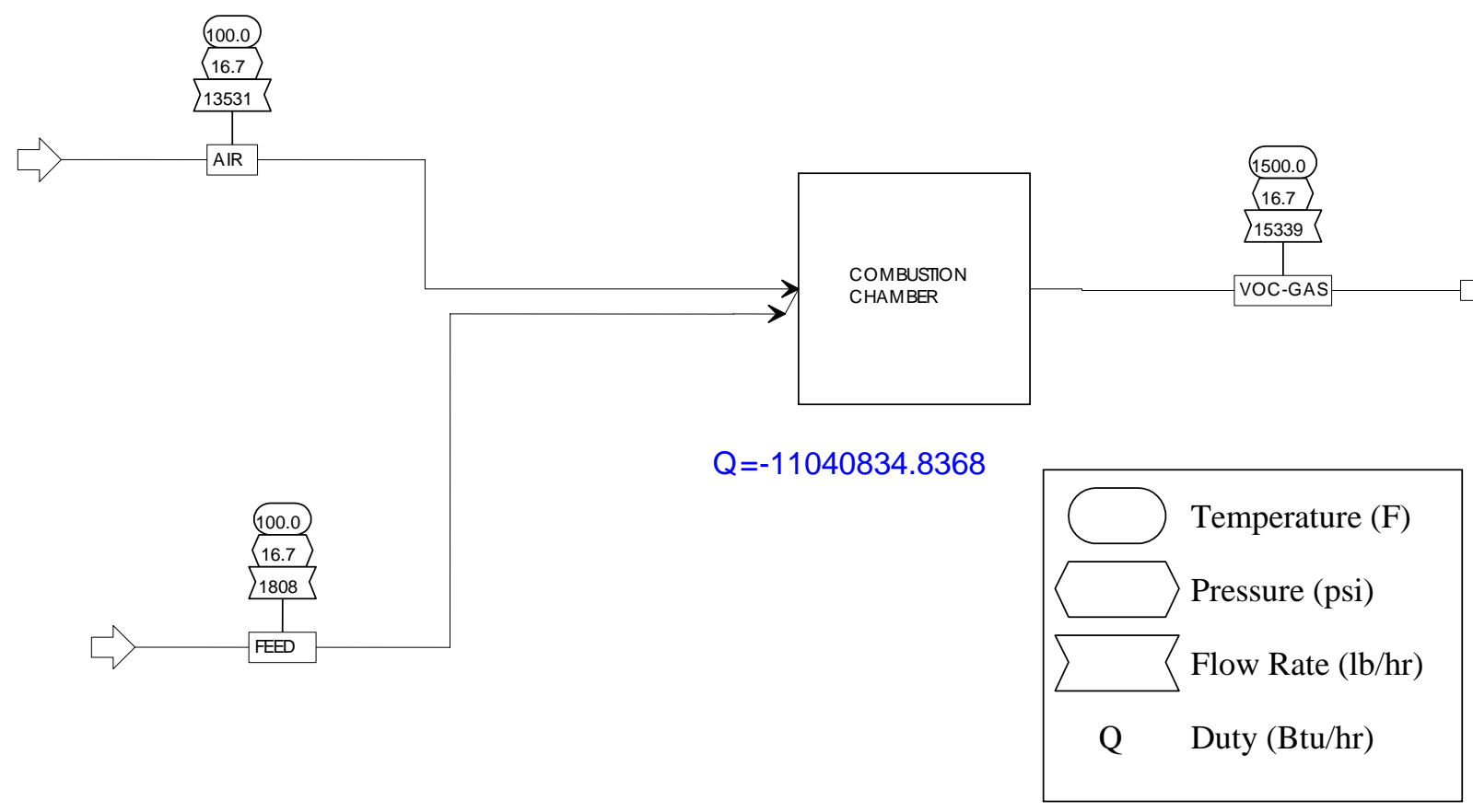


Table A3: ASPEN model results for product gas from pyrolysis of MBAP- 1 at $400^{\circ} \mathrm{C}, 45 \mathrm{~min}$

\begin{tabular}{|c|c|c|c|}
\hline & AIR & FEED & VOC-GAS \\
\hline \multicolumn{4}{|l|}{ Mole Flow $\mathrm{lbmol} / \mathrm{hr}$} \\
\hline $\mathrm{CO}$ & 0 & 0 & 0 \\
\hline $\mathrm{O} 2$ & 98.49 & 0 & 0.04999999 \\
\hline $\mathrm{N} 2$ & 370.51 & 0 & 370.51 \\
\hline $\mathrm{CO} 2$ & 0 & 21.8259793 & 78.1779988 \\
\hline $\mathrm{H} 2 \mathrm{O}$ & 0 & 0 & 84.1759611 \\
\hline $\mathrm{C} 4 \mathrm{H} 10$ & 0 & 0 & 0 \\
\hline $\mathrm{C} 3 \mathrm{H} 8$ & 0 & 0 & 0 \\
\hline $\mathrm{C} 2 \mathrm{H} 6$ & 0 & 4.38311251 & 0.00438311 \\
\hline $\mathrm{CH} 4$ & 0 & 17.6142116 & 0.01761421 \\
\hline $\mathrm{HE}$ & 0 & 0 & 0 \\
\hline $\mathrm{C} 5 \mathrm{H} 12$ & 0 & 5.74327896 & 0.00574327 \\
\hline $\mathrm{C} 6 \mathrm{H} 14$ & 0 & 0.11119033 & 1.11E-04 \\
\hline $\mathrm{C} 2 \mathrm{H} 4$ & 0 & 0.32222724 & 0.00032222 \\
\hline \multicolumn{4}{|l|}{ Mass Flow $\mathrm{lb} / \mathrm{hr}$} \\
\hline $\mathrm{CO}$ & 0 & 0 & 0 \\
\hline $\mathrm{O} 2$ & 3151.56181 & 0 & 1.59993978 \\
\hline N2 & 10379.2745 & 0 & 10379.2745 \\
\hline $\mathrm{CO} 2$ & 0 & 960.556985 & 3440.59809 \\
\hline $\mathrm{H} 2 \mathrm{O}$ & 0 & 0 & 1516.45351 \\
\hline $\mathrm{C} 4 \mathrm{H} 10$ & 0 & 0 & 0 \\
\hline $\mathrm{C} 3 \mathrm{H} 8$ & 0 & 0 & 0 \\
\hline $\mathrm{C} 2 \mathrm{H} 6$ & 0 & 131.798615 & 0.13179862 \\
\hline $\mathrm{CH} 4$ & 0 & 282.58057 & 0.28258057 \\
\hline $\mathrm{HE}$ & 0 & 0 & 0 \\
\hline $\mathrm{C} 5 \mathrm{H} 12$ & 0 & 414.379185 & 0.41437918 \\
\hline $\mathrm{C} 6 \mathrm{H} 14$ & 0 & 9.58206667 & 0.00958206 \\
\hline $\mathrm{C} 2 \mathrm{H} 4$ & 0 & 9.03968554 & 0.00903968 \\
\hline Total Flow Ibmol/hr & 469 & 50 & 532.942134 \\
\hline Total Flow lb/hr & 13530.8363 & 1807.93711 & 15338.7734 \\
\hline Total Flow cuft/hr & 168634.783 & 17873.7865 & 671465.215 \\
\hline Temperature F & 100 & 100 & 1500 \\
\hline Pressure psi & 16.6959488 & 16.6959488 & 16.6959488 \\
\hline Vapor Frac & 1 & 1 & 1 \\
\hline Liquid Frac & 0 & 0 & 0 \\
\hline Solid Frac & 0 & 0 & 0 \\
\hline \begin{tabular}{|ll} 
Enthalpy & Btu/lbmol
\end{tabular} & 156.65923 & -95312.574 & -29521.012 \\
\hline Enthalpy Btu/lb & 5.43005454 & -2635.9483 & -1025.7007 \\
\hline Enthalpy $\mathrm{Btu} / \mathrm{hr}$ & 73473.1787 & -4765628.7 & -15732991 \\
\hline Entropy $\quad$ Btu/lbmol-R & 1.05415323 & -20.535677 & 10.251008 \\
\hline Entropy $\quad$ Btu/lb-R & 0.0365386 & -0.5679312 & 0.3561689 \\
\hline Density lbmol/cuft & 0.00278115 & 0.00279739 & 0.0007937 \\
\hline Density $\quad \mathrm{lb} /$ cuft & 0.08023751 & 0.1011502 & 0.02284373 \\
\hline Average MW & 28.8503972 & 36.1587422 & 28.7813112 \\
\hline Liq Vol 60F cuft/hr & 402.361505 & 51.0024445 & 409.348805 \\
\hline
\end{tabular}


Table A4: Heat content calculation

\begin{tabular}{|l|r|r|r|}
\hline & Hc at $\mathbf{2 5}^{\circ} \mathbf{C}^{*}$ (B.t.u/lb) & Mass Fraction & Heat Content (B.t.u/lb) \\
\hline CarbonDioxide & 0 & 0.531299999 & 0 \\
\hline Methane & 23861 & 0.1563 & 3729.474296 \\
\hline Ethane & 22304 & 0.0729 & 1625.961596 \\
\hline Ethene & 21625 & 0.005 & 108.1249999 \\
\hline Propane & 21646 & 0 & 0 \\
\hline Butane & 21293 & 0 & 0 \\
\hline Pentane & 21072 & 0.2292 & 4829.702393 \\
\hline Hexane & 20928 & 0.0053 & 110.9183998 \\
\hline Mixture & & 0.999999998 & 10404.18168 \\
\hline
\end{tabular}

*: $\mathrm{Hc}$ to form $\mathrm{H} 2 \mathrm{O}$ (liq) and $\mathrm{CO} 2$ (gas) at $25^{\circ} \mathrm{C}$

\section{MBAP-1 $\left(425^{\circ} \mathrm{C}, 15 \mathrm{~min}\right)$}

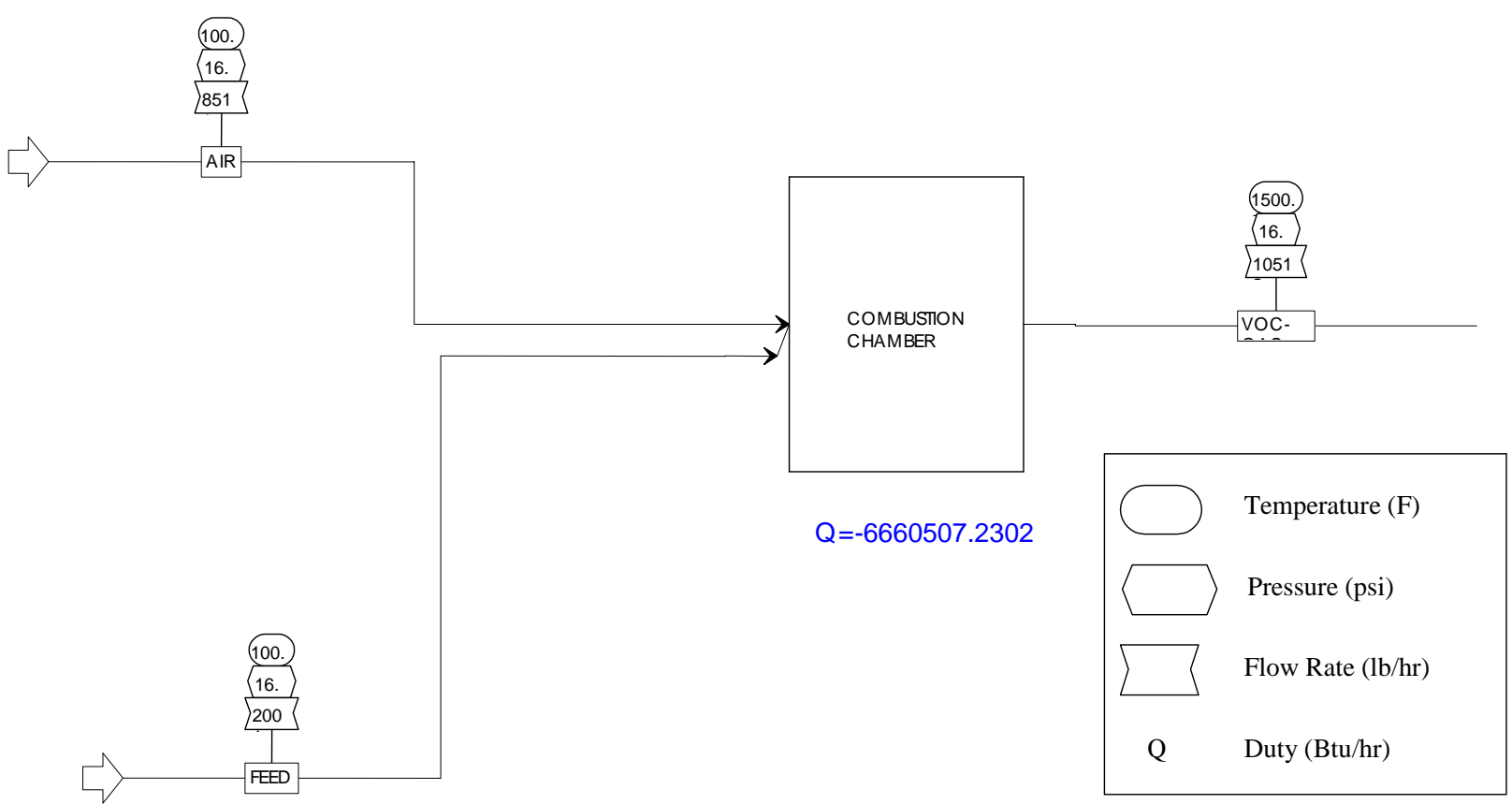


Table A5: ASPEN model results for product gas from pyrolysis of MBAP- 1 at $425^{\circ} \mathrm{C}, 15 \mathrm{~min}$

\begin{tabular}{|c|c|c|c|}
\hline & AIR & FEED & VOC-GAS \\
\hline \multicolumn{4}{|l|}{ Mole Flow $\mathrm{lbmol} / \mathrm{hr}$} \\
\hline $\mathrm{CO}$ & 0 & 0 & 0 \\
\hline $\mathrm{O} 2$ & 61.95 & 0 & 0.00410618 \\
\hline $\mathrm{N} 2$ & 233.05 & 0 & 233.05 \\
\hline $\mathrm{CO} 2$ & 0 & 33.2868959 & 69.1374724 \\
\hline $\mathrm{H} 2 \mathrm{O}$ & 0 & 0 & 52.1906346 \\
\hline $\mathrm{C} 4 \mathrm{H} 10$ & 0 & 1.41170664 & 0.0014117 \\
\hline $\mathrm{C} 3 \mathrm{H} 8$ & 0 & 0 & 0 \\
\hline $\mathrm{C} 2 \mathrm{H} 6$ & 0 & 4.79198974 & 0.00479198 \\
\hline $\mathrm{CH} 4$ & 0 & 7.734357 & 0.00773435 \\
\hline $\mathrm{HE}$ & 0 & 0 & 0 \\
\hline $\mathrm{C} 5 \mathrm{H} 12$ & 0 & 2.30224577 & 0.00230224 \\
\hline $\mathrm{C} 6 \mathrm{H} 14$ & 0 & 0.1161153 & 1.16E-04 \\
\hline $\mathrm{C} 2 \mathrm{H} 4$ & 0 & 0.35668967 & 0.00035668 \\
\hline \multicolumn{4}{|l|}{\begin{tabular}{|ll} 
Mass Flow $\mathrm{lb} / \mathrm{hr}$ \\
\end{tabular}} \\
\hline $\mathrm{CO}$ & 0 & 0 & 0 \\
\hline $\mathrm{O} 2$ & 1982.32566 & 0 & 0.13139284 \\
\hline N2 & 6528.54151 & 0 & 6528.54151 \\
\hline $\mathrm{CO} 2$ & 0 & 1464.94963 & 3042.72633 \\
\hline $\mathrm{H} 2 \mathrm{O}$ & 0 & 0 & 940.228895 \\
\hline $\mathrm{C} 4 \mathrm{H} 10$ & 0 & 82.0531897 & 0.08205319 \\
\hline $\mathrm{C} 3 \mathrm{H} 8$ & 0 & 0 & 0 \\
\hline $\mathrm{C} 2 \mathrm{H} 6$ & 0 & 144.093406 & 0.14409341 \\
\hline $\mathrm{CH} 4$ & 0 & 124.080433 & 0.12408043 \\
\hline $\mathrm{HE}$ & 0 & 0 & 0 \\
\hline $\mathrm{C} 5 \mathrm{H} 12$ & 0 & 166.107677 & 0.16610768 \\
\hline $\mathrm{C} 6 \mathrm{H} 14$ & 0 & 10.0064865 & 0.01000648 \\
\hline $\mathrm{C} 2 \mathrm{H} 4$ & 0 & 10.0064865 & 0.01000648 \\
\hline Total Flow lbmol/hr & 295 & 50 & 354.398926 \\
\hline Total Flow lb/hr & 8510.86717 & 2001.29731 & 10512.1645 \\
\hline Total Flow cuft/hr & 106070.919 & 17876.5415 & 446515.359 \\
\hline Temperature F & 100 & 100 & 1500 \\
\hline Pressure psi & 16.6959488 & 16.6959488 & 16.6959488 \\
\hline Vapor Frac & 1 & 1 & 1 \\
\hline Liquid Frac & 0 & 0 & 0 \\
\hline Solid Frac & 0 & 0 & 0 \\
\hline Enthalpy $\quad$ Btu/lbmol & 156.65923 & -125250.99 & -36334.316 \\
\hline Enthalpy $\quad$ Btu/lb & 5.43005454 & -3129.245 & -1224.9468 \\
\hline Enthalpy Btu/hr & 46214.4727 & -6262549.5 & -12876843 \\
\hline Entropy $\quad$ Btu/lbmol-R & 1.05415323 & -12.15394 & 10.7166213 \\
\hline Entropy $\quad$ Btu/lb-R & 0.0365386 & -0.3036515 & 0.36129182 \\
\hline Density $\quad$ lbmol/cuft & 0.00278115 & 0.00279696 & 0.00079369 \\
\hline Density $\mathrm{lb} /$ cuft & 0.08023751 & 0.11195104 & 0.02354267 \\
\hline Average MW & 28.8503972 & 40.0259462 & 29.6619535 \\
\hline Liq Vol 60F cuft/hr & 253.084529 & 48.9049493 & 274.364678 \\
\hline
\end{tabular}


Table A6: Heat content calculation

\begin{tabular}{|l|r|r|r|}
\hline & Hc at 25C* (B.t.u/lb) & Mass Fraction & Heat Content (B.t.u/lb) \\
\hline CarbonDioxide & 0 & 0.732 & 0 \\
\hline Methane & 23861 & 0.062 & 1479.381997 \\
\hline Ethane & 22304 & 0.072 & 1605.887996 \\
\hline Ethene & 21625 & 0.005 & 108.1249995 \\
\hline Propane & 21646 & 0 & 0 \\
\hline Butane & 21293 & 0.041 & 873.0129999 \\
\hline Pentane & 21072 & 0.083 & 1748.976003 \\
\hline Hexane & 20928 & 0.005 & 104.6399995 \\
\hline Mixture & & 0.999999999 & 5920.023995 \\
\hline
\end{tabular}

*: $\mathrm{Hc}$ to form $\mathrm{H} 2 \mathrm{O}$ (liq) and $\mathrm{CO} 2$ (gas) at $25^{\circ} \mathrm{C}$

MBAP-2 $\left(425^{\circ} \mathrm{C}, 15 \mathrm{~min}\right)$

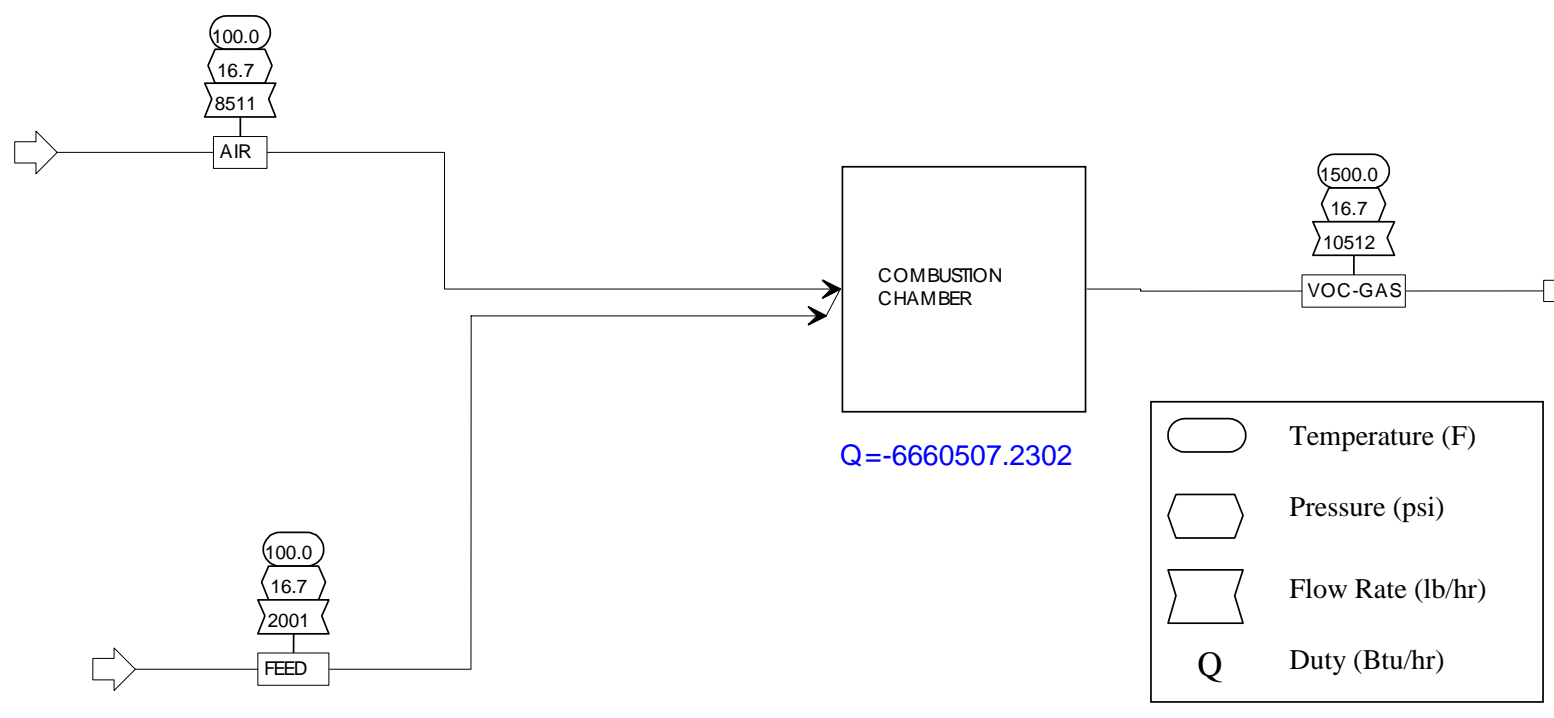


Table A7: ASPEN model results for product gas from pyrolysis of MBAP-2 at $425^{\circ} \mathrm{C}, 15 \mathrm{~min}$

\begin{tabular}{|c|c|c|c|}
\hline & $\overline{A I R}$ & FEED & VOC-GAS \\
\hline \multicolumn{4}{|l|}{ Mole Flow $\mathrm{lbmol} / \mathrm{hr}$} \\
\hline $\mathrm{CO}$ & 0 & 0 & 0 \\
\hline $\mathrm{O} 2$ & 155.19 & 0 & 0.09827419 \\
\hline N2 & 583.81 & 0 & 583.81 \\
\hline $\mathrm{CO} 2$ & 0 & 12.3647213 & 106.95231 \\
\hline $\mathrm{H} 2 \mathrm{O}$ & 0 & 0 & 121.008275 \\
\hline $\mathrm{C} 4 \mathrm{H} 10$ & 0 & 3.96224875 & 0.00396224 \\
\hline $\mathrm{C} 3 \mathrm{H} 8$ & 0 & 7.5937594 & 0.00759375 \\
\hline $\mathrm{C} 2 \mathrm{H} 6$ & 0 & 10.4444915 & 0.01044449 \\
\hline $\mathrm{CH} 4$ & 0 & 2.60460707 & 0.0026046 \\
\hline $\mathrm{HE}$ & 0 & 0 & 0 \\
\hline $\mathrm{C} 5 \mathrm{H} 12$ & 0 & 0.87004386 & 0.00087004 \\
\hline $\mathrm{C} 6 \mathrm{H} 14$ & 0 & 0.97198295 & 0.00097198 \\
\hline $\mathrm{C} 2 \mathrm{H} 4$ & 0 & 11.1881452 & 0.01118814 \\
\hline \multicolumn{4}{|l|}{\begin{tabular}{|ll} 
Mass Flow $\mathrm{lb} / \mathrm{hr}$ \\
\end{tabular}} \\
\hline $\mathrm{CO}$ & 0 & 0 & 0 \\
\hline $\mathrm{O} 2$ & 4965.89377 & 0 & 3.1446563 \\
\hline N2 & 16354.5498 & 0 & 16354.5498 \\
\hline $\mathrm{CO} 2$ & 0 & 544.16891 & 4706.94976 \\
\hline $\mathrm{H} 2 \mathrm{O}$ & 0 & 0 & 2179.99795 \\
\hline $\mathrm{C} 4 \mathrm{H} 10$ & 0 & 230.299369 & 0.23029937 \\
\hline $\mathrm{C} 3 \mathrm{H} 8$ & 0 & 334.858363 & 0.33485836 \\
\hline $\mathrm{C} 2 \mathrm{H} 6$ & 0 & 314.062099 & 0.3140621 \\
\hline $\mathrm{CH} 4$ & 0 & 41.7850861 & 0.04178508 \\
\hline $\mathrm{HE}$ & 0 & 0 & 0 \\
\hline $\mathrm{C} 5 \mathrm{H} 12$ & 0 & 62.7739082 & 0.0627739 \\
\hline $\mathrm{C} 6 \mathrm{H} 14$ & 0 & 83.7627303 & 0.08376273 \\
\hline $\mathrm{C} 2 \mathrm{H} 4$ & 0 & 313.869541 & 0.31386954 \\
\hline Total Flow lbmol/hr & 739 & 50 & 811.906494 \\
\hline Total Flow $\mathrm{lb} / \mathrm{hr}$ & 21320.4435 & 1925.58001 & 23246.0235 \\
\hline Total Flow cuft/hr & 265716.641 & 17816.4134 & 1022941.58 \\
\hline Temperature F & 100 & 100 & 1500 \\
\hline Pressure psi & 16.6959488 & 16.6959488 & 16.6959488 \\
\hline Vapor Frac & 1 & 1 & 1 \\
\hline Liquid Frac & 0 & 0 & 0 \\
\hline Solid Frac & 0 & 0 & 0 \\
\hline Enthalpy $\quad$ Btu/lbmol & 156.65923 & -59317.116 & -26172.431 \\
\hline Enthalpy $\quad$ Btu/lb & 5.43005454 & -1540.2402 & -914.11618 \\
\hline Enthalpy Btu/hr & 115771.171 & -2965855.8 & -21249566 \\
\hline Entropy $\quad$ Btu/lbmol-R & 1.05415323 & -29.747552 & 10.1687772 \\
\hline Entropy $\quad$ Btu/lb-R & 0.0365386 & -0.772431 & 0.35516166 \\
\hline \begin{tabular}{|ll} 
Density & Ibmol/cuft \\
\end{tabular} & 0.00278115 & 0.0028064 & 0.00079369 \\
\hline Density $\mathrm{lb} /$ cuft & 0.08023751 & 0.108079 & 0.02272468 \\
\hline Average MW & 28.8503972 & 38.5116001 & 28.6314049 \\
\hline Liq Vol 60F cuft/hr & 633.998192 & 62.7500875 & 627.738389 \\
\hline
\end{tabular}


Table A8: Heat content calculation

\begin{tabular}{|l|r|r|r|}
\hline & Hc at 25C* (B.t.u/lb) & Mass Fraction & Heat Content (B.t.u/lb) \\
\hline CarbonDioxide & 0 & 0.2826 & 0 \\
\hline Methane & 23861 & 0.0217 & 517.7836986 \\
\hline Ethane & 22304 & 0.1631 & 3637.782393 \\
\hline Ethene & 21625 & 0.163 & 3524.874993 \\
\hline Propane & 21646 & 0.1739 & 3764.239392 \\
\hline Butane & 21293 & 0.1196 & 2546.642798 \\
\hline Pentane & 21072 & 0.0326 & 686.9471986 \\
\hline Hexane & 20928 & 0.0435 & 910.3679985 \\
\hline Mixture & & 0.999999998 & 15588.63847 \\
\hline
\end{tabular}

*: $\mathrm{Hc}$ to form $\mathrm{H} 2 \mathrm{O}$ (liq) and $\mathrm{CO} 2$ (gas) at $25^{\circ} \mathrm{C}$

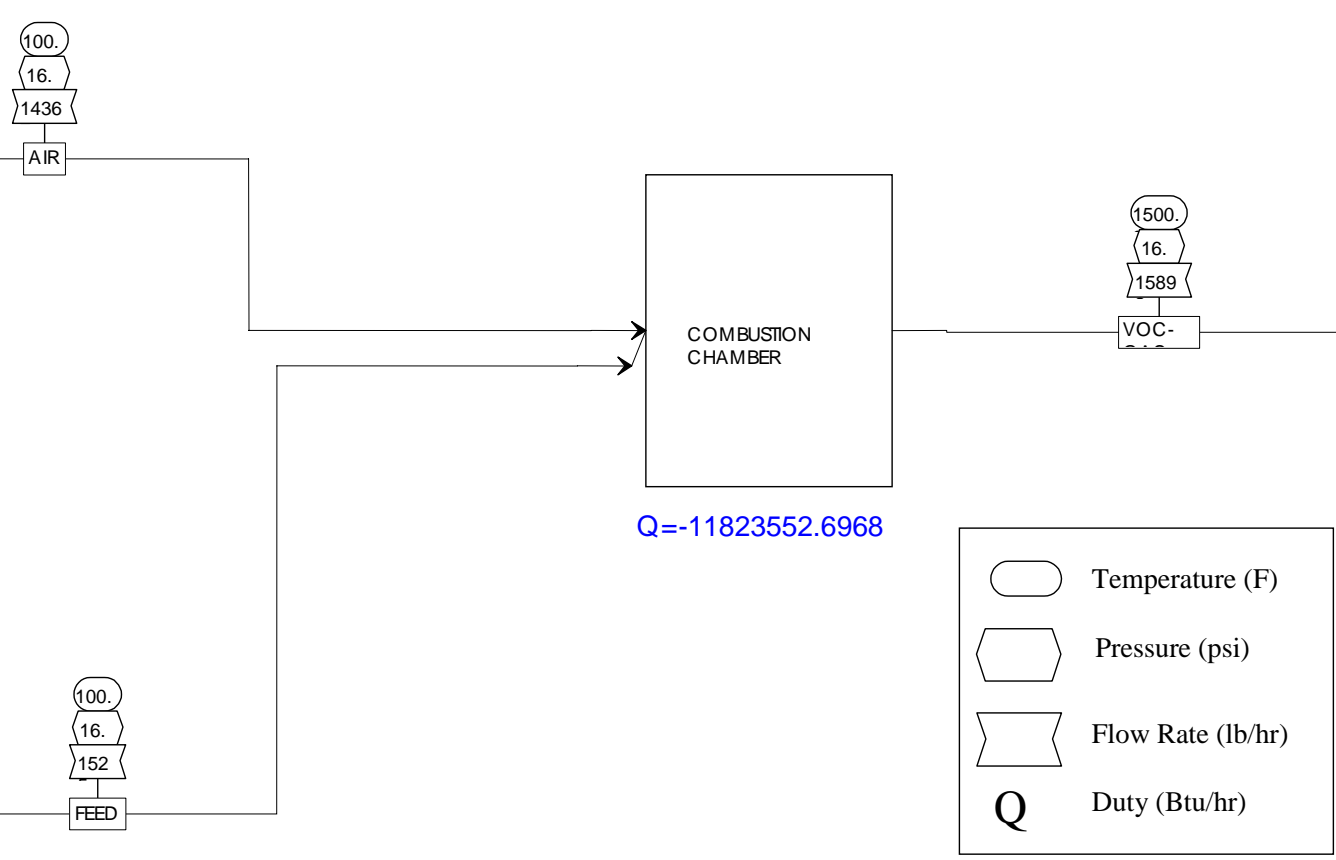


Table A9: ASPEN model results for product gas from pyrolysis of MBAP-2 at $425^{\circ} \mathrm{C}, 30 \mathrm{~min}$

\begin{tabular}{|c|c|c|c|}
\hline & $\overline{A I R}$ & FEED & VOC-GAS \\
\hline \multicolumn{4}{|l|}{ Mole Flow $\mathrm{lbmol} / \mathrm{hr}$} \\
\hline $\mathrm{CO}$ & 0 & 0 & 0 \\
\hline $\mathrm{O} 2$ & 104.58 & 0 & 0.09830572 \\
\hline N2 & 393.42 & 0 & 393.42 \\
\hline $\mathrm{CO} 2$ & 0 & 14.5340418 & 72.5593316 \\
\hline $\mathrm{H} 2 \mathrm{O}$ & 0 & 0 & 92.912809 \\
\hline $\mathrm{C} 4 \mathrm{H} 10$ & 0 & 2.26393325 & 0.00226393 \\
\hline $\mathrm{C} 3 \mathrm{H} 8$ & 0 & 4.09403187 & 0.00409403 \\
\hline $\mathrm{C} 2 \mathrm{H} 6$ & 0 & 7.09403489 & 0.00709403 \\
\hline $\mathrm{CH} 4$ & 0 & 21.4704417 & 0.02147044 \\
\hline $\mathrm{HE}$ & 0 & 0 & 0 \\
\hline $\mathrm{C} 5 \mathrm{H} 12$ & 0 & 0 & 0 \\
\hline $\mathrm{C} 6 \mathrm{H} 14$ & 0 & 0 & 0 \\
\hline $\mathrm{C} 2 \mathrm{H} 4$ & 0 & 0.54351653 & 0.00054351 \\
\hline \multicolumn{4}{|l|}{ Mass Flow $\mathrm{lb} / \mathrm{hr}$} \\
\hline $\mathrm{CO}$ & 0 & 0 & 0 \\
\hline $\mathrm{O} 2$ & 3346.4345 & 0 & 3.14566512 \\
\hline N2 & 11021.0633 & 0 & 11021.0633 \\
\hline $\mathrm{CO} 2$ & 0 & 639.640272 & 3193.32167 \\
\hline $\mathrm{H} 2 \mathrm{O}$ & 0 & 0 & 1673.85027 \\
\hline $\mathrm{C} 4 \mathrm{H} 10$ & 0 & 131.587498 & 0.1315875 \\
\hline $\mathrm{C} 3 \mathrm{H} 8$ & 0 & 180.532558 & 0.18053256 \\
\hline $\mathrm{C} 2 \mathrm{H} 6$ & 0 & 213.315075 & 0.21331507 \\
\hline $\mathrm{CH} 4$ & 0 & 344.445143 & 0.34444514 \\
\hline $\mathrm{HE}$ & 0 & 0 & 0 \\
\hline $\mathrm{C} 5 \mathrm{H} 12$ & 0 & 0 & 0 \\
\hline $\mathrm{C} 6 \mathrm{H} 14$ & 0 & 0 & 0 \\
\hline $\mathrm{C} 2 \mathrm{H} 4$ & 0 & 15.2476823 & 0.01524768 \\
\hline Total Flow Ibmol/hr & 498 & 50 & 559.025912 \\
\hline Total Flow $\mathrm{lb} / \mathrm{hr}$ & 14367.4978 & 1524.76823 & 15892.266 \\
\hline Total Flow cuft/hr & 179062.093 & 17893.2586 & 704327.465 \\
\hline Temperature F & 100 & 100 & 1500 \\
\hline Pressure psi & 16.6959488 & 16.6959488 & 16.6959488 \\
\hline Vapor Frac & 1 & 1 & 1 \\
\hline Liquid Frac & 0 & 0 & 0 \\
\hline Solid Frac & 0 & 0 & 0 \\
\hline Enthalpy $\quad$ Btu/lbmol & 156.65923 & -73705.718 & -27603.055 \\
\hline Enthalpy $\quad$ Btu/lb & 5.43005454 & -2416.9482 & -970.9643 \\
\hline Enthalpy Btu/hr & 78016.2963 & -3685285.9 & -15430823 \\
\hline Entropy $\quad$ Btu/lbmol-R & 1.05415323 & -20.383363 & 10.0551305 \\
\hline Entropy $\quad$ Btu/lb-R & 0.0365386 & -0.6684086 & 0.35369899 \\
\hline Density lbmol/cuft & 0.00278115 & 0.00279434 & 0.0007937 \\
\hline $\begin{array}{ll}\text { Density } & \mathrm{lb} / \text { cuft }\end{array}$ & 0.08023751 & 0.08521467 & 0.02256374 \\
\hline Average MW & 28.8503972 & 30.4953646 & 28.4284962 \\
\hline
\end{tabular}


Table A10: Heat content calculation

\begin{tabular}{|l|r|r|r|}
\hline & Hc at 25C* (B.t.u/lb) & Mass Fraction & Heat Content (B.t.u/lb) \\
\hline CarbonDioxide & 0 & 0.4195 & 0 \\
\hline Methane & 23861 & 0.2259 & 5390.199898 \\
\hline Ethane & 22304 & 0.1399 & 3120.329594 \\
\hline Ethene & 21625 & 0.01 & 216.25 \\
\hline Propane & 21646 & 0.1184 & 2562.886394 \\
\hline Butane & 21293 & 0.0863 & 1837.585897 \\
\hline Pentane & 21072 & 0 & 0 \\
\hline Hexane & 20928 & 0 & 0 \\
\hline Mixture & & 0.999999999 & 13127.25178 \\
\hline
\end{tabular}

*: Hc to form $\mathrm{H} 2 \mathrm{O}$ (liq) and $\mathrm{CO} 2$ (gas) at $25^{\circ} \mathrm{C}$ 


\section{APPENDIX B}

A brief description of the pertinent polymers mentioned through out this thesis is presented below ${ }^{22}$ :

\section{Polyvinylchloride (PVC):}

PVC is formed from the free radical polymerization of vinyl chloride (Figure B1):

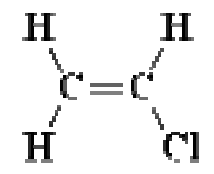

vimyl chloride

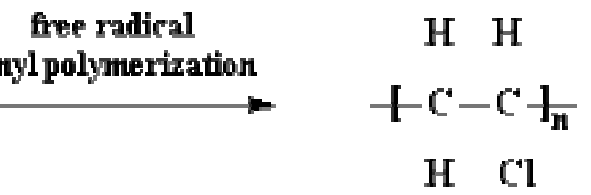

polyuinyl chloride')

Figure B1: Polymerization of vinyl chloride to form PVC

PVC is widely used in areas that require fire and water retardancy. Hence it is used in making raincoats, shower curtains etc, and also forms an important part of plastics used to build computers.

\section{Polyethylene (PE):}

Polyethylene is probably the most popular plastic in the world. It is used in making grocery bags, plastic bottles to bulletproof vests. Polyethylene is formed from monomer ethylene by the following reaction:

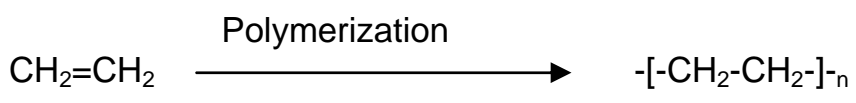

The two common forms of polyethylene are Low-Density Polyethylene (LDPE) and High-Density Polyethylene (HDPE). If the carbon atoms in the polymer chain have long chains of PE attached to them instead of hydrogen, the resulting polymer is a branched polymer called LDPE (Figure B2). If the PE is 
linear then it is called HDPE. HDPE (Figure B3) is stronger than LDPE but requires more stringent polymerization conditions and hence is more expensive.

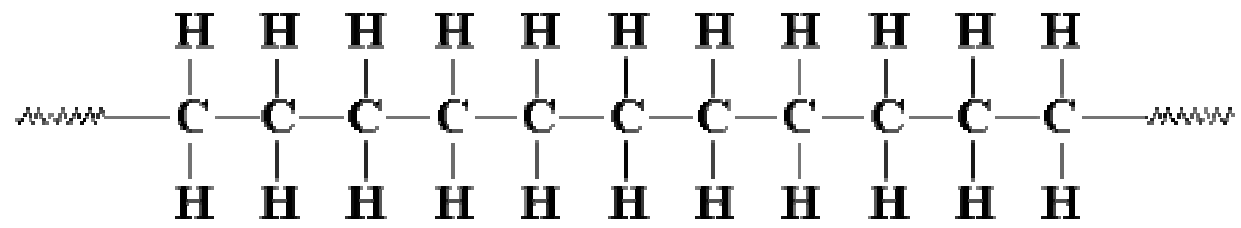

Figure B2 Structure of HDPE

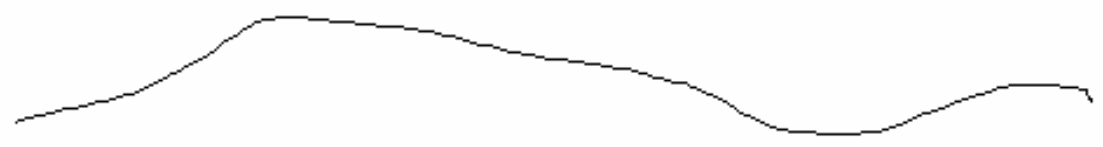

A molecule of linear polyethylene, or HDPE

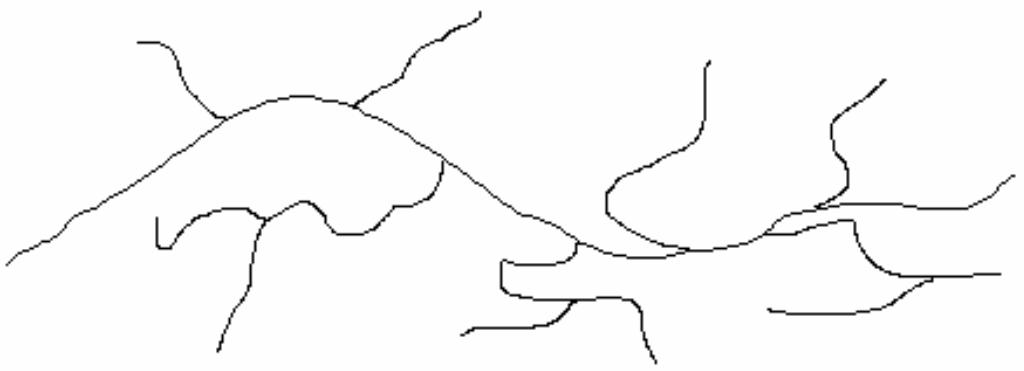

A molecule of branched polyethylene, or LDPE

Figure B3: Structure of LDPE

Additionally, copolymerization of ethylene monomer with an alkyl-branched co-monomer leads to formation of Linear Low-Density Polyethylene (LLDPE). LLDPE is often used to make plastic films and has shorter hydrocarbon branches than LDPE (Figure B4). 


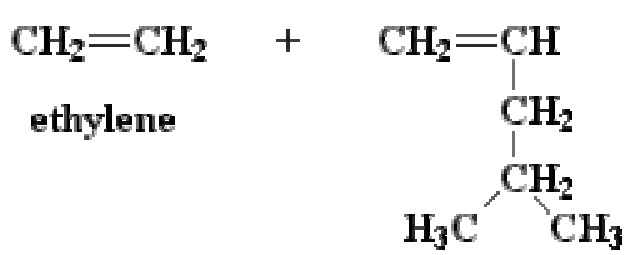

\section{4-methyl-1-pentene}
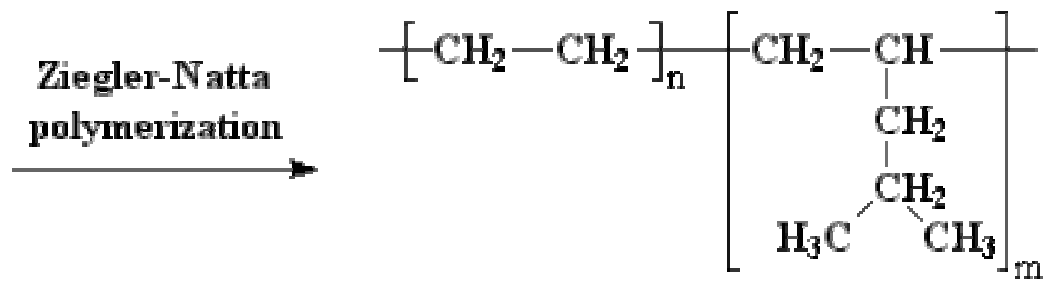

poly(ethylene-co-4-methyl-1-pentene)

(BP's Innovex ${ }^{\mathbb{8}}$, a form of LLDPE)

Figure B4: Ziegler-Natta Polymerization to form LLDPE

\section{Polystyrene (PS):}

Polystyrene is a hard plastic and is a major component of computer casings. It is extensively used in the electronics industry. Polystyrene is a vinyl polymer and is formed by the polymerization reaction of styrene monomer (Figure B5).

The polystyrene most popular in the electronics industry is the High Impact Polystyrene (HIPS) formed by the free radical polymerization of polybutadiene (PB) with styrene monomer (Figure B6). This is a graft copolymer and forms immiscible blend of PB and PS. The polybutadiene in this structure make the polymer "rubbery" and hence better suited to absorb shocks/impacts than simple PS.

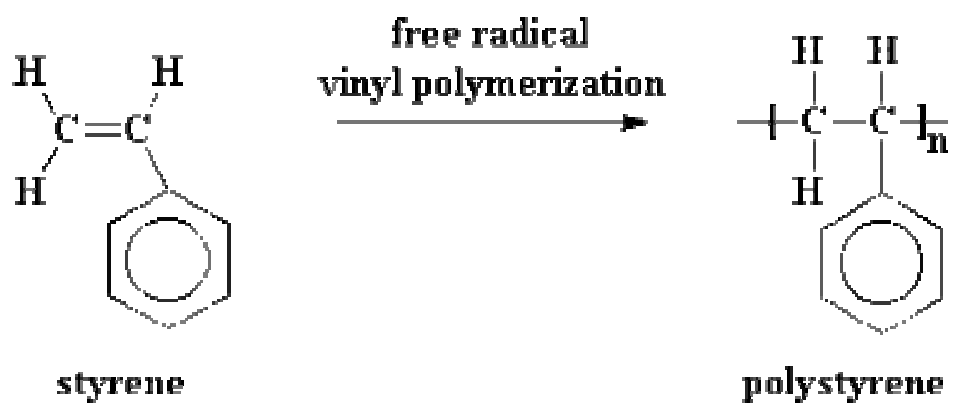

Figure B5: Polymerization of Styrene monomer to Polystyrene 


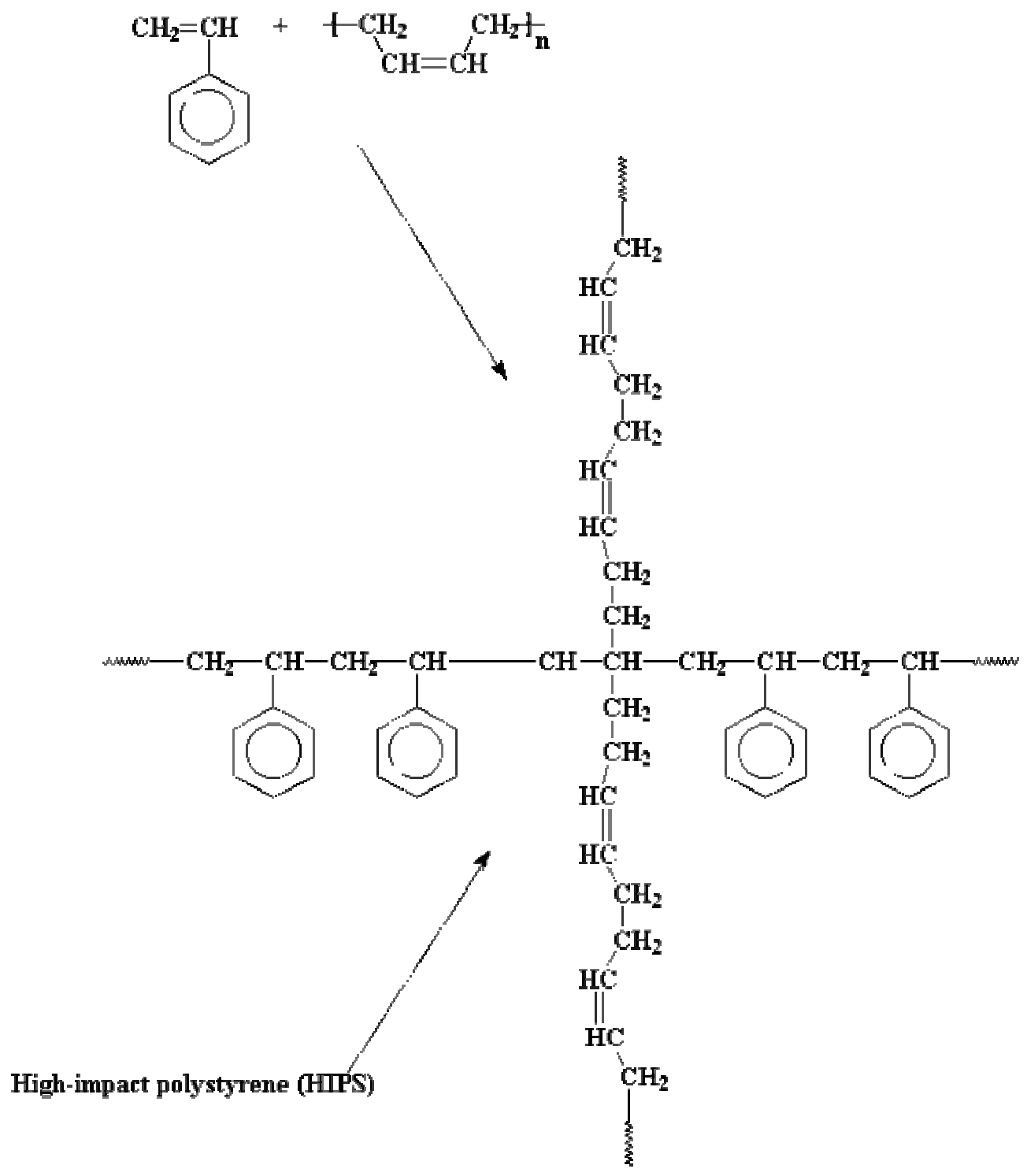

Figure B6: Structure of HIPS

\section{Polycarbonates (PC):}

Polycarbonate of bisphenol $\mathrm{A}$, isa clear plastic that used in making computer screens and eye wear. It is formed by the polymerization reaction of sodium salt of bisphenol A with phosgene (Figure B7 and Figure B8). 


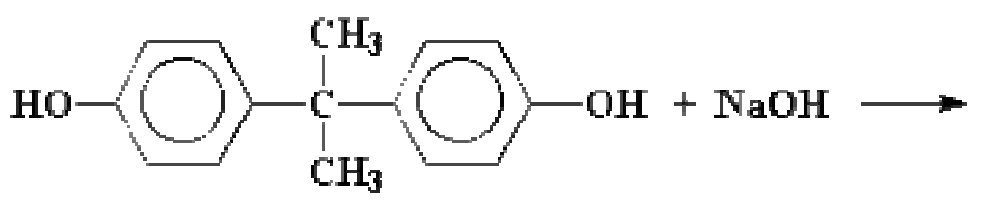

bisphenol A

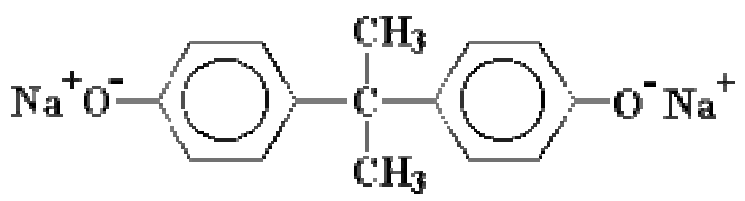

sodium salt of bisphenol $A$

Figure B7: Formation of Bisphenol A
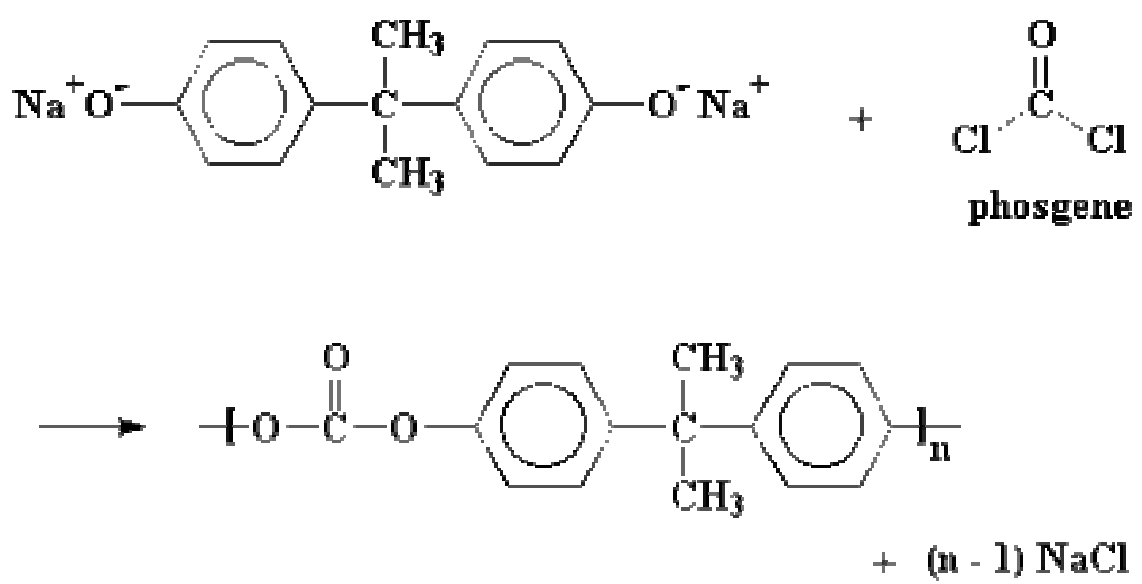

Figure B8: Formation of Polycarbonate of Bisphenol-A

\section{Acrylonitrile-Butadiene-Styrene Copolymer (ABS):}

ABS is formed by polymerization of styrene and acrylonitrile in the presence of polybutadiene (Figure B9). ABS is very strong and lightweight and is similar to HIPS in properties. Hence it is used in the electronic industry for its light weight, strength and impact resistance. 


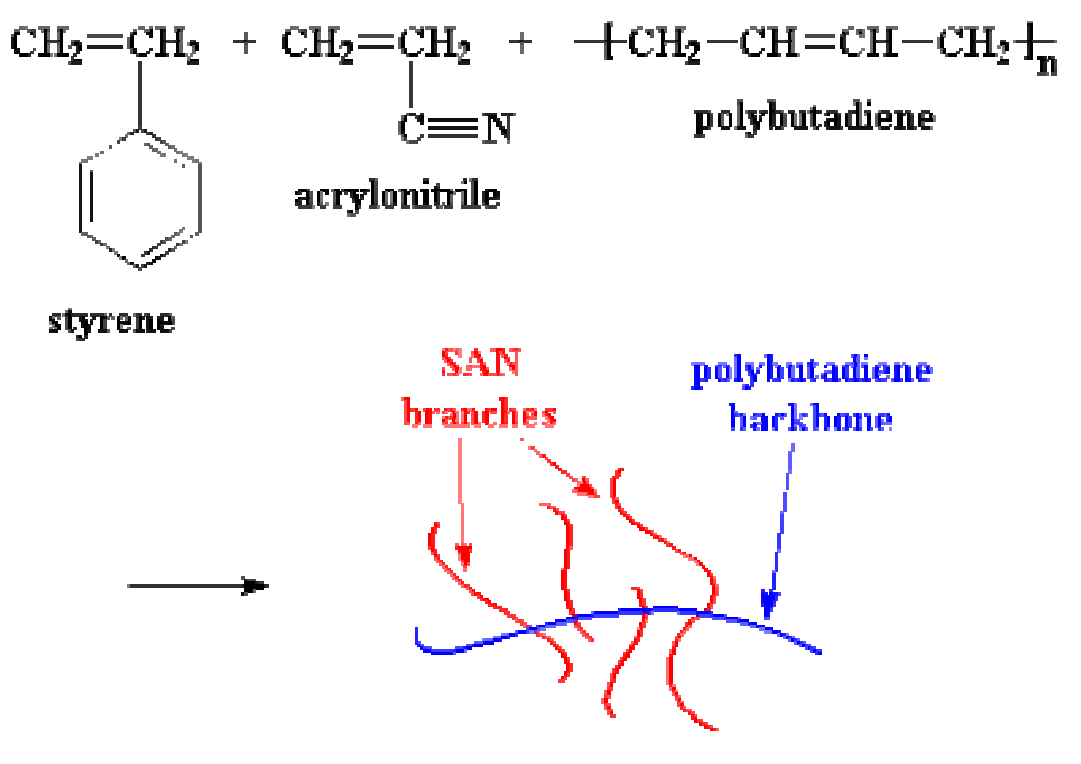

ABS

Figure B9: Structure of ABS 


\section{APPENDIX C}

The raw data for the product gas composition is given in the following table:

\begin{tabular}{|c|c|c|c|c|c|c|c|c|c|c|c|c|c|c|c|c|c|c|}
\hline & \multicolumn{2}{|c|}{$\mathrm{CO} 2$} & \multicolumn{2}{|c|}{$\mathrm{C} 1$} & \multicolumn{2}{|c|}{$\mathrm{C} 2 \mathrm{H} 4$} & \multicolumn{2}{|c|}{$\mathrm{C} 2$} & \multicolumn{2}{|c|}{$\mathrm{C} 3$} & \multicolumn{2}{|c|}{$\mathrm{C} 4$} & \multicolumn{2}{|c|}{ Alkanes } & \multicolumn{2}{|c|}{ Wt of Gas in Sample } & \multicolumn{2}{|c|}{ Wt of Quantified Gas/Wt of total gas (\%) } \\
\hline & MBAP1 & MBAP2 & MBAP1 & MBAP2 & MBAP1 & MBAP2 & MBAP1 & MBAP2 & MBAP1 & MBAP2 & MBAP1 & MBAP2 & MBAP1 & MBAP2 & MBAP1 & MBAP2 & MBAP1 & MBAP2 \\
\hline $375 \mathrm{C}, 15 \mathrm{~min}$ & 18 & 30 & 4 & 12 & 1 & 8 & 3 & 12 & 4 & 12 & 28 & 13 & 39 & 49 & 0.11 & 0.030 & $58 \%$ & $87 \%$ \\
\hline $375 \mathrm{C}, 30 \mathrm{~min}$ & 22 & 29 & 2 & 14 & 0.5 & 7 & 1 & 19 & 3 & 11 & 31 & 12 & 37 & 56 & 0.37 & 0.036 & $60 \%$ & $92 \%$ \\
\hline $375 \mathrm{C}, 45 \mathrm{~min}$ & 19 & 28 & 5 & 15 & 1 & 7 & 4 & 13 & 3 & 8 & 31 & 14 & 43 & 50 & 0.24 & 0.039 & $63 \%$ & $85 \%$ \\
\hline $400 \mathrm{C}, 15 \mathrm{~min}$ & 49 & 27 & 6 & 20 & 0 & 14 & 8 & 12 & 3 & 7 & 20 & 5 & 37 & 44 & 0.11 & 0.027 & $86 \%$ & $85 \%$ \\
\hline $400 \mathrm{C}, 30 \mathrm{~min}$ & 53 & 26 & 9 & 20 & 0 & 14 & 6 & 10 & 1 & 8 & 21 & 7 & 37 & 45 & 0.12 & 0.027 & $90 \%$ & $85 \%$ \\
\hline $400 \mathrm{C}, 45 \mathrm{~min}$ & 51 & 28 & 15 & 19 & 0 & 17 & 7 & 8 & 1 & 8 & 22 & 7 & 45 & 42 & 0.19 & 0.069 & $96 \%$ & $87 \%$ \\
\hline $425 \mathrm{C}, 15 \mathrm{~min}$ & 71 & 25 & 14 & 25 & 0.5 & 20 & 7 & 8 & & 5 & 4 & 9 & 25 & 47 & 0.13 & 0.096 & $97 \%$ & $92 \%$ \\
\hline $425 \mathrm{C}, 30 \mathrm{~min}$ & 66 & 30 & 16 & 28 & 1 & 17 & 7 & 6 & & 4 & 4 & 8 & 27 & 46 & 0.15 & 0.069 & $94 \%$ & $93 \%$ \\
\hline $425 \mathrm{C}, 45 \mathrm{~min}$ & 70 & 30 & 17 & 26 & & 20 & 6 & 10 & & 3 & 3 & 6 & 26 & 45 & 0.33 & 0.084 & $96 \%$ & $95 \%$ \\
\hline $450 \mathrm{C}, 15 \mathrm{~min}$ & 70 & 29 & 19 & 34 & 1 & 23 & 7 & 6 & & 3 & & & 26 & 43 & 0.26 & 0.066 & $97 \%$ & $95 \%$ \\
\hline $450 \mathrm{C}, 30 \mathrm{~min}$ & 68 & 25 & 20 & 36 & 0.5 & 22 & 8 & 7 & & 2 & & 5 & 28 & 50 & 0.33 & 0.066 & $97 \%$ & $97 \%$ \\
\hline $450 \mathrm{C}, 45 \mathrm{~min}$ & 68 & 29 & 20 & 31 & 0.5 & 22 & 5 & 7 & & 5 & & 3 & 25 & 46 & 0.30 & 0.072 & $94 \%$ & $97 \%$ \\
\hline
\end{tabular}




\section{APPENDIX D}

The raw data for ASTM D-86 analysis of AT oil is presented below:

For Raw AT-1 Oil:

Distillation Data before Removal of Impurities

\begin{tabular}{|c|c|}
\hline Temperature (F) & Distillate Volume (ml) \\
\hline 113 & IBP \\
\hline 242 & 5 \\
\hline 344 & 10 \\
\hline 400 & 15 \\
\hline 444 & 20 \\
\hline 464 & 25 \\
\hline 492 & 30 \\
\hline 508 & 35 \\
\hline $\mathbf{5 2 2}$ & $\mathbf{4 0}$ \\
\hline $\mathbf{5 2 8}$ & $\mathbf{4 3}$ \\
\hline $\mathbf{5 2 4}$ & $\mathbf{4 5}$ \\
\hline 530 & 50 \\
\hline 538 & 55 \\
\hline 544 & 60 \\
\hline 556 & 65 \\
\hline 566 & 70 \\
\hline $\mathbf{5 7 2}$ & $\mathbf{7 5}$ \\
\hline $\mathbf{5 8 2}$ & $\mathbf{8 0}$ \\
\hline $\mathbf{5 8 6}$ & $\mathbf{8 5}$ \\
\hline $\mathbf{5 7 5}$ & $\mathbf{9 0}$ \\
\hline & \\
\hline
\end{tabular}

For AT-1 Oil after settling time of 12 hours:

\begin{tabular}{|c|c|}
\hline Temperature (F) & Distillate Volume (ml) \\
\hline 120 & 0 \\
\hline 243 & 5 \\
\hline 355 & 10 \\
\hline 423 & 15 \\
\hline 463 & 20 \\
\hline 490 & 25 \\
\hline $\mathbf{5 2 2}$ & $\mathbf{3 0}$ \\
\hline $\mathbf{5 2 8}$ & $\mathbf{3 1}$ \\
\hline $\mathbf{5 2 3}$ & $\mathbf{3 3}$ \\
\hline $\mathbf{5 2 3}$ & $\mathbf{3 5}$ \\
\hline 534 & 40 \\
\hline 540 & 45 \\
\hline 544 & 50 \\
\hline 558 & 55 \\
\hline 559 & 60 \\
\hline 562 & 65 \\
\hline $\mathbf{5 7 5}$ & $\mathbf{7 0}$ \\
\hline $\mathbf{5 8 9}$ & $\mathbf{7 5}$ \\
\hline $\mathbf{5 6 5}$ & $\mathbf{7 7}$ \\
\hline & \\
\hline
\end{tabular}


For AT-1 Oil after settling time of 24 hours:

\begin{tabular}{|c|c|}
\hline Temperature (F) & Distillate Volume (ml) \\
\hline 121 & IBP \\
\hline 278 & 5 \\
\hline 412 & 10 \\
\hline 481 & 15 \\
\hline 515 & 20 \\
\hline 523 & 25 \\
\hline 537 & 30 \\
\hline 537 & 35 \\
\hline 541 & $\mathbf{4 0}$ \\
\hline $\mathbf{5 4 0}$ & $\mathbf{4 2}$ \\
\hline 564 & $\mathbf{4 5}$ \\
\hline 572 & 50 \\
\hline 573 & 55 \\
\hline $\mathbf{5 7 1}$ & $\mathbf{6 0}$ \\
\hline $\mathbf{5 8 3}$ & $\mathbf{6 5}$ \\
\hline $\mathbf{5 7 7}$ & $\mathbf{7 0}$ \\
\hline
\end{tabular}

For AT-1 Oil with settling time of 48 hours:

\begin{tabular}{|c|c|}
\hline Temperature (F) & Distillate Volume (ml) \\
\hline 120 & 0 \\
\hline 280 & 5 \\
\hline 406 & 10 \\
\hline 476 & 15 \\
\hline 492 & 20 \\
\hline 515 & 25 \\
\hline 528 & 30 \\
\hline 530 & 35 \\
\hline $\mathbf{5 3 4}$ & $\mathbf{4 0}$ \\
\hline $\mathbf{5 4 2}$ & $\mathbf{4 2}$ \\
\hline $\mathbf{5 3 8}$ & $\mathbf{4 3}$ \\
\hline $\mathbf{5 4 6}$ & $\mathbf{4 5}$ \\
\hline 558 & 50 \\
\hline 572 & 55 \\
\hline $\mathbf{5 8 0}$ & $\mathbf{6 0}$ \\
\hline $\mathbf{5 9 0}$ & $\mathbf{6 5}$ \\
\hline $\mathbf{5 7 8}$ & $\mathbf{7 0}$ \\
\hline
\end{tabular}

